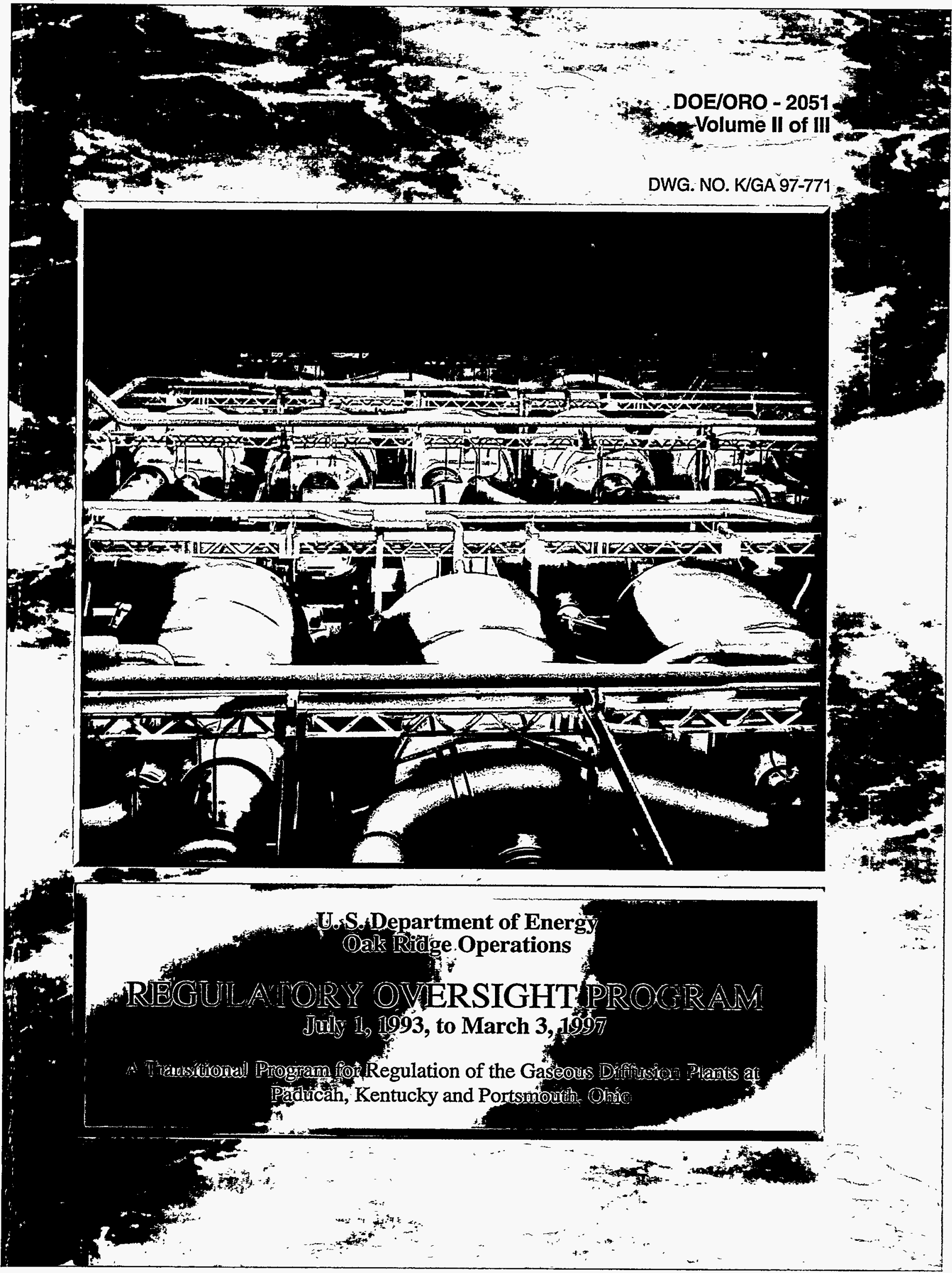


A Transitional Program for Regulation of the Gaseous Diffusion Plants at

Paducah, Kentucky, and Portsmouth, Ohio

\section{APPENDICIES}

REGULATORY OVERSIGHT PROGRAM

July 1, 1993 to March 3, 1997

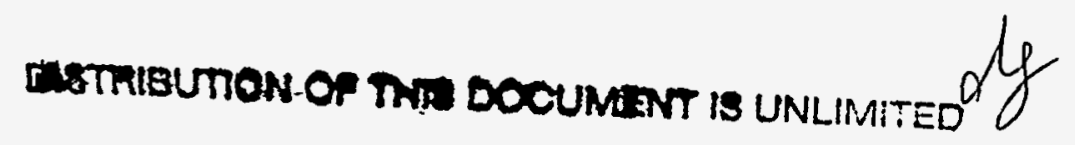

Prepared by

Regulatory Oversight Office

for

U. S. Department of Energy Oak Ridge Operations

MASTER

Oak Ridge, Tennessee 37830 
This Volume contains Joints Statements of Understanding, Memorandum of Agreement, and Memorandum of Understanding that were cited in the Regulatory Oversight Report as well as a Month-by-month Summary of Activities. 


\section{DISCLAIMER}

This report was prepared as an account of work sponsored by an agency of the United States Government. Neither the United States Government nor any agency thereof, nor any of their employees, makes any warranty, express or implied, or assumes any legal liability or responsibility for the accuracy, completeness, or usefulness of any information, apparatus, product, or process disclosed, or represents that its use would not infringe privately owned rights. Reference herein to any specific commercial product, process, or service by trade name, trademark, manufac. turer, or otherwise does not necessarily constitute or imply its endorsement, recommendation, or favoring by the United States Government or any agency thereof. The views and opinions of authors expressed herein do not necessarily state or reflect those of the United States Government or any agency thereof. 


\section{V0.1.MII.}

Volume I provides a succinct chronicle summary of the formal development, operation and key activities of the DOE/ORO Regulatory Oversight organization from its beginning in July 1993, until the turnover of the responsibility to the NRC on March 3, 1997. The following lists the primary headings of Volume I for your information.

\subsection{PURPOSE}

\subsection{EXECUTIVE SUMMARY}

3.0 PROGRAM ORGANIZATION AND OPERATION OBJECTIVES

\subsection{OVERVIEW}

\subsection{DESCRIPTION OF RO PROGRAM ACTIVITIES}

Volume I is available upon request from:

\section{US DEPARTMENT OF ENERGY REGULATORY OVERSIGHT \\ ATTN RANDALL M. DEVAULT ROOM 560 POST OFFICE BOX 62 \\ OAK RIDGE TN 37831}

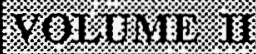

\section{Gonturne}

NOTE: Volume II contains copies of the documents which established the relationship between NRC, DOE, USEC, and DOL required to facilitate regulatory oversight transition. Appendix $\mathrm{H}$ contains the monthly program highlights for the regulatory oversight effort.

APPENDIX A Memorandum from Secretary of Energy to Heads of Offices, Dated: June 15, 1993, Subject: Department Oversight Responsibilities of Uranium Enrichment Activities by United States Enrichment Corporation, in which regulatory oversight authority and responsibility for PDGP and PORTS was assigned to DOE/ORO during transition to regulation by NRC.

APPENDIX B Regulatory Oversight Agreement between USDOE and USEC (Exhibit D of Lease Agreement), July 1, 1993. 
APPENDIX C Joint Statement of Understanding between The Nuclear Regulatory Commission and The Department of Energy on Implementing The Energy Policy Act Provisions on Regulation of Gaseous Diffusion Uranium Enrichment Plants, Signed December 20, 1993, Ivan Selin and Hazel R. O'Leary.

APPENDIX D Memorandum of Agreement Establishing Guidance for NRC Inspection Activities at the Paducah and Portsmouth Gaseous Diffusion Plants between Department of Energy Oversight Manager and Nuclear Regulatory Commission, Signed August 11, 1994, J. Dale Jackson and NRC, which establishes guidance for NRC observation activities at PGDP and PORTS.

APPENDIX E Memorandum of Agreement Relating to the Transfer Functions and Activities from the United States Department of Energy to the United States Enrichment Corporation, Signed December 15, 1994, Hazel R. O'Leary and William H. Timbers, Jr., which relates to the agreement between DOE and USEC in which DOE retains title and control of HEU material until it is blended to less than $10 \%$ of the $\mathrm{U}^{235}$ isotope.

APPENDIX F Memorandum of Understanding Between The U.S. Department of Labor Occupational Safety and Health Administration and the U.S. Department of Energy Office of Environments, Safety and Health, Signed December 21, 1994, Joseph A. Dear and Tara O’Toole, M.D., to minimize potential gaps (OSHA).

APPENDIX - G Joint Policy Statement by USEC and DOE on Resolution of Shared Site Issues at the Gaseous Diffusion Plants, Sent by USEC Letter, Dated: January 25, 1996, in which an administrative policy statement addresses PGDP shared site issues the surrounding DOEretained reservation as well as other issues that require formal mechanisms for interface and control.

APPENDIX - H DOE/ORO RO STAFF MONTHLY PROGRAM HIGHLIGHTS

(This is a detailed list of month-by-month activity/events summaries.)

Volume II is available upon request from:

\author{
US DEPARTMENT OF ENERGY \\ REGULATORY OVERSIGHT \\ ATTN RANDALL M. DEVAULT ROOM 560 \\ POST OFFICE BOX 62 \\ OAK RIDGE TN 37831
}




\title{
VOMUME III
}

NOTE: Volume III contains copies of two reports that documents the DOE/ORO regulatory oversight inspection and enforcement history for each GDP site.

\section{APPENDIX I}

\section{DOE TO NRC REGULATORY OVERSIGHT TRANSITION - DOE:ORO:PGDP INSPECTION SUMMARY}

(The purpose of this report was to document the DOE regulatory oversight inspection and enforcement ( $I$ and $E$ ) history of PGDP. Also the report provides a formal mechanism by which $\mathrm{DOE} / \mathrm{ORO}$ could communicate PGDP's I and E history to NRC. The scope of the report encompasses the inspection activities that occurred at the PGDP site during July 1, 1993 through March 2, 1997.)

APPENDIX I

$$
\begin{aligned}
& \text { DOE TO NRC REGULATORY OVERSIGHT } \\
& \text { TRANSITION - DOE:ORO:PORTS } \\
& \text { INSPECTION SUMMARY }
\end{aligned}
$$

(The purpose of this report was to document the DOE regulatory oversight inspection and enforcement ( $I$ and $E$ ) history of PORTS. Also the report provides a formal mechanism by which DOE/ORO could communicate PORTS' I and E history to NRC. The scope of the report encompasses the inspection activities that occurred at the PORTS site during July 1, 1993 through March 2, 1997.)

Volume III is available upon request from:

\author{
US DEPARTMENT OF ENERGY \\ REGULATORY OVERSIGHT \\ ATTN RANDALL M. DEVAULT ROOM 560 \\ POST OFFICE BOX 62 \\ OAK RIDGE TN 37831
}




$\begin{array}{ll}\text { ANS } & \text { American Nuclear Society } \\ \text { ASME } & \text { American Society of mechanical Engineers } \\ \text { CAAS } & \text { Criticality Accident Alarm System } \\ \text { CFR } & \text { Code of Federal Regulations } \\ \text { D\&D } & \text { Decommissioning and Decontamination } \\ \text { DMSA } & \text { DOE Material Storage Area } \\ \text { DOE } & \text { U. S. Department of Energy } \\ \text { DOE ES\&H } & \text { DOE Environmental, Safety and Health } \\ \text { DOE/HQ } & \text { DOE Headquarters } \\ \text { DOE/HQ-EH } & \text { DOE Headquarters - Environmental Health } \\ \text { DOE/HQ-EM } & \text { DOE Headquarters - Environmental Management } \\ \text { DOE/HQ-NE } & \text { DOE Headquarters - Nuclear Energy } \\ \text { DOE/HQ-NS } & \text { DOE Headquarters - Nuclear Safety } \\ \text { DOE/ORO } & \text { DOE Oak Ridge Operations } \\ \text { DOT } & \text { Department of Transportation } \\ \text { EASI } & \text { Enterprise Advisory Services, Inc. } \\ \text { EH } & \text { Environmental Health } \\ \text { EOC } & \text { Emergency Operations Center } \\ \text { EP } & \text { Emergency Planning } \\ \text { ERP } & \text { Extended Range Product } \\ \text { ES\&H } & \text { Environmental, Safety and Health } \\ \text { FY } & \text { Fiscal Year } \\ \text { GDP } & \text { Gaseous Diffusion Plant } \\ \text { HEU } & \text { Highly Enriched Uranium } \\ \text { I\&E } & \text { Inspection and Enforcement } \\ \text { IAEA } & \text { International Atomic Energy Agency } \\ \text { IRMS } & \text { Integrated Resources Management System } \\ \text { ISA } & \text { Independent Safety Assessment } \\ \text { JCO } & \text { Justification for Continued Operation } \\ \text { LAW } & \text { Low Assay Withdrawal } \\ \text { LLNL } & \text { Lawrence Livermore National Laboratory } \\ \text { LMES } & \text { Lockheed Martin Energy Services } \\ \text { LMUS } & \text { Lockheed Martin Utility Services } \\ \text { LSSS } & \text { Limiting Safety System Setting } \\ \text { MMES } & \text { Martin Marietta Energy Services } \\ \text { NCS } & \text { Nuclear Criticality Safety } \\ \text { NOV } & \text { Notice of Violation } \\ \text { NRC } & \text { Nuclear Regulatory Commission } \\ \text { NRC/HQ } & \text { NRC Headquarters } \\ \text { OCC } & \text { Office of Chief Counsel } \\ \text { OIG } & \text { Office of Inspector General } \\ \text { ORE } & \text { Operational Readiness Evaluation } \\ & \end{array}$




\begin{tabular}{ll} 
ORO/RO & Oak Ridge Operations - Regulatory Oversight \\
ORR & Operational Readiness Review \\
OSHA & Occupational Safety and Health Administration \\
OSR & Operational Safety Requirement \\
OSRTSR & Operational Safety Requirement / Technical \\
& \multicolumn{1}{c}{ Safety Requirement } \\
PAAA & Price Anderson Amendment Act \\
PCB & Polychlorinated Biphenyls \\
PCB/R & PCB/Radioactive Mixed Waste \\
PGDP & Paducah Gaseous Diffusion Plant \\
PORTS & Portsmouth Gaseous Diffusion Plant \\
QA & Quality Assurance \\
RO & Regulatory Oversight \\
ROA & Regulatory Oversight Agreement \\
ROP-IP & Regulatory Oversight Procedure-Inspection Procedure \\
S/RDS & Environmental Management Enrichment Facilities Standards/ \\
& \\
SAR & Safety Analysis Report Requirements Identification Documents \\
SE & Safety Evaluation (by USEC) \\
SER & Safety Evaluation Report \\
SMEs & Subject Matter Experts \\
SSR & Site Safety Representative \\
TSR & Technical Safety Requirement \\
U 235 & Uranium - 235 \\
UF 4 & Uranium Tetrafluoride \\
UF & Uranium Hexafluoride \\
UO & Unusual Occurrences \\
USEC & United States Enrichment Corporation \\
USQ & Unreviewed Safety Question \\
USQD & Unreviewed Safety Question Determination \\
&
\end{tabular}


DOE/ORO - 2051

Intentionally Blank 


\title{
A Transitional Program for Regulation of the Gaseous Diffusion Plants at \\ Paducah, Kentucky, and Portsmouth, Ohio
}

\begin{abstract}
APPENDIX A
REGULATORY OVERSIGHT PROGRAM
\end{abstract}

July 1, 1993 to March 3, 1997

Prepared by

Regulatory Oversight Office for

U. S. Department of Energy

Oak Ridge Operations

Oak Ridge, Tennessee 37830 
Memorandum from Secretary of Energy to Heads of Offices, Dated: June 15, 1993, Subject: Department Oversight Responsibilities of Uranium Enrichment Activities by United States Enrichment Corporation, in which regulatory oversight authority and responsibility for PDGP and PORTS was assigned to DOE/ORO during transition to regulation by NRC. 


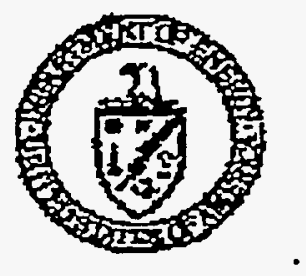

\author{
The Secreisty of Enargy \\ thasinutor, DC ansas \\ JuTy 13, 1993
}

YIOHORAHDUM +UR

ACTIKG ASSISTAHT SEERETARY OF EMIROHELET, SAFETH AMD HEALTH

ACTING DIRECTOR OF HULEAR EREEGY

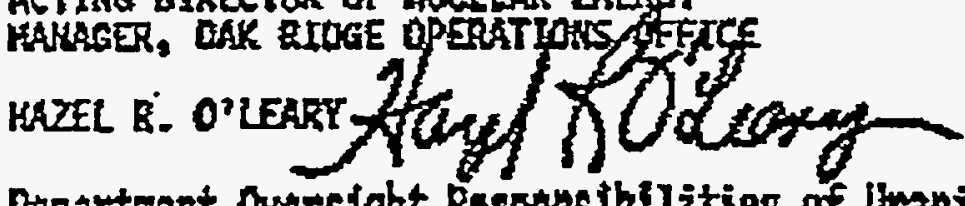

FRET:

SUESECT:

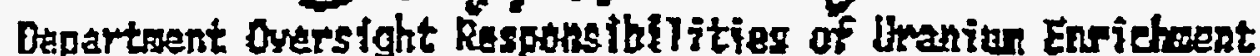
Autivjties by the Uaited states Enrlcterent corporation

The purpase of this menoranduri is to estabi ish clear Tines of authority and responsibility for the Departwent's role the regutator of the Ual ted Stater Emriciment corparation regarding nuclear safety ard sufeguards and serisrity activities at the uraniun emichost gaseous diffusion piants at Paducst, Kentucky, and Portsmorth, Osio.

The Departanert and the United States Enrichatat Corporation bave negotiatod a Rogufatory Oversight Agraterent, as contained in the lease, and, estabif ished an overstght strecture. This structure provides for a Regulatory Oversight Manzer, ansite nucizar sofiety representatives, and Oak Ridgi Operations office ard Headquarters support. The Regulatory Gyersight Agreanent includes provisions for independent Hezdertarters audits and rayfens.

The Office of Nuclesr Energy will be responsible for prograne polfey and guidance. The oat Ridge ogerations dffice ufll carry out the activitist in accordanc: with the lease agreesont. The office of Environareat, safety and Heal th will continte to proytde fndependent ussessments of anclear safoty activities and rake the assessnents ayajiable to the Reguiztory Oyersight Fanzer and the Office of tuclear Energy.

The Regulatory Ouersight Kanager, as appointed by the Hanager of the Oak RidgorOperations office, will manage the daily operations of the oversight function and Ampleastst the Regulatory arorsight Agraeneft of tha lease inciluding enforcenent provisions. In additien, the Regulatory Ovarsight Hangger is uthorized, following Houdquarters concurrence, to rake thanges to the oversight requirements as needed to adress micleat safety and nafegusards mo security issues and to facilitate transition to the huclear Regulatory Cormission-

The Depertment is comitted to the suscessful transition of the gaseaus diffusion niant operazions frow the Begartwent of Exargy to the United States Enrichrient Corporation and, Jater, to the successful transition of regulatory oyersight responsibitities from the Departhent of Energy to the Hurlear Regal atary Condentission. 
Intentionally Blank 

A Transitional Program for Regulation of the Gaseous Diffusion Plants at
Paducah, Kentucky, and Portsmouth, Ohio

\section{APPENDIX B}

\section{REGULATORY OVERSIGHT PROGRAM July 1, 1993 to March 3, 1997}

Prepared by

Regulatory Oversight Office

for

U. S. Department of Energy

Oak Ridge Operations

Oak Ridge, Tennessee 37830 
Regulatory Oversight Agreement between USDOE and USEC (Exhibit D of Lease Agreement), July 1, 1993. 
EXHIBIT D

\author{
REGULATOPY OVERSIGHT AGREEMENT \\ between \\ UNITED STATES DEPARTMENT OF ENERGY \\ and \\ UNITED STATES ENRICHMENT CORPORATION
}

July 1, 1993 
DOE/ORO - 2051 


\author{
REGULATORY OVERSIGHT AGREEMENT \\ between \\ UNITED STATES DEPARTMENT OF ENERGY \\ and \\ UNITED STATES ENRICHMENT CORPORATION
}

THIS AGREEMENT, entered into as of this 1st day of July: 1993, by and between the UNITED STATES OF AMERICA (hereinafter referred to as the "Government"), represented by the SECRETARY of ENERGY (hereinafter referred to as the "secretary"), the statutory head of the DEPARTMENT OF ENERGY (hereinafter referred to as "DOE"), and the UNITED STATES ENRICHMENT CORPORATION (hereinafter referred to as "USEC");

\title{
WITNESSETH THAT:
}

WHEREAS, until the Nuclear Regulatory Commission ("NRC") issues a Certificate of Compliance to USEC or approves a Compliance Plan pursuant to Section 1701 of the Atomic Energy Act of 1954, as amended ("AEA"), the DOE is required to promote and protect the radiological health and safety of the public and workers and to provide for the common defense and security at DOE-owned facilities by exercising nuclear safety and safeguards and security oversight authority at the Leased Premises as defined in the Iease Agreement between DOE and USEC dated as of July 1, 1993 (hereinafter refered to as the "Lease");

NOW, THEREFORE, the parties hereto agree as follows:

\section{ARTICLE I - DEFINITIONS}

As used throughout this agreement, including the appendices hereto, the following terms, when capitalized, mean:

1. The term "Appraisal Team Member" means a DOE safety and health or safeguards and security professional supporting DOE Nuclear Safety and Safeguards and security Requirements oversight activities.

2. The term "Civil Penalty" means a monetary penalty that may be imposed for violation of Nuclear Safety and Safeguards and security Requirements.

3. The term "Clear And Present Danger" means a condition or hazard that could be expected to cause: (a) either death or serious harm to plant workers or the public, or (b) serious damage to the common defense and securi- 
ty, immediately or before such condition or hazard could be eliminated through the normal enforcement mechanisms discussed in this Agreement.

4. The term "DOE ORO Manager" means the Manager of DOE Oak Ridge operations office or one or more DOE employee(s). whom that Manager has designated, in writing, to act for him in all, or a portion, of the matters addressed herein.

5. The term "DOE Regulatory Oversight Manager" means the DOE representative, or his designee, responsible for implementation of all facets of DOE regulatory oversight of the Leased Premises.

6. The term "Notice of Violation" means a document setting forth the determination of the DOE Regulatory Oversight Manager that one or more violations of Nuclear Safety and Safeguards and security Requirements has occurred.

7. The term "Nuclear safety and safeguards and security Requirements" means the implementation requirements. with respect to the nuclear safety, safeguards and security objectives as set forth in chapter 3 of Appendix A to this Agreement, entitled "Safety Basis and Framework for DOE Oversight of the Gaseous Diffusion Plants."

8. The term "Violation" means a failure of the UsEc or its contractor(s) to meet any of the Nuclear safety and Safeguards and Security Requirements incorporated into this Agreement. Each failure may be considered a separate occurrence of a violation, as may each day that the same violation persists.

All other capitalized terms shall have the meaning ascribed to them elsewhere in this Agreement or the appendices hereto, or the Lease.

\section{ARTICLE II - STATEMENT AND PURPOSE}

The general purpose of this Regulatory Oversight Agreement ("Agreement") is to reflect the DOE determinations and requirements and the mutual commitments, understandings, and arrangements between the DOE and the USEC concerning the regulatory oversight of the leased Premises by DOE with respect to Nuclear safety and Safeguards and Security Requirements.

\section{ARTICIE III - TERM OF AGREEMENT}

The term of this Agreement shall commence on July 1, 1993, and continue until the NRC issues standards and certifies 
compliance with such standards, or approves a plan, prepared by DOE, for compliance with such standards and assumes responsibility for regulatory oversight over the Leased Premises with respect to nuclear safety and safeguards and security. Such period of time during which DOE exercises regulatory oversight shall be known, as the "Interim Period."

\section{ARTICLE IV - DOE OVERSIGHT/ENFORCEMENT AUTHORITY}

1. DOE has determined that the Implementation Requirements set forth in Chapter 3 of the "Safety Basis and Framework for DOE Oversight of the Gaseous Diffusion Plants" (the "Plan"), attached hereto and incorporated by : reference herein as Appendix $A$, are reasonable andappropriate, and shall constitute the Nuclear safety and safeguaras and Security Requirements applicable to the Leased Premises during the Interim Period, and that compliance with these Nuclear Safety and Safeguards and Security Requirements during the Interim Period will enable the Ieased Premises to continue to operate safely and protect the public health and safety and provide for the common defense and security during the Interim Period.

2. DOE has determined that the comprehensive program of USEC self-assessments and DOE inspections, reviews, and other activities set forth in Chapter 4 of the 'Plan (the "Oversight Program") is reasonable and appropriate, and, when coupled with the USEC commitments contained herein, will provide adequate assurance that the Leased Premises will continue to comply with the Nuclear Safety and Safeguards and security Requirements set forth in the Plan during this Interim Period. DOE and USEC further agree that, unless and until such time as DOE promulgates and implements nuclear safety regulations applicable to the USEC pursuant to the PriceAnderson Amendments of 1988, this Oversight Program will constitute the mechanism by which DOE will exercise regulatory oversight and control over the Leased Premises with respect to nuclear safety, safeguards and security during the Interim period. In the event that DOE promulgates and implements nuclear safety regulations applicable to the USEC pursuant to the priceAnderson Amendments of 1988, DOE and USEC will make appropriate revisions to the plan.

3. DOE represents to USEC that the portions of the Plan entitled "How the Requirements Are Being Met" in Chapter 3 summarize the significant policies, procedures, practices, and other implementation measures which currently exist at the Leased Premises with respect to each of the Nuclear safety and Safeguards and security 
Requirements in the Plan and summarize the current status of conformance of the Leased Premises with the. Nuclear Safety and safeguards and Security Requirements as set forth in the portions of Chapter 3 entitled "Status of Conformance." The applicable portions of the DOE Orders which are referenced in Chapter 3 of the plan provide additional guidance concerning the implementation measures that would enable the Leased Premises to meet the Nuclear safety and safeguards and Security Requirements.

4. USEC agrees to ensure that the Leased Premises continue to comply with the Nuclear Safety and Safeguards and Security Requirements in Chapter 3 of the Plan during the Interim Period through the continuation of the policies, procedures, practices, and other implementation measures described in the Plan. USEC agrees to impose this commitment on the contractor operating the leased Premises on behalf of USEC and include appropriate provisions in the contract for the operation of the Leased Premises to provide further assurance that USEC and the operating contractor will continue to meet this commitment. USEC further agrees, as part of the oversight Program, to undertake the self-assessment activities described in the plan with respect to the Nuclear safety and Safeguards and Security Requirements; cooperate with DOE in the inspections, reviews, and other activities conducted by DOE in accordance with the oversight Program; and implement or cause its operating contractor to implement corrective or preventive actions as a result of these assessments, inspections, reviews, and other activities.

5. A. DOE has determined that DOE's regulatory oversight of the Leased Premises during the Interim Period, including all of the self-assessments, inspections, reviews, and other activities described in the oversight program, will be coordinated by the DOE Regulatory oversight Manager. The DOE Regulatory oversight Manager will have the authority to modify the Nuclear Safety and safeguards and security Requirements set forth in the plan, including the authority to make additions or deletions to these requirements, if the DOE Regulatory oversight Manager determines that the additional requirement is necessary to protect the public health and safety or to provide for the common defense and security, or the deleted requirement is no longer necessary to protect the public health and safety or to provide for the common defense and security in connection with the operation of the Leased Premises. 
B. USEC is authorized to add to, modify, or delete ("Change") any of the policies, procedures, practices and other implementation measures described in the Plan to meet the Nuclear Safety and Safeguards and Security Reguirements, provided (1) there will be no material diminution in the level of protection of the public health and safety or common defense and security as a result of such Change; (2) the Change does not involve an Unreviewed Safety Question or a Change in the Authorization Basis or an opérational safety Requirement; (3) auditable records containing a sumary of the Changes performed and retrievabie evaluation packages required by the DOE requirements specified in Chapter 3 are maintained; and (4) a summary of-the Changes is made available to DOE annually for review and concurrence.

C. For proposed changes which involve an Unreviewed Safety Question or a Change in the Authorization Basis or an operational safety Requirement, as these. terms are defined in DOE Order 5480.21, USEC shall obtain DOE review and approval before implementing the proposed Change.

D. In reviewing the proposed modification of any specific Nuclear Safety and Safeguards and Security Requirement or implementation measure, the DOE Regulatory Oversight Manager will, whenever possible, attempt to facilitate the transition to compliance with the regulatory standards and requirements likely to be imposed on the Leased Premises by the NRC at the conclusion of the Interim Period.

6. The enforcement procedures available to DOE in the event that the USEC fails to comply with the Nuclear safety and Safeguards and Security Requirements are attached hereto, and incorporated by reference herein as Appendix $B$.

\section{ARTICIE $V$ - NOTICES}

With the exception of shutdown authority (as described in Appendix $B$ of this Agreement) invoked by the DOE Regulatory oversight Manager pursuant to Appendix B, no notice, Notice of Violation, answer, order, determination, requirement, consent, or approval under this Agreement shall be of any effect unless in writing. All notices and communications pursuant to this agreement required or desired to be given by DOE or the USEC to 
either party shall be addressed to the USEC or to the DOE and sent to the following addresses:

TO DOE: James C. Hall

Assistant Manager for Enriching operations

U. S. Department of Energy

Oak Ridge operations

P. O. Box 2001

Oak Ridge, Tennessee. 37831

To USEC: General Counsel

United States Enrichment Corporation

$2300 \mathrm{M}$ Street, N. W.

Washington, D. C. 20037

Either party may, by notice given as aforesaid, change its address for notices and communications to be given thereafter.

ARTICIE VI - DOE PIAN UNDER SECTION 1701

The USEC will submit to DOE an initial draft of a plan for DOE's consideration in meeting DOE's obligation to prepare a plan under section 1701 (d) of the AEA for achieving compliance by the Leased Premises with the rules, regulations, and standards of the NRC. DOE shall consult with USEC during the preparation of DOE'S plan and any subsequent revision thereof. DOE and USEC will use their best efforts to agree on a DOE plan prior to its submittal for approval by the NRC and any subsequent submittals to NRC related to the plan.

IN WhTNESS WHEREOF, the parties hereto have executed this agreement as of the de ard year first, above written.

HAZEI R. d'/ IEARY

SECRETARY OF ENERGY

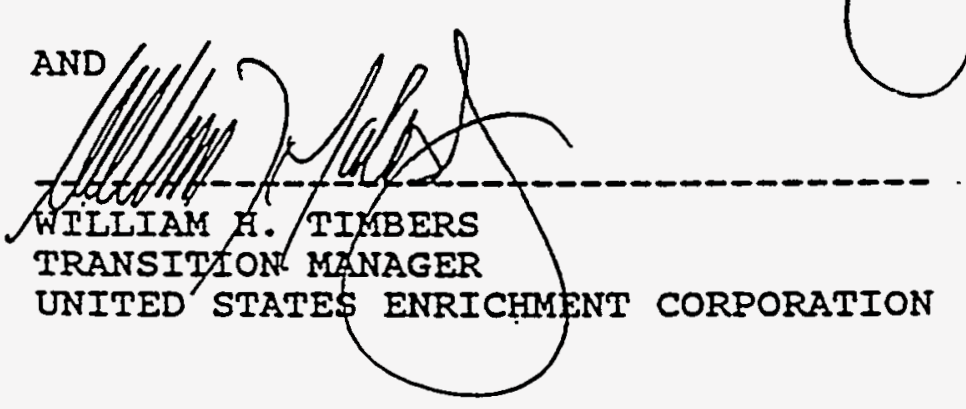


APPENDIX A

SAFETY BASIS AND FRAMEWORK FOR DOE OVERSIGHT

OF THE GASEOUS DIFFUSION PLANTS

July 1,1993 
DOE/ORO - 2051 


\section{CONTENTS}

Page

LIST OF FIGURES AND TABLES $\ldots \ldots \ldots \ldots \ldots \ldots \ldots \ldots \ldots \ldots \ldots \ldots \ldots$

PREFACE $\ldots \ldots \ldots \ldots \ldots \ldots \ldots \ldots \ldots \ldots \ldots \ldots \ldots \ldots \ldots \ldots \ldots \ldots \ldots$

LIST OF ACRONYMS $\ldots \ldots \ldots \ldots \ldots \ldots \ldots \ldots \ldots \ldots \ldots \ldots \ldots \ldots$

EXECUTIVE SUMMARY $\ldots \ldots \ldots \ldots \ldots \ldots \ldots \ldots \ldots \ldots \ldots \ldots \ldots \ldots$

1. INTRODUCTION ............................. $1-1$

1.1 GASEOUS DIFFUSION PROCESS $\ldots \ldots \ldots \ldots \ldots \ldots \ldots \ldots \ldots \ldots \ldots \ldots \ldots$

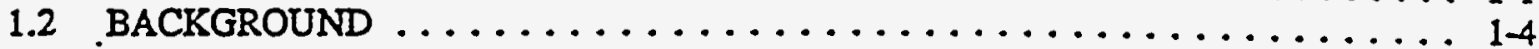

1.3 PURPOSE . . . . . . . . . . . . . . . . . . . . . . . $1-4$

1.4 REPORT STRUCTURE $\ldots \ldots \ldots \ldots \ldots \ldots \ldots \ldots \ldots \ldots \ldots \ldots \ldots$

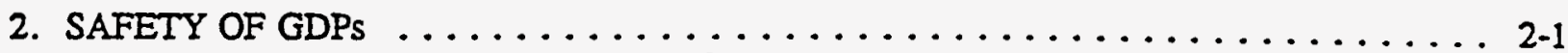

2.1 SAFETY DEMONSTRATED BY OPERATING HISTORY $\ldots \ldots \ldots \ldots \ldots \ldots \ldots 2-1$

2.1.1 Early History . . . . . . . . . . . . . . . . . . . . . 2-2

2.1.2 Cascade Improvement Program and Cascade Uprating Programs ... . . . 2-2

2.1.3 Formal Review of Operating Experience ................ 2-3

2.1.4 Recent Operating Experience ................... 2-3

2.2 SAFETY ANALYSIS SUMMARY FOR THE GASEOUS DIFFUSION PLANTS _. . $2-6$

2.2.1 Gaseous Diffusion Plant Hazards . . . . . . . . . . . . . . . . 2-9

2.2.2 Safety Analysis Reports ....................... 2-11

2.2.3 Operational Safety Requirements .................. 2-30

2.2.4 Maintenance of Safety Basis . . . . . . . . . . . . . . . . . . . 2-30

2.3 EFFECTS OF PLANT AGING ON SAFETY ... . . . . . . . . . . 2-30

2.3.1 Process Boundary Materials and Corrosion . . . . . . . . . . . . 2-31

2.3.2 Reliability Study Program . . . . . . . . . . . . . . . . . . . 2-31

2.4 UPGRADES TO EXISTING SAFETY ANAIYSES . . . . . . . . . . . 2-32

2.5 DOE OVERSIGHT AND MANAGEMENT OF THE GDP $\ldots \ldots \ldots \ldots \ldots \ldots \ldots$

2.5.1 Department of Energy Oversight Responsibilities ............. 2-33

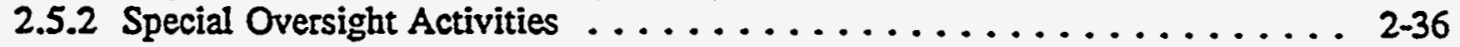

2.5.3 FY-1992 Oversight Activities . . . . . . . . . . . . . . . . 2-37

2.6 COMPLIANCE WITH DEPARTMENT OF ENERGY ORDERS . . . . . . . . . 2-38

2.6.1 Environment, Safety, and Health Compliance . . . . . . . . . . . 2-38

2.6.2 Environmental Compliance ..................... 2-38

2.6.3 Safeguards and Security Compliance ... . . . . . . . . . . . . 2-39

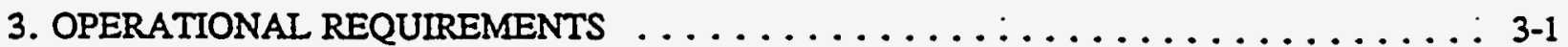

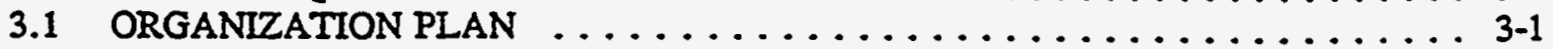

3.1 .1 Basic Objective ........................... 3-1

3.1 .2 Implementation Requirements . . . . . . . . . . . . . . . 3-2

3.1.3 How Requirements Are Met ..................... 3-2

3.1 .4 Status of Conformance $\ldots \ldots \ldots \ldots \ldots \ldots \ldots \ldots \ldots . \ldots \ldots$

iii 
3.2 MANAGERIAL CONTROLS AND OVERSIGHT $\ldots \ldots \ldots \ldots \ldots \ldots \ldots \ldots \ldots$

3.2 .1 Basic Objective . . . . . . . . . . . . . . . . . . 3-3

3.2.2 Implementation Requirements . . . . . . . . . . . . . $3-3$

3.2 .3 How Requirements Are Met . . . . . . . . . . . . . . . 3-3

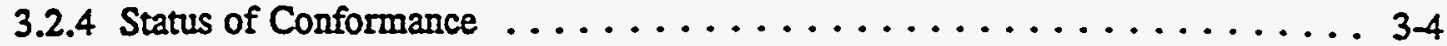

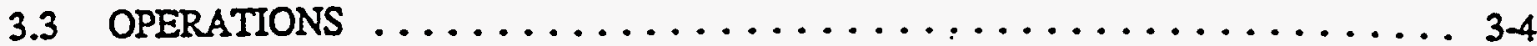

3.3 .1 Basic Objective . . . . . . . . . . . . . . . . . . . 34

3.3.2 Implementation Requirements . . . . . . . . . . . . . . . . 34

3.3 .3 How Requirements Are Met . . . . . . . . . . . . . . . 3-5

3.3.4 Status of Conformance . . . . . . . . . . . . . . . . . 3-5

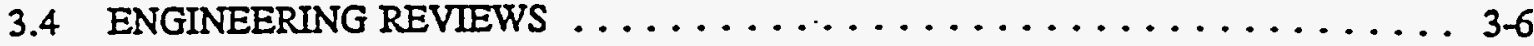

3.4 .1 Basic Objectives . . . . . . . . . . . . . . . . . . . 36

3.4 .2 Implementation Requirements $\ldots \ldots \ldots \ldots \ldots \ldots \ldots \ldots \ldots . \ldots \ldots$

3.4 .3 How Requirements Are Met . . . . . . . . . . . . . . . . 3-6

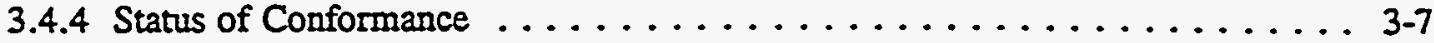

3.5 TRAINING AND QUALIFICATION $\ldots \ldots \ldots \ldots \ldots \ldots \ldots \ldots \ldots \ldots \ldots \ldots \ldots$

3.5 .1 Basic Objective ........................... 3-7

3.5.2 Implementation Requirements . . . . . . . . . . . . . . 3-7

3.5 .3 How Requirements Are Met . . . . . . . . . . . . . . . 3-8

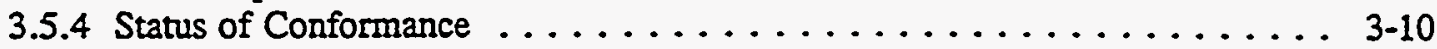

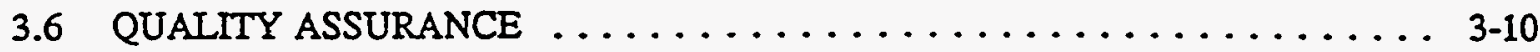

3.6 .1 Basic Objective . . . . . . . . . . . . . . . . . . . . 3-10

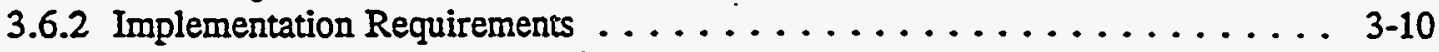

3.6.3 How the Requirements Are Met ................. 3-11

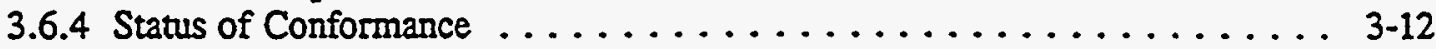

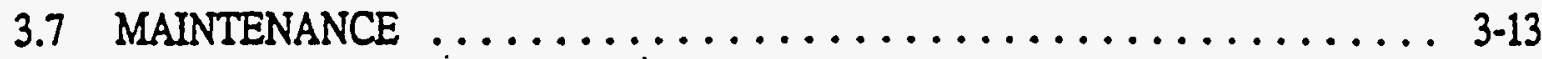

3.7 .1 Basic Objective . . . . . . . . . . . . . . . . . . . 3-13

3.7.2 Implementation Requirements . . . . . . . . . . . . . . . 3-13

3.7.3 How Requirements Are Met . . . . . . . . . . . . . . . . . 3-13

3.7.4 Status of Conformance $\ldots \ldots \ldots \ldots \ldots \ldots \ldots \ldots \ldots \ldots . \ldots \ldots$ 3-14

3.8 RADIATION PROTECTION PROGRAMS, SYSTEMS, DESIGNS, AND PERMITS ............................... 3-14

3.8 .1 Basic Objective . . . . . . . . . . . . . . . . . . . 3-14

3.8.2 Implementation Requirements . . . . . . . . . . . . . . . 3-14

3.8 .3 How Requirements Are Met . . . . . . . . . . . . . . . 3-16

3.8 .4 Status of Conformance $\ldots \ldots \ldots \ldots \ldots \ldots \ldots \ldots \ldots . \ldots \ldots$ 3-17

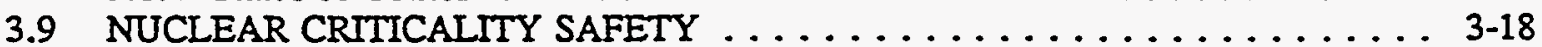

3.9 .1 Basic Objectives ......................... 3-18

3.9 .2 Implementation Requirements . . . . . . . . . . . . . . 3-18

3.9 .3 How Requirements Are Met . . . . . . . . . . . . . . . . . . . . 3-19

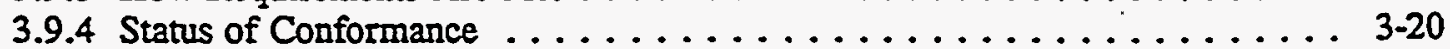

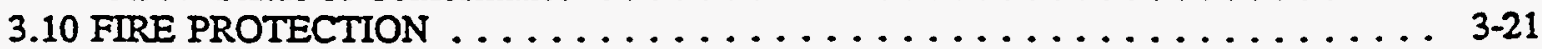

3.10 .1 Basic Objective ........................ 3-21

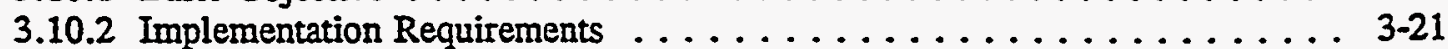

3.10 .3 How Requirements Are Met . . . . . . . . . . . . . . . . . 3-22

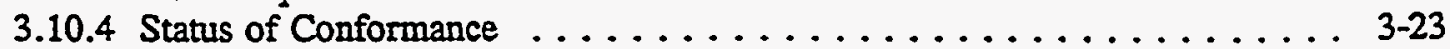

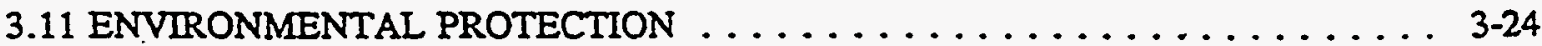

3.11 .1 Basic Objective . . . . . . . . . . . . . . . . . . . . . . . 3-24

3.11.2 Implementation Requirements $\ldots \ldots \ldots \ldots \ldots \ldots \ldots \ldots \ldots$. . . . . . . . . .

3.11.3 How Requirements Are Met . . . . . . . . . . . . . . . 3-24 
3.11.4 Status of Conformance $\ldots \ldots \ldots \ldots \ldots \ldots \ldots \ldots \ldots \ldots \ldots \ldots \ldots .24$

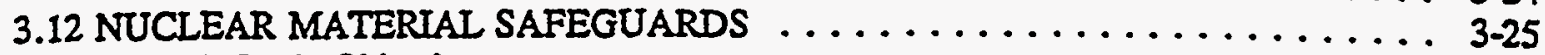

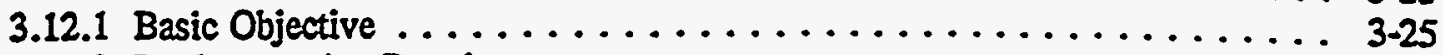

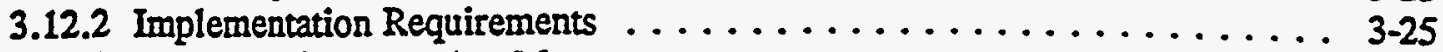

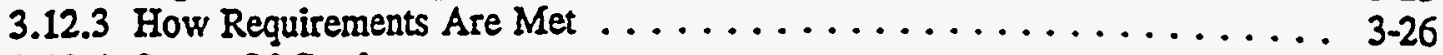

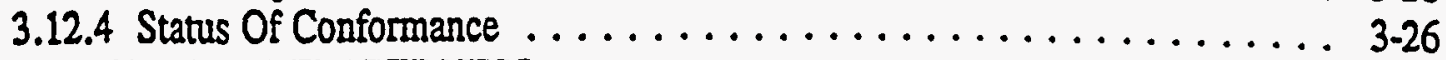

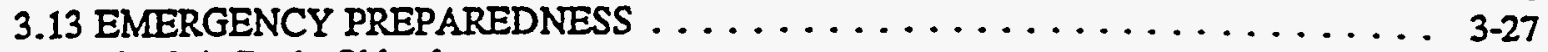

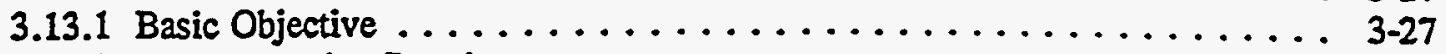

3.13.2 Implementation Requirements $\ldots \ldots \ldots \ldots \ldots \ldots \ldots \ldots \ldots$ 3-27

3.13.3 How Requirements Are Met $\ldots \ldots \ldots \ldots \ldots \ldots \ldots \ldots \ldots \ldots \ldots \ldots \ldots .28$

3.13.4 Status of Conformance $\ldots \ldots \ldots \ldots \ldots \ldots \ldots \ldots \ldots \ldots . .29$

3.14 PACKAGING AND TRANSPORTING NUCLEAR MATERIALS $\ldots \ldots \ldots \ldots ; 3-29$

3.14 .1 Basic Objective . . . . . . . . . . . . . . . . 3-29

3.14 .2 Implementation Requirements $\ldots \ldots \ldots \ldots \ldots \ldots \ldots \ldots \ldots$. $3-29$

3.14.3 How Requirements Are Met $\ldots \ldots \ldots \ldots \ldots \ldots \ldots \ldots \ldots .3-30$

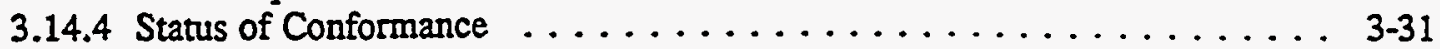

3.15 SAMPLING AND ANALYSIS $\ldots \ldots \ldots \ldots \ldots \ldots \ldots \ldots \ldots \ldots \ldots \ldots \ldots \ldots$

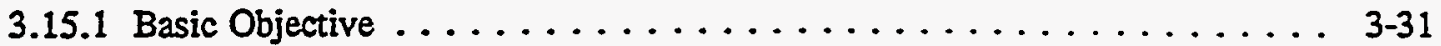

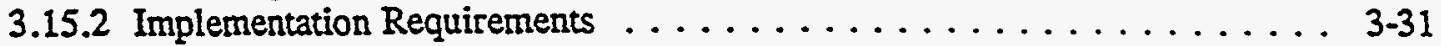

3.15.3 How Requirements Are Met $\ldots \ldots \ldots \ldots \ldots \ldots \ldots \ldots \ldots \ldots \ldots .3 .32$

3.15.4 Status of Conformance $\ldots \ldots \ldots \ldots \ldots \ldots \ldots \ldots \ldots \ldots \ldots \ldots \ldots \ldots \ldots, 33$

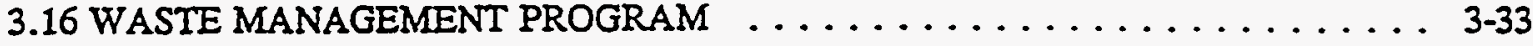

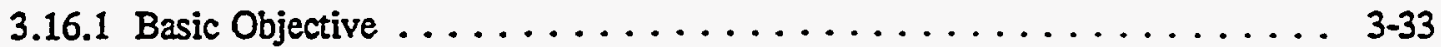

3.16 .2 Implementation Requirements $\ldots \ldots \ldots \ldots \ldots \ldots \ldots \ldots \ldots . .3-33$

3.16.3 How Requirements Are Met $\ldots \ldots \ldots \ldots \ldots \ldots \ldots \ldots \ldots \ldots .3 .34$

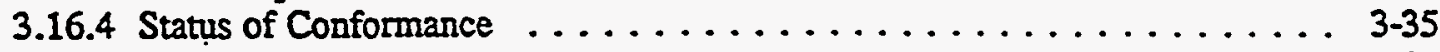

3.17 ACCDENT ANALYSES $\ldots \ldots \ldots \ldots \ldots \ldots \ldots \ldots \ldots \ldots \ldots \ldots \ldots \ldots \ldots \ldots \ldots$

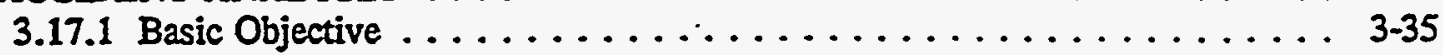

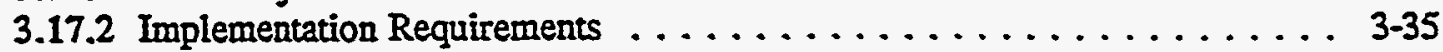

3.17.3 How the Requirements Are Met $\ldots \ldots \ldots \ldots \ldots \ldots \ldots \ldots \ldots$ 3-35

3.17 .4 Status of Conformance $\ldots \ldots \ldots \ldots \ldots \ldots \ldots \ldots \ldots \ldots \ldots \ldots \ldots$

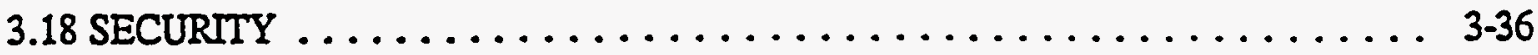

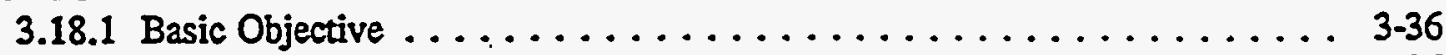

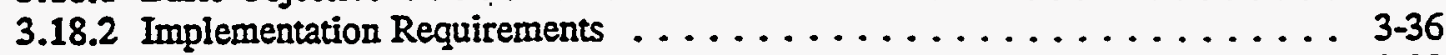

3.18.3 How the Requirements Are Met $\ldots \ldots \ldots \ldots \ldots \ldots \ldots \ldots \ldots .3 .38$

3.18.4 Status of Conformance $\ldots \ldots \ldots \ldots \ldots \ldots \ldots \ldots \ldots \ldots \ldots \ldots \ldots \ldots, 38$

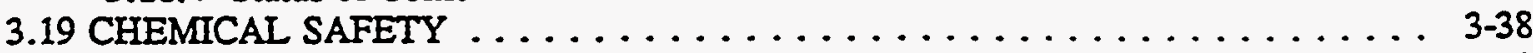

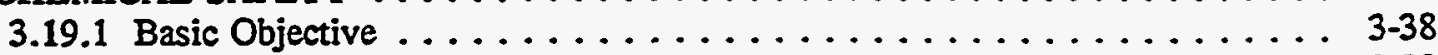

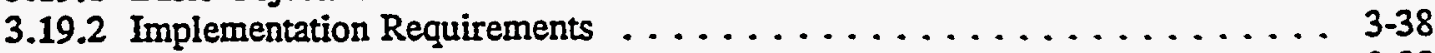

3.19.3 How the Requirements Are Met $\ldots \ldots \ldots \ldots \ldots \ldots \ldots \ldots \ldots .3 .38$

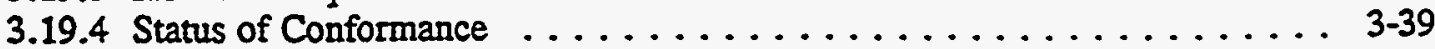

4. DEPARTMENT OF ENERGY OVERSIGHT $\ldots \ldots \ldots \ldots \ldots \ldots \ldots \ldots \ldots \ldots$ 4-1

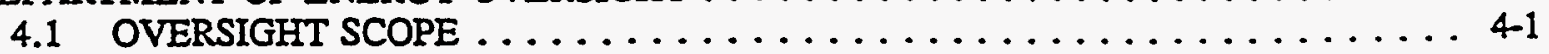

4.2 PROGRAM FOR OVERSIGHT OF USEC $\ldots \ldots \ldots \ldots \ldots \ldots \ldots \ldots \ldots \ldots \ldots, 4$

4.2 .1 Regulatory Oversight Manager $\ldots \ldots \ldots \ldots \ldots \ldots \ldots \ldots \ldots \ldots \ldots \ldots \ldots \ldots \ldots \ldots \ldots \ldots, 4$

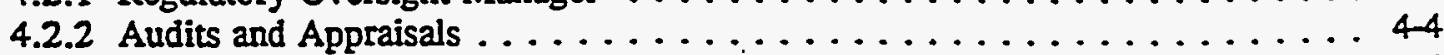

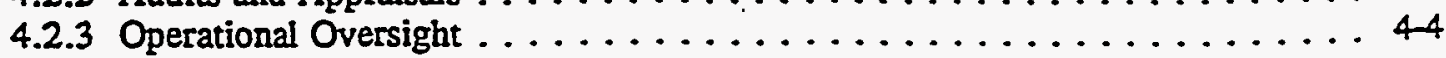

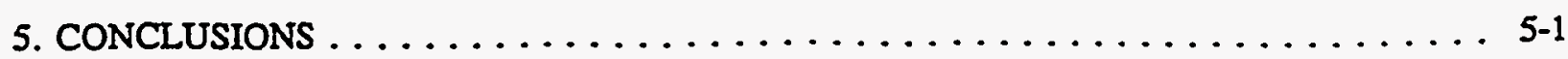


DOE/ORO - 2051

6. BIBLIOGRAPHY $\ldots \ldots \ldots \ldots \ldots \ldots \ldots \ldots \ldots \ldots \ldots \ldots \ldots \ldots \ldots \ldots \ldots \ldots$

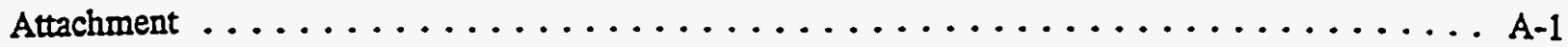

vi 


\section{FIGURES}

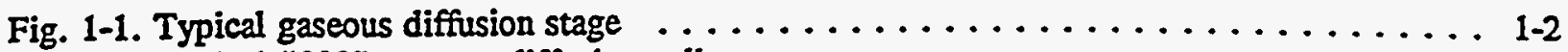

Fig. 1-2. Typical "000" gaseous diffusion cell $\ldots \ldots \ldots \ldots \ldots \ldots \ldots \ldots \ldots \ldots \ldots \ldots$

Fig. 2-1. Uranium releases to the atmosphere $\ldots \ldots \ldots \ldots \ldots \ldots \ldots \ldots \ldots \ldots \ldots$

Fig. 2-2. PORTS Collective External Exposures . . . . . . . . . . . . . . . . . 2-7

Fig. 2-3. PGDP Collective External Exposures . . . . . . . . . . . . . . . . . 2-8

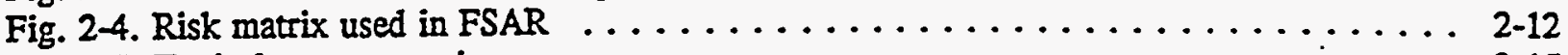

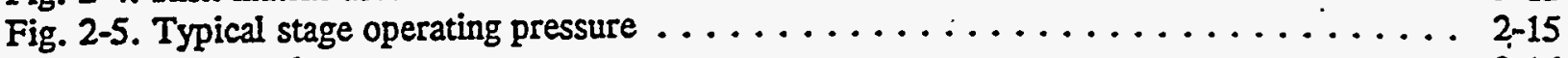

Fig. 2-6. Plant peak power usage $\ldots \ldots \ldots \ldots \ldots \ldots \ldots \ldots \ldots \ldots \ldots \ldots \ldots \ldots \ldots . \ldots \ldots$

Fig. 2-7. Typical Paducah cascade configuration and conditions at $3040 \mathrm{MW} \ldots \ldots \ldots . . .2-17$

Fig. 2-8. PORTS typical cascade flow, pressure, and average assays at $2100 \mathrm{MW} \ldots \ldots . . .2-18$

Fig. 2-9. Typical Paducah cascade configuration and conditions at $1600 \mathrm{MW} \ldots \ldots . . .$. . . . 19

Fig. 2-10. PORTS typical cascade flow, pressure, and average assays at $1900 \mathrm{MW} \ldots \ldots$. . 2-20

\section{TABLES}

Table 2-1. Major Potential Hazards at GDPs. . . . . . . . . . . . . . . 2-10

Table 2-2. Hazard rating scale. . . . . . . . . . . . . . . . . . . . . . 2-13

Table 2-3. Toxic material release accident scenario summary . . . . . . . . . . . . . . . . . 2-22

Table 2-4. Criticality accident scenario summary . . . . . . . . . . . . . . . . 2-24

Table 4-1. Department of Energy Orders Impacting Nuclear Safety . . . . . . . . . . . 4-1

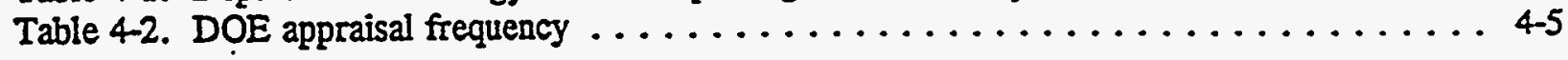


DOE/ORO - 2051 


\section{PREFACE}

The Energy Policy Act of 1992 (the Act) transfers responsibility for the gaseous diffusion plants (GDPs) at Portsmouth, Ohio, and Paducah, Kentucky, from the Department of Energy (DOE) to the newly created United States Enrichment Corporation (USEC) effective July 1, 1993. The Act requires the Nuclear Regulatory Commission (NRC) to establish regulatory standards by October 1994 which the NRC will use to certify and regulate the GDPs. Until NRC assumes regulatory oversight for the GDPs, USEC will assume responsibility for the plants under DOE requirements and oversight for nuclear safety and safeguards and security.

DOE's nuclear safety and safeguards and security programs derive their authority from the DOE orders system. However, not all DOE orders have nuclear safety or safeguards and security implications for the GDPs. The primary purpose of this document is to define the critical set of nuclear safety and safeguards and security requirements and the bases for DOE regulatory oversight that are essential for the continued safe and secure operations of the GDPs. This document applies to DOE regulatory oversight from July 1, 1993, until the NRC issues regulatory standards, certifies compliance, and/or approves a pian for compliance and assumes regulatory oversight for the GDPs.

The document describes how the applicable requirements are implemented at the GDPs and how these requirements will continue to be met during the period of DOE oversight.

A secondary purpose of this document is to make information available to the NRC regarding the DOE safety and safeguards and security bases for the GDPs; these may be useful to the NRC in developing regulatory standards for the GDPs. 
Blank page 


\section{LIST OF ACRONYMS}

\begin{tabular}{|c|c|}
\hline ACR & Area Control Room \\
\hline AËA & Atomic Energy Act \\
\hline AEC & Atomic Energy Commission \\
\hline AHIJ & Authority Having Jurisdiction \\
\hline AIHA & American Industrial Hygiene Association \\
\hline ALARA & As Low As Reasonably Achievable \\
\hline ANS & American Nuclear Society \\
\hline ANSI & American National Standards Institute \\
\hline ASME & American Society of Mechanical Engineers \\
\hline CCR & Central Control Room \\
\hline CFR & Code of Federal Regulations \\
\hline CIP & Cascade Improvement Program \\
\hline $\mathrm{CoC}$ & Certificate of Compliance \\
\hline CUP & Cascade Uprating Program \\
\hline DMR-QA & Discharge Monitoring Report-Quality Assurance \\
\hline DOE & Department of Energy \\
\hline DOE-HQ & Department of Energy-Headquarters \\
\hline DOELAP & Department of Energy Laboratory Accreditation Program \\
\hline DOE/ORO & DOE's Oak Ridge Operations Office \\
\hline DOT & Department of Transportation \\
\hline EAI & Emergency Action Level \\
\hline EDE & Effective Dose Equivalent \\
\hline EML & Environmental Measurements Laboratory \\
\hline EMSL-IV & Environmental Measurements Systems Laboratory-Las Vegas \\
\hline Energy Systems & Martin Marietta Energy Systems, Inc. \\
\hline EOC & Emergency Operations Center \\
\hline EPA & Environmental Protection Agency \\
\hline ERDA & Energy Research and Development Administration \\
\hline ESH & Environment, Safety, and Health \\
\hline ES\&H & Environmerital, Safety, and Health \\
\hline ESO & Engineering Service Orders \\
\hline FSAR & Final Safety Analysis Report \\
\hline FY & Fiscal Year \\
\hline GDP & Gaseous Diffusion Plant \\
\hline HAUP & Higher Assay Upgrading Project \\
\hline HAZWOPER & Hazardous Waste Operations and Emergency Response \\
\hline HEU & High Enriched Uranium \\
\hline HQ & Headquarters \\
\hline HSRC & Health and Safety Review Committee \\
\hline IAEA & International Atomic Energy Agency \\
\hline INPO & Institute of Nuclear Power operators \\
\hline ISRC & Independent Safety Review Committee \\
\hline $\mathrm{K}-25$ & Oak Ridge K-25 Site \\
\hline LEU & Low Enriched Uranium \\
\hline LLRW & Low Level Radioactive Waste \\
\hline M\&TE & Measuring and Test Equipment \\
\hline $\mathrm{MC} \& \mathrm{O}$ & Management Controls and Oversight \\
\hline M\&O & Management and Operations \\
\hline
\end{tabular}




\section{- LIST OF ACRONYMS (Continued)}

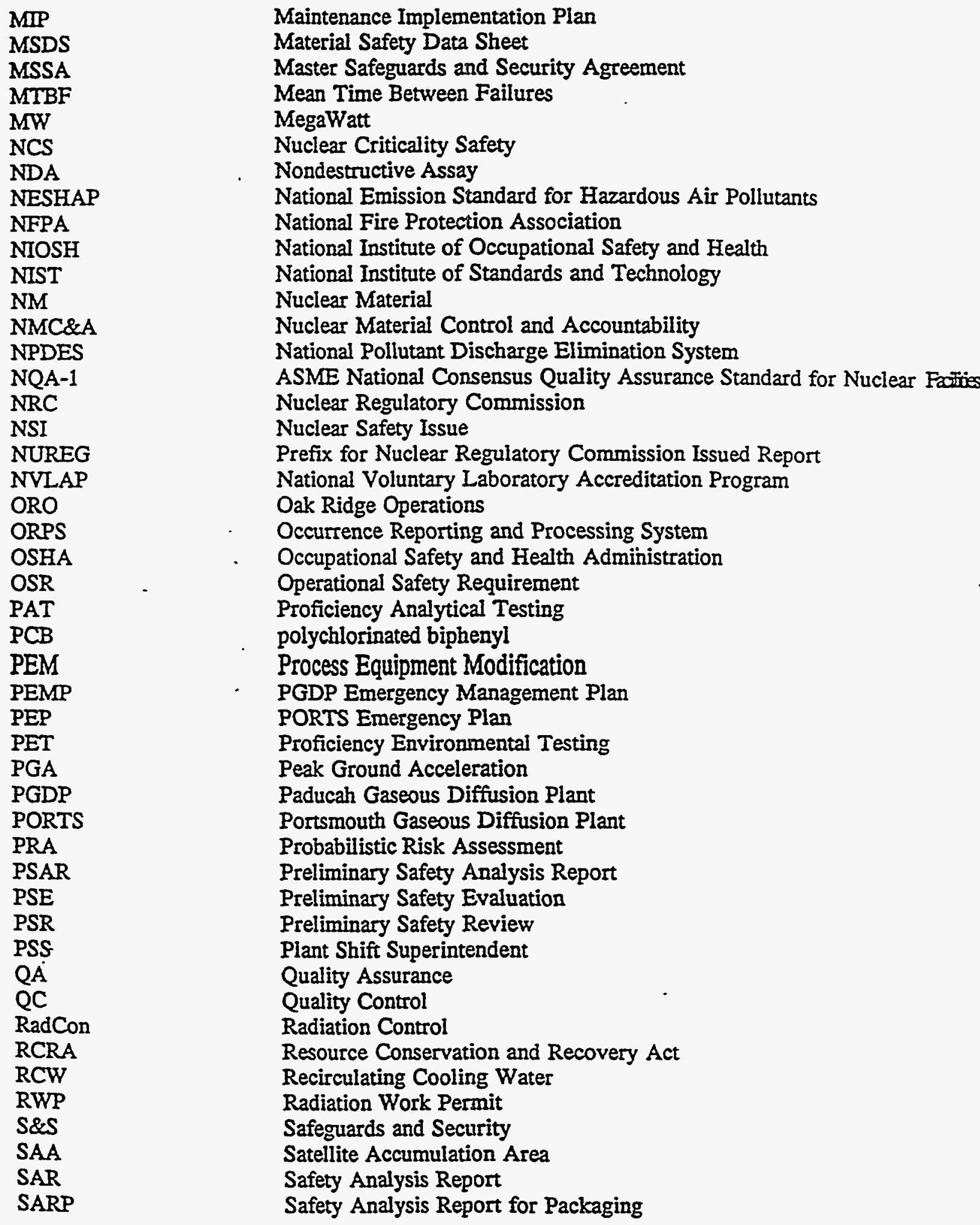




\section{LIST OF ACRONYMS (Continued)}

SEN

SNM

SPP

SSA

SWU

TDAG

ILD

TSCA

TSD

UE

UEQPP

USAEC

USEC

USQ

USQD

WAC
Secretary of Energy Notices

Special Nuclear Material

Standard Practice and Procedure

System Safety Analysis

Separative Work Unit

Training Development and Administrative Guide

thermoluminescent dosimeter

Toxic Substances Control Act

Treatment, Storage, and Disposal

Uranium Enrichment

Uranium Enrichment Quality Program Plan

United States Atomic Energy Commission

United States Enrichment Corporation

Unreviewed Safety Question

Unreviewed Safety Question Determination

Waste Acceptance Criteria 


\section{EXECUTIVE SUMMARY}

The Energy Policy Act of 1992 (the Act) transfers responsibility for the gaseous diffusion plants (GDPs) at Portsmouth, Ohio, and Paducah, Kentucky, from the Department of Energy (DOE) to the newly created United States Enrichment Corporation (USEC) effective July 1, 1993. The Act requires the Nuclear Regulatory Commission (NRC) to establish regulatory standards by October 1994 which the - NRC will use to certify and regulate the GDPs. Until NRC assumes regulatory oversight for the GDPs, USEC will assume responsibility for the plants under DOE requirements and oversight for nuclear safety and safeguards and security. In support of this DOE oversight, this report

- defines the essential safety and safeguards and security requirements for GDP operations, :

- defines a continuing framework of safety and safeguards and security requirements for DOE oversight of the GDPs until regulatory oversight for the GDPs is assumed by NRC.

- provides information with respect to overall GDP safety, and

- provides information that may be useful to NRC in the development of regulatory standards for the GDPs.

To accomplish these objectives, this report contains five chapters that present the following information:

- introduction and background;

- plant safety, safety analyses, and historical DOE oversight programs;

- safety and safeguards and security requirements and how they will be implemented during the period of DOE oversight;

- DOE's oversight plan for nuclear safety and safeguards and security at the GDPs; and

- conclusions.

The information contained in this report supports the following conclusions.

1. The plants are currently operating safely under DOE nuclear safety and safeguards and security management and oversight program. This conclusion is supported by the results of both routine DOE audits and appraisal programs and special assessments.

2. The proven safety of the original GDP design has been enhanced through upgrade projects and the application of lessons learned over the GDPs' operational lifetimes. This conclusion is reinforced by the 1985 Final Safety Analysis Reports (FSARs), revisions to the FSARs, and the Operational Safety Requirements(OSRs). (PGDP KY-374, KY-315, and upgrades; PORTS GAT/GDP 1073 and GAT/GDP-1074 Parts A through L).

3. The plants can continue to operate safely and securely under the Implementation Requirements set forth in Chapter 3. 
DOE/ORO - 2051

4. The USEC's commitment to continue to meet these requirements coupled with DOE's regulatory oversight plan set forth in Chapter 4 provide adequate assurance that the plants will continue to meet the Implementation Requirements and operate safely under DOE regulatory oversight. 


\section{INTRODUCTION}

\subsection{GASEOUS DIFFUSION PROCESS}

Two operating plants in the United States use gaseous diffusion technology to enrich uranium for government programs and commercial customers, primarily electric utilities that operate nuclear power plants. These are the Portsmouth Gaseous Diffusion Plant (PORTS), located on 3800 acres in Pike County, Ohio, and the Paducah Gaseous Diffusion Plant (PGDP), located on 3423 acres in McCracken County, Kentucky. Presently Martin Marietta Energy Systems, Inc., (Energy Systems) operates the two plants for the Department of Energy (DOE).

The gaseous diffusion enrichment process uses the UF, form of uranium, which is a white, crystalline solid at ambient conditions and a gas at process conditions. The enrichment method increases ${ }^{235} \mathrm{U}$ concentrations by physical processes; the $\mathrm{UF}_{6}$ gas is not chemically altered.

The gaseous diffusion process employs a series of compressors and converters to enrich the ${ }^{25 s} U$ isotope of the process gas. The fundamental building block of the process consists of a compressor and a converter and is known as a stage. Stages are grouped together in series to form cells. The cells are then interconnected to provide what is known as a cascade. The compressors, which are driven by electric motors, are used to circulate the process gas and maintain flow through the cascade. The converters contain porous tubes or barriers through which the process gas is diffused. In each converter, a portion of the process gas diffuses through the barrier and is fed to the next higher stage, with the undiffused gas being recycled to the next lower stage. The diffused stream is slightly enriched with respect to ${ }^{255} \mathrm{U}$, while the undiffused stream is depleted of ${ }^{25} \mathrm{U}$ to the same degree. Each stage also contains a gas cooler to remove the heat of compression from the process gas and a control valve for process control. (See Figs. 1-1 and 1-2, which depict a stage and a cell, respectively.) The output of PGDP is now one of the feed streams to PORTS.

PORTS can produce 7.9 million separative work units (SWUs) annually at a rated power consumption of 2100 megawatts (MW), while PGDP can produce 11.3 million SWUs annually at its rated power consumption of $3040 \mathrm{MW}$. The maximum assay at PGDP is currently limited to 2 wt \% ${ }^{235} \mathrm{U}$. PORTS uses PGDP's product as enriched feed and can enrich product to nearly 20 wt \% ${ }^{235} \mathrm{U}$. Safety documentation has been submitted, and modifications are in progress to increase the maximum PGDP assay. When the regulating authority approves the safety documentation and when the modifications are completed, PGDP will be able to produce assay, at up to $5 \mathrm{wt} \%{ }^{23} \mathrm{U}$. PORTS also produced fully enriched uranium until 1992. 


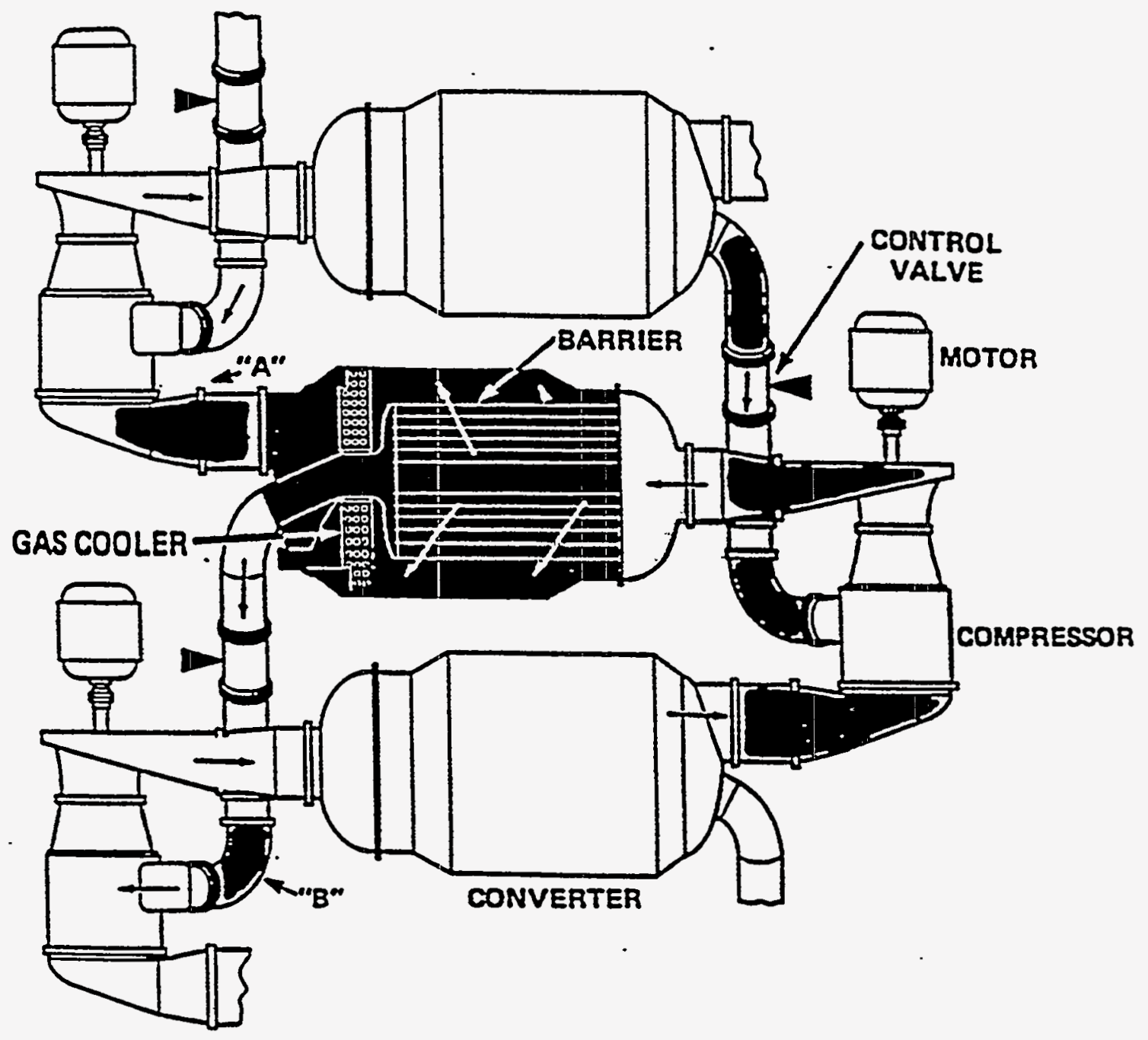

Fig. 1-1. Typical gaseous diffusion stage. 

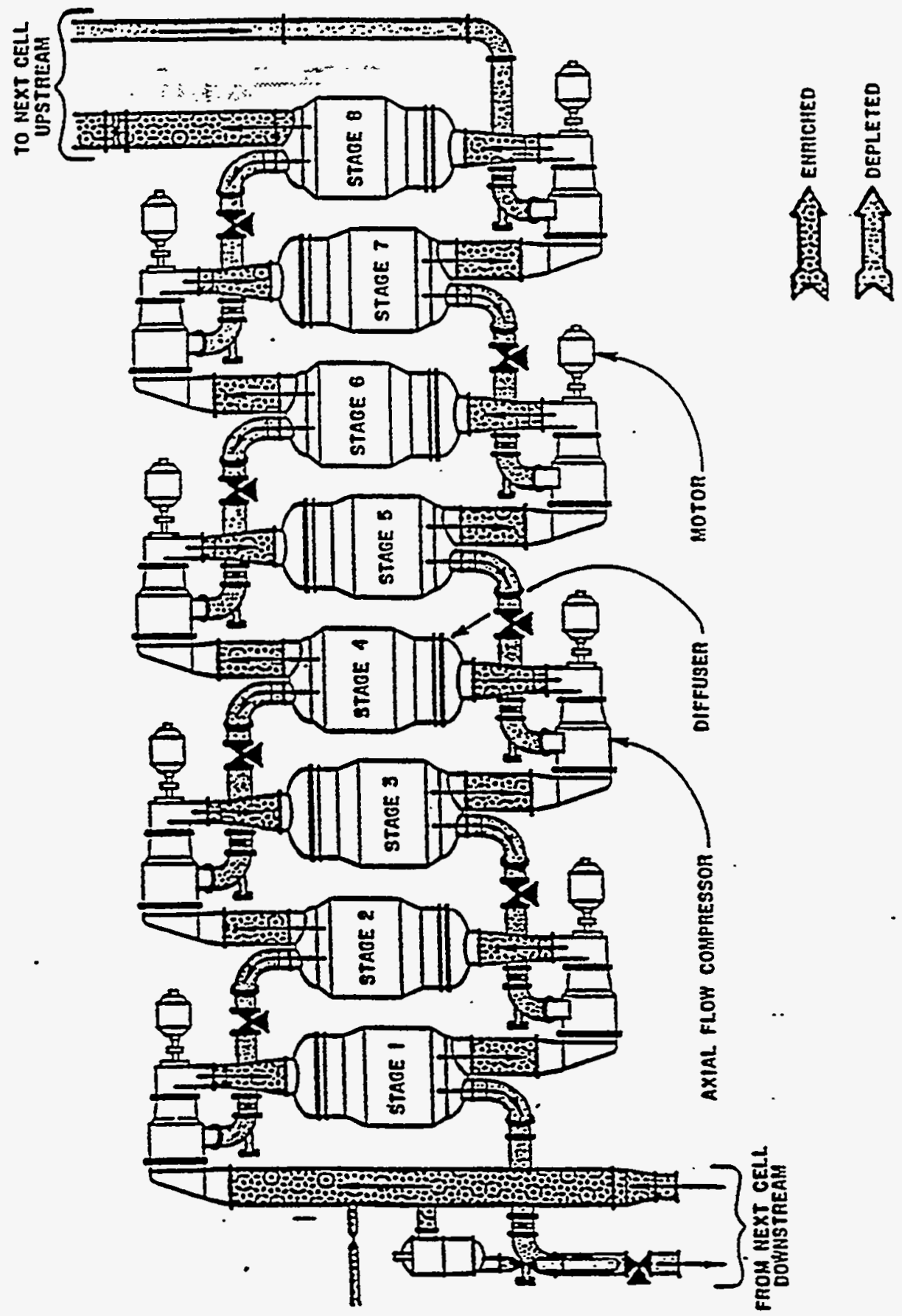

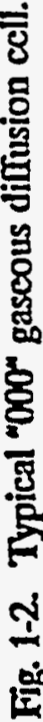




\subsection{BACKGROUND}

The Energy Policy Act of 1992 transfers responsibility for the gaseous diffusion plants (GDPs) at Portsmouth, Ohio, and Paducah, Kentucky, from the Department of Energy (DOE) to the newly created United States Enrichment Corporation (USEC) effective July 1, 1993. The Act requires the Nuclear Regulatory Commission (NRC) to establish regulatory standards by October 1994 which the NRC will use to certify and regulate the GDPs. Until NRC assumes regulatory oversight for the GDPs, USEC will assume responsibility for the plants under DOE requirements and oversight for nuclear safety and safeguards and security.

DOE requirements for nuclear safety and safeguards and security are derived from the DOE Orders system. However, not all DOE Orders have nuclear safety or safeguards and security implications for the GDPs. Only those orders that address nuclear safety and safeguards and security requirements applicable to the GDPs are discussed in this report.

\subsection{PURPOSE}

The purpose of this report is to:

- define the essential nuclear safety and safeguards and security requirements for continued safe and secure GDP operations;

- outline the framework of nuclear safety and safeguards and security requirements for DOE oversight of GDP operations, which will continue until NRC assumes regulatory oversight of the GDPs;

- provide information to the NRC with respect to overall GDP safety; and

- provide information which may be useful to NRC in developing its regulatory standards for GDPs.

\subsection{REPORT STRUCTURE}

This report consists of five chapters including this introduction. Chapter 2 discusses the historically safe operation of the GDPs, the DOE oversight programs with respect to the GDPs and the safety characteristics of the plants as documented in safety analysis and hazards assessments. Chapter 3 defines safety objectives, Implementation Requirements to meet these objectives, the manner in which the Implementation Requirements are met and summarizes the status of conformance with these requirements. The GDPs will operate under DOE oversight with respect to these requirements until the NRC assumes regulatory oversight responsibility for the GDPs.

Chapter 4 describes the DOE oversight plan for nuclear safety and safeguards and security of the GDPs during the interim period, and Chapter 5 presents the conclusions drawn from the review. 


\section{SAFETY OF GDPS}

The safety of PORTS and PGDP operations is demonstrated by the excellent nuclear and process safety record established by more than 40 years of operation at each of the plants and by the analysis of postulated accidents and anticipated operational incidents. In addition, through DOE's oversight and Energy Systems' corporate responsibility, numerous periodic and special reviews and assessments have been conducted to ensure continued safe operations. For safety significant incidents, internal and external investigations are systemically employed to ensure that incident precursors and root causes are identified and addressed to prevent recurrence.

This section describes the safety basis for current GDP operations through a discussion of the following:

- The early history of the DOE enrichment complex and the significant safety improvements at the plants, including those identified from analysis of significant incidents experienced within the complex;

- The low levels of off-site hazardous releases resulting from recent operating experience;

- The safety basis as described in the Safety Analysis Reports (SARs), including discussion of the hazards and accident scenarios;

- Maintenance of safety documentation;

- The limitations on plant operation contained within the Operational Safety Requirements (OSRs);

- The effects of plant aging on safety;

- Efforts to upgrade the safety. documentation to meet current DOE requirements; and

- Historical DOE oversight of GDPs.

\subsection{SAFETY DEMONSTRATED BY OPERATING HISTORY}

PORTS and PGDP were constructed in the early 1950s to supply enriched uranium to both the United States Government Weapons Production Program and to the Atomic Energy Program. Through more than 100 years of collective operating experience (including the K-25 Site in Oak Ridge which operated from 1945 to 1985), the gaseous diffusion enrichment facilities have been characterized by an attention to process safety and have proven to be well designed for the wide variety of operating conditions that have been experienced.

During the more than 100 years of collective operating experience, no incidents at any of the GDPs have caused death or serious injury to plant personnel from exposure to radioactive materials or radiation. Likewise, no incidents at any of the GDPs have resulted in off-site releases of radiation or radioactive materials that could cause committed doses in excess of established limits. This excellent operating record attests to the quality of the safety measures designed into the GDPs and to the safety consciousness of facility personnel, particularly because much of this operating history occurred when the requirements for environmental protection, safety, and health protection were less stringent than they are today. The 
safety consciousness during this period has also been enhanced by the incorporation into daily operations of the lessons learned from operating experience. Furthermore, DOE and the operating contractors have continually upgraded the technology at the GDPs to enhance safety, production capacity, and overall efficiency. These activities are described briefly in the following sections.

\subsubsection{Early History}

The first full-production-size GDP was built on the K-25 Site in Oak Ridge, Tennessee, as part of the original Manhattan Project in Worid War II. The gaseous diffusion processes at the K-25 Site are shut down and are no longer used to enrich uranium. Although the K-25 GDP performed safely throughout its entire operating life, the lessons learned from its early operations provided insights on design, construction, and operational improvements that were used to enhance safety at the two currently operating GDPs, built during the early 1950s. Examples of the enhancements incorporated in the design, construction, and operations of PORTS and PGDP include:

- surveys to detect uranium deposits in the process system,

- improvements in the handling of $\mathrm{UF}_{6}$ cylinders;

- replacement of carbon chemical traps in the seal exhaust systems with alumina traps, eliminating a reaction threat; and

- installation of $\mathrm{UF}_{6}$ containment autoclaves.

\subsubsection{Cascade Improvement Program and Cascade Uprating Programs}

Although the enrichment complex was originally constructed to produce nuclear weapons-grade enriched uranium, the 1960 s brought an added mission for these plants, the production of low enriched uranium (LEU) for civilian nuclear power plants. To fulfill this mission in an era of increasing orders for new civilian nuclear power plants and increasing demand for enriched uranium, the efficiency and capacity of the three GDPs were increased. The \$1.4 billion Cascade Improvement Plan (CIP) and Cascade Uprating Program (CUP) significantly increased efficiency and capacity; both were initiated in the early 1970s and completed in the early 1980s. The CIP increased the separative efficiency of the GDPs through installation of more efficient gaseous diffusion barriers and larger equipment and by improving the flow of the uranium hexafluoride gas. The CUP increased the production capacity of the plants. For each change, technological improvements were made to the original design and construction of the GDP. The design of these upgrades also incorporated appropriate safety improvements based, in part, upon the GDP operating experience between the 1950s, when the plants were initially built, and the early 1970s, when the upgrades were designed and installed. Ultimately, the combined effect of the CIP and CUP programs was to increase the overall separative capacity of the GDPs by $58 \%$ at substantially lower cost than would be expended on designing and constructing equivalent new facilities. As part of these modifications, the following safety improvements were made to the plants:

- UF, leak detectors,

- double-wall bellows on thermal expansion joints, and

- improvements to compressor seals. 


\subsubsection{Formal Review of Operating Experience}

In addition to the early lessons learned at the K-25 Site, the sharing of operating experience and the investigation of incidents have further enhanced the safety programs at PORTS and PGDP. Significant incidents have typically been the subject of formal, structured reviews that included a detailed review of the circumstances surrounding the events, and the identification of the root or apparent causes of the events, the development of corrective action(s) to prevent the recurrence of the particular events and similar events. DOE has initiated and led reviews of the more significant events. In many other cases, DOE did not deem the event to be sufficiently significant to merit a DOE-led review, and the DOE Management and Operations (M\&O) contractor for the sites (presently Martin Marietta Energy Systems, Inc., previously Union Carbide for PGDP and K-25 until 1984, and Goodyear Atomic for PORTS until 1986) conducted the reviews. Two significant incidents which were examined in this manner are described below as examples of this process.

Event

Hydrocarbon oil reacted with liquid $\mathrm{UF}_{6}$ in a cylinder at $\mathrm{K}-25$ in 1975 . The cylinder ruptured, but less than 20 pounds of $U_{6} F_{6}$ were released. No irreversible health effects to plant workers and no off-site releases above established limits occurred.

A 14-ton UF, cylinder (in liquid state) was dropped from a straddle carrier and ruptured at PORTS in 1978. No irreversible health effects to plant workers and no off-site releases above established limits occurred.
Corrective Action

Use of hydrocarbon oil sealed pumps without an in-line trap which can hold the entire oil contents of the pump to purge cylinders was prohibited.

Maintenance practices for straddle carriers were improved, administrative controls to enhance the safety of cylinder moves were designed, and subsequently procedures were revised to prohibit moving UF $_{6}$ cylinders in the liquid state with straddle carriers.

\section{Safety Improvement}

The risks of $\mathrm{UF}_{6}$ reaction and of personnel exposure to $U_{6}$ were reduced.

In addition to conducting formal reviews of specific incidents, representatives of the operating plants (including K-25 when gaseous diffusion operations were being conducted there) and technical experts have been meeting regularly to share the lessons learned from operating experiences related to safety and operational issues.

More recently, the DOE requirements have been changed to institute a more formal process of reporting safety significant occurrences throughout the $D O E$ complex. These requirements, which include the investigation of root cause(s), the development of corrective actions, and the preparation of initial and follow-up reports, are described in Sect. 3.2.

\subsubsection{Recent Operating Experience}

Both sites have active programs to monitor and control environmental releases and personnel radiation exposures. These programs include extensive requirements for reporting to DOE (e.g., 
performance indicators and annual environmental reports) and responsible environmental protection agencies. As shown in the following paragraphs, PGDP and PORTS release only a minute quantity of the $U F_{6}$ handled every year and release minimum quantities of radionuclides; therefore, individual exposures are limited to extremely low doses of radioactivity.

\subsubsection{Uranium Releases}

The quantity of uranium released to the atmosphere has decreased significantly in recent years (as shown in Fig. 2-1) because procedure development, training, and conduct of operations have been emphasized. Aside from the 14-ton cylinder release at PORTS in 1978 (which is discussed in Sect. 2.2.2.2), the release data demonstrates the effectiveness of the application of lessons learned by the decreasing trend of the release quantities. More than $95 \%$ of the total releases occurred before 1970. Less than $1 \%$ of the total releases has occurred in the last 12 years.

\subsubsection{Radionuclides}

\section{Radionuclide Releases}

Radionuclide release monitoring programs are designed to comply with federal and state environmental regulatory requirements and DOE Orders. To ensure compliance, potential and actual sources of any releases must be identified, controls must be implemented to abate emissions within specified limits, and routine measurements must be taken to demonstrate compliance. Plant emissions must comply with National Emissions Standards for Hazardous Air Pollutants (NESHAP) as mandated by EPA. The NESHAP standard for air emission from plant operations at the GDPs is $10 \mathrm{mrem} / \mathrm{year}$. 


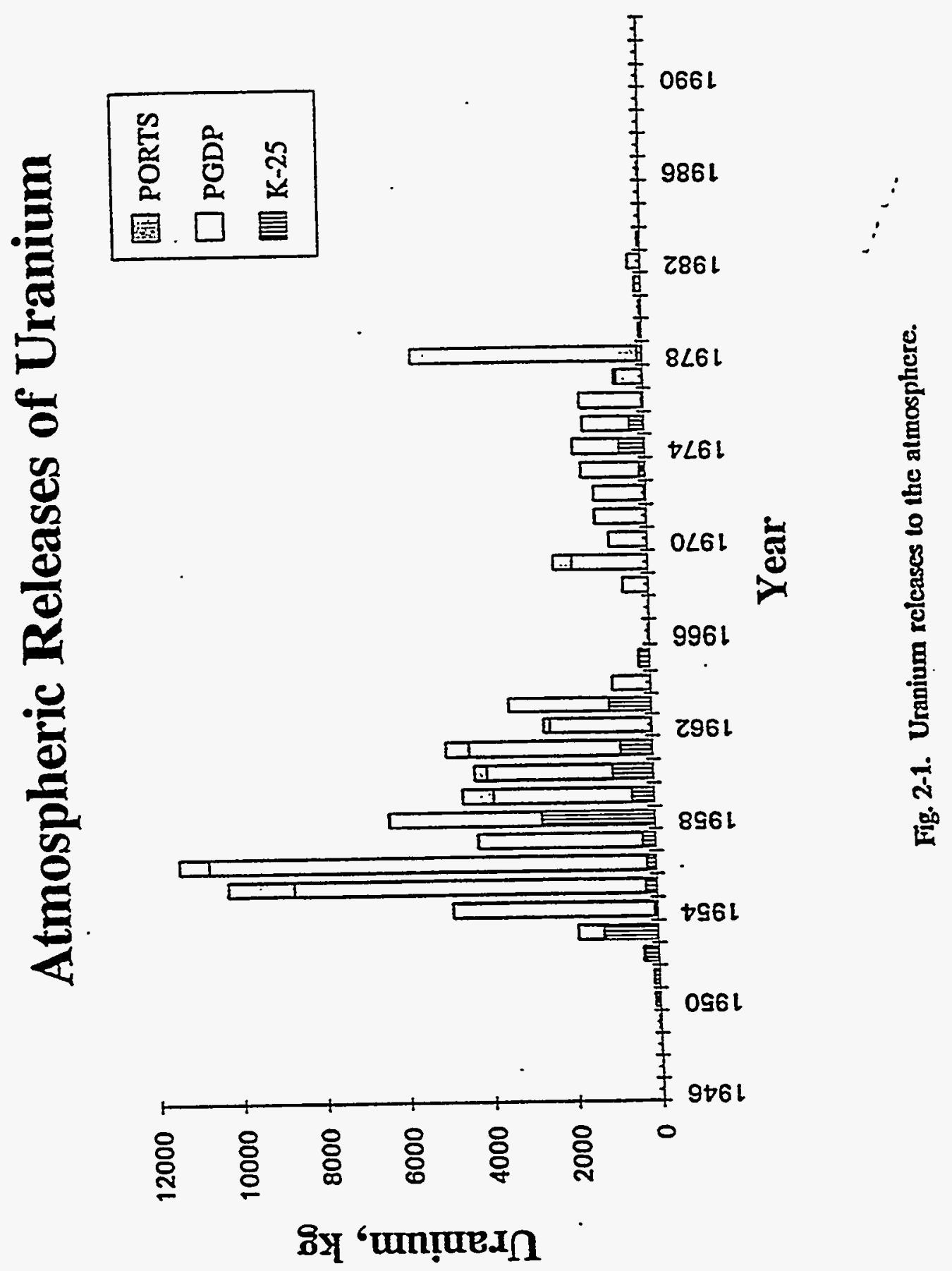




\section{Air Releases}

A risk-equivalent dose equivalent is used to estimate health effect risks to exposed persons and to the public from GDP operations. The effective dose equivalent (EDE) is a weighted sum of dose equivalents to specified organs. During the last several years, the maximum potential 50 -year committed EDE to any individual from airborne emissions has been a fraction of a millirem in any one year. Thus, the releases to the public have been well below the NESHAP standard allowable limit of $10 \mathrm{mrem} / \mathrm{year}$.

\section{Waterborne Releases}

Waterborne radionuclide emissions are monitored through the National Pollutant Discharge Elimination System (NPDES) process. Measured plant discharges have insignificant to no noticeable effect on radioactivity levels in the receiving waters. Conservative estimates of EDEs from waterborne discharges are much less than the Environmental Protection Agency (EPA) public drinking water limit of $4 \mathrm{mrem} / y e a r$ for beta-emitting radionuclides in a public water supply and are much less than the DOE limit of $100 \mathrm{mrem} / \mathrm{year}$ for all exposure pathways (waterborne plus airborne).

\subsubsection{Exposure levels}

Radiation levels at the GDPs are inherently low, and both sites include all on-site workers in personnel monitoring programs. As shown in Figs. 2-2 and 2-3 for PGDP and PORTS, respectively, the average doses for personnel are on the order of several mrem, and the cumulative dose received onsite by all personnel is normally less than 25 person-rem per-quarter. The average dose per person onsite has been less than $10 \mathrm{mrem}$ for both sites for the past 2 years and generally no more than a few tenths of mrem. The maximum annual deep penetrating dose for each plant is on the order of $250 \mathrm{mrem}$. This dose is inconsequential when compared to the current annual exposure limit, $5000 \mathrm{mrem}$ for the DOE and the NRC per DOE Order 5480.11 and per 10 CFR Part 20 (NRC requirement). Note that typically PORTS personnel receive a higher dose than PGDP personnel. This is due to the handling of higher assay material at PORTS than PGDP.

\subsection{SAFETY ANALYSIS SUMMARY FOR THE GASEOUS DIFFUSION PLANTS}

Documented safety analyses of nuclear and nonnuclear operations and facilities have been required for many years. In response to these requirements, various safety analyses have been conducted in conjunction with overall plant evaluations, specific modifications, and operational occurrences. Since the initial requirements relating to safety analysis were issued, DOE has modified its requirements in this area to require increased documentation rigor and formality and to reflect the evolution of safety analysis techniques. The current requirements for the performance and documentation of safety analyses are described in Sect. 3.17.

This section (1) summarizes the types of potential hazards associated with GDPs that could affect public health and safety; (2) presents an overview of the analyses of postulated accidents and abnormal conditions presented in the Final Safety Analysis Reports (FSARs) for PORTS and PGDP, which demonstrate that the GDPs can be operated safely and which, in conjunction with the OSRs, provide an envelope for safe operations; and (3) discusses the measures employed to address the 


\section{PORTS COLLECTIVE EXTERNAL EXPOSURES}

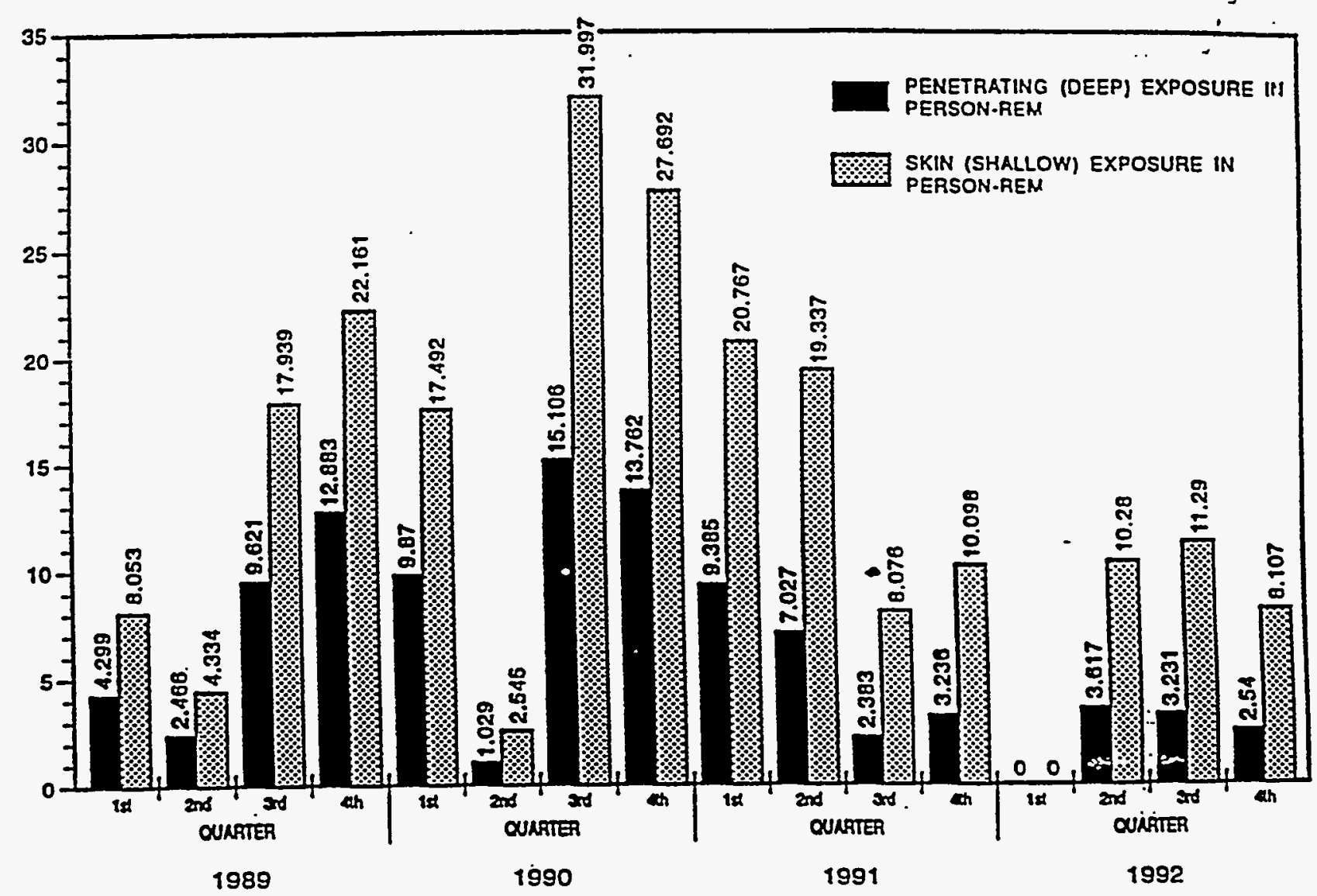

Fig. 2-2 PORTS Collective External Exposures. 


\section{PGDP COLLECTIVE EXTERNAL EXPOSURES}

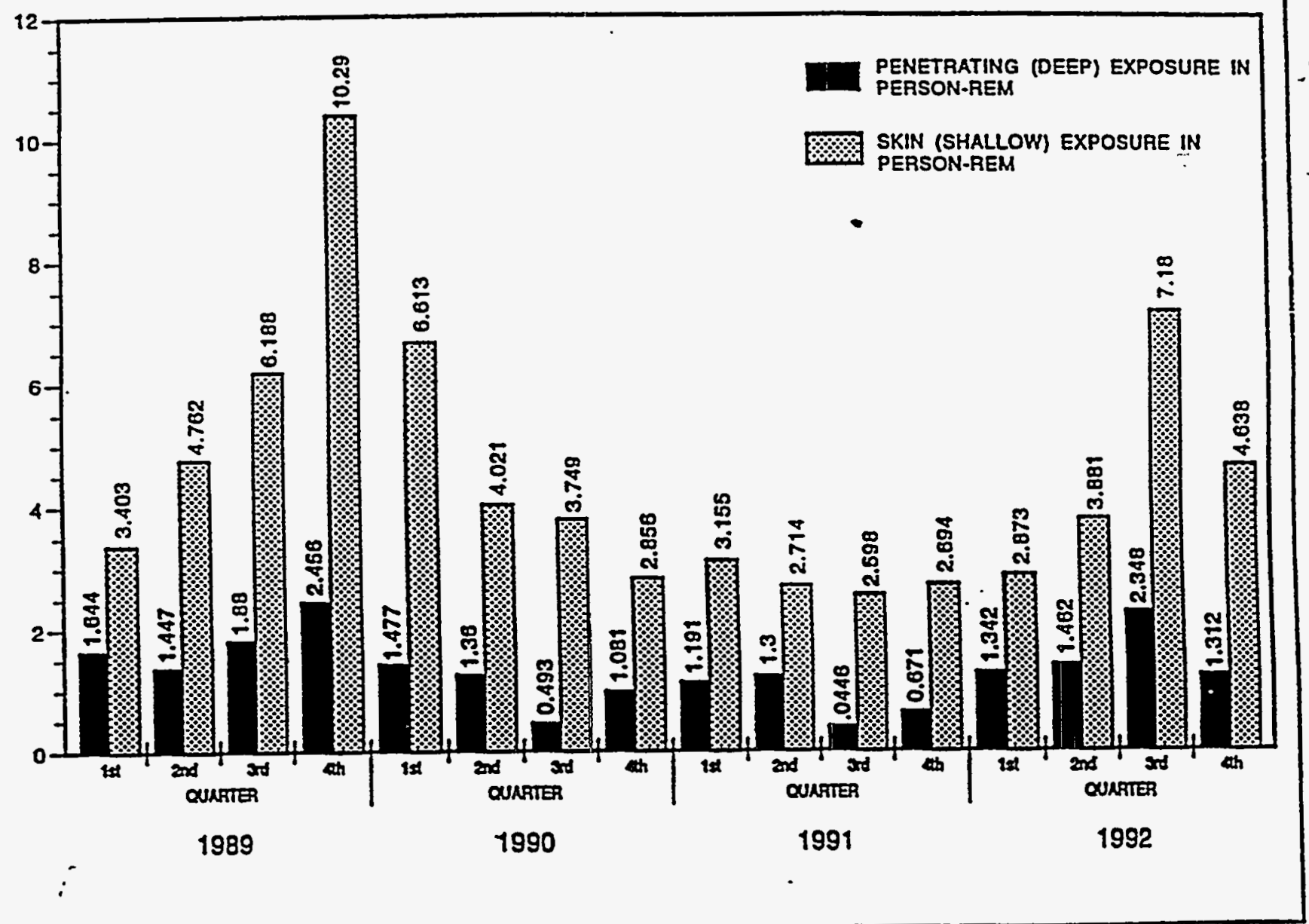

Fig. 2-3. PGDP Collective External Exposures. 
potential impact of aging on plant safety. Because DOE's safety analysis requirements have changed since the issue of the FSARs, this section also inciudes a brief description of efforts underway to enhance these analyses to comply with the current $\mathrm{DOE}$ requirements.

- nin

\subsubsection{Gaseous Diffusion Plant Hazards}

$\mathrm{UF}_{6}$ is the primary hazard of concern at the diffusion plants. Principally, this is because of the chemical toxicity of $\mathrm{UF}_{6}$ and its reaction products and because of the radioactivity and toxicity of uranium. In addition, in a $U_{F}$ release to the atmosphere, $U_{F} F_{6}$ reacts exothermically with water vapor in the air to create HF which is a highly toxic material. A previous NRC study compared the toxicity of uranium and HF to $10 \mathrm{CFR}$ Part 100 off-site radiation guidelines, which NRC uses for reactor regulation. These comparisons and studies performed for releases of large quantities of UF 6 revealed that the primary concern to the health and safety of the public is the chemical toxicity of $\mathrm{UF}_{6}$ and its reaction products. Thus, any significant risk to the health and safety of the public would arise from the chemical toxicity of the materials used in the operation of the GDPs rather than from their radioactive properties. Nevertheless, radioactive properties of uranium have been considered in the safety analyses. 
Table 2-1 lists the major potential hazards involved in the current operations of the GDPs. These hazards represent a compilation of the hazards considered in each plant's SAR and the Justification for Continued Operation reports for each plant completed subsequent to the SARs.

Table 2-1. Major Potential Hazards at GDPs

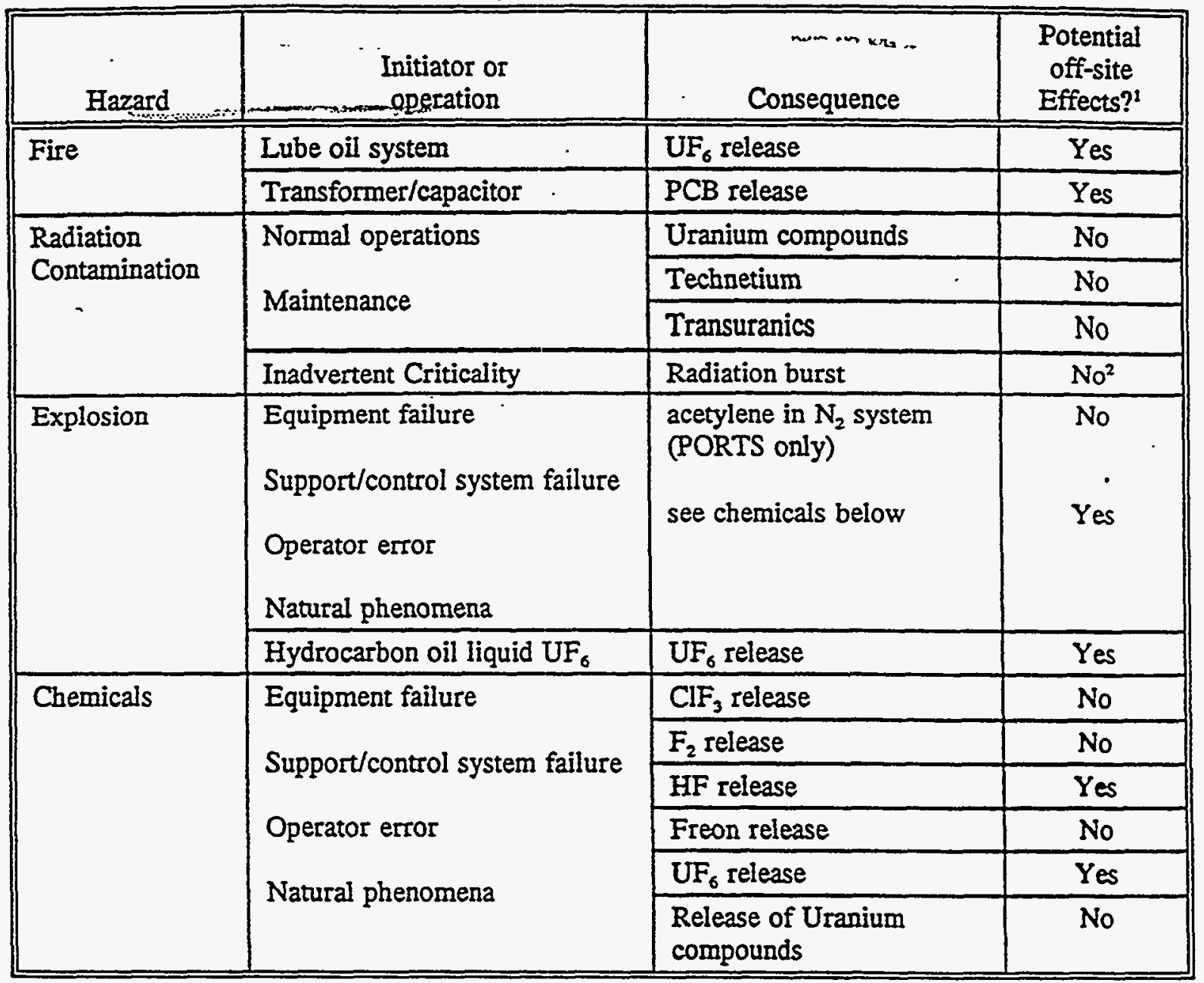

'The potential off-site effects column reflects a conservative assessment of unmitigated consequences for postulated bounding accidents involving the subject hazards.

$:{ }^{2}$ Criticality events do not resuit in direct radiation consequences off-site.

Criticality events are not considered to have a potential impact on the public. Because criticality produces primarily local radiation effects, the expected consequences are limited to the on-site workers with no off-site effects to the public health and safety. No significant fission product release and transport are anticipated from an inadvertent criticality event.

Each of the potential hazards is discussed further in the following sections. 


\subsubsection{Safety Analysis Reports}

PGDP and PORTS each has produced a FSAR between 1980 and 1985, in accordance with DOE Orde: Saro-4A ma S481. IA. These orders were the governing requirements for safety analysis at that time. (See Sect. 2.4.) These documents identify the major safety events (major hazards, initiators, and sequences) and establish an envelope $50 \mathrm{~s}$ safoperations, which is defined in the Gins. The FSARs

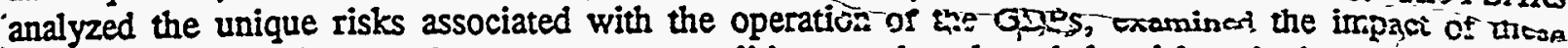
hazards during accident and process upset conditions, and evaluated the risk to both on- and off-site personnel.

During FSAR development, significant reliance was placed on operational experience, engineering judgment, an in-depth understanding of the overall operation and associated hazards, and senior staff'with first-hand experience and understanding of the theory and operations. Credible accident scenarios were developed by (1) examination of previous accident reports and reports of significant events, (2) discussions with personnel possessing extensive practical knowledge of plant operations, and (3) engineering analyses of theoretical situations. Maximum credible consequences associated with on- and off-site personnel exposure to toxic materiais and radionuclides were also analyzed. In the absence of comprehensive reliability data for GDP systems and components, many of which are unique to the GDPs, estimates of the likelihood of postulated accidents were made, based upon engineering judgment, to permit the qualitative evaluation of risks. The FSARs detail the rationale for these estimates.

The guidelines used for the qualitative risk determination are provided in Fig. 2-4 and Table 2-2. The risk of the individual events postulated is defined by the probability and consequence of each event.

\subsubsection{Important operational parameters}

The two most significant parameters related to safe operations of the GDPs are maximum cascade power level and ${ }^{235} U$ assay. Power level principally determines the cascade operating pressure, in-process $\mathrm{UF}_{6}$ inventory, and the production level of the plant. The maximum power levels are $3040 \mathrm{MW}$ for PGDP and $2100 \mathrm{MW}$ for PORTS. Assay levels also relate to the risk of an inadvertent criticality; as a general rule, the higher the assay, the smaller the amount of material required for criticality. The maximum assay production is $2 \%$ for PGDP and less than $20 \%$ for PORTS. PGDP is performing modifications and analyses to increase its maximum assay to $5 \%$. PORTS, before the suspension of highly enriched uranium (HEU) production in 1992, could produce assays greater than $90 \%$. 


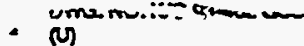

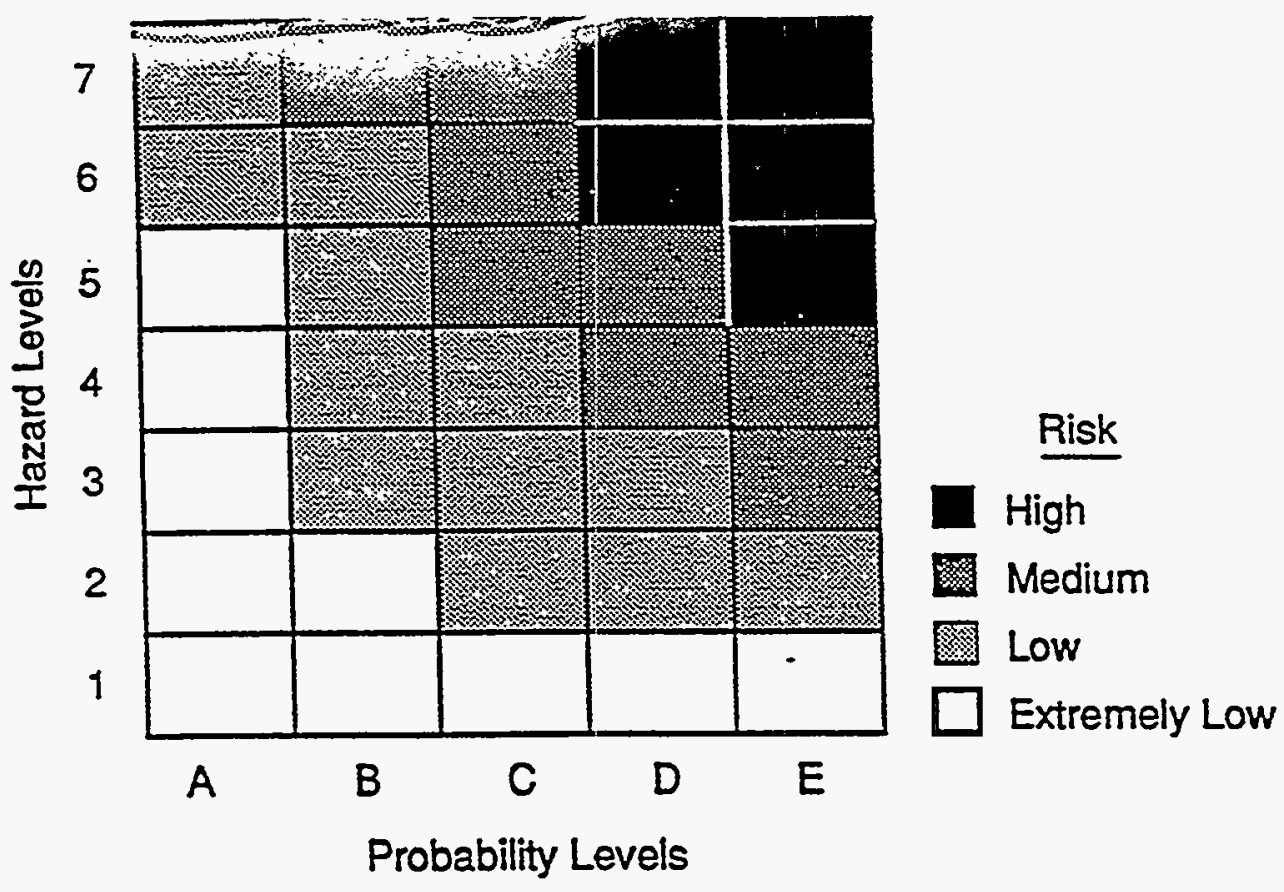

\begin{tabular}{lc}
\hline Probability Scale & $\begin{array}{c}\text { Estimated Range of } \\
\text { Probability of Accident } \\
\text { Occurrence, per year }\end{array}$ \\
\hline E Extremely high & $p \geq 1.0$ \\
D High & $10^{-1} \leq p<1.0$ \\
C Medium & $10^{-2} \leq p<10^{-1}$ \\
B Low & $10^{-3} \leq p<10^{-2}$ \\
A Extremely low & $p<10^{-3}$ \\
\hline
\end{tabular}

Fig. 2-4. Risk matrix used in FSAR. 
Table 2-2. Hazard rating scale ${ }^{1}$

\begin{tabular}{|c|c|}
\hline Hazard Level & Maximum Consequence \\
\hline \multirow[t]{3}{*}{7 CATASTROPHIC } & Extremely serious on- and off-site impact for lengthy periods of time \\
\hline & Large geographical areas and large population groups affected \\
\hline & Large number of fatalities, both on- and off-site \\
\hline \multirow[t]{3}{*}{6 EXTREMELY HIGH } & $\begin{array}{l}\text { Extremely serious on-site impact to large numbers of people and to the } \\
\text { environment }\end{array}$ \\
\hline & $\begin{array}{l}\text { Many on-site fatalities and possible fatalities to the public located on adjaçent } \\
\text { properties }\end{array}$ \\
\hline & Moderate impact beyond the exclusion area ${ }^{2}$ \\
\hline \multirow[t]{4}{*}{5 HIGH } & Extremely serious on-site impact and considerable impact on the environment \\
\hline & Multiple fatalities among operating and other on-site personnel .. \\
\hline & Moderate health and safety concerns to the public located close to the site \\
\hline & Minor impact off-site beyond the exclusion area \\
\hline \multirow[t]{4}{*}{4 MEDIUM } & $\begin{array}{l}\text { Serious on-site impact and significant impact within the exclusion area and to } \\
\text { the environment }\end{array}$ \\
\hline & Fatality, severe injury, or severe illness to operating personnel \\
\hline & Significant health concern to workers at nearby facilities \\
\hline & Few people off-site seriously affected \\
\hline \multirow[t]{4}{*}{3 LOW } & Significant on-site but only minor off-site impact \\
\hline & $\begin{array}{l}\text { Moderate injury or creation of moderate health concerns for operating } \\
\text { personnel }\end{array}$ \\
\hline & Minor health and safety concerns for nearby facility workers \\
\hline & Slight contamination of off-site environs \\
\hline \multirow[t]{4}{*}{2 EXTREMELY LOW } & Minor on-site but no off-site impact \\
\hline & Slight injury or illness to operating personnel \\
\hline & $\begin{array}{l}\text { Local facility contamination requiring only routine procedures to control or } \\
\text { correct }\end{array}$ \\
\hline & No health and safety concerns for workers at nearby facilities \\
\hline \multirow[t]{3}{*}{1 NEGLIGIBLE } & Detectable on-site and no off-site impact \\
\hline & No identifiable safety and health consequences \\
\hline & Negligible contamination of the environment \\
\hline
\end{tabular}

'This is the hazard rating scale used in the PORTS and PGDP FSARs.

${ }^{2}$ Exclusion area is the area surrounding the facility in which the owner has the authority to determine all activities, including exclusion or removal of personnel and property from the area. 
The operating pressure is important in the event of a process system boundary breach. Most stages of the cascade operate at pressures below atmospheric pressure. At operation above atmospheric

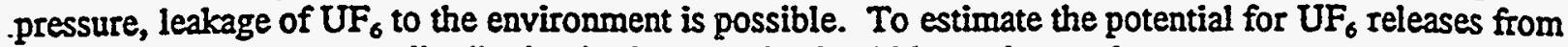
the cascade, the pressure distribution in the cascade should be understood.

The cascade pressure distribution is determined by power level, cascade configuration (number and location of on-stream cells), and, to a lesser extent, depleted and product withdrawal assay. To perform this process function, the compressors add significant amounts of energy to the UF 6 process gas. As a consequence, the process pressure in each stage is highest at the outlet of the compressors. Based on the overall cascade arrangement, the highest pressures within the cascade are in the larger equipment sections of the cascade. In a typical stage, the pressure drops significantly through the barrier for the " $A$ " or enriched stream such that this portion of each stage throughout the cascade is less than atmospheric pressure up to the next higher compressor in the cascade. The " $\mathrm{B}$ " or depleted stream does not experience as significant a pressure drop through the converter as the " $A$ " stream does. In some portions of the cascade, the "B" stream may be entirely above atmospheric pressure at higher power levels. For a typical stage operating above atmospheric pressure, approximately $30 \%$ of the process boundary surface area will experience this higher pressure, while the remaining $70 \%$ area will experience substantially less pressure and always remain subatmospheric. To illustrate this reaction, Fig. 2-5 shows a typical stage with representative high pressures. In this figure, the "B" stream pressure is approximately 18 psia while the " $A$ " stream pressure is less than 4 psia. Even under maximum " $B$ " stream pressure conditions of approximately $20 \mathrm{psia}$, significant portions of the cascade operate at subatmospheric pressures. Also, should the cascade be shut down, system pressure will fall to below atmospheric, regardless of initial operating power level.

To illustrate the power level conditions under which the plants typically operate, Fig. 2-6 shows the peak monthly power levels for each plant for the last several years. These data show that PGDP has operated well below its rated power level for this time period, and PORTS has operated near its rated power level. Figures 2-7 and 2-8 show the general arrangement of the cascades and representative average high-side pressures for rated power levels at PGDP (3040 MW) and PORTS (2100 MW), respectively. For PGDP, which has typically operated well below rated power, Fig. 2-9 shows the pressure for a representative power level $(1600 \mathrm{MW})$ for operation during the last few years. At this power level, the typical pressure distribution shows that the entire cascade will likely be below atmospheric pressure. In fact, PGDP has not operated above atmospheric pressure since 1978. PORTS has operated portions of its cascade above atmospheric pressure; however, Fig. 2-10 shows that only a small portion of the cascade will be above atmospheric at $1900 \mathrm{MW}$, which is more typical of PORTS operation over the last 2 years.

- If a breach in the process system boundary occurs during below-atmospheric-pressure operation, air will leak into the cascade. Air inleakage presents an operational upset condition which the operators are well trained to mitigate and correct. Upon recognition of excessive inleakage, the operators deenergize the compressor motors in, and isolate, the affected cell. Air inleakage will be noted by operators and indicated by changes in the compressor motor load and the highly sensitive line recorders. Operators in both the Area Control Room (ACR) and in the Central Control Room (CCR) have instrumentation to alert them to inleakage. Both $A C R$ and $C C R$ personnel can initiate shutdown. 
DHG NO. KE P3475 GSS

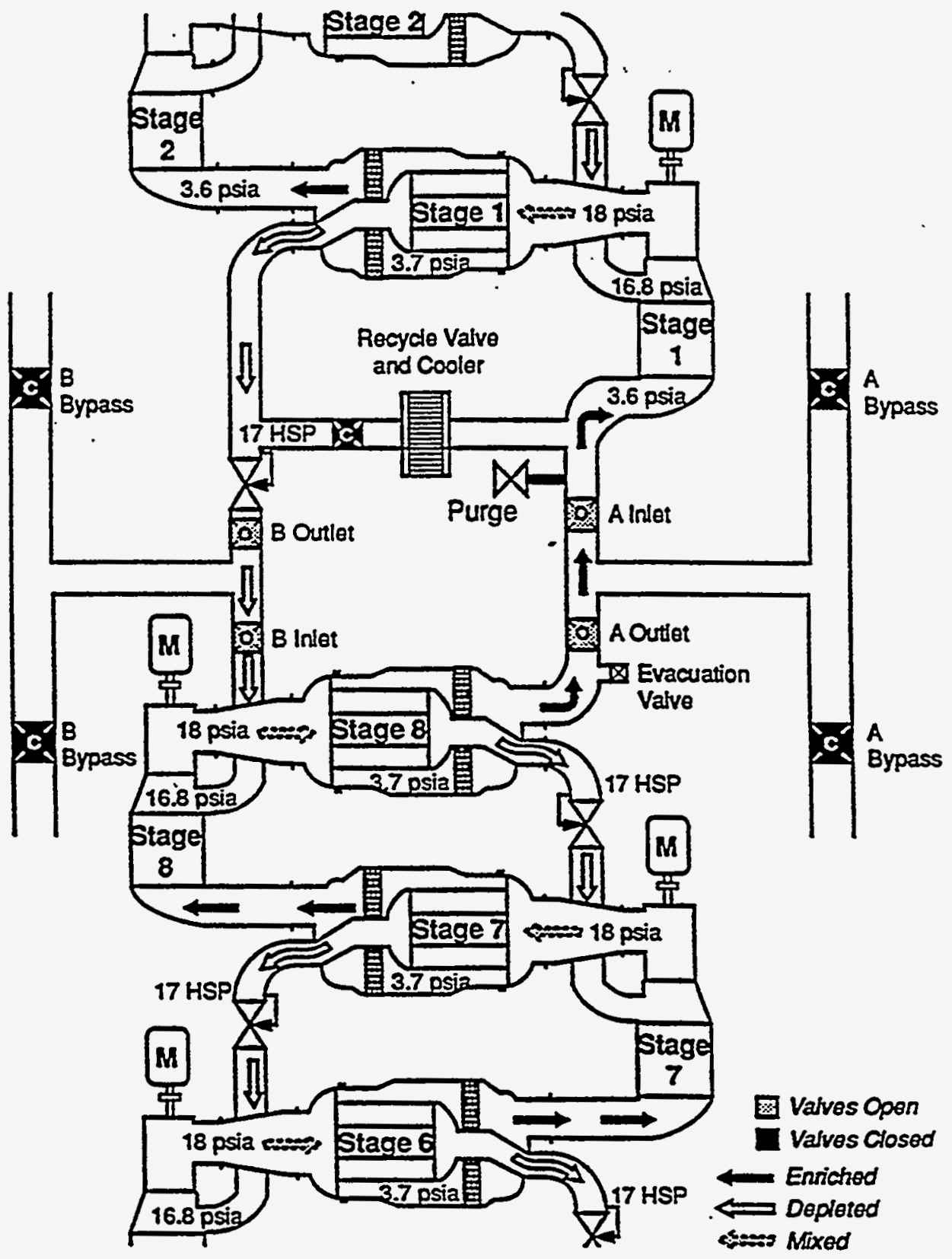

Fig. 2-5. Typical stage operating pressure. 


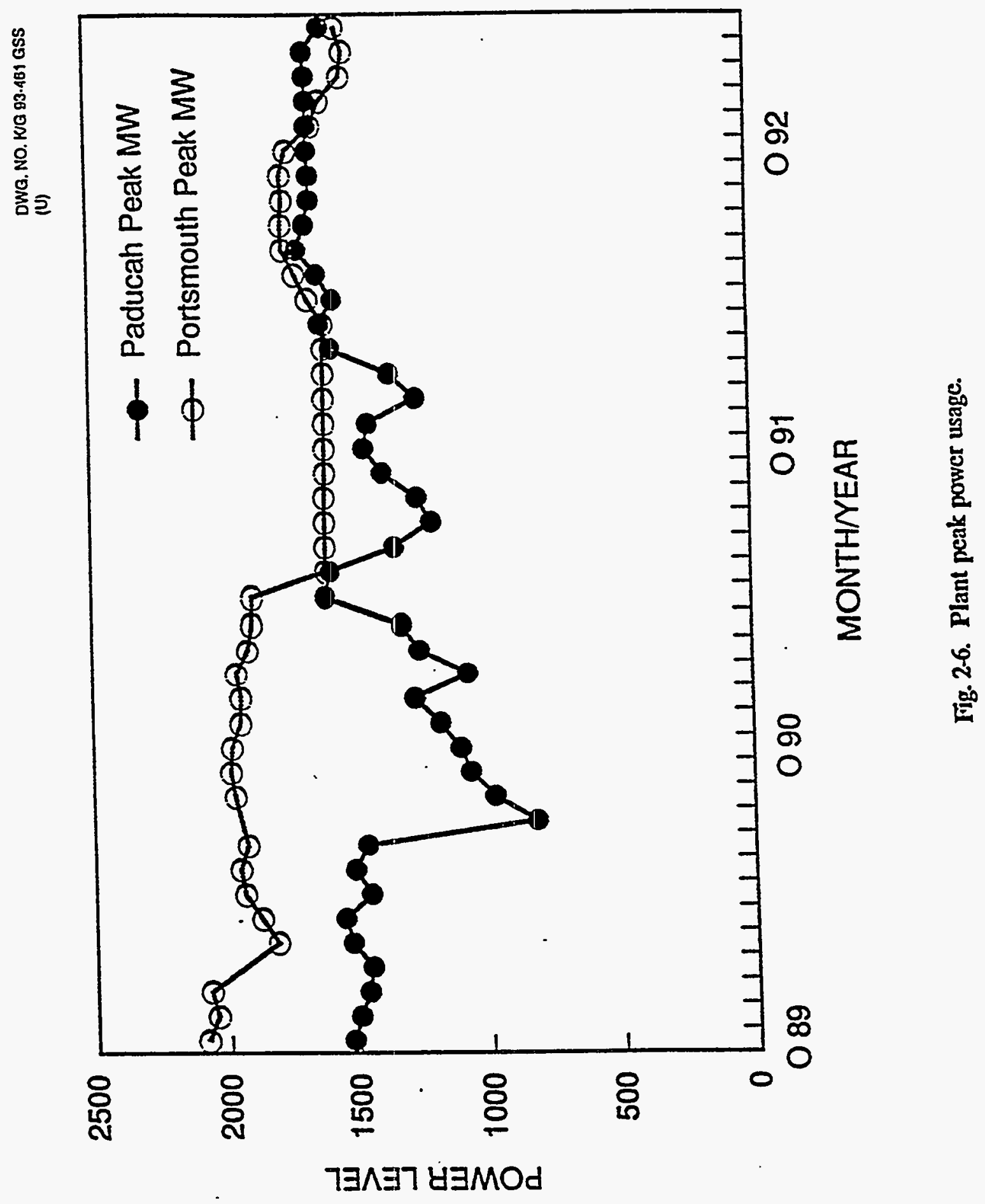




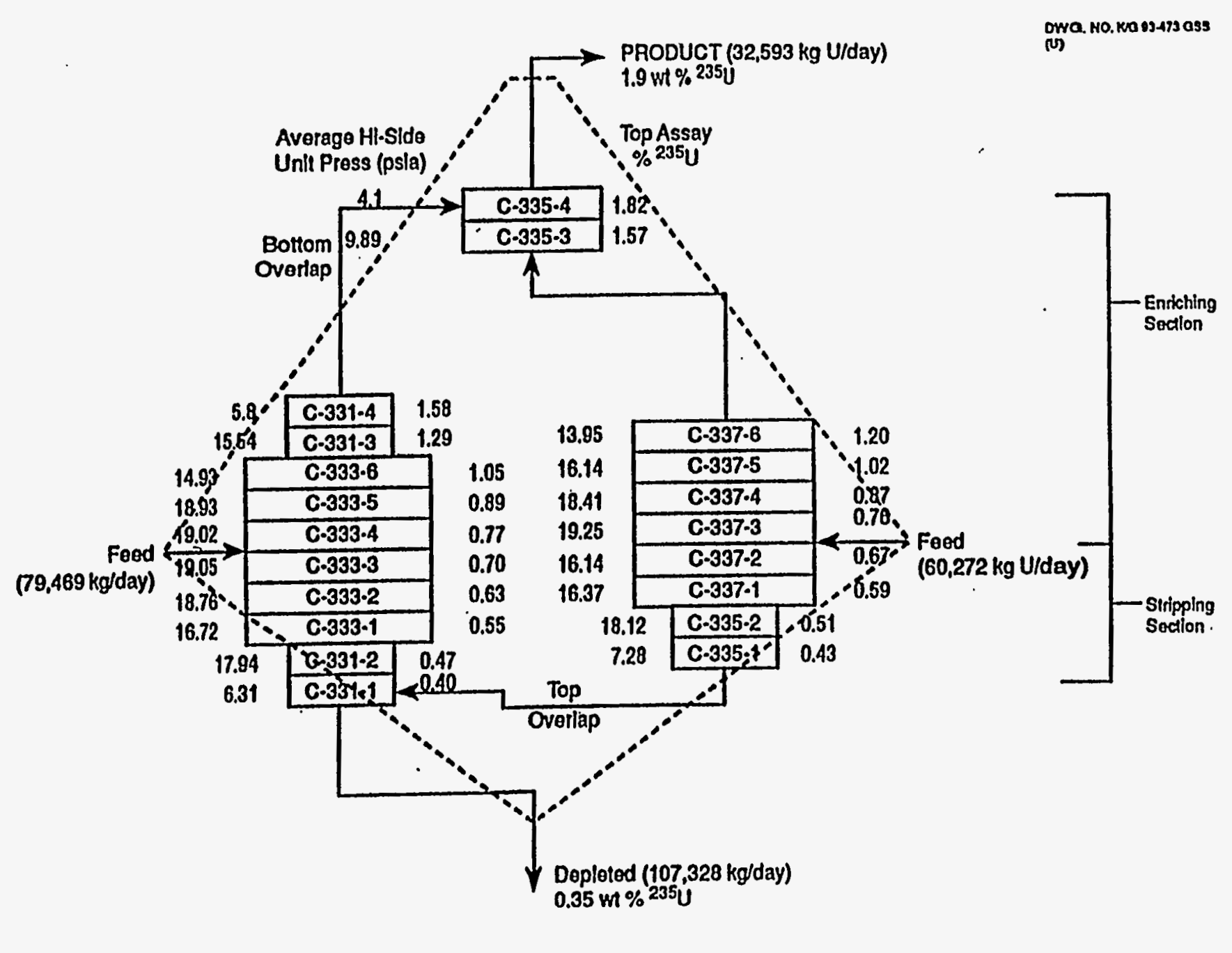

Fig. 2-7. Typical Paducah cascade configuration and conditions at 3040 MW2-17. 


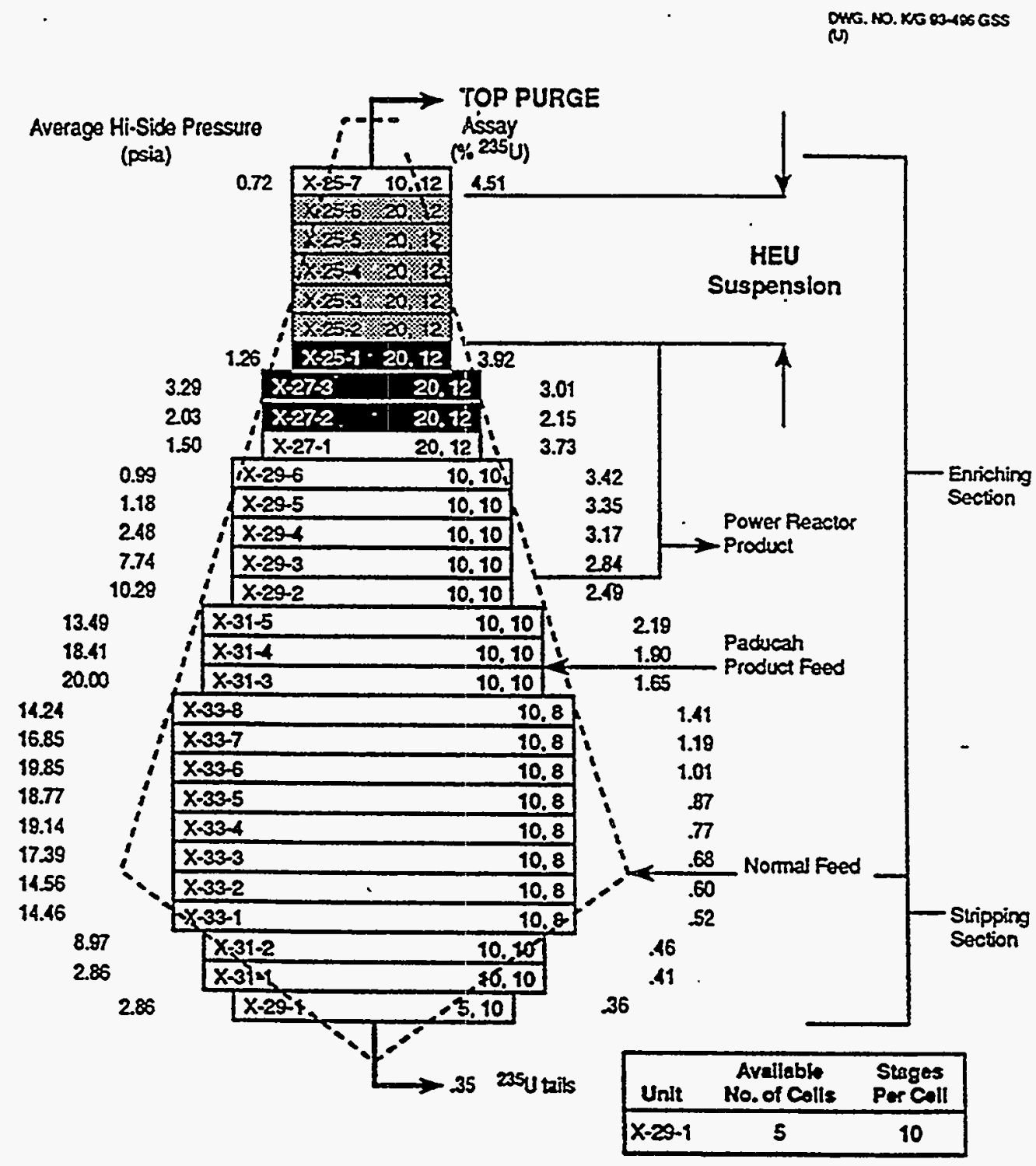

Fig. 2-8. PORTS typical cascade flow, pressure, and average assays at $2100 \mathrm{MW}$. 


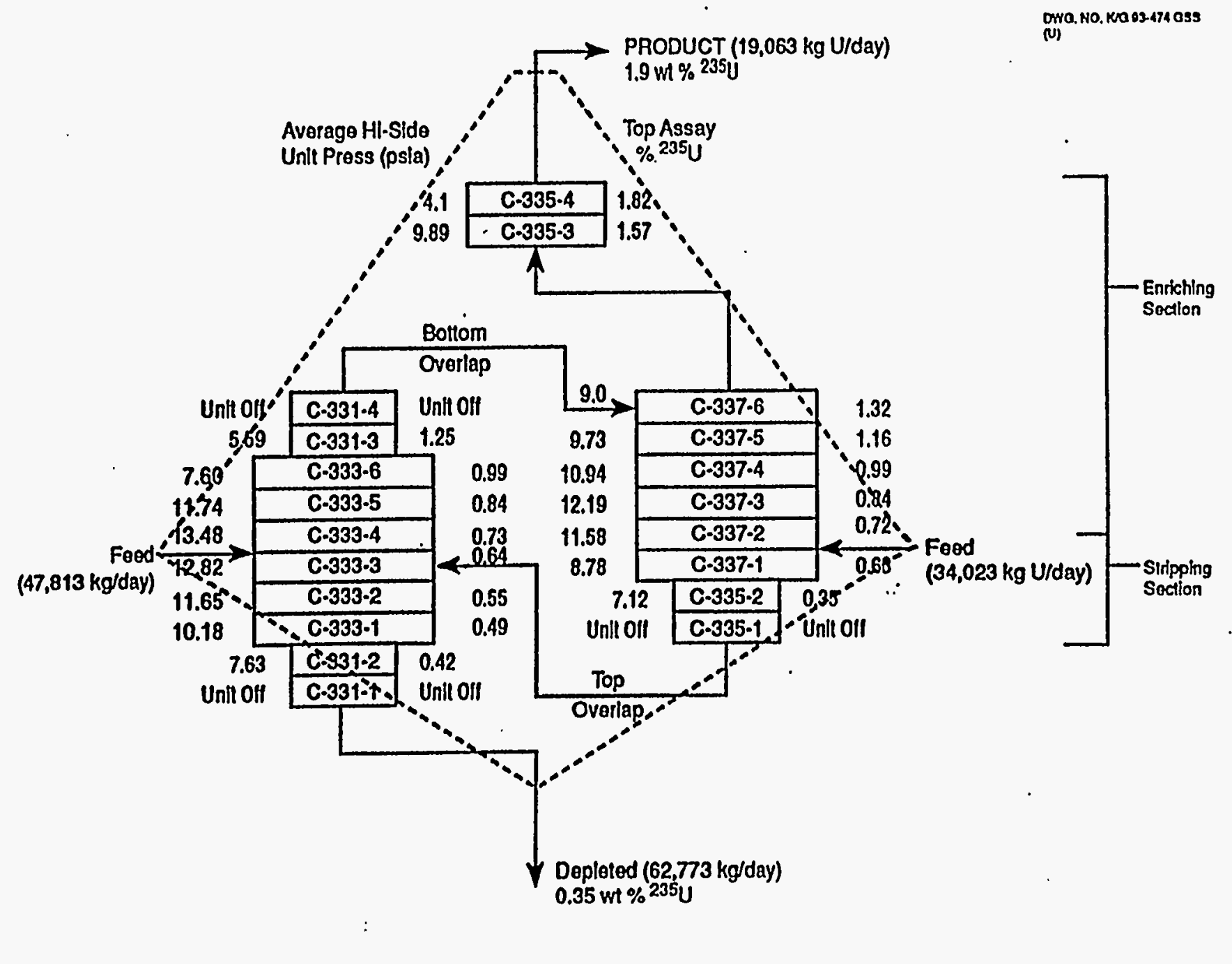

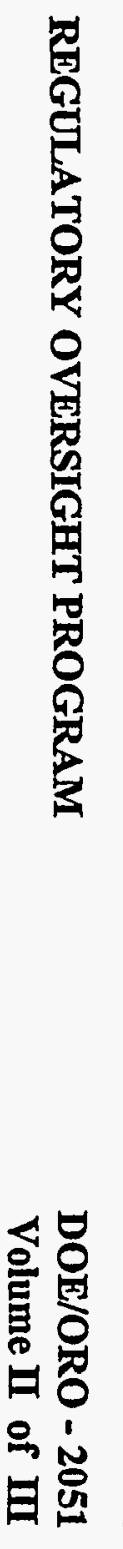

Fig. 2-9. Typical Paducah cascade configuration and conditions at $1600 \mathrm{MW}$. 


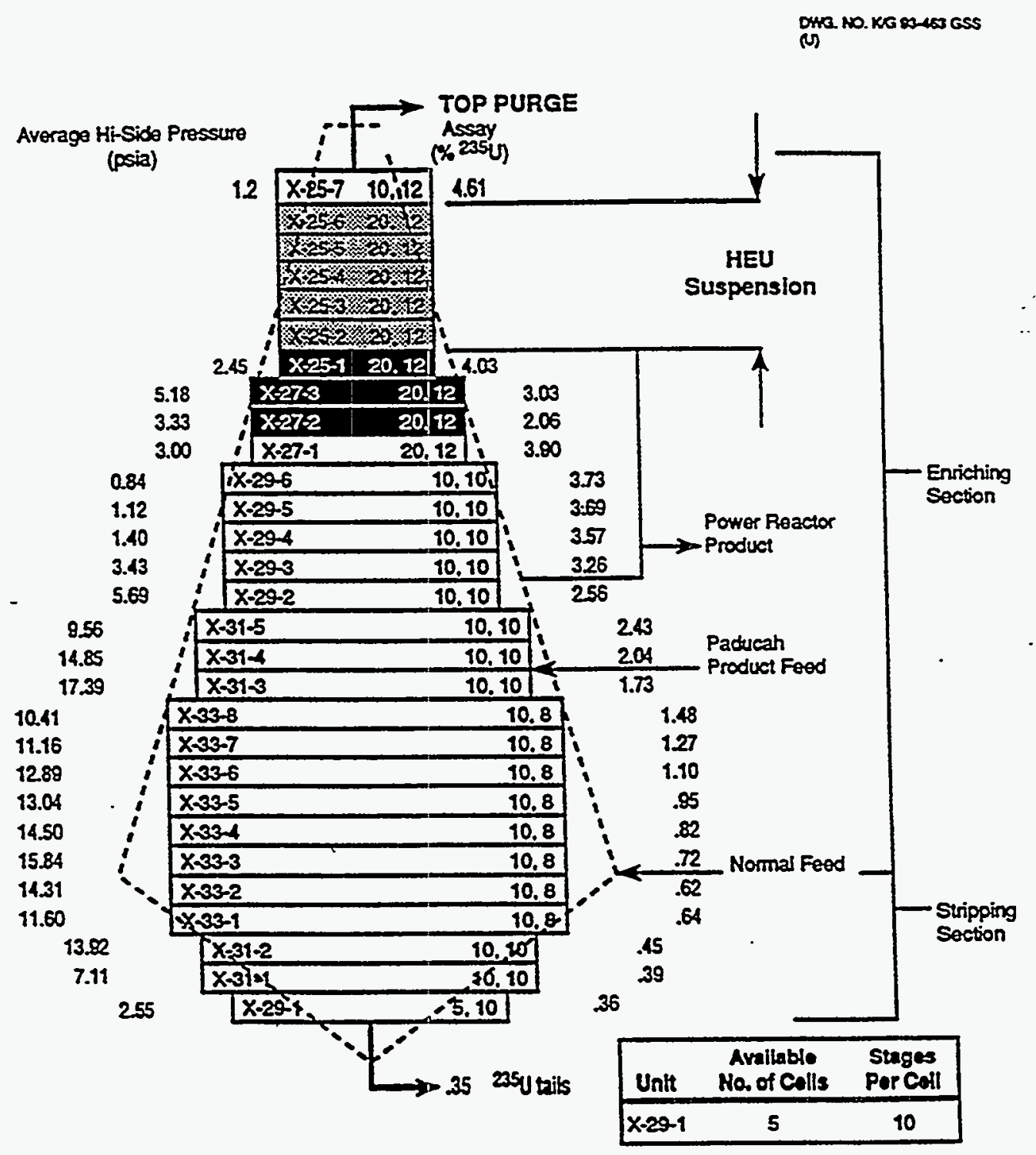

Fig. 2-10. PORTS typical cascade flow, pressure, and average assays at $1900 \mathrm{MW}$ 
As further precautions against the release of $\mathrm{UF}_{6}$, the plant design includes a secondary confinement scheme for potentially sensitive components in areas of the cascade that may be operated above atmospheric pressure. Specifically, the expansion joints, which are the most likely leakage points in the process piping, are double-bellows type designs; the space between the bellows is air pressurized with dry plant air to pressures greater than the process pressure, which ensures inleakage rather than $\mathrm{UF}_{6}$ outleakage. Also, UF, leak detectors are provided in these areas; they alarm in the ACR and CCR to alert the operators if a UF 6 leak occurs. These detectors are provided in the cell enclosures and above the compressor discharge seals and must be operational or have other precautionary measures (e.g., operator watch) available in their place before the GDP can be operated at pressures above atmospheric.

Finally, in the event of leakage during operations at above atmospheric pressure, the operators must isolate the affected cell and deenergize the affected cell's compressor motors. This action immediately drops the pressure throughout the cell to below atmospheric pressure. The drive motors for the compressors in each cell are electrically connected so that when one compressor motor is tripped, all compressor motors in the cell are tripped. The expected $U F_{6}$ releases from a process system rupture are discussed in Sect. 2.2.2.2 under "Other UF 6 Releases."

\subsubsection{Gaseous diffusion plant accident scenarios}

The postulated accident scenarios developed in the existing FSARs were based on consideration of initiating events including (1) operator error, (2) equipment failure, (3) loss of support system, (4) fire, (5) explosion, (6) natural phenomena, and (7) the impact of events at adjacent facilities. Based on these considerations, the data in Tables $2-3$ and 2-4 summarize the accident scenarios for the two plants and the relative risk of these accident scenarios. The accidents may be grouped by accident type or by facility. The more consequence-significant incidents will be discussed in the following paragraphs to provide the basis for risk categorization. These scenarios demonstrate the depth of analysis with regard to the subject hazards and scenarios.

\section{UF 6 Release from Cylinder}

The out-of-doors rupture of a 14-ton cylinder containing liquid $U F_{6}$ is generally regarded as the event that presents the highest risk. This highest risk status is caused by the rapid releases observed during previous events involving liquid cylinders and by the calculated consequences from a-worse-case event. Since liquid $U_{F_{6}}$ cannot exist at atmospheric pressure, when liquid $U_{F_{6}}$ is released from a cylinder, approximately $70 \%$ of the liquid mass vaporizes and the remaining $30 \%$ solidifies: The UF vapors then react with moisture in the air to generate HF. For every mole of UF, reacting, 4 moles of $\mathrm{HF}$ are formed. Both $\mathrm{UF}_{6}$ and $\mathrm{HF}$ are toxic chemicals that potentially threaten on-site workers and the public health and safety.

Both plants typically allow liquid cylinders to cool out of doors because in-doors storage capacity is limited. When cylinders are transported from sampling or withdrawal operations to cooldown locations, liquid-filled cylinders with the valves protected are only handled by overhead cranes. Liquidfilled cylinders are moved, in general, at as low a height as possible, usually on the order of 1 foot, to minimize damage if the cylinder is dropped. Cylinders are placed on cradles and are appropriately spaced to ensure that no interference or contact between cylinders that might threaten cylinder 
DOE/ORO - 2051

Table 2-3. Toxic material release accident scenario summary.

\begin{tabular}{|c|c|}
\hline Accident Scenario ${ }^{2}$ & Relative.Risk ${ }^{2}$ \\
\hline \multicolumn{2}{|l|}{ UF, RELEASE SCENARIOS } \\
\hline \multicolumn{2}{|l|}{ Enrichment Facilities } \\
\hline Cell Overheat & \\
\hline Loss of Instrument Air & Extremely Low \\
\hline Loss of RCW & Extremely Low \\
\hline Operator Drains Coolant & Extremely Low \\
\hline $\begin{array}{l}\text { Improper Manual Control of Coolant System } \\
\text { Compressor Failure }\end{array}$ & Extremely Low \\
\hline Cell Orerpressure & \\
\hline "B" Stream Block Valve Closure - Onstream & Extremely Low \\
\hline Stage Control Valve Failure (non-trimmer valves) - Onstream & Extremely Low \\
\hline Recycle Valve Failure - Offstream & Extremely Low \\
\hline Pressure Instrument Failure or Instrument Line Freeze Out & Extremely Low \\
\hline Mechanical Containment Breach & \\
\hline Heavy Equipment Drop on “ $\mathrm{B}^{\prime \prime}$ Line & Extremely Low \\
\hline Vehicular Impact & Extremely Low \\
\hline - Fatigue Failure of Process Piping & Extremely Low \\
\hline Motor Coupling Failure & Extremely Low \\
\hline Compressor Seal Failure & Extremely Low \\
\hline Treatment Gas Explosion & Extremely Low \\
\hline Seismic Event & Low \\
\hline Expansion Joint or Weld Joint Failure & Extremely Low \\
\hline Local Fire & \\
\hline Lube Oil Fire & Extremely Low \\
\hline$\frac{\text { Operator Error }}{\text { Imnroner Purging of Process System }}$ & \\
\hline $\begin{array}{l}\text { Improper Purging of Process System } \\
\text { Evacuation Jet Valving Error }\end{array}$ & $\begin{array}{l}\text { Extremely Low } \\
\text { Low }\end{array}$ \\
\hline $\begin{array}{l}\text { Purge Cascade } \\
\text { Failure to Obtain UF, Negative } \\
\text { Misvalving to Ejector Station }\end{array}$ & $\begin{array}{l}\text { Low } \\
\text { Low }\end{array}$ \\
\hline $\begin{array}{l}\text { Freezer/Sublimer Systems } \\
\text { Stress Rupture of Freezer/Sublimer Vessels }\end{array}$ & Extremely Low \\
\hline 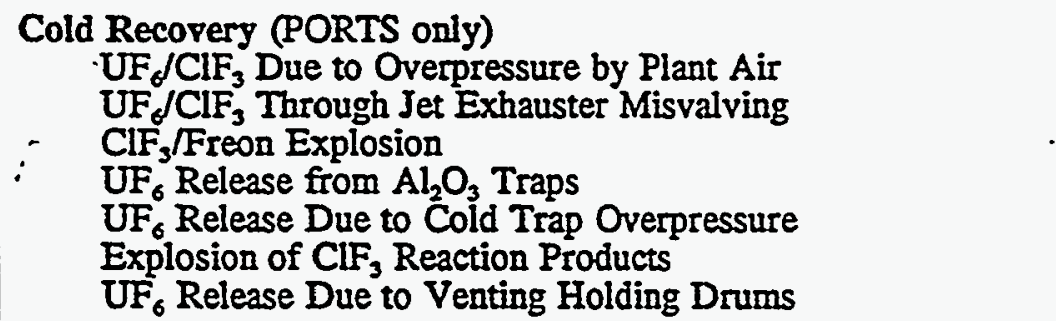 & $\begin{array}{l}\text { Low } \\
\text { Extremely Low } \\
\text { Extremely Low } \\
\text { Extremely Low } \\
\text { Extremely Low } \\
\text { Extremely Low } \\
\text { Extremely Low }\end{array}$ \\
\hline
\end{tabular}


Table 2-3. (continued)

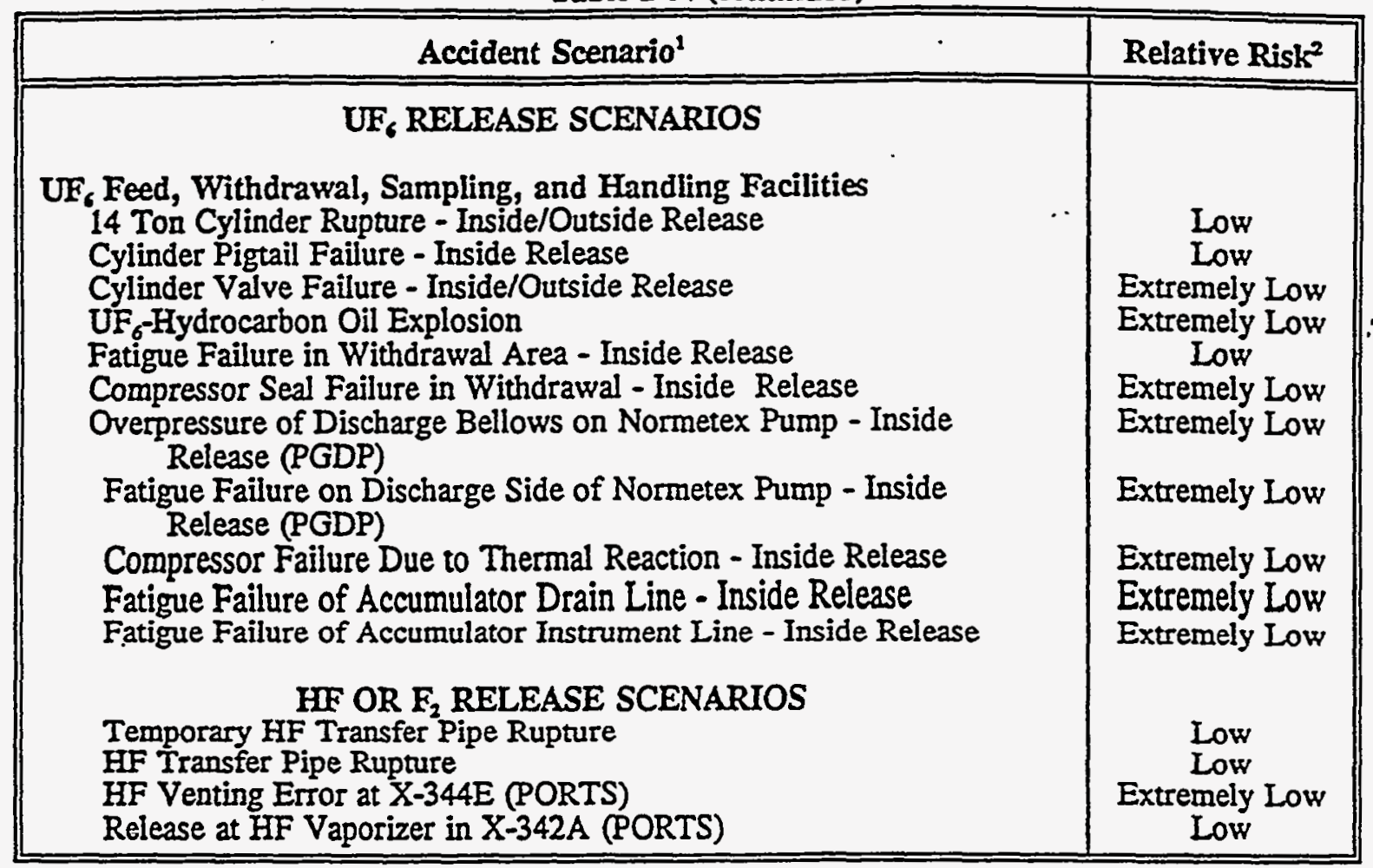

${ }^{1}$ Note that in general these events apply to both plants. Each of these events, however, may not have been considered at both plants and documented in one or both of the respective FSARs.

${ }^{2}$ See Fig. 2-4. 
Table 2-4. Criticality accident scenario summary.

\begin{tabular}{|c|c|}
\hline Accident Scenario & Relative Risk \\
\hline \multicolumn{2}{|l|}{ PORTS CRITICALITY SCENARIOS } \\
\hline \multirow{11}{*}{$\begin{array}{l}\text { Enrichment Facilities } \\
\text { A-Line Cooled Cell, Top Stage Freeze Out } \\
\text { Lube Oil Inleakage Through the Labyrinths of Compressor } \\
\text { Bearings and Process Seals } \\
\text { UF, Freeze Out in Piping Elbows, B-Line Drops, and Building Tie } \\
\text { Lines } \\
\text { Wet Air Inleakage } \\
\text { Prolonged Power Failure } \\
\text { Water Control Valve Leak and Cell Block Valve Leak on } \\
\text { Shutdown Cell } \\
\text { UF. Freeze Out in Interbuilding Booster Station } \\
\text { Equipment Removal for Maintenance } \\
\text { Solid Mass in X-330 or X-333 Evacuation Booster Station } \\
\text { Stage Compressor Vibration and X-Joint Rupture } \\
\text { Exothermic Reactions Resulting in Uranium Compound Deposits }\end{array}$} & \\
\hline & Extremely Low \\
\hline & Extremely Low \\
\hline & Extremely Low \\
\hline & Extremely Low \\
\hline & Extremely Low \\
\hline & Extremely Low \\
\hline & Extremely Low \\
\hline & Extremely Low \\
\hline & $\begin{array}{l}\text { Extremely Low } \\
\text { Extremely Low }\end{array}$ \\
\hline & Extremely Low \\
\hline $\begin{array}{l}\text { Purge Cascade } \\
\text { Dry Solid Mass of UF } \\
\text { Dry Mass of } \mathrm{UO}_{2} \mathrm{~F}_{2} \\
\text { Moderated Solid Mass - UF } \mathrm{UF}_{6} \text { or } \mathrm{UO}_{2} \mathrm{~F}_{2}\end{array}$ & $\begin{array}{l}\text { Extremely Low } \\
\text { Extremely Low } \\
\text { Extremely Low }\end{array}$ \\
\hline $\begin{array}{l}\text { Cold Recovery } \\
\text { Criticality in X-333 } 8^{n} \text { Cold Trap } \\
\text { Criticality in X-330 } 5^{n} \text { Cold Trap } \\
\text { Criticality in X-333 } 24^{*} \mathrm{Al}_{2} \mathrm{O}_{3} \text { Trap } \\
\text { Criticality in X-330 or X-333 Surge Drums } \\
\text { Criticality in X-330 or X-333 Holding Drums }\end{array}$ & $\begin{array}{l}\text { Extremely Low } \\
\text { Low } \\
\text { Extremely Low } \\
\text { Extremely Low } \\
\text { Extremely Low }\end{array}$ \\
\hline $\begin{array}{l}\text { UF، Cylinders in Storage } \\
\text { Criticality in X-344A Due to Improper Cylinder Handling }\end{array}$ & Extremely Low \\
\hline $\begin{array}{l}\text { Chemical Operations } \\
\text { Criticality at the Uranium Recovery Calciners }\end{array}$ & Low \\
\hline $\begin{array}{l}\text { PGDP CRITICALITY SCENARIO } \\
\text { - Uranium Solution in Geometrically Unfavorable Configuration }\end{array}$ & Extremely Low. \\
\hline
\end{tabular}


integrity during movement occurs. All cylinders are allowed to cool 3 to 5 days, depending on cylinder size, to ensure that all of the $\mathrm{UF}_{6}$ has solidified before they are moved again.

In support of the FSARs, DOE funded the development of a computer code to estimate the consequences of $\mathrm{UF}_{6}$ releases. This code included models describing the unique chemistry of $\mathrm{UF}_{6}$ and HF as well as the phenomena associated with dispersion of a gas cloud (e.g., atmospheric dispersion, cloud buoyancy, deposition of reaction products). Based on this code, representative UF 6 releases were analyzed, and the consequences to humans were estimated. These estimates considered conservative atmospheric wind conditions to maximize the consequences. In addition, data were assimilated to support the assessment of effects on human health from exposure to the toxic materials.

The bounding results presented in the SARs assumed conservative meteorological conditions in assessing both on- and off-site effects of a 14-ton liquid $\mathrm{UF}_{6}$ cylinder rupture in the open atmosphere. Bounding on-site effects were obtained from an assumed windspeed of $15 \mathrm{mph}$ and Class D stability with a temperature of $30^{\circ} \mathrm{F}$ and $60 \%$ relative humidity using a Gaussian dispersion model. Bounding off-site effects were obtained from $2-\mathrm{mph}$ windspeed and stability Class $F$. The results of these analyses indicate potential lethal conditions for on-site individuals downwind of the release if no protective action is taken. Potential health effects were also calculated for persons located off-site. These health effects included the potential for renal injury due to uranium toxicity, mild health effects, and possible irritation. These off-site consequences were conservatively calculated to extend 5 miles from the release point. These consequence estimates reflect the cumulative exposure to any.individual in a fixed location for the duration of the release. Therefore, the estimated consequences due to UF 6 and its reaction products may be characterized as very conservative by assuming (1) very conservative atmospheric conditions, (2) constant wind direction and velocity for the duration of the analysis; (3) that potentially affected individuals will take no protective actions despite the smell and irritation of HF, and (4) that conservative estimates are used for health effects threshold concentrations for the toxic chemicals. This calculation also estimated the committed dose, which was negligible in comparison with the chemical effects of the materials released.

To contrast the calculated results to actual events, comparisons were made with several large, accidental $U_{6}$ releases which have occurred. The most significant event occurred in 1978 at P.ORTS when a liquid UF $\sigma$ filled 14-ton cylinder was dropped from a straddle carrier. The dropped cylinder ruptured and released more than 20,000 pounds of UF in less than 5 minutes directly to the atmosphere. This event is notable in that no personnel, including the straddle carrier operator, suffered irreversible health effects. Environmental conditions were favorable since the temperature was $32^{\circ} \mathrm{F}$, winds were approximately $5 \mathrm{mph}$, and precipitation was occurring at the time of release.- Two other major UF 6 releases of note occurred in France, in which no one was injured, and at Kerr McGee's Sequoyah Uranium Conversion Plant. The accident at Kerr McGee involved the rupture of an overfilled $\mathrm{UF}_{6}$ cylinder while it was being heated in an confined area. It resulted in the death of a plant worker who was trapped in the plume. There were no irreversible injuries to other workers or to anyone off-site. Note that unlike the Kerr McGee Sequoyah Plant and most fuel cycle facilities that handle UF 6 in cylinders, all cylinder heating at the GDPs is performed inside containment autoclaves in order to prevent the release of $\mathrm{UF}_{6}$ in the event that an overfilled cylinder is heated. Therefore, an unmitigated release of $\mathrm{UF}_{6}$ from the rupture of an overfulled cylinder during heating, like the one that occurred at the Kerr McGee Sequoyah Plant, could not occur at the GDPs.

The absence of actual health effects on exposed personnel within the GDP complex is an important piece of data in evaluating and interpreting calculated consequences. The straddle carrier operator did not have his gas mask with him at the time of the event. He identified the event and upon smelling HF, which has a very strong and distinctive odor, immediately left the scene and promptly notified appropriate management of the event. The emergency crews who responded and took action to stop the release 
likewise received no irreversible health effects. The accident occurred shortly after a shift change, and personnel leaving the site unknowingly drove through the release plume. These individuals were identified and examined as well and demonstrated no irreversible health effects from the release. In comparison to calculated consequences, the most important variable is clearly the response of the human to the event. The operator was able to quickly vacate the affected area and avoid serious injury. The individuals who unknowingly drove through the plume were exposed for such a brief time period that any effects were minimized. Atmospheric conditions also minimized the release of any toxic materials offsite.

Following the event, an accident investigation team was formed to investigate the event, its causes, and to recommend corrective actions. The team's findings dealt mainly with the maintenance of straddle carriers. Subsequent to this investigation, the plants implemented new procedures which preclude the use of straddle carriers in moving liquid-filled cylinders as a further corrective action. All liquid cylinders are now moved only by overhead cranes and specially designed lifting fixtures.

As previously mentioned, a key difference between the GDPs and most fuel cycle facilities which handle $\mathrm{UF}_{6}$ in cylinders is that all cylinder heating at the GDPs is performed inside containment autoclaves to prevent a release of $\mathrm{UF}_{6}$ in the event an overfilled cylinder is heated. These autoclaves effectively preclude a catastrophic $\mathrm{UF}_{6}$ release because an overfilled cylinder has been heated. As a result, the cylinder drop event is the only credible event for release of the entire contents of a UF cylinder. The potential does exist for the valve to be knocked off a liquid cylinder during movement operations. However, the cylinder orientation is unlikely to be affected such that the boundary breach would be to the vapor space of the cylinder. A release from the vapor space will be limited by the area of the valve hole and the rate at which the liquid can vaporize. Because energy is required to vaporize the liquid, the release rate will be low in comparison to a ruptured cylinder, which would allow for mitigative actions.

One other cylinder scenario involves the reaction of hydrocarbon oil with liquid UF 6 . These materials react exothermically and can rupture a cylinder. This event occurred at the K-25 GDP in 1975, resulting in the release of less than 20 pounds of $\mathrm{UF}_{6}$. Corrective action from this event has been to disallow the use of hydrocarbon oil-sealed vacuum pumps without an in-line trap which can hold the entire contents of the pump when cylinders are being purged.

\section{Natural Phenomena}

The existing SARs considered the possibility of natural phenomena events with regard to plant safety. Both GDPs were analyzed for the potential safety implications of seismic events, flooding, and extreme winds. For seismic and wind, these analyses were predicated upon a recurrence interval judged to provide acceptable risk. This recurrence interval was determined by considering the remaining life of the GDP facilities and the probability of equaling or exceeding a certain peak ground acceleration. (PGA) that would cause structural failure during this remaining life. Based on an exceedance probability of $10 \%$ and a remaining facility life of 25 years, the resulting recurrence interval was estimated to be about 250 years. This same recurrence interval was applied to the evaluation of extreme winds.

Seismic. Based on the evaluation return interval described above, both plants were analyzed to determine the PGA. These values were determined to be $0.18 \mathrm{~g}$ for PGDP. and $0.05 \mathrm{~g}$ for PORTS. The seismic criteria were based upon the nominal spectrum shape of USAEC Regulatory Guide 1.60, Design Response Spectra for Seismic Design of Nuclear Power Plants. Based on these values, facilities containing hazardous materials at each site were evaluated for integrity.

\footnotetext{
'g equals the force resulting from acceleration due to gravity.
} 
Irrespective of the acceleration used, the primary safety concern was associated with process piping thermal expansion joints located in portions of the plants potentially being operated at or above atmospheric pressure. To estimate the potential consequences of a seismic event, assumptions were developed based on the failure of these expansion joints. Test data developed in conjunction with the expansion joint manufacturer were used to estimate process boundary areas where breaches could occur during the evaluation basis event. From these areas, $\mathrm{UF}_{6}$ source term estimates were developed based on the operating pressure distribution of the cascade.

For PGDP, two cases were considered, $3040 \mathrm{MW}$ (rated power) and $2300 \mathrm{MW}$. For both cases, releases were assumed to occur only in locations in the cascade that would be operating above atmospheric pressure both at the time of the event and for the time required for operators to take mitigative action to deenergize the compressor motors. Stopping the compressors immediately reduces the cascade pressure to less than atmospheric pressure, effectively terminating the release.

For the $3040-\mathrm{MW}$ case, approximately 64,000 pounds of $U \mathrm{UF}_{6}$ were estimated to be released within 8 minutes to the process buildings and, ultimately, to the atmosphere. For the 2300-MW case, approximately 9,000 pounds of $\mathrm{UF}_{6}$ were estimated to be released within 8 minutes from the process system.

For PORTS, two cases were considered, $2260 \mathrm{MW}$ (rated power condition prior to HEU suspension) and $1940 \mathrm{MW}$. Also, assumptions regarding releases similar to those used for PGDP were made. For $2260 \mathrm{MW}$, an estimated 20,000 pounds of $\mathrm{UF}_{6}$ would be released. For $1940 \mathrm{MW}$, the release was estimated to be less than 3,000 pounds of $U_{6}$.

Calculations were performed to estimate the health consequences of these events to on-site personnel and to the public. In all cases, the postulated 14-ton liquid UF, cylinder release bounds the effects of these events. This statement is true even for the large PGDP release because the distributed nature of the release means that the source for dispersion is not from a single location.

The release would not be entirely terminated as assumed in these analyses, because inleakage of air into the cascade would eventually equalize pressures within the process boundary with the atmosphere. At that time, a slow release of $\mathrm{UF}_{6}$ and $\mathrm{HF}$ would be expected to occur for some extended period of time until the remaining $\mathrm{UF}_{6}$ solidified as it cooled or until mitigative action was taken to reestablish containment. These release rates would be expected to be much less than that estimated above, which would allow for significant dispersion of the toxic materials.

Subsequent to publication of the FSARs, additional modifications were made to each plant to strengthen seismically vulnerable components. Particularly, the expansion joints assumed to fail in the above analysis were replaced with expansion joints designed to withstand the evaluation basis earthquake. The seismic analysis has not been revised to reflect these modifications.

Extreme Winds. Based on the approximately 250-year return interval, an evaluation basis windspeed was determined to be $70 \mathrm{mph}$. Based on this windspeed, the risk of an accident that resulted in a chemical release or an inadvertent nuclear criticality was judged to be low. Also, any chemical releases are bounded by other assumed events considered in the SAR. In extreme wind conditions, atmospheric dispersion would obviously be enhanced.

Floods. Both plants are sited above the historic maximum flood stages of record-120 feet for PORTS and 28 feet for PGDP. Thus, the probability of flooding was judged to be extremely low. Any flooding at either site as a result of extremely heavy precipitation would be expected to be minor and not to result in a toxic material release or in an inadvertent nuclear criticality. 


\section{Other UF $\mathbf{6}$ Releases}

In addition to $\mathrm{UF}_{6}$ releases from cylinder ruptures and seismic events, many other release scenarios were considered in the SARs. These events can be grouped into categories based on the amount of UF, released. There are four general categories of release amounts, 5 to 50 pounds; 100 to 1,000 pounds; 10,000 to 17,500 pounds; and greater than 20,000 pounds. The latter case obviously represents the 14ton liquid $U_{6}$ cylinder rupture and seismic events which have previously been considered. In all cases, the liquid UF 6 cylinder rupture bounds the consequences.

Based on dispersion and consequence evaluations performed for the SARs, the $10,000-$ to 17,500 pounds release category warrants discussion because releases of this size pose potential but non-severe off-site consequences. The events which result in a release this size are primarily associated with overpressurization of an onstream cell or with the motor coupling mechanical failure.

The overpressurization events are fundamentally the same event initiated by different events. This event is the closure of a cell block valve on the " $\mathrm{B}$ " stream without the associated recycle valve being opened, either as the resuit of operator error or control system failure. In the event no corrective action is taken, a rapid pressure rise occurs in the stages adjacent to the closed valve in the next upstream cell. Without operator action, the cell compressor motors will ordinarily be deenergized by their protective overload relay. For the SAR analysis, this action was conservatively ignored, and operator action was assumed to require 5 minutes from event initiation. Based on this time to operate and on an assumed breach of the process boundary in the highest pressure stage, a UF 6 release of 10,000 pounds was estimated. These assumptions are conservative because:

- the ACR operator would most likely respond by opening the affected valve or shutting down the compressors because he or she would be alerted by load alarms and valve position indicators, and the central control facility operator would be alerted by audible valve alarms when the $B$ valve changes position;

- the resulting severe compressor motor overloads would likely deblade the compressors, terminating the pressure transient;

- the motor overloads would trip the electrical breakers; and

- the overpressure condition would more than likely result in a distortion of the cell components rather than a catastrophic rupture.

Another event in this release category is failure of a motor-compressor coupling. These couplings have sufficient kinetic energy to penetrate the process system containment boundary. The evaluation of this event estimated a release of 17,500 pounds of $U F_{6}$ from a breach of the process boundary equivalent in size to the coupling failure. This event, however, has never been experienced at the GDPs.

\section{Other Chemical Releases}

Other chemicals present on-site in quantities to be considered potentially significant hazards in the SAR include HF, $\mathrm{F}_{2}$, and $\mathrm{CIF}_{3}$. Each of these materials is highly toxic. Evaluation of these chemicals and potential release scenarios demonstrate that HF is the most significant of these chemicals and potentially poses an off-site hazard from the bounding release scenario. $F_{2}$ is stored in limited quantities and is such a strong fluorinating chemical that it will react rapidly with the air upon release and disperse quickly. $\mathrm{ClF}_{3}$ is also a strong fluorinating chemical and is typically used in sub-atmospheric systems. Like $\mathrm{F}_{2}, a \mathrm{ClF}_{3}$ release would be of limited quantities and would quickly react with moisture in the air and disperse. 
PCBs are also noted as a potential off-site hazard. PCBs are potential carcinogens found in transformers and capacitors. Release of this hazard in conjunction with a fire could potentially affect the public health and safety. Projects are developed to replace all PCB containing capacitors and transformers.

Another chemical present at each plant in quantities to pose potential on- and off-site hazards is chlorine, $\mathrm{Cl}_{2}$. $\mathrm{Cl}_{2}$ was not considered in the SARs because it is not a hazard unique to the GDPs and is common to many other industrial facilities. $\mathrm{Cl}_{2}$ could potentially pose an off-site hazard to the public. This hazard will be analyzed in the SAR Upgrade Program described in Sect. 2.5.

\section{Criticality}

Nuclear criticality safety is achieved by exercising control over both the mass and distribution of all fissile material and the mass, distribution, and use of the nuclear properties of other materials with which fissile materials are associated. Typical controls of fissile materials include mass control, density control, geometry control, and spacing control. For non-fissile materials in contact with or in proximity to fissile material, moderation.control, neutron reflection, and neutron absorbers may be employed to prevent inadvertent criticality. Many of these controls are implemented through administrative controls.

As stated previously, PGDP currently can produce a maximum assay of 2 wt \% ${ }^{235}$, while PORTS can produce a maximum assay of up to $20 \mathrm{wt} \%{ }^{255} \mathrm{U}$. The bulk of the uranium inventory within the process equipment is maintained in the gaseous phase which cannot be made critical. The liquid and solid phases of $U_{6}$ can become critical if adequately moderated and if assembled in a favorable geometry. The above controls are employed in situations involving the handling of solid or liquid $\mathrm{UF}_{6}$ to prevent inadvertent criticality events.

Both plants are equipped with instrumentation to detect an inadvertent criticality event; to sound a distinct, audible alarm in warning; and to initiate visual warning lights at entrances of the affected building. This instrumentation is strategically located throughout the plant wherever fissile material is handled.

The formation of solid masses of $\mathrm{UF}_{6}$ within the cascade is effectively controlled by maintaining temperatures and pressures at levels that prevent $\mathrm{UF}_{6}$ desublimation. Deposits of $\mathrm{UO}_{2} \mathrm{~F}_{2}$ and other uranium .compounds can accumulate within the cascade as a result of inleakage of wet air and other reactions within the cascade. To detect the potential buildup of large solid uranium masses, both plants employ gamma detection instrumentation to periodically survey the cascade equipment for significant deposits. Gamma surveys can indicate the size of the deposit but not with reliable acciracy. Nondestructive assay (NDA) technology was recently introduced at PORTS in conjunction with the HEU suspension effort. This technology allows for a direct estimate of the mass of deposits based on detection of ${ }^{24} \mathrm{U}$ decay. The amount of ${ }^{234} \mathrm{U}$ is proportional to the amount of ${ }^{255} \mathrm{U}$, such that a mass of ${ }^{25} \mathrm{U}$ can be estimated. NDA has been used to prioritize cells for recovery treatment as part of the suspension effort and clean-up of X-326, the HEU portion of the cascade. PORTS will continue to use the NDA technique to monitor for deposits in the cascade. Because PGDP deals with a maximum of $2 \%{ }^{25} U$, criticality concerns from cascade deposits are significantly less.

The criticality scenarios addressed in the SARs are much more extensive at PORTS than at PGDP because of the ${ }^{250} U$ assays, and these-scenarios conservatively reflect the pre-HEU suspension maximum assay of greater than $90 \mathrm{wt} \%$ zsU. Table $2-4$ summarizes the accident scenarios considered. To evaluate the potential consequences from an inadvertent criticality, representative calculations were performed to analyze the potential radiation doses resulting from several postulated nuclear excursion scenarios. These calculations show that the consequences of an inadvertent criticality event are limited to a finite region around the critical array. The effects generally only affect the building in which such 
an event might occur, and no adverse off-site effects are predicted. With the operating scheme employed in these plants, namely a local control room in each process building and a central control facility, operators in the central control room can take the necessary actions to shut down equipment if an inadvertent criticality forces evacuation or incapacitation of the building operators.

\subsubsection{Operational Safety Requirements}

PGDP and PORTS both have OSRs documents which define operational safety limitations. These documents define safety systems, their limits and settings, limitations on conditions of operation, and equipment surveillance requirements.

\subsubsection{Maintenance of Safety Basis}

Both plants evaluate all plant changes for safety implications according to the operating authorization basis per the requirements of DOE Order 5480.21, "Unreviewed Safety Questions." The authorization basis inciudes the aspects of the facility design basis and operational requirements relied upon by DOE to authorize operation. The authorization basis is described in the FSARs and other safety analyses, OSRs, and facility-specific commitments made in order to comply with DOE orders or policies. Plant changes are evaluated with respect to this basis, and if there are no adverse impacts to this basis; the changes may be implemented without prior DOE approval. This process is similar to the 10 CFR 50.59 process by which commercial reactors evaluate all changes, tests, and experiments for potential "unreviewed safety questions."

This DOE Order 5480.21 process is relatively new. However, safety evaluations and safety assessments have been commonly employed at both plants for several years. These evaluations provide reasonable assurance that the safety analyses defined in the FSARs remain bounding.

\subsection{EFFECTS OF PLANT AGING ON SAFETY}

The existing FSARs do not explicitly consider the effects of plant aging on safety. Aging effects could potentially lead to many of the events considered in the safety analyses, particularly the UFF ${ }_{6}$ and other chemical releases. Aging effects could also result in additional challenges to safety systems and operators. To present a complete picture of the safety of the GDPs, the aspects of aging on plant safety must be examined. Thus, this section addresses the following facets of aging:

- material selection and potential corrosion effects,

- equipment reliability,

$\because$ equipment monitoring, and

- cylinder monitoring.

\subsubsection{Process Boundary Materials and Corrosion}

$\mathrm{UF}_{6}$ is highly corrosive as are other chemicals (e.g., $\mathrm{F}_{2}, \mathrm{CIF}_{3}$ ) used in other operations at the GDPs. Due to the use of these chemicals, the materials of construction were carefully chosen in the design of the GDPs. As a result, the GDPs have not experienced any corrosion problems with properly chosen materials of construction for those systems in contact with UF. Equipment repairs and the CIP/CUP modifications have provided additional confirmation that corrosion due to $U_{6}$ is not a problem. Equipment removed for repairs and modifications has shown little indication of corrosion. 


\subsubsection{Reliability Study Program}

The GDPs have performed several reliability-related efforts to provide assurance that aging concerns for plant equipment and facilities are identified and appropriate corrective action is taken. This section will describe the more recent reliability effects.

Current reliability efforts are derived from the Reliability Core Study Program which was initiated in the late 1970's. This effort evaluated the general condition of principal production-related equipment, facilities, and systems and associated costs to repair or replace. The availability of replacement parts was also considered, given the age of the plants and potential obsolescence of some equipment. From this information, management prioritized repairs and/or replacements based on available resources. This effort was maintained until the late 1980's. A recent update to these assessments was conducted as part of the USEC transition effort. This assessment addressed the overall physical condition of property and specific conditions which could result in short-term financial burdens.

\subsubsection{Preventive maintenance program}

Both GDPs have Preventive Maintenance (PM) programs which are intended to preserve and extend the useful life of all plant real property. These programs implement positive measures to reduce unscheduled outages and extend the useful life of equipment. Computerized databases provide the capability to schedule PM work, to document its completion, and to assess future requirements. Of particular importance is the inclusion in the PM database of all OSR tests, calibrations, and inspections that are used to verify performance and availability of equipment required for safety.

\subsubsection{Key process equipment monitoring}

As the key active component in the enrichment process, the compressors form the basis for the reliability monitoring programs at the GDPs. Experience has indicated that the compressor seals and motors, and the converters are also worthy of reliability monitoring. Accordingly, the compressors, compressor seals, compressor motors, and converters are routinely monitored for reliability, predicted failures per year, and mean time between failures (MTBF). For the compressors and compressor seals, failure data are collected and input to compressor and seal failure databases which are accessible throughout the GDP operations. These databases are updated, and reports are generated monthly; the capability exists to assure 1-day turnaround on report evaluation.

Statistical analysis of past failure rates indicate that increases in power level and the corresponding number of cascade cells, which may be on- or off-stream as power levels are adjusted, may directly increase failure frequency. Accordingly, the current reliability monitoring analyses consider changes in power levels and actual on-stream time of compressors in establishing the failure history of the compressors. However, the Weibull analysis failure predictions do not consider these changes in severity of service, but, instead, rely solely on compressor age. Nonetheless, the predictions have been reasonably close to actual failure data, as indicated by the FY 1992 data (e.g., 14 actual failures vs 13 predicted failures).

As a result of CIP/CUP, pre-Process Equipment Modification (PEM) target failure rates for the compressors were established at $1.7 \%$ failures/stage-year for the 000 compressors and $5.1 \%$ failures/stage-year for the 00 compressors. These values were the average failure rates of the period 1960-1973. Failure rates for FY 1992 were $0.63 \%$ for 000 compressors and $0.58 \%$ for 00 compressors, much lower than the target values. Overall failure rates for the history of operation of the PORTS, PGDP, and Oak Ridge GDPs are $1.05 \%$ for the 000 compressors and $1.92 \%$ for 00 compressors, also considerably lower than the target values. The predicted MTBF for the compressors is many times the expected lifetime of the plant. 
The results of this program are used as input to maintenance and modification activities and to plans for improvements in performance and, therefore, safety.

\subsubsection{Cylinder Monitoring}

Aging of cylinders is not considered a safety concern or issue because of the stringent requirements for inspections, tests, and rejections of cylinders used in the transportation and handling of UF . DOE ORO-651, Uranium Hexafluoride: A Manual of Good Handling Practices, invokes the requirements of ANSI N14.1 for new cylinders and provides guidance for the acceptable use of existing cylinders. This guidance includes inspections at various stages (i.e., before receipt, before filling, after maintenance or repair), instructions for rejecting cylinders based on visually observed indications of damage, and periodic tests. All cylinders must be inspected and tested at intervals not to exceed 5 years (except cylinders that were filled before the 5-year expiration date, which need not be tested until the cylinder has been emptied). A UF, cylinder shall be removed from service or repaired when it is found to have leaks, excessive corrosion, cracks, bulges, dents, gouges, defective valves, damaged stiffening rings or skirts, or other conditions which render the cylinder unsafe.

For cylinders used in long-term depleted assay storage, the Cylinder Integrity Management program has developed a risk based inspection program to monitor the condition of these cylinders. These cylinders, which are stored out-of-doors, are inspected on specific intervals according to location and previous corrosion. Since the material in these cylinders is solid $U F_{6}$, ro significant release of $U F_{6}$ will result in the event of a breach in the cylinder wall.

\subsection{UPGRADES TO EXISTING SAFETY ANALYSES}

As discussed in Sects. 2.2 and 2.2.2, the DOE safety analysis requirements have been revised since the FSARs were issued in 1985. These revisions have added requirements for more formal analysis methods and rigorous documentation. There are no indications that the existing FSARs omitted any significant hazards or failed to provide a conservative estimate of their likelihood, consequences, and risk.

- However, the bases for the selection and elimination of some of the hazards are not well documented. The risk evaluation in the FSARs is primarily qualitative. Nevertheless, the GDPs were, when FSARs were issued, one of the few nonreactor nuclear facilities within DOE with such safety documentation.

The current SAR upgrade effort is based upon the requirements of DOE Order 5480.23, "Nuclear Safety Analysis Reports," and DOE/OR-901, Guidance for Preparation of Safety Analysis Reports, which provide format and content guidance for the development of a SAR based upon a comprehensive, riskbased safety analysis.

\section{5. -DOE OVERSIGHT AND MANAGEMENT OF.THE GDP}

DOE and its predecessor organizations have been responsible for the oversight and management of the two operating GDPs since their initial design and construction. Historically, the earliest guidance for oversight of DOE [then the Atomic Energy Commission (AEC)] facilities was provided by the AEC Manual, which was highly prescriptive. In the early 1970s, when the AEC was reorganized into the NRC and the Energy Research and Development Administration (ERDA), the AEC Manual became the ERDA Manual. The ERDA Manual retained the same general format, content, and prescriptive requirements as its predecessor.

When DOE was established in 1977, it codified the existing guidance on nuclear safety requirements for its facilities (contained in the AEC Manual) through a system of Departmental directives known as DOE orders. These orders typically promulgated detailed guidance on facility safety requirements. In 
addition, the DOE orders contained DOE policies and requirements associated with protection of assets, environmental compliance, OSHA compliance, good practices, and other elements which would not apply directly to nuclear safety and safeguards and security.

The DOE orders present requirements for all DOE facilities. Thus, GDP compliance requirements are a subset of the requirements specified in DOE orders. For example, DOE Order 5480.11 requires a radiological control program which implements the provisions set forth in the DOE Radiation Control (RadCon) Manual. However, the RadCon Manual includes requirements for plutonium and accelerator facilities and for hot particles which are not applicable to the GDPs. Thus, compliance of the GDPs with the DOE orders for nuclear safety does not imply compliance with all elements of the orders. Therefore, the discussion of requirements presented in Chapter 3 focuses on those applicable requirements which are instrumental to supporting nuclear safety and safeguards and security and to providing commensurate protection to the public and environment specifically for the GDPs.

The requirements specified in DOE orders are also supplemented by DOE field organization orders and DOE notices, and more recently; DOE Standards and Guidelines. The field organization orders provide specific directions and define responsibilities within the field organizations for the implementation of a particular order. In general, the DOE notices provide specific directives for compliance with certain requirements and are valid for a specified time only (with the intent that any necessary changes in the requirements will be incorporated into the base order to provide for long-term compliance). DOE Standards and Guidelines provide accepted interpretations of DOE orders and notices.

\subsubsection{Department of Energy Oversight Responsibilities}

In the past, compliance with the order requirements has been a line management function because DOE was responsible for both management and oversight. As new standards were issued, DOE allocated the resources to achieve compliance based on an assessment of priority for achieving compliance with the new requirements and resource constraints. An integral relationship berween DOE's oversight of compliance and management of the facilities was, therefore, essential for the success of the oversight program.

In 1989, the Secretary of Energy changed the DOE organization to improve the safety and management of. DOE facilities because the implementation of the oversight function was considered ineffective. Thus, a key element of these changes was the increased emphasis on self-assessment and oversight activities. At the headquarters level, an oversight function was established to report directly to the Secretary of Energy to advise on the adequacy of line management and self-assessment functions. This function had no line authority, but it did have broad responsibilities to monitor and audit all aspects of nuclear safety through the examination of field office and contractor performance. This function was also responsible for identifying special circumstances indicative of deteriorating or poor performance that might warrant further in-depth appraisals. Such appraisals included special safety appraisals conducted with teams including outside expertise representing a bridge to experience in the commercial nuclear industry.

Additionally, separate offices within the DOE elements of Environmental, Safety \& Health (ES\&HI) and S\&S were established to conduct independent assessments of DOE and contractor performance. These offices were complemented by similar self-assessment organizations located in the field at DOE and contractor sites. 


\subsubsection{Environmental, safety and health oversight}

DOE Order 5482.1B establishes the basic requirements for DOE Headquarters and field office oversight of DOE-contractor ES\&H programs and includes requirements for the following types of appraisals.

1. Management Appraisals: a documented determination of managerial effectiveness in establishing and implementing ES\&H program plans that conform to DOE policy requirements. It is based on an analysis of functional appraisals, internal appraisals, and other information. The appraisal covers all ES\&H disciplines and management responsibilities to assure proper program balance.

2. Technical Safety Appraisals: a documented multi-discipline appraisal of selected DOE reactors and nuclear facilities conducted by a team representing the DOE Office of Environment Safety, Health and Quality (ESH\&Q). The team assesses proper department-wide application of particular safety elements of the ES\&H program, nuclear industry lessons learned, and comparability to licensed facility requirements.

3. Functional Appraisals: a documented review of an ES\&H specialty discipline performed in accordance with written guidance and criteria to verify, by examination and evaluation of objective evidence at the facility or operation, that applicable elements of the program have been developed, documented, and effectively implemented in accordance with specific ES\&H requirements and needs.

4. Internal Appraisals: an examination and evaluation by the operating level (either federal or contractor) of those portions of an organization's internal ES\&H program, program plan implementation, and operations retained under direct control.

5. Environmental Surveys: a documented, multi-discipline assessment (with sampling and analysis) of a facility to determine environmental conditions and to identify problem areas of environmental risk requiring corrective action.

6. Environmental Audits: a documented assessment of a facility to monitor the progress of necessary corrective actions, to assure compliance with environmental laws and regulations, and to evaluate field organization practices and procedures.

This order requires the quality, frequency, and depth of appraisals to be commensurate with the hazard of the respective operating activities; consistent with both the DOE policy of comparability and equivalence with similar regulatory programs; and consistent with DOE policy of protection of personnel, property, and the environment. Independent of the hazard, this order requires management appraisals to be conducted as least every 3 years and the other appraisals to be conducted at sufficient frequencies to provide meaningful input to the management appraisals.

Although the DOE organization was modified to achieve more effective independent assessment and appraisal, the line organization still remains responsible for ensuring adequate ES\&H performance, including reactor and nonreactor nuclear facility safety. Nuclear safety responsibility embraces all systems and activities that can influence the potential for uncontrolled release of fission products or for nuclear criticality. Certainty of nuclear safety involves not only verification that nuclear reactor and nonreactor nuclear facility designs comply with applicable standards but also verification that plant modifications, operations, maintenance, and plant material conditions meet nuclear safety requirements and that human performance facets which could potentially affect nuclear safety are receiving appropriate attention. DOE Order 5480.5, "Safety of Nuclear Facilities,". delineates the basic requirements for 
ensuring nuclear safety and includes, among other elements, the requirement for a contractor-independent safety and appraisal system.

\subsubsection{Occurrence Reports and Lessons Learned}

DOE Order 5000.3B identifies requirements for occurrence reporting and processing. One major purpose of this reporting system is to provide operational and safety feed-back from a facility Occurrence Report to other DOE nuclear facilities. Sect. 3.2 of this document discusses this aspect of the order and its use in the GDPs. This reporting system also provides a mechanism for DOE oversight of operations information. According to DOE Order 5000.3B, DOE must establish and maintain an unclassified, central DOE operational database containing unclassified Occurrence Reports entered into the database by the Facility Managers and must make the database available to all DOE operating contractors and departmental elements. DOE must review Occurrence Reports to identify circumstances that indicate deteriorating or poor program performance in the areas of nuclear safety, ES\&H, and emergency planning to determine if further actions are warranted. Additionally, the DOE Facility Representative and DOE Program Manager, in conjunction with the Facility Manager, should review the database to identify good practices and lessons learned from.other facilities that can be used in their facilities. Other DOE oversight responsibilities for Program Managers and Facility Representatives include:

- ensuring that lessons-learned and generic or programmatic implications are identified and elevated to the Headquarters or Operations Office head, as applicable, for appropriate action;

- ensuring that actions are taken to minimize or prevent recurrence;

- reviewing and assessing Reportable Occurrences information from facilities under their cognizance to assess significance, root causes, generic implications, and the need for corrective action; and

- ensuring that Occurrence Reports and operations information from other organizations are disseminated to appropriate DOE and contractor activities, are reviewed for geñeric implications, and are used to improve operations.

DOE Facility Representatives must also monitor day-to-day operations and performance of facilities and activities under their cognizance.

Before January 1993, DOE 5000.3A, implemented on September 1, 1990, was in force. Since September 1, 1990, the GDPs have reported and analyzed approximately 850 occurrences; related corrective actions have been submitted to DOE for approval.

DOE Order 5000.3A was implemented by Energy Systems through the issuance of a policy document (ES-OP-300) and Energy Systems Standard (ESS.OP.301). PGDP and PORTS sites then issued plant standard practice procedures to implement the order. These procedures are now being combined into a UE procedure format.

Per DOE Order 5000.3A, the GDPs created a site-specific reporting criteria based on the general criteria within the order. These site criteria were approved by DOE-HQ (NE-33) on December 28, 1992, and immediately implemented at both sites.

Additionally, the sites report less significant events through an internal Energy Systems reporting system per Energy Systems Standard ESS.OP.301. To date, the GDPs have reported and analyzed approximately 2,800 events under this system. 
Individuals within the site line organizations who are trained and experienced in event root cause analysis investigate DOE Order 5000.3B occurrences. This process begins with the report of an event to the PSS who categorizes the event in the appropriate reporting level per the site reporting criteria.

If the event meets the DOE reporting threshold, a notification report is filed within 24 hours to DOE by way of the EG\&G occurrence reporting and processing system (ORPS) database. Telephone notification is also required for those events classified as emergencies (within 15 minutes) or unusual occurrences (within 2 hours of classification).

Events not reportable to DOE are reported through the Energy Systems internal system for investigation.

For DOE reportable events, a follow-up report that further explains the event and updates the information in the notification report is required within ten working days. Within 45 calendar days, a final report, including corrective actions, must be issued to DOE for the approval of both the local site office and then DOE-HQ (NE-33).

Each event is analyzed to determine root, contributing, and direct casual factors for which corrective actions are created and scheduled. This analysis and its conclusions are validated independent of the line organization before the reports are transmitted to DOE.

The corrective actions are entered into the DOE and plant tracking systems. Corrective actions must be independently verified before official closure. Since September 1990, approximately 4000 actions have been directed at event casual factors.

The occurrence reporting system is supported by the Energy Systems Lessons Learned Systems, which captures lessons from various internal and external sources for review.

As a result of this operational information oversight, DOE may identify a Nuclear Safety Issue (NSI) which multiple facilities must address.

\subsubsection{Safeguards and security oversight}

DOE Order 5630.12A establishes the basic requirements for DOE Headquarters oversight of Safeguards and Security programs, while DOE Order 5634.1A establishes the basic requirements for DOE Field Office oversight of DOE-contractor Safeguards and Security programs. DOE Order $5630.12 \mathrm{~A}$ requires a program of independent inspections, assessments, special studies, and other appropriate activities to determine the effectiveness of DOE's Safeguards and Security policies, programs, and implementation across the department. This inspection and assessment program must be independent of other line management responsibilities for protection program activities; however, it must also remain supplemental and complementary to the line management oversight responsibilities, including their selfassessment activities. DOE Order 5634.1A identifies the requirements for granting facility approvals before permitting Safeguards and Security interests on the premises and identifies the conduct of on-site security or nuclear material surveys of facilities with Safeguards and Security interests. Through these surveys, the adequacy and effectiveness of Safeguards and Security programs and the protection afforded DOE Safeguards and Security interests are evaluated at the facility level.

\subsubsection{Special Oversight Activities}

Tiger Team assessments were performed at PORTS in October-November 1989, and at PGDP in June-July 1990. The Tiger Team assessments reviewed three primary areas: ES\&H, and Management. These assessments are related to the performance-based appraisals performed by Institute of Nuclear 
Power Operators (INPO) on nuclear reactors. They are conducted by multidisciplinary teams appraising key functional elements in a coordinated fashion to provide an overall facility or site assessment.

The Safety and Health assessments were based on Technical Safety Appraisal performance objectives derived from DOE orders, Secretary of Energy Notices (SENs), and other policy statements, industry standards, and nuclear industry lessons learned. These Technical Safety Appraisals are operationally focused evaluations intended to appraise how safely a facility or site is operated and the condition of its equipment. The concerns identified by the Safety and Health assessment were obtained by (1) observing routine operations, emergency excrcises, and the physical condition of the site and facilities; (2) interviewing management, staff, operators, and craft personnel; and (3) reviewing policy statements, records, procedures, and other relevant documents. The Safety and Health Appraisal findings were classified according to the following:

The Tiger Teams found that plant management had processes in place for improving plant safety performance. There were no Category I findings involving clear and present danger to workers or members of the public, and only four Category II findings "representing significant risk or substantial non-compliance with DOE orders but not involving clear and present danger." Two of the Category II findings were related to electrical safety and $x$-ray calibration and were corrected immediately. The other Category II findings were related to fire protection. One of these involved failure to comply with the life safety code. As discussed in Sect. 3.18.4, DOE has been asked for an exemption from this requirement because compliance would require replacement of the process buildings. Corrective actions in response to the other finding are mostly complete, with the last scheduled action not due to be completed until September 1993.

Most of the Tiger Team findings involved Category III actions that will be addressed in order of priority. Some of these findings included a lack of full compliance with DOE orders and mandatory standards. On the other hand, the Tiger Teams recognized the commitment of management and the efforts of the staffs to achieve full implementation of the Secretary of Energy's policies, directives, and initiatives. With respect to the Tiger Teams' findings of lack of full compliance with DOE orders, the following should be noted.

- The DOE orders contain more requirements than necessary to protect the health and safety of the public, employees, and environment, as discussed in the introduction and Sect. 2.5.

- The Technical Safety Appraisal criteria and objectives of the assessment, including the determination of compliance with DOE orders, include a broader scope than nuclear safety.

The GDPs have expended significant efforts and money to resolve the findings and issues identified by the Tiger Team assessments.

\subsubsection{FY-1992 Oversight Activities}

During fiscal year 1992, DOE conducted routine audits and appraisals of PGDP that involved approximately 3.25 staff-years of on-site effort. During the same year, DOE conducted routine audits and appraisals of PORTS, involving approximately 5 staff-years of on-site effort. Additionally, other agencies such as the EPA and state regulatory agencies conducted audits/inspections of PGDP and PORTS. Furthermore, DOE maintains resident site safety representatives at both PGDP and PORTS who also perform routine oversight activities. 


\subsection{COMPLIANCE WITH DEPARTMENT OF ENERGY ORDERS}

The following information describes the means, identified in DOE orders, by which the field organizations and their contractors ensure compliance with the requirements of DOE orders related to public health and safety or Safeguards and Security programs.

\subsubsection{Environment, Safety, and Health Compliance}

DOE Order 5480.1B establishes the ES\&H program for DOE operations. Paragraph 8.d of this order specifies that heads of field operations are responsible for assuring that all operations under their jurisdiction are carried out consistent with sound ES\&H practices and in accordance with ES\&H orders. To carry out these responsibilities, Paragraph 8.d requires, among other things, that the heads of field operations prepare implementation plans for DOE Order 5480.1B and other DOE Order 5480 series orders that include:

- the designation of ES\&H responsibilities and authorities by the field organization and their contractors, and

- a concise description of the approach, resources, and time period planned for implementing orders that require such plans on a sitewide basis, including a description of the execution of ES\&H responsibilities and authorities by the field organization and any proposed generic exemptions to parts of such orders.

\subsubsection{Environmental Compliance}

DOE Order 5400.1 establishes environmental protection program requirements, authorities, and responsibilities for DOE operations for assuring compliance with applicable federal, state, and local environmental protection laws and regulations, executive orders, and internal DOE policies. This order more specifically defines environmental protection requirements that are generally established in DOE Order 5480.1B. The provisions for developing and reviewing specific measures to comply with DOE environmental requirements are specified in Chapter III, Paragraph 2, "Implementation Plan," and Paragraph 3, "Long-Range Environmental Protection Plan."

The Implementation Plan section requires each field organization to prepare a plan for implementing the requirements of DOE Order 5400.1 for each facility or group of facilities. The purpose of the plan is to provide management direction, including assigning responsibilities and authorities, to ensure that all DOE facilities are operated and managed in a manner that will protect, maintain, and where necessary, restore environmental quality, minimize potential threats to the environment and the public health, and to comply with environmental regulations and DOE policies. Specifically, the implementation plan shall do the following.

1. Provide environmental protection goals and objectives for the organization and identify strategies and timetables for attaining them. - Organization and staffing, including assignment of responsibilities for environmental activities, policies, facility operating procedures, and budgeting, will be described.

2. Provide an overall framework for the design and implementation of an environmental protection program for each DOE facility.

3. Assign responsibilities for complying with requirements under all federal, state, and local environmental laws and regulations for all DOE facilities. 
As an element of ES\&H long-range planning, each field organization must develop a long-range environmental protection plan that comprehensively defines specific environmental objectives and the means and schedules for attaining objectives and completing programs and projects at each facility or group of facilities. The plan serves as a mechanism for Headquarters and field organizations to coordinate strategies for addressing environmental needs.

\subsubsection{Safeguards and Security Compliance}

DOE Order 5630.13A, "Master Safeguards and Security Agreements (MSSA)," and DOE Order 5630.14, "Safeguards and Security Program Planning," identify the provisions for developing and reviewing specific measures to comply with DOE Safeguards and Security requirements. The MSSA establishes a formal agreement requiring the joint approval of Headquarters and field organizations for the levels of protection of graded Safeguards and Security interests from theft, sabotage, and other malevolent acts associated with SNM or vital assets which may adversely affect national security or the health and safety of the public. Such agreements take into account DOE policy applicable to specific sites and programs to achieve acceptable protection levels that minimize inherent risks on a cost-effective basis. The joint approval of the MSSA allows the responsible field organizations to develop plans for protecting Safeguards and Security interests which are acceptable to appropriate Headquarters personnel.

DOE Order 5630.14 establishes a standardized approach to protection program planning by consolidating various protection program plans, previously required reports, and planning-type documents into one planning document-the site-Safeguards and Security Plan. The site Safeguards and Security Plan is composed of three volumes: (1) the MSSAs, (2) the Facility Descriptions and Operations Plans, and (3) the Resource Plans. 'The three volumes of the site Safeguards and Security Plan depict the existing condition of Safeguards and Security sitewide and by facility, establish improvement priorities, and provide for an estimate of resources required for making the necessary improvements. The site Safeguards and Security Plan must be reviewed and updated annually; modifications to the MSSAs are made per the requirements of DOE Order 5630.13. 
DOE/ORO - 2051 


\section{OPERATIONAL REQUIREMENTS}

This chapter describes the envelope of plant operating requirements that are being followed and are considered necessary to protect public health and safety and to assure adequate safeguards and security of the GDP facilities. These requirements and the implementation of these requirements will result in continued safe operation of the GDPs.

A number of sources, listed in the Bibliography (Chapter 6), have been reviewed to substantiate the basic content of these safety requirements. This review has confirmed that the current GDP safety requirements encompass the spectrum of essential nuclear safety and safeguards and security requirements contained in the referenced documents.

The basic objective of each of the topical areas is provided, followed by a set of Implementation Requirements that define what must be done to address the basic objective. These are followed by a description of how the GDPs are meeting the Implementation Requirements. Finally, the status of the conformance of GDP programs and practices with the Implementation Requirements is summarized for each topical area.

A reference is provided for each of the Implementation Requirements. The citation of a DOE Order, American National Standards Institute (ANSI) standard, or National Fire Protection Association (NFPA) standards does not imply that all requirements listed in the order or standard are a mandatory part of the safety basis for the GDPs. The DOE Order, ANSI standard, or NFPA standard is listed only to indicate the source of the implementation requirement.

The programs, procedures, and practices used by the GDPs to satisfy the Implementation Requirements at the time this report was prepared are described in the "How the Requirements Are Met" sections. The plant or Uranium Enrichment governing documents supporting the implementation of the requirement are shown at the end of each paragraph of the description of how the requirement is met. All implementation measures identified in such documents may not apply to the particular requirement in question or may not be fully implemented in the detail specified by the referenced document. The implementation of the requirements can, however, be audited against the descriptions provided in the "How The Requirements Are Met" sections.

This document often refers to safety systems and authorization basis. Safety systems or components are defined as "Systems, components, and structures, including portions of process systems, whose failure could adversely affect the safety and health of the public. These are necessary to prevent accidents or mitigate their consequences, or to monitor releases that could result in potential off-site exposures." Safety systems for the GDPs are identified in the respective OSR documents for each plant. The authorization basis is described in documents such as the facility Safety Analysis Report and other safety analyses; Hazard Classification Documents, the OSRs, DOE-issued safety evaluation reports, and facilityspecific commitments made in order to comply with DOE Orders or policies.

\subsection{ORGANIZATION PLAN}

\subsubsection{Basic Objective}

Operation of the GDPs shall be organized in a manner to ensure that responsibility and authority for safe operations are clearly defined, and that critical safety functions such as Nuclear Criticality Safety (NCS), radiation protection, quality assurance, and preparation of USQDs are independent of production. 


\subsubsection{Implementation Requirements}

1. Each plant shall have procedures or other appropriate documentation which clearly defines authority, responsibility, and accountability for safe operations. The documentation shall contain the following elements.
a. Authority for safe operation shall be clearly defined for each position of responsibility (DOE Order 5480.5, DOE Order 5480.1B).
b. Responsibility for safe operations shall be clearly delineated in each position description and in each "roles and responsibility" document (DOE Order 5480.1B, DOE Order 5480.20).

2. Quality assurance, radiation protection, NCS, and USQD preparation functions shall be independent of production and personnel assigned in these areas should be authorized to halt unsafe activities (DOE Order 5700.6C, DOE Order 5630.11A, DOE Order 5480.19).

\subsubsection{How Requirements Are Met}

1. The plants are organized in an hierarchical fashion. Each plant maintains an organization chart and written position descriptions. The plant manager is the senior Uranium Enrichment official with on-site responsibility for safe operations. There is a direct chain of command from the Plant Manager to the shift operating staff. On back-shifts and weekends, the plant shift superintendent represents the plant manager. Managers of all the line and support functions needed for the safe and efficient operation of the GDPs report to the plant manager.

- Responsibility for safe operation and compliance with regulations resides with the plant management. The plant manager assigns responsibility for safe aspects of operations to all levels of management and supervision within the plant. These responsibilities are outlined in plant procedures describing specific operations.

- Position descriptions and roles and responsibilities documents are prepared for managerial and supervisory positions. Periodic performance reviews are conducted to re-enforce desired supervisory behavior.

- Each division manager has the authority and responsibility to enforce safe operations within his or her division.

- Each department manager has the authority and responsibility to ensure safe operation within his or her department.

- $\quad$ - Each supervisor is charged with the safety of the personnel and the facility that he or she supervises.

- Each worker has the authority to stop work if he or she recognizes an imminent danger that the worker cannot immediately address or correct.

2. Quality assurance, radiation protection, NCS, and USQD preparation are independent from production activities at both plants. Quality Assurance is the responsibility of the Management Systems and Compliance Divisions, which are also separate from production at both plants. Department and division managers for these functions have direct access to the plant manager. Department managers and personnel responsible for radiation protection, NCS, USQD preparation and Quality Assurance have the authority to halt activities they consider unsafe. Stop work actions 
initiated for safety reasons can only be removed with the concurrence of the function manager responsible for the stop work order.

\subsubsection{Status of Conformance}

The requirements set forth in Section 3.1.2 are met as described in Section 3.1.3 with the following general exceptions:

- Some of the plant procedures and other documentation describing the organizational structure are not consistent with the organization as it currently exists and need to be updated.

\subsection{MANAGERIAL CONTROLS AND OVERSIGHT}

\subsubsection{Basic Objective}

Management Controls and Oviersight (MC\&O) shall ensure that activities directly relevant to nuclear safety and safeguards and security are conducted in an appropriately controlled manner that ensures protection of employee and public health and safety and protection of the national security interests.

\subsubsection{Implementation Requirements}

1.. Procedures and documents important to nuclear safety and safeguards and security shall be developed, revised, reviewed, approved, distributed, and used in accordance with identified, written requirements and authorizations (DOE Order 5700.6C and DOE Order 5630.11A).

2. An internal and independent safety review process shall be established and maintained (DOE Order 5480.5).

3. Occurrences shall be reported and investigations conducted on events that could affect the health and safety of the public, or endanger the health and safety of workers (DOE Order 5000.3B and DOE Order 5480.21).

4. A commitment tracking system shall be maintained to monitor the status of formal commitments to improve nuclear safety and safeguards.

5. Administrative controls shall provide standard methods and requirements for creating, collecting, maintaining, and disposing of records related to nuclear safety and safeguards and security (DOE Order 1324.2A; DOE Order 1324.5A).

\subsubsection{How Requirements Are Met}

MC\&O at the UE facilities is assured through implementation of applicable parts of the Uranium Enrichment Quality Program Plan (UEQPP). The UEQPP assigns accountability for quality attainment and assessment of performance of the management systems to the line organizations.

1. Management has established a procedure that defines the expectations for procedure use. Procedure use is consistent with a graded approach based on the significance of the activity (both plants, UESPP-PS-100, Sects. 1.0,6.2,6.3, and 6.4). Procedures exist at the UE and plant levels that define how safety and safeguards and security procedures are developed, revised, reviewed and approved, and distributed (UE-2-PS-PS1001; P-GP-1, Rev. 2; SPP-PS-001). 
2. The Health and Safety Review Committee (HSRC) at PGDP and the Independent Safety Review Committee (ISRC) at PORTS, provide independent health and safety oversight to safety analysis documentation, (FSARs, OSRs) and Unreviewed Safety Questions (USQs).

3. Unusual Occurrence Reporting and investigation of abnormal events include identification and categorization of events as well as analysis of root cause, effectiveness of response to the occurrence, and impact or effect of the occurrence on nuclear safety, safeguards and security. Corrective actions are entered into the commitment tracking system, and their completion is independently validated, appropriately verified, and documented (both plants, UE2-MC-CI-1001, Chapters 2, 6.3, and 7). See also Section 2.5.1.2 for more detail concerning current practice on Unusual Occurrence Reporting.

4. Commitment tracking is provided through a dedicated database for tracking, trending, and managerial review. All corrective actions and commitments from the safety review committees actions, internal and external assessments, Lessons Learned, and unusual occurrences are independently validated, tracked, trended, appropriately verified, and documented (both plants, UE2-MC-CI-1001, Chapters 2, 6.3, and 7).

5. A records management process is established by documented administrative controls that provide standard methods and requirements for the creation, collection, maintenance, and disposition of records related to nuclear safety, safeguards and security. Designated retention times and storage requirements are provided (both plants, UEQPP, Criterion 4).

\subsubsection{Status of Conformance}

The requirements set forth in Section 3.2.2 are met as described in Section 3.2.3.

\subsection{OPERATIONS}

\subsubsection{Basic Objective}

Management shall ensure that plant operations are performed within the controls developed through the use of hazard analysis and safety reviews.

\subsubsection{Implementation Requirements}

1. Operating bounds for safety systems and components as established by OSRs shall be observed (DOE Order 5480.5, DOE Order 5480.22).

2.- Safety system surveillance requirements, as established in the OSRs, shail be conducted as specified. Additional tests to verify proper operation of systems and integrity of confinement structures shall be conducted after significant maintenance as specified in post-maintenance testing procedures. Completed OSR surveillance tests and safety system check sheets shall be independently reviewed. (DOE Order 4330.4A, DOE Order 5480.19, and DOE Order 5700.6C).

3. Procedures shall be prepared to facilitate initial and periodic tests of safety-related equipment to ensure it operates and meets design objectives (DOE Order 5480.5, DOE Order 5480.21, and DOE Order 5700.6C).

4. Management shall assess plant operations and personnel performance through a program of monitoring and plant tours (DOE Order 5480.5, DOE Order 5480.21). 
5. Turnovers conducted for selected shift stations shall ensure the effective and accurate transfer of information between shift personnel (DOE Order 5480.19).

6. Management shall ensure that proposed changes which involve an Unreviewed Safety Question or a change in the Authorization Basis or an Operational Safety Requirement are not implemented without DOE consent and written approval (DOE 5480.21).

7. Management shall ensure that "As Found" conditions which potentially involve an Unreviewed Safety Question or a change in the Authorization Basis or an Operational Safety Requirement that DOE is notified and that appropriate engineering reviews and safety assessments of the condition are performed and submitted to DOE for review (DOE 5000.3B, 5480.21).

\subsubsection{How Requirements Are Met}

1. The OSR (PORTS GAT/GDP-1074, Parts A through L; PGDP KY-315) provide safety, limits, operating limits, surveillance requirements, bases, and administrative controls to ensure safe operations. The OSRs are implemented through site procedures, which are required to be used (both plants UE-SPP-PS-100).

2. System surveillance requirements are contained in the OSRs (PORTS GAT/GDP-1074, Parts A through L; PGDP KY-315). Post-maintenance testing and inspections are performed in accordance with procedures (PORTS OPS-13; PGDP OPS-13). Completed OSR surveillance tests and safety system check sheets are independently reviewed (PGDP P-GP-1).

3. Requirements for initial and periodic testing of safety-class systems are contained in the OSR (PORTS GAT/GDP-1074, Parts A through L; PGDP KY-315). The OSRs are implemented through site procedures, which are required to be used (both plants UE-SPP-PS-100). Completed OSR surveillance tests and safety system check sheets are independently reviewed (PGDP P-ESH-57; PGDP P-GP-1).

4. A management self-assessment program is currently being implemented to monitor the effectiveness of operational safety activities. Management personnel are walking their spaces (both plants, UE2MC-CI 1003).

5. Shift turnovers are conducted in accordance with written procedures developed to ensure the effectiveness and accuracy of the transfer of information between shift personnel (PORTS OPS-11; PGDP P-GP-104).

6. Proposed changes that involve an Unreviewed Safety Question or a change in the Authorization Basis or an Operational Safety Requirement are not implemented without submission to DOE and without DOE consent and written approval (PORTS-SA-001, PGDP-P-ENG-4).

7. Engineering reviews and safety assessments of the "as found" conditions which potentially involve an Unreviewed Safety Question or a change in the authorization basis or an Operational Safety Requirement are performed and submitted to DOE. "As found" conditions are reported to DOE.

\subsubsection{Status of Conformance}

The requirements set forth in Section 3.3.2 are met as described in Section 3.3.3 with the following general exceptions:

- Reviews of OSR surveillance tests and safety-systems checks are not yet conducted at PORTS. 


\subsection{ENGINEERING REVIEWS}

\subsubsection{Basic Objectives}

There shall be a documented review process to ensure (1) that all plant and procedure changes are reviewed to confirm that adequate nuclear safety, and safeguards are maintained and to identify Unreviewed Safety Questions and (2) that appropriate performance requirements are included in procurement specifications for safety system items.

\subsubsection{Implementation Requirements}

1. Procedures and controls shall be established to ensure appropriate reviews of the following.

- Each change to procedures and plant or equipment design impacting safety systems to ensure the adequacy of configuration control, radiation, criticality, nuclear safety and safeguards considerations and to maintain appropriate limits (DOE Order 5480.5, DOE Order 5480.21, DOE Order 5480.22, DOE Order 5480.23, and DOE Order 5700.6C).

- Each procurement document for safety systems to ensure that they contain appropriate information on established radiological and criticality safety requirements and to ensure that vendors shall supply equipment that will perform under expected service conditions (DOE Order 5480.5; DOE Order 5480.21; DOE Order 5480.22; DOE Order 5480.23; and DOE Order 5700.6C).

2. Listings of all changes to plant and equipment safety systems evaluated through the use of engineering reviews, safety assessments and USQDs shall be maintained for each calendar year. Appropriate documentation shall be made available for regulatory oversight review if requested (DOE Order 5480.21, DOE Order 5480.22, DOE Order 5480.23, and DOE Order 5700.6C).

3. Engineering reviews of proposed changes to the plant facilities, procedures, and or tests (or additional tests not included in the authorization basis) which involve an unreviewed safety question or a change in the authorization basis or an operational safety requirement are submitred to DOE for review and concurrence prior to implementation (DOE Order 5480.21).

\subsubsection{How Requirements Are Met}

1. Procedures and controls have been established as described below

The manager of each nuclear facility (building or operation) is required to notify the nuclear safety organization of any proposed changes to a safety system; any significant facility or process modification, tests, or experiments being performed without an Engineering Service Order (ESO); - and any temporary modifications, as defined in plant procedures. The nuclear safety organization reviews these to confirm that adequate radiation protection, criticality safety, and safeguards are maintained and to identify Unreviewed Safery Questions. For significant facility or process modification, tests, or experiments being performed under an ESO, the nuclear safety organization reviews ESO to confirm that adequate radiation protection, criticality safety, and safeguards are maintained and to identify USQ (both plants UEQPP, Criterion 6; PORTS SPP-H-45, Sect. C, SA001 , Sect.6.2; PGDP SPP-P-ENG-4, Sect. 6.2.). Similarly, each procedure change request is screened by a qualified USQ reviewer to determine whether its implementation would involve a USQ (both plants UE2-PS-PS-001, Sect. 6.4). Procedure change requests are also required to be reviewed by a procedure configuration control board, which is required to have representation in sufficiently broad functional areas to enable it to confirm that adequate radiation protection, criticality safety, and safeguards are maintained (PORTS SPP-PS-001, SPP-PS-002; PGDP P-GP92). 
Specific measures have been implemented to require that the information within procurement documents for safety system components conforms to approved specifications. All safety system component purchase orders or bills of materials are required to be marked as requiring special inspections unless the requirement for special inspections is clearly identified on the engineering data sheets from which orders are made. Furthermore, engineering specifies the inspections and quality assurance documentation that are required from the yendors as a condition of purchase for safety system components prior to its acceptance for use within the plants (PORTS SPP-H-31, SPP-H-45; PGDP P-ESH 57, Sect.5.1). Procedures require that engineering approve all data sheets - for safety system components before their actual procurement (PORTS SPP-H-31, SPP-H-45; PGDP P-ESH 57, Sect.5.2).

2. Appropriate documentation is maintained at both GDPs (PGDP: P-ESH-20; PORTS: SPP-H-30).

3. Engineering reviews of proposed changes as described in the Implementation Requirements are submitted to DOE for review and concurrence prior to implementation (PORTS-SA-001, PGDP-PENG-4).

\subsubsection{Status of Conformance}

The requirements set forth in Section 3.4.2 are met as described in Section 3.4.3 with the following general exceptions:

- The configuration control process (including as-built drawings) for safety systems is not fully implemented.

\subsection{TRAINING AND QUALIFICATION}

\subsubsection{Basic Objective}

Plant personnel must be aware of and trained to recognize and cope with safety hazards and safeguards requirements that they will encounter in their jobs, and they must be appropriately trained and qualified for nuclear safety-related functions they perform.

\subsubsection{Implementation Requirements}

1. Line managers are responsible for defining training needs and assuring completion of training and demonstration of performance proficiency (qualification) of their employees consistent with their job content (DOE Order 5480.18A, 5480.19, and 5480.20).

2. The independent training organization shall co-develop with line management a description of each organization's training requirements and record status in satisfying these requirements, thereby ensuring effective implementation and control of training activities (DOE Order 5480.20).

3. Plant personnel and visitors or contractors shall successfully complete training in the areas listed below before they are granted unescorted access to controlled areas (DOE 5480.11, and DOE Order 5480.20).

- Plant radiological, chemical, criticality, and industrial safety hazards;

- Plant safety rules; and

- Plant evacuation procedures. 
4. Plant personnel shall successfully complete radiation protection training before they are granted unescorted access to radiological areas (DOE 5480.11, and DOE Order 5480.20).

5. As required, personnel shall successfully complete performance based training for safety-related activities. (DOE Order 5480.19, and DOE Order 5480.20).

6. Personnel shall successfully complete nuclear safety and safeguards and security training, retraining and requalification at established intervals. (DOE Order 5480.19, and DOE Order 5480.20).

7. Training requirements shall be defined and training provided to all supervisors and managers with respect to their responsibilities in the areas of safety and safeguards and security (DOE Order 5480.18A, DOE Order 5480.19, and DOE Order 5480.20).

\subsubsection{How Requirements Are Met}

1. Line management establishes operating standards, communicates performance expectations to all personnel, approves training programs developed jointly with plant training organizations, and verifies successful completion of these programs (reference UE-SPP-TRN-1, 5.0).

2. Both GDPs have dedicated independent training organizations. These training departments. Serve the operations, production, and maintenance organizations but remain functionally separate. "The training departments have dedicated facilities, equipment, and staff to support training functions. The training staff at both facilities is comprised of certified instructors, suitably qualified in their fields and experts in the subjects they teach.

Both plant's training organizations document and track training requirements and completion using training data base software. The training organizations, together with line management, have developed a Training Development and Administrative Guide (TDAG) and Qualification Standard to describe and control training activities. Plant training procedures have recently been reviewed for detail, applicability, and usability.

3. The following safety and safeguard-related training is given to plant personnel and to visitors or contractors who require unescorted access to controlled areas. (Standard Practice and Procedure (SPPs) currently shown as DRAFT are expected to be final by July 1, 1993.)

- General Topics: Following review of Martin Marietta-Uranium Enrichment (MM-UE) programs, the trainee is expected to be able to identify health and safety programs; employee and visitor responsibilities; and emergency programs, signals, and actions required [PGDP SPP P-ESH-1; PORTS SPP TQ-014 (draft)].

- Hazard Communication: The purpose of this general overview, awareness-level course is to make every employee aware that hazardous chemicals are present in the workplace and to help them understand the function of warning labels and signs, MSDSs, and the written Hazard Communication Program (PGDP SPP P-ESH-30; PORTS H\&S SPP H-58, Sect. J).

- General Employee Radiation Training: The training covers the employee's responsibilities for maintaining exposures to radiation and radioactive materials as low as reasonably achievable (ALARA). It reviews natural background and man-made sources of radiation, the whole body radiation dose limit for nonradiological workers, the potential biological effects from chronic radiation doses, ALARA concepts and practices; and methods used to control radiological materials (UE-SPP-ESH-5, Sect. 6.2). 
- Emergency Preparedness: Introduces the trainee to the basic Emergency Preparedness Program elements including: the definition of "emergency" plant safety objectives and priorities, ways to report emergencies, the recognition and correct responses to plant alarm signals, the correct response to evacuations caused by radiological and nonradiological emergencies, personnel accountability; and each employee's responsibilities related to emergencies (PGDP SPP P-ESH-500; PORTS H\&S SPP-Ḥ-6, Sect. 5.12.4).

- General NCS: The training emphasizes the prevention of accidental nuclear criticality and describes the hazards and risks of a nuclear criticality accident, recall, and criticality safety responsibilities and identifies the proper response to a nuclear criticality alarm (PGDP SPP PESH-20; PORTS H\&S SPP H-30, Sect. 2.C).

- Health and Safety Rights: Covers the employee's rights and responsibilities and employer duties (PGDP SPP P-ESH-1; PORTS H\&S SPP H-24, B.2.).

4. Radiation Worker Training includes a comprehensive classroom and practical curriculum consisting of radiological theory and site-specific applications. Proper use of radiological protective clothing and equipment is stressed during the practical exercise (UE-SPP-ESH-5, Sect. 6.3).

5. Based on job assignment as specified in the TDAG or Qualification Standard, appropriate employees also attend higher level performance based training in the following areas.

- Hazard Communication and Chemical Safety (PGDP SPP P-ESH-30; PORTS H\&S SPP H-49, Sect. 6.1.1, SPP H-58, Sect. J).

- Lockout/Tagout for Authorized Employee (PGDP SPP P-ESH-113, SPP P-ESH-116; PORTS H\&S SPP M-4, Sect. 5.3.2).

- Reproductive Hazards (UE SPP-ESH-3; PORTS H\&S SPP H-64, Sect. 6.13.a).

The Emergency Response Training Program is designed to meet emergency response training needs for plant emergency response team personnel. Emergency response team members from key functional areas are trained. Training in these key functional areas is designed to meet the individual training requirements. Documentation of training is maintained within the Safeguards, Security, and Emergency Services Division records or in the plant central training records files.

The Maintenance training programs are designed to provide a skilled workforce that has the technical expertise and safety-related knowledge and skills necessary to ensure the integrity of plant safety systems and/or critical components during maintenance operations. Craft personnel and supervisors are trained in key maintenance functional positions. Training in these key functional positions is designed to meet the individual training requirements. Documentation of training is controlled by the Training Department and maintained by Records Management (UETRN-1, Sect. 1.2; UETRN-6, Sect. 6.2; and UETRN-7, Sect. 7.2).

The Operations training programs are designed to meet the operational training needs for plant operations personnel. Operators and supervisors are trained in key functional positions. Documentation of training is controlled by the Training Department and maintained by Records Management (UETRN-1, Sect. 1.2; UETRN-6, Sect. 6.2; UETRN-7, Sect. 7.2; PORTS PX-008, Sect. 5.2).

Mobile Equipment and Transportation Safety Training Program is designed to meet Mobile Equipment and Transportation training needs to support plant operations. Training in these key functional areas is designed to meet the individual training requirements. Documentation of training 
DOE/ORO - 2051

will be maintained with Mobile Equipment and Transportation Safety Training or in the plant central training records files (PGDP SPP P-ESH-102; PORTS H\&S SPP H-11).

6. Personnel complete nuclear safety and safeguards and security-related initial training, retraining, and requalification training at established intervals as described in the TDAG, Qualification Standard, or site-specific procedures and policies.

7. Supervisors and managers attend initial training as noted for radiological, chemical, criticality, and industrial safety. In addition, based on documented requirements regarding applicability, supervisors and managers attend additional classroom training on the following subjects.

- NCS Training for Supervisors (PGDP SPP P-ESH-20; PORTS H\&S SPP H-30, Sect. 2.C).

- Hazard Communication Training for Supervisors (PGDP SPP P-ESH-30; PORTS H\&S SPP H58, Sect. J).

- Lockout/Tagout Training Issuing Authorities (PGDP SPP P-ESH-113, SPP P-ESH-116; PORTS H\&S SPP M-4, Sect. 5.3.2).

\subsubsection{Status of Conformance}

The requirements set forth in Section 3.5.2 are met as described in Section 3.5.3 with the following general exceptions:

- Performance-based training has not been implemented for all specialties.

\subsection{QUALTTY ASSURANCE}

\subsubsection{Basic Objective}

A Quality Assurance program shall be established to ensure that planned and systematic actions will provide adequate confidence that nuclear safety and safeguards and security related structures, systems, and components will perform satisfactorily in service.

\subsubsection{Implementation Requirements}

For nuclear safety and safeguards and security-related systems, structures, components, and related operations, the Quality Assurance Program shall include, as a minimum, the following elements (ANSI/NQA-1, DOE Order 5700.6C).

1.- A written Quality Assurance Program which describes the established QA organizational structure, functional responsibilities, levels of authority, duties, and interfaces shall be developed and maintained.

2. Personnel shall be trained and qualified to ensure that they can perform their assigned work and to ensure that job proficiency is maintained.

3. The organization shall establish and implement processes to detect and prevent quality problems. Items and processes that do not meet established requirements shall be identified, acceptably controlled, and corrected. 
4. Documents shall be prepared, reviewed, approved, issued, used, and revised to prescribe processes, specify requirements, and establish designs for items that can impact public health and safety. Related records shall be identified, prepared, reviewed, approved, and maintained.

5. Safety-related work shall be performed to established technical standards using appropriate administrative controls and under controlled conditions using approved instructions, procedures, or other appropriate specifications.

6. Safety-related items and processes shall be designed using appropriate standards. Design work, including changes, shall be conducted to applicable requirements and design bases. Design interfaces shall be identified and controlled. The adequacy of design products shall be validated by individuals or groups other than those who perform the work. Verification and validation' of work results shall be completed before the design is approved and implemented.

7. The organization shall ensure that procured safety-related items and services meet-established requirements and perform as specified.

8. Inspection and acceptance testing of specified items and processes shall be conducted using established performance criteria.

9. Management at all levels shall periodically assess performance to the requirements of the integrated quality assurance program. Problems that hinder the organization from achieving its objectives shall be identified and corrected.

3.6.3 How the Requirements Are Met

For safety and safeguards and security systems, structures, components and related operations, the Quality Assurance Program for the GDPs includes the following elements.

1. The Uranium Enrichment Quality Program Plan (UE QPP) is described in UEO-221, Rev 0, Quality Program Plan for Uranium Enrichment. The Quality Assurance program is derived from the consensus standard ANSI/ASME NQA-1 (1989) and meets the requirements set forth in Section 3.6.2.

2. Persons performing Quality Assurance related activities are trained to ensure that they are sufficiently knowledgeable to perform assigned activities (both plants, UE2-MC-1100 if: UE4-MCQI1001, and UE4-MC-QI1002).

3. A system of independent assessments to verify compliance with key aspects of the Quality Program and to determine the effectiveness of the program is in place and is implemented through plant policies and procedures (both plants, UE2-MC-11001). Controls for the identification and disposition of nonconforming items are implemented through plant and department policies and procedures [both plants, UE2-MC-CI. 1002 (Draft)].

A corrective action system is established to control management of identified deficiencies. Line management determines the root cause of the deficiency and develops a corrective action plan. Corrective actions for deficiencies identified in assessments, occurrence reporting, Health and Safety Review Committee (HSRC) reviews, nonconformance reports, and Lessons Learned are entered in a dedicated database for tracking, trending, and managerial review. Commitments made in connection with completion of corrective actions are entered in a commitment tracking data base. These are independently validated, tracked, trended, and, upon closure, verified with documentation of the complete process [both plants UE2-MC-CI 1001 and UE2-MC-CI 1005 (Draft)]. 
4. Development, review, approval, distribution, and change control of documents that specify quality requirements or prescribe activities affecting quality are implemented through plant policies and procedures (both plants, UE2-PS-PS1001).

5. Work on safety systems is controlled and performed through the use of approved procedures [both plants, UE2-MC-MC1001 (Draft)].

6. Design controls are implemented through plant and departmental policies and procedures.

- Applicable design requirements are specified and translated into design documents (both plants, UE2-EN-1002).

- Design interfaces are identified and controlled [both plants, UE2-EN-1001 (Draft)].

- Independent reviews and supervisory reviews verify the adequacy of nuclear safety and safetyrelated designs prior to design implementation [both plants UE2-EN-1003 (Draft)].

- Control measures commensurate with those applied to the original designs govern design changes, field changes, and nonconformance dispositions (both plants UE2-MC-CI 1002 and UE2-EN-1002).

7. Procurement documentation requirements are implemented through plant policies and procedures (PGDP P-GP-24; PORTS SOP 320.15, SPP-P-1). Controls for procurement of materials, parts, components, and services that are intended for use in designated safety systems are implemented through plant policies and procedures (PGDP P-GP-28, P-GP-48, P-PRO-3, Energy Systems Procurement Division Operating Manual, PORTS procedure required).

Controis for shipping, handiing, and storing materials, parts, and components intended for use in safety systems are implemented through plant and department policies and procedures (PGDP P-GP-23; PORTS procedure required).

8. Performance criteria for inspection and testing of work on safety systems are implemented through plant policies and procedures (both plants UE2-MC-QS1001 and UE2-MC-QI1002).

9. Management assessments are conducted considering performance to assigned objectives, trends reviews, performance observation in the workplace, deficiency review, and adequacy of management system documentation [both plants, UE2-MC-CI 1004 (Draft)].

\subsubsection{Status of Conformance}

The requirements set forth in Section 3.6.2 are met as described in Section 3.6.3 with the following general exceptions:

- Not all procedures required to support the quality assurance program have been prepared and approved.

- Records-management programs for nuclear safety, safeguards and security need to be fully implemented at both plants.

- However, certain compensatory and mitigating actions have been approved by DOE pending full implementation of the $Q A$ requirements set forth in section 3.6.2. These compensatory and mitigating actions are described in the following documents: 
- PGDP, a letter to the DOE site office dated December 18, 1992. (Subject: Status of 21 Quality Management Systems), and

- for PORTS, a letter to DOE site office dated February 18, 1993. (Subject: Compensatory Actions, Portsmouth).

\subsection{MAINTENANCE}

\subsubsection{Basic Objective}

Nuclear safety and safeguards and security-related maintenance shall include effective programs fór preventive maintenance, corrective maintenance, and calibration of instruments.

\subsubsection{Implementation Requirements}

1. A corrective maintenance program shall be implemented to ensure that prompt and effective maintenance is performed on malfunctioning nuclear safety systems, safeguards, and security equipment (DOE Order 4330.4A).

2. A preventive maintenance program shall be implemented to ensure the operability of nuclear safety systems, safeguards, and security equipment (DOE Order 4330.4A).

3. A documented instrument calibration program, employing standards traceable to the national standards system or to nationally accepted standards, shall be implemented for the calibration of equipment and monitoring devices necessary for the proper maintenance and operation of nuclear safety systems and safeguards equipment (DOE Order 4330.4A, DOE 5633.3A, and DOE $5700.6 \mathrm{C})$.

4. Controls shall be established to ensure safety systems are not disabled or diminished by planned activities.

\subsubsection{How Requirements Are Met}

1. The corrective maintenance program ensures that facility systems, structures, and components are returned to their designed condition in a timely and effective manner (both plants; Maintenance Implementation Plan, Sect. 3, MAP-WC-001, MAP-CM-001, MAP-PSC-001, and MAP-PCU-001; PORTS SPP-M-1, SPP-PS-001, SPP-PS-002, SPP-PS-003, SPP-PS-004).

2. The operability of nuclear safety systems is ensured by proper application of surveillance testing and preventive maintenance program elements. The preventive maintenance program uses a computer data base to track and report program performance. Preventive maintenance schedules are derived from vendor recommendations, engineering analysis, and 40 years of operating experience (both plants, MAP-PM-001; PORTS MAP-PM-002).

3. All nuclear safety-related measuring and test equipment standards are included in the plant recall system and are calibrated using procedures that provide for traceability to National Institute of Standards and Technology (NIST). Measurement control programs are in place to assure that equipment used to measure SNM is calibrated in a manner traceable to national standards (PORTS POEF 1197, Sect. 6.0; PGDP KY/D-3899, Sect. III.D).

4. A Safety System Permit is required at PGDP when a designed "safety system" will be disabled, diminished, or affected by planned tasks. At PORTS, work on safety systems is controlled by 
marking the Safety System block on the Maintenance Service Request (MSR) when requesting maintenance for safety systems and using the Safety System Data Sheet to Document the work.

\subsubsection{Status of Conformance}

The requirements set forth in Section 3.7.2 are met as described in Section 3.7.3.

\subsection{RADIATION PROTECTION PROGRAMS, SYSTEMS, DESIGNS, AND PERMITS}

\subsubsection{Basic Objective}

The radiation exposure of employees, contractors, and visitors and the release of radioactive effluents to unrestricted areas shall be maintained as far below the regulatory limits as is reasonably achievable, economic and societal factors being taken into account.

\subsubsection{Implementation Requirements}

1. A radiation control program that defines steps to be taken to limit exposure of workers and the public shall be established (DOE Order 5480.5, DOE Order 5480.11).

2. Line management shall be responsible for radiation protection (DOE Order 5480.11).

3. A radiation protection organization, independent of production or operations, shall be provided to guide and assist line managers in fulfilling their radiation protection responsibilities (DOE Order 5480.11).

4. A radiation protection manager shall be provided to advise and consult with line managers and to guide the radiation protection activities (DOE Order 5480.11).

5. Instructions concerning all the activities of radiation protection technicians shall be provided. Radiation protection procedures for the control and use of radioactive materials and radiationgenerating devices shall provide for safe operations (DOE Order 5480.11).

6. A formally structured, auditable ALARA program with established milestones to ensure that exposures are maintained at ALARA levels shall be in place (DOE Order 5480.11).

7. A respiratory protection program to limit the intake of airborne radioactive materials and to protect employees from potentially hazardous atmospheres shall be established (DOE Order 5480.11).

8. A bioassay system shall be established that will evaluate Committed Effective Dose Equivalents (CEDE) to personnel who are occupationally exposed to radiation with the likelihood to receive intakes of 100 mrem or more (CEDE) (DOE Order 5480.11).

9. Engineering and administrative controls and personal protective equipment shall be used to control the exposure of employees to internal radiation sources; occupational exposures shall be evaluated and recorded when the potential exposure could exceed $2 \%$ of the regulatory limit (DOE Order 5480.11).

10. Employee exposure to external radiation sources shall be controlled using postings, interlock systems, monitoring, and surveys. Occupational exposures shall be evaluated and recorded when the potential exposure could exceed $2 \%$ of the annual limit for effective dose equivalent. Exposure of extremities and the skin shall be evaluated as appropriate (DOE Order 5480.11). 
11. Radiation areas, high radiation areas, very high radiation areas, contamination areas, high contamination areas, airborne radioactivity areas, and radioactive materials (storage) areas shall be prominently and distinctly marked to preclude inadvertent or unknowing entry by employees, visitors, and contractors (DOE Order 5480.11).

12. Plant alarms to alert personnel in and around facilities of emergency conditions or impending hazards shall be provided (DOE Order 5480.11).

13. The radiation monitoring and contamination control program shall ensure worker protection from radiation exposures. Sources of radioactive contamination shall be controlled at the source and steps shall be taken to limit the extent of contamination. The extent of contaminated areas shall be limited by vigorous decontamination efforts (DOE Order 5480.11, DOE Order 5480.1B).

14. Airborne radioactive materials, surface contamination, and external radiation exposures shall be monitored and surveyed to assure that employee internal accumulations of radioactive materials can be routinely estimated and to ensure that exposures are at ALARA levels (DOE Order 5480.11, DOE Order 5480.1B).

15. Personnel dosimetry shall be used and maintained so that results will be accurately determined (DOE Order 5480.15, DOE Order 5480.11).

16. A formal inventory program to account for nonexempt byproduct material sources and to provide for their control, movement, and leak testing shall be maintained (DOE N5400.10).

17. Provisions shall be made to provide for oversight of radiation protection programs. The audit program for both routine operations and unusual radiological occurrences shall provide for adequate assessment of performance (DOE Order 5480.11).

18. A Radiation Work Permit (RWP) system to ensure that radiation exposure and contamination controls are applied to all activities involving entry into radiation, airborne radioactivity, and contamination areas and to other work areas with radioactive materials shall be established (DOE Order 5480.11).

19. Radiation protection instructions to workers such as RWPs shall be available for review at the entry of the work area to which they apply (DOE Order 5480.11).

20. Radiation measuring instruments used to evaluate hazards or define employee exposite shall be subject to periodically scheduled maintenance and calibration in accordance with approved procedures; the sources of radiation measured will be NIST traceable (DOE Order 5480.11).

21. Employees shall be provided with an annual report of their occupational exposure history in accordance with Paragraph 9.n of DOE Order 5480.11, and visitors shall be provided with information with respect to their exposure in accordance with Paragraph IV.3.d of DOE Order 5484.1A. Summary exposure information containing the data specified in Paragraph IV.4.a of DOE Order 5484.1A shall be reported annually to DOE (DOE Order 5480.11 and DOE Order 5484.1A).

22. Records related to occupational radiation exposure shall be maintained in a manner that permits easy recovery of the data, allows for trend analysis, and aids in the protection of the individual and the control of radiation exposure (DOE Order 5480.11, DOE 1324.2A, and DOE 1324.5A).

23. An occupational health program shall be established to oversee, promote, and protect the radiological and nonradiological health of plant personnel. 


\subsubsection{How Requirements Are Met}

1. A radiation protection program consisting of specific radiation protection procedures has been established (see UE-SPP-ESH-2-14).

2. Radiation Protection, Maintenance, and Operations procedures list and assign line managers' and supervisors' responsibilities for radiation protection.

3. Each GDP has a dedicated radiation protection organization that is separate from the GDP operations and production and maintenance operations.

4. Radiation Protection Managers have been designated at both plants.

5. Operating procedures and instructions concerning the activities of the Radiation Protection Technicians have been prepared and are incorporated in departmental procedures at both plants.

6. The approved ALARA program requires that the radiation protection staff review employee radiation exposures, the results of air and contamination monitoring, proposed operating procedures, and other technical documents used in pre-job planning, incident and occurrence reports, and other information pertinent to the reduction of exposure. Lessons learned from such reviews are distributed and made available throughout the plants. ALARA reviews are also conducted when new facilities are designed and when existing facilities and processes are modified (both plants, UE-SPP-ESH-3, Sect. 5.3; UE-SPP-ESH-6; UE-SPP-ESH-7, Sect. 7; UE-SPP-ESH-8, Sect. 5.3, 6 , and 7$)$.

7. A respiratory protection program has been established to govern the selection and use of respirators to reduce the internal exposure of employees. Procedures govern related training, define the medical qualifications and fit testing of employees, and ensure employee medical fitness to use respiratory protection (PGDP P-ESH-9; PORTS SPP-H-42).

8. Routine urinalysis programs are conducted to determine the uptake of uranium compounds. In vivo analysis is performed upon selected employees working in restricted (radiological) areas. Dose estimates, using standard programs, are made as required (both plants, UE-SPP-ESH-8, Sect. 5.3, 6 , and 7$)$.

9. Engineering controls, postings, personnel monitoring, and protective clothing are used to control the spread of radioactive materials in the workplace. Containment devices to control contamination at the source are being introduced at the two sites. Decontamination, where required, is being conducted and achieves ALARA objectives (both plants, UE-SPP-ESH-6).

10.:- All employees, contractors, and visitors who work within or who have reason to enter the restricted areas of the plant are provided with a TLD. Restricted areas within the plant are posted. Also see paragraphs $11,12,18$, and 19.

11. Radiation Areas, High Radiation Areas, Airborne Activity Areas, High Airborne Radioactivity Areas, Contamination Areas, High Contamination Areas, Controlled Areas, Radiological Areas, and Radioactive Materials Storage Areas are posted with warning signs (both plants; UE-SPP-ESH-6, Sect. 6.1).

12. Alarm systems are installed to provide visual or audible warning signals to alert personnel to evacuate or to refrain from entering areas where high external radiation fields exist or where a criticality event may have occurred. These systems are periodically tested (both plants, UE-SPPESH-11, UEHP-E-2, UEHP-E-4.). (See also the Sect. on Nuclear Criticality.) 
13. The contamination control program incorporates radiological monitoring, radiological survey inspections, audits, reviews, investigations, training, and the use of portable containment structures to maintain program effectiveness (both plants, UE-SPP-ESH-6).

14. Continuous and periodic air sampling and periodic contamination surveys are performed routinely using calibrated instruments in accordance with approved procedures. Material, tools, equipment, and personnel leaving contaminated areas are surveyed for contamination before release. Nonradiological areas are surveyed periodically. Personnel also perform self-monitoring when leaving radiological (restricted) areas (both plants, UE-SPP-ESH-6, Sect. 6.5).

15. The external dosimetry program at PGDP and PORTS are DOELAP accredited. DOELAP, is DOE's accreditation program for dosimetry and is similar to NVLAP (both plants, UE-SPP-ESH'-7, Sect. 5.22 and 7).

16. A source custodian is designated for each nonexempt, sealed, byproduct material source and for each radiation-producing machine. Central filing systems, computer inventories are maintained for radioactive materials sources; and radiation-generating machines. These inventories are validated by physical inventory. Leak testing of sealed sources is accomplished at specified intervals (both plants, UE-SPP-ESH-12, Sect. 5.9, 6.9, 6.11; UEHP-O-11, Sect. 8).

17. Audit teams conduct audits and surveillances of radiological activities to determine adequacy, compliance, and effectiveness of radiation protection programs by investigation, examination, and evaluation of established procedures, instructions, drawings, and other applicable documents. See also the sections on MC\&O and Quality Assurance (both plants, UE-SPP-ESH-2, Attachment).

18. RWPs are completed in accordance with plant procedures (both plants, UE-SPP-ESH-9).

19. RWPs are posted at the entry of appropriate restricted areas, airborne radioactivity areas, and contamination areas. RWPs are also required for performing any task that involves exposure to radiation or to radioactive materials above established limits. The RWP specifies monitoring and entry and exit requirements and the level of personal protective equipment required (both plants, UE-SPP-ESH-9, Sect, 5).

20. Radiation protection instruments are calibrated and maintained periodically (both plants, UE-SPPESH-10, Sect. 5.6 and 6.1).

21. Employees are given annual dose summaries. Employee doses are trended and tracked. Other radiation protection-related operational-type records are also maintained (both plants, UE-SPP-ESH2, Attachment; UE-SPP-ESH-3, Sect. 5.3; UE-SPP-ESH-7, Sect. 6 and 7; UE-SPP-ESH-8, Sect. 5.3, 6, and 7; UE-SPP-ESH-13). (See also the sections, on MC\&O and Quality Assurance.)

22. Records to document the conduct of monitoring activities and surveys of occupational doses received by employees, contractors, and visitors are prepared and maintained.

23. Medical staffs perform required medical examination, review records of occupational exposure, define biological monitoring requirements and interpret results, investigate overexposure, and otherwise support the occupational medicine programs at both plants.

\subsubsection{Status of Conformance}

The requirements set forth in Section 3.8.2 are met as described in Section 3.8.3 with the following general exceptions: 
- The UE-SPP procedures and plant Health Physics procedures are not internally consistent.

- Prescribed survey frequencies are not consistentily being met.

- The radiation protection record keeping procedures have not been fully implemented.

- Radiation warning signs and other signs need to be made consistent on a plant-wide basis.

- Issues with respect to the management of fixed and removable contamination need to be resolved.

- The in vivo counter at PGDP requires upgrade, new calibration phantoms, and upgraded software in order to be functional at a state-of-the-art level.

- Additional personnel contamination monitors, and other contamination control instrumentation are needed to support program activities.

\subsection{NUCLEAR CRITICALITY SAFETY}

\subsubsection{Basic Objectives}

A NCS Program shall provide the necessary elements to protect personnel from potentially dangerous effects of a nuclear criticality accident. This goal shall be accomplished by implementing administrative and engineered process controls. These controls will minimize the possibility of a nuclear criticality accident, and implementing emergency response plans will minimize personnel exposure if a nuclear criticality accident occurs.

\subsubsection{Implementation Requirements}

1. Management shall be responsible for the safety of operations. Responsibility for NCS shall be clearly defined and established. Management shall provide personnel skilled in the interpretation of data pertinent to NCS and familiar with operations to serve as advisors to supervision (ANSI 8.1, DOE Order 5480.24).

2. Before a new operation with fissionable materials is begun or before an existing operation is changed, the entire process must be shown to be subcritical under both normal and credible abnormal conditions. This demonstration includes a peer review of NCS evaluations. NCS evaluations shall determine and explicitly identify the controlled parameters and their associated limits upon which NCS depends (ANSI 8.1, DOE Order 5480.24).

3. Process designs shall, in general, incorporate sufficient factors of safety to require that at least two

$\therefore$ unlikely, independent, and concurrent changes in process conditions occur before a criticality accident is possible. A single means of preventing a nuclear criticality accident is acceptable, provided the process control is determined to be adequately reliable within an approved Final Safety Analysis Report. Where practicable, equipment design, in which dimensions are limited, ratherthan administrative controls shall be relied upon. Full advantage may be taken of any nuclear characteristics of the process materials and equipment. All dimensions and nuclear properties which are relied upon shall be verified before operations begin, and control shall be exercised to maintain them (ANSI 8.1, DOE Order 5480.24).

4. NCS training programs shall be established (ANSI 8.20, DOE Order 5480.20). 
5. Fissile materials labeling and area posting, specifying material identification and all limits on parameters that are subject to procedural control, shall be maintained (ANSI 8.1, DOE Order 5480.24).

6. Operations to which NCS pertains shall be governed by written procedures. All persons participating in these operations shall understand and be familiar with these procedures. The procedures shall specify parameters which must to be controlled. The procedures shall be structured in such a way that no single departure from a procedure can cause a criticality accident (ANSI 8.1, DOE Order.5480.24).

7. Deviations from procedures and unforeseen alterations in process conditions that affect NCS shall be reported to appropriate management and shall be documented and investigated promptly. Action shall be taken to prevent recurrence (ANSI 8.1, DOE Order 5000.3B).

8. Operations shall be reviewed periodically to ascertain that procedures are being followed and that process conditions have not been altered so as to affect the NCS of the operation: Qualified individuals who are knowledgeable of the operation shall conduct these reviews, and they shall be documented (ANSI 8.1, DOE Order 5480.24).

9. Reliance may be placed on neutron-absorbing materials that are incorporated in process materials, or equipment, or both. When absorbers are used as a primary or secondary NCS control, appropriate precautions shall be exercised to maintain their continued presence with the intended distributions and concentrations (ANSI 8.5, DOE Order 5480.24).

10. Where applicable data are available, subcritical limits shall be established on bases derived from experiments, with adequate allowance for uncertainties in the data. In the absence of directly applicable experimental measurements, the limits may be derived from calculations made by a method validated by comparison with experimental data (ANSI 8.1, DOE Order 5480.5).

11. Criticality accident alarm systems shall comply with ANSI 8.3, 1986 (DOE Order 5480.24).

12. Emergency response planning for a criticality accident shall comply with ANSI 8.19, 1984 (DOE 6430.1A).

\subsubsection{How Requirements Are Met}

1. Plant procedures at the GDPs designate management responsibilities concerning NCS: A staff of NCS specialists within the Health and Safety Divisions at the GDPs provide the necessary technical oversight for implementing the NCS program. NCS staff members become qualified through onthe-job training under the supervision of experienced professionals. Qualification requirements have been established for NCS engineers and are used in selection of NCS engineers (PGDP P-ESH-20, Sect. 5.0; PORTS SPP-H-30).

2. Documented NCS evaluations are used to determine and identify the limits and controls required to provide NCS for new or modified operations. NCS evaluations are peer reviewed before NCS approvals are issued and before an operation starts up (PGDP P-ESH-20, Sect. 5.3; PORTS SPP-H30).

3. NCS engineers review the design of fissionable processes before new operations or modifications to existing operations are started up. Safe geometries have been used for NCS where practical. Physical controls, rather than administrative controls, are relied upon for NCS in fissionable material operations where practical. In general, process designs meet the double contingency principle. Approved exceptions to the double contingency principle adopted at the GDPs are 
documented in approved Final Safety Analysis Reports and USQs (PGDP P-ESH-20, Sect. 6.0; PORTS SPP-H-30).

4. The Training Department administers NCS training. NCS staff members are directly involved in the NCS training program as subject matter experts and review and approve all lesson plans (PGDP P-ESH-20, Sect. 5.3.1; PORTS SPP-H-30).

5. Procedures are in place requiring the posting of permanent fissile material storage areas (PGDP PESH-20, Appendix B). (PGDP P-ESH-20, Sect. 5.1.3; PORTS SPP-H-30).

6. Operations involving fissile material have operational procedures which are marked "safety related" (PGDP P-GP-1, Sect. 6.5.3). The Nuclear Safety staff reviews safety-related procedures to ensure that NCS requirements are incorporated. NCS controls are implemented in plant operational procedures (PGDP P-ESH-20, Sect. 5.1.3; PORTS SPP-H-30).

7. Procedure violations and incidents which affect NCS are tracked within the NCS program as well as within the plant occurrence reporting program system. Corrective actions are generated within the occurrence reporting system to address programmatic and system deficiencies (PGDP P-GP-43, Sect. 5.6; PORTS SPP-H-30).

8. NCS specialists review fissionable material operations periodically in conjunction with other safety specialists. The reviews are conducted through a "walking the spaces" program as well as through a formal surveillance program to ensure that NCS controls are properly implemented (PGDP P-GP46, Sect. 5.4.2; PORTS SPP-H-30).

9. Neutron absorbers materials are installed in accordance with applicable standards (ANSI 8.5, 1986).

10. NCS limits are based either directly or indirectly upon experimental data. Indirect methods such as computer software calculations are validated. The validation of computer software addresses the safety margin and calculational bias in accordance with ANSI 8.1.

11. The need for criticality accident alarm systems is evaluated for all activities in which the inventory of fissionable material in individual, unrelated areas exceeds 700 grams of ${ }^{255} \mathrm{U}$. The design of the alarm system and procedural requirements reduce the frequency and impact of false alarms. The radiation detection systems and alarm signals are uniform within each GDP. (PGDP P-ESH-84, Sect. VII.B) The criticality alarm system is tested periodically to confirm continuing instrument performance. Tests are documented in accordance with plant procedures. When tests reveal inadequate performance of the criticality alarm system, corrective action is taken without: unnecessary delay (PGDP P-ESH-84, Sect. VI; PORTS SPP-H-30). A design criteria waiver for - this alarm system has been approved by DOE.

12. Both sites have emergency response plans which deal with criticality accidents. Employees who work in areas where exposure to radiation resulting from a criticality accident might occur receive annual training in emergency response to a criticality alarm system. Employees are familiarized with the sound of the alarm system through both training and periodic alarm system drills (PGDP P-ESH-84, Sect. VI; PORTS SPP-H-30).

\subsubsection{Status of Conformance}

The requirements set forth in Section 3.9.2 are met as described in Section 3.9.3 with the following general exceptions: 
- The documentation of the application of the double contingency (or exemption waivers) for process designs in operation prior to 1992 is not adequate. Documentation is in the process of being upgraded by the GDPs in conjunction with the FSAR upgrade activities.

- Posting of operational limits and improved labeling for NCS are scheduled to be completed by June 1994.

- At PORTS, SPP-H-30, "Nuclear Criticality Safety," is being revised.

- Raschig rings used as a primary control meet the criteria of ANSI 8.5, 1986 at the time of installation, however surveillance requirements do not meet the criteria.

- Job-specific NCS training of maintenance personnel is being added to the training programi at PGDP: The maintenance personnel will be fully trained by June 1994 .

\subsection{FIRE PROTECTION}

\subsubsection{Basic Objective}

The Fire Protection Program shall ensure that no undue threats to the public or employees will result from fire and resultant perils.

\subsubsection{Implementation Requirements} elements:

Requirements necessary to implement an adequate standard of protection include the following

1. Strong management commitment to fire protection shall be provided along with policy statements that implement specific plant criteria (DOE 5480.7).

2. The Fire Protection Program shall be under the direction of an individual who has been assigned as Authority Having Jurisdiction (AHJ) commensurate with the responsibilities of the position (DOE 5480.7).

3. Fixed fire suppression systems, where provided, shall be tested and maintained such that fires in those areas are controlled promptly (DOE 5480.7).

4. Automatic fire suppression systems shall be provided for areas containing safety systems (DOE 5480.7).

5. A reliable water supply, with sectional isolation valves shall be maintained (DOE 5480.7).

6. Closing of valves supplying fire suppression systems shall be controlled by a written permit system (DOE 5480.7).

7. A fire department shall be maintained on-site as an acceptable means of redundant fire protection (DOE 5480.7).

8. Fire Department personnel shall be on-site at all times and shall be trained and equipped to handle anticipated types of fires and other emergencies (29 CFR 1910.156).

9. Mobile fire apparatus that is required to support fire fighting operations shall be provided and maintained (DOE 5480.7). 
10. Manual fire suppression equipment and/or systems shall be provided in order that at least one effective hose stream can reach any area within an important building (DOE 5480.7).

11. Breathing air used in fire fighting shall meet a minimum quality of Grade D (29 CFR 1910.134).

12. On-site fire protection support shall be available to evaluate the fire hazards of changes to maintenance and process systems (DOE 5480.7).

13. A fire protection review of design documents for new facilities and for modifications to existing facilities shall be made to insure that fire protection issues have been properly addressed (DOE 5480.7).

14. Fire protection appraisals of important buildings shall be conducted periodically to identify changes that adversely impact existing fire protection levels. Means of emergency egress shall be regularly inspected for all areas that are normally occupied. Personnel who are trained and knowledgeable in detecting fire hazards shall conduct periodic inspections of all important buildings and other structures (DOE 5480.7).

15. All fires shall be investigated and root causes determined (DOE 5500.3A).

16. Portable fire extinguishers shall be available throughout the plant commensurate with the hazard (29 CFR 1910.157).

17. A fire alarm system that reports to a continuously manned location shall monitor fire alarms in all important buildings and structures (DOE 5480.7).

18. Welding/burning/hot work shall be controlled by a written permit system to minimize the fire hazards of open flame equipment (DOE 5480.7).

19. Emergency medical services shall be provide to assure proper emergency care of injured employees (29 CFR 1910.151).

\subsubsection{How Requirements Are Met}

The methodology employed in order to comply with requirements includes the following components:

1. Management commitment to fire protection as found in the GDPs Fire Protection Programs (PGDP P-ESH-21; PORTS SPP-S-20).

2. Direction of the Fire Protection Program has been delegated to the Fire Services Department $\therefore$ manager at Paducah and the department head of Fire Services at Portsmouth as the AHJ for fire protection and egress issues.

3. Fixed fire suppression systems are tested and maintained in accordance with approved plant procedures.

4. Automatic fire suppression is provided for areas containing safety systems. Redundant fire suppression capability is provided by on-site fire departments at both GDPs.

5. A reliable water supply, with sectional isolation valves, is maintained. Reliability is established through the use of multiple pumps and an elevated water tank. 
6. Closing of valves supplying fire suppression systems is controlled by a written permit system (PGDP P-ESH-17;.PORTS.FP 1.2, FP 1.3).

7. A fire department is maintained at both GDPs as a means of redundant fire protection.

8. Fire Department personnel are on site at all times and are trained and equipped in accordance with departmental procedures.

9. Mobile fire apparatus is provided and maintained in accordance with departmental procedures.

10. Manual fire suppression capability is provided by means of interior hose stations or connections or by the use of fire hoses from mobile fire apparatus such that one effective hose stream is capable of reaching any area within an important building.

11. Breathing air used for fire protection meets the minimum quality of Grade $D$ and is sampled periodically (PGDP P-ESH-9; PORTS SPP-H-43).

12. On-site fire protection engineering support is provided to evaluate the fire hazards of changes in maintenance and process systems. Review by appropriate Fire Protection personnel of proposed changes is required by the charge control process.

13. Fire protection engineering reviews of the design documents for new facilities and modifications to existing facilities are routinely conducted (PGDP P-ESH-21; PORTS SPP-S-20).

14. Fire protection appraisals of important buildings and strictures are conducted periodically to identify changes that adversely impact the level of fire protection provided. Means of egress for normally occupied areas are regularly inspected. Trained Fire Department personnel conduct these inspections (PGDP P-ESH-21, PORTS SPP-S-20). Means of emergency egress are regularly inspected in accordance with departmental procedures for all normally occupied areas.

15. All fires are investigated and the cause determined in accordance with departmental procedures.

16. Portable fire extinguishers are positioned throughout the GDPs commensurate with hazards present in the area.

17. A fire alarm system reporting to continuousiy manned locations which monitors fire alarms in all important buildings and structures is operational at both GDPs (PGDP P.ESH-21).

18. Welding/burning/hot work is controlled by a written permit system (PGDP P-ESH-64, PORTS SPP$\mathrm{M}-4)$.

19. State-certified emergency medical technicians in the fire departments provide emergency medical response with transport capability to an off-site facility.

\subsubsection{Status of Conformance}

The requirements set forth in Section 3.10.2 are met as described in Section 3.10.3 with the following general exceptions:

- The process buildings do not conform to the life safety code requirements for emergency egress because travel distances are too long. An exemption for the travel distance requirements is currently pending DOE approval. 


\subsection{ENYIRONMENTAL PROTECTION}

\subsubsection{Basic Objective.}

Radioactive effluents released to the environment from USEC Operations shall be maintained as far below regulatory limits as is reasonably achievable, in order to protect the health and safety of the general public.

\subsubsection{Implementation Requirements}

1. A program of environmental surveillance monitoring shall be in place to determine the effects that on-site airborne radioactive emissions have on off-site environmental locations, natural resources, and the public health (DOE Order 5400.1, DOE Order 5400.5).

2. A program to obtain and maintain representative meteorological data to comply with regulations requiring the assessment of the impact of radioactive airborne releases shall be maintained (DOE Order 5400.1, DOE Order 5400.5).

3. Sampling and analysis of radionuclides in environmental media shall be conducted in such a way as to provide representative defensible data (DOE Order 5400.1, DOE Order 5400.5).

4. A program to estimate radiation dose limits for members of the public shall be maintained (DOE Order 5400.1; DOE Order 5400.5 40 CFR 61, Subpart H).

\subsubsection{How Requirements Are Met}

1. Air monitoring of radionuclides is conclucted in accordance with the GDPs' environmental monitoring plans (PGDP KY-E-118; "PORTS Environmental Monitoring Plan," November 12, 1991). The results of the air monitoring programs are reported in the GDPs' annual Environmental Reports ("PGDP Environmental Report for 1992"; PORTS, "Portsmouth Gaseous Diffusion Plant Environmental Report for 1992" [Draft]). All atmospheric releases from sources which have the potential, with no controls, to produce an effective dose equivalent (EDE) to the most affected area resident greater than 0.10 mrem per year are continuously monitored for radionuclide effluents.

2. Each GDP is collecting meteorological data to document wind speed and direction, barometric pressure, relative humidity, and rainfall. This information is used to forecast atmospheric dispersion in the event of unplanned radioactive materials releases or other events causing concern for the public health and safety. Due to calibration difficulties and lightening damage at PORTS, the meteorological data may not be representative (PGDP KY-E-118; PORTS Environmental Monitoring Plan, November 12, 1991).

3. Air measurements of radionuclides are made in accordance with the GDPs Monitoring Plans and "Standard Methods" (PGDP KY-E-118; "PORTS; Environmental Monitoring Plan," November 1992).

4. Programs are implemented to determine radiation dose for members of the public near the facility (PGDP KY-E-118; PORTS Environmental Monitoring Plan, November 12, 1991).

\subsubsection{Status of Conformance}

The requirements set forth in Section 3.11.2 are met as described in Section 3.11.3 with the following general exceptions: 
- The meteorological monitoring equipment at PORTS is difficult to salibrate, due to age and lightning damage, and may not be producing adequate data to support dispersion calculations and dose assessments. New equipment is being procured.

\subsection{NUCLEAR MATERIAL SAFEGUARDS}

\subsubsection{Basic Objective}

A documented program shall be implemented (1) to protect SNM from unauthorized removal, (2) to control and account for SNM using standard methods; and (3) to protect SNM facilities against radiological sabotage.

\subsubsection{Implementation Requirements}

The program for safeguarding and accounting for special nuclear material shall include the following elements:

1. Written plans and procedures that identify the strategies, mechanisms, and commitments to protect SNM from unauthorized removal, to account for SNM, and to protect SNM facilities against radiological sabotage, including:

- Physical Security Protection Plans (DOE Order 5632.2A),

- Protective Force Procedures (DOE Order 5632.7 and 5632.7.1), and

- Nuclear Materials Control and Accountability Plans (DOE Order 5633.3A)

2. A system for tracking, accounting for, and reporting to the Nuclear Materials Management and Safeguards System (NMSS), all special nuclear material above threshold limits that has been received and is present on all plant sites (DOE Order 5633.3A, 5633.4, and 5633.5A).

3. A measurement control program for ensuring that equipment used to measure nuclear materials is properly calibrated using standards traceable to national standards and for supporting the estimation of the contribution of measurement uncertainty to inventory difference (DOE Order 5633.3A).

4. Physical barriers, vaults, intrusion detection systems, and access controls designed to protect SNM from access by unauthorized personnel or from unauthorized removal (DOE Order 5632.2A)

5. A trained protective force to respond to unauthorized attempts to gain access to, or to remove, SNM (DOE Orders 5632.2A, 5632.7, and 5632.7.1).

6. A fitness for entry program to reduce the likelihood of SNM theft or radiological sabotage by ensuring a drug-free and alcohol-free workplace (DOE Order 5480.8A).

7. A system of independent audits and assessments to verify the effectiveness of the elements of the NMC\&A program, including measurement controls, material controls, and accounting systems (DOE 5633.3A).

8. A system of performance testing to verify the effectiveness of the SNM protection program (DOE Orders 5630.16 and 5632.8).

9. A program for providing such information about, and such access to, GDP facilities and operations as may be required to support the United States in meeting its obligations to the International Atomic Energy Agency (IAEA) relating to SNM safeguards at the GDPs (DOE Order 1270.2B). 


\subsubsection{How Requirements Are Met}

1. The GDPs maintain writien plans and prosedures that identify the strategies. mechanisms, and commitments to protect SNM from unauthorized removal, to account for SNM, and to protect SNM facilities against radiological sabotage (PORTS POEF-1197; PGDP KY/D-3899), including
a) Physical Security Protection Plans (classified reference);
b) Protective Force Procedures (classified reference); and
c) Nuclear Materials Control and Accountability Plans.

2. The GDPs maintain nuclear material accounting systems to track; to account for, and to report to the Nuclear Materials Management and Safeguards System (NMSS), all special nuclear material above threshold limits that has been received and is present on all plant sites (PORTS POEF 1197, PGDP KY/D-3899).

3. The GDPs maintain measurement control programs to assure that programs used to measure nuclear materials are calibrated in a manner that is traceable to national standards. These programs are capable of developing information to support the estimation of the contribution of measurement uncertainty to inventory differences (PORTS POEF 1197, Sect. 6.0; PGDP KYID-3899; Sect. III.D).

4. The GDPs employ physical barriers, including fences and hardened structures; vaults; intrusion detection systems; and access controls to protect SNM from access by unauthorized personnel or from unauthorized removal (both sites' Site Safeguards and Security Plan).

5. The GDPs maintain trained protective forces to respond to unauthorized attempts to gain access to, or to remove, SNM (both sites' Site Safeguards and Security Plan).

6. The GDP fitness-for-duty program includes preemployment drug screening and for-cause drug testing. Positive test results, which are rare, are dealt with on a case-by-case basis. The fitness-forduty program also includes an employee assistance program that is available to employees and members of their families.

7. Audits and assessments are performed to verify the effectiveness of the elements of the NMC\&A program, including measurement controls, material controls, and accounting systems (PORTS POEF 1197, Sect. 9.0; PGDP KYID-3899 Sect. II.F, P-GP-46).

8. The GDPs employ performance testing to verify the effectiveness of the SNM protection program (both sites' Site Safeguards and Security Plan).

9. - The GDP nuclear material and accounting systems are capable of providing such information about the status of SNM at the GDPs as may be required to support the United States in meeting its obligations to the IAEA relating to SNM safeguards at the GDPs (PORTS POEF-1197, PGDP KYID-3899).

\subsubsection{Status Of Conformance}

The requirements set forth in Section 3.12.2 are met as described in Section 3.12.3. 


\subsection{EMERGENCY PREPAREDNESS}

\subsubsection{Basic Objective}

The Emergency Preparedness Program shall ensure that adequate protective measures can be taken in the event of an emergency.

\subsubsection{Implementation Requirements}

1. An individual shall be designated to administer the emergency management program. An emergency response organization shall be established, and responsibilities of all individuals supporting emergency response are clearly defined (DOE Order 5500.3A).

2. A hazards assessment shall be developed and maintained for use in emergency planning. This assessment shall consider the broad spectrum of events that could affect the facility and be used in the development of the Emergency Plan (DOE Order 5500.3A, DOE Order 5480.1B).

3. An Emergency Plan shall be developed and maintained as a controlled document. The Emergency Plan and its associated support documents shall be reviewed and updated as appropriate, annually (DOE Order 5500.3A).

4. Emergency planning support and coordination relationships with federal, state, and local organizations shall be developed and formally documented through plans, agreements, and memoranda of understanding (DOE Order 5500.3A).

5. An assured means of promptly notifying the federal, state, and local authorities of the details of an emergency shall be installed and maintained (DOE Order 5500.3A).

6. Emergency response activities shall be coordinated with federal, state, and local agencies and organizations and facility officials through continued communication during the event (DOE Order 5500.3A).

7. Facilities and equipment, adequate to support emergency response shall be established and maintained. An emergency operations center that it is capable of adequately supporting assessment, evaluation, and direction of emergency response organization activities shall be established (DOE Order 5500.3A).

8. The EOC shall be habitable in all postulated emergencies, or an alternate EOC shall be established and maintained (DOE Order 5500.3A).

9. Provisions shall be in place to adequately assess the actual or potential consequences of an emergency. Specific predetermined actions to be taken in response to postulated emergency conditions shall be developed (DOE Order 5500.3A).

10. An adequate record or log of emergency response actions shall be kept (DOE Order 5500.3A).

11. Arrangements for medical treatment for injuries sustained in postulated emergencies, inciuding radiologically related injuries, shall be in place (DOE Order 5500.3A).

12. Provisions shall be made for recovery from an emergency and reentry into affected buildings. These provisions shall include specific procedures for termination of an emergency, dissemination of information, establishment of a recovery organization, and criteria for resumption of normal operations (DOE Order 5500.3A). 
13. A public information program shall be established and integrated into the emergency management program (DOE Order 5500.3A, and DOE Order 5500.4).

14. Training for emergency response organization individuals on their duties in the emergency response plan shall be developed and delivered on an established schedule (DOE Order 5500.3A).

15. The emergency plan shail be exercised, inciuding opgortunities for off-site agency participation, at least annually (DOE Order 5500.3A, and DOE Order 5500.10).

\subsubsection{How Requirements Are Met}

1. At PGDP, the Emergency Management Department Manager is designated as the emergency management program administrator. Responsibilities for the administrator and emergency response organization members are described in the PGDP Emergency Management Plan (PEMP, KY/H-143, Sect. 3). The requirements of the PEMP are implemented by procedure SPP P-ESH-500. At PORTS, the Emergency Management Coordinator is the emergency management program administrator. Responsibilities for the administrator and emergency response organization members are described in Sect. 14 of the PORTS Emergency Plan (PEP), and the requirements are implemented by procedure SPP H-6.

2. Hazard analyses have been performed, and hazards have been identified and documented. (PGDPPEMP, Sect. 2.0; PORTS-PEP, Sect. 6). Hazard analyses and impact analyses were performed for each facility using various available technical documents and reports. Emergency Action Levels are in place for the spectrum of emergencies identified in the hazard analyses. These EALs are described in the respective plant documents (PGDP-PEMP, Sect. 3, SPP P-ESH-500 series; PORTS-PEP, Sect. 7, SPP H-6).

3. At PGDP, the PEMP is the controlled document which describes the emergency management program. Plant emergency procedures which implement the program are in the SPP P-ESH-5XX Series. At PORTS, the PEP is the controlled document which describes the emergency management program. Plant emergency procedures which implement the program are in the associated appendices to the PEP.

4. Interface and coordination with federal, state and local agencies and organizations responsible for off-site response and protection of the public are in place (PGDP-PEMP, Sect. 3, App B; PORTSPEP, Sect. 3, App B). Both sites maintain Memoranda of Understanding and Letters of Agreement which implement the requirements of the respective emergency plans.

5. Procedures for prompt notification of emergency response personnel and response organizations, - including federal, state, and local organizations and for continuing communications among the various organizations are in place and described in the respective plant documents (PGDP-PEMP, Sect.3, P-ESH-505; PORTS-PEP, Sect. 5, and Appendix D).

6. Emergency response activities are coordinated with local, state, and federal officials through the use of continued communications during the event (PGDP, P-ESH-5XX Series; PORTS; PEP).

7. Emergency facilities, equipment, and materials necessary to adequately support emergency response activities are in place and described in the respective plant documents (PGDP PEMP; PORTS-PEP, Sect. 11).

8. Permanent EOCs have been established at each GDP. Alternate locations have also been established. 
9. The capability for assessing the potential consequences of an emergency is in place. The details are deseribed in the respective plant documents (PGDP-PEMP, Sect. 3, SPP P-ESH-505; PORTS, PEP, Sect. 6).

10. Logs of emergency response actions are maintained (PGDP KY/H-143: PORTS; PEP).

11. Resources for medical support provided to injured individuals, including those with radiological or hazardous material injuries, are in place. The specific arrangements are described in the respective plant documents (PGDP-PEMP, Sect. 4, SPP P-ESH 503, 511; PORTS PEP, Sect. 8, SPP H-6).

12. Procedures and criteria for recovery from an emergency and reentry into an affected facility are in place. The specific arrangements are described in the respective plant documents (PGDP- PEMP, Sect. 3, SPP P-ESH 519; PORTS-PEP Sect. 9, SPP S-30).

13. The emergency public information program is in place. The specific details are described in the respective plant documents (PGDP PEMP, Sect. 3, P-ESH-518).

14. Emergency response training programs for instruction and qualification of all emergency response personnel are in place for each facility. The specific details are described in the respective plant documents (PGDP- PEMP, Sect. 3, SPP P-ESH 521; PORTS-PEP Sect. 12).

15. The coordinated emergency drill and exercise program is in place at both facilities. The specific details are described in the respective plant documents (PGDP- PEMP, Sect. 3, SPP P-ESH 521; PORTS-PEP Sect. 13, Proc 923-P-014).

\subsubsection{Status of Conformance}

The requirements set forth in Section 3.13.2 are met as described in Section 3.13.3.

\subsection{PACKAGING AND TRANSPORTING NUCLEAR MATERIALS}

\subsubsection{Basic Objective}

The GDPs Packaging and Transportation Safety Program shall ensure that packaging and transportation activities for radioactive materials are conducted in accordance with applicable regulations to protect public health and safety.

\subsubsection{Implementation Requirements}

1. The shipper shall prepare proper shipping papers and shall appropriately package, label, and placard each shipment of radioactive material (DOE Order 1540.1A).

2. A Safety Analysis Report for Packaging (SARP) shall be prepared in the format specified by U.S. NRC Regulatory Guide 7.9 to support the issuance or renewal of a certificate of compliance (CoC), which permits a package to be used for shipment of quantities of fissile radioactive materials and materials exceeding the $A_{1} / A_{2}$ quantities, as defined in DOE and NRC regulations (DOE Order 1540.2).

3. Type A packaging, which may be used to ship quantities of radioactive materials less than the $A_{1} / A_{2}$ quantities as defined in DOE and NRC regulations, shall meet the design and structural standards in 49 CFR 173, Subpart I (DOE Order 1540.2, DOE Order 5480.3). 
4. Type A packaging used to ship fissile materiais shall be (1) designed, fabricated, inspected, tested, and marked in accordance with American National Standard N14.1; specifications for Class DOT-106A; or appropriate parts of the ASME Code (depending upon the manufacture date) and (2) evaluated against the requirements in 49 CFR 173 Subpart I and in 10 CFR 71 (DOE Order 1540.2, DOE Order 5480.3).

5. A Quality Assurance Program shall be established to assure that packaging for radioactive material is fabricated, maintained, and used in accordance with the applicable regulatory requirements and approved design features.

6. Before using a package, for shipment of radioactive or fissile materials, the shipper shall ascertain that the package satisfies specific inspection criteria (DOE Order 1540.2, DOE Order 5480.3).

7. The shipper shall maintain records of each shipment of fissile material for 2 years or more (DOE Order 5480.3).

8. Workers, involved in transportation and packaging of radioactive materials, who qualify as "hazardous material workers" under DOT regulations shall be provided with the training required by those regulations (DOE Order 1540.1A).

\subsubsection{How Requirements Are Met}

1. The GDPs prepare shipping papers and packaging, labeling, and placarding for shipments of radioactive material. In addition PORTS uses an extract from the regulations to identify the requirements that must be met in preparing various types of fissile materials for shipment.

2. The only package currently undergoing recertification review is the PGDP Tiger Overpack for Model 48X 10-ton UF $\mathrm{UF}_{6}$ cylinders used to transport UF 6 enriched to between 1 and $4.5 \mathrm{wt} \%{ }^{25} \mathrm{U}$. The SARP for the PGDP Tiger Overpack, SARP KY-773, Revision 8, has been prepared in the format specified by U.S. NRC Regulatory Guide 7.9 and has been submitted to DOE for renewal of CoC USA/6553/AF, which expired on May 31, 1993. The NRC CoC expires on September 30, 1993. DOE is currently reviewing the SARP and the use of the package is being continued during the DOE review period.

3. Compliance with the structural standards for Type A packaging is achieved through use of Type A packages for which documentation that demonstrates compliance is known to exist.

4. Use of Type A packages to ship fissile material is limited to those packages for which documentation is known to exist that demonstrates that they have been: (1) designed, fabricated, inspected, tested, and marked in accordance with American National Standard N14.1; specifications - for Class DOT-106A; or appropriate parts of the ASME Code (depending upon the manufacture date) and (2) evaluated against the requirements in 49 CFR 173 Subpart I and in 10 CFR 71.

5. The quality assurance program requirements for specific types of packages are documented in the SARP for the package type. These requirements for each type of package are-met through the implementation of GDP site protocols for required inspection, maintenance, testing, and procurement of; control of design modifications to; and maintenance of records concerning; the specific package type.

6. Inspections are conducted prior to shipping radioactive material in specific packages to verify that the packages meet applicable regulatory requirements, SARP commitments, industry standards and site operating protocols. 
7. Shipping records are maintained in accordance with 49 CFR 173.415 for DOT Specification 7A Type A packages and in accordance with SARP KY-773 quality assurance record retention requirements, which are taken from 10 CFR 71.19 for the PGDP Tiger Overpack.

8. Workers, involved in transportation and packaging of radioactive materials, who qualify as "hazardous material workers" under DOT regulations are trained in accordance with those regulations.

\subsubsection{Status of Conformance}

The requirements set forth in Section 3.14.2 are met as described in Section 3.14.3.

\subsection{SAMPLING AND ANALYSIS}

\subsubsection{Basic Objective}

Sampling and analysis for the radiation protection of employees and the public and for safeguards purposes shall be conducted in such a way as to provide representative, defensible data.

\subsubsection{Implementation Requirements}

1. All sampling and analysis activities shall be performed in accordance with documented and approved procedures which describe in detail the quality measures for that activity (DOE Order 5400.1, DOE Order 5480.10, and DOE Order 5633.3A).

- Sampling shall be conducted in such a manner as to ensure collection of representative samples, and precautions shall be taken to maintain sample integrity.

- Sample chains of custody shall be maintained for occupational health and environmental protection samples.

- The frequency and types of QC samples, including replicate samples, shall be defined in controlled documents and procedures.

- A formal program to control standards and reagents shall be implemented.

- The reliability of the sampling technique shall be commensurate with the significance of the sample to safety and safeguards.

2. A sampling and analysis control program for assuring that equipment used to measure nuclear material is properly calibrated with standards traceable to NIST, where available, shall be established (DOE Order 5633.3A).

- An instrument control program, including such requirements as preventative maintenance, efficiency, and functional and background checks, shall be established and maintained.

- Logs of instrument usage shall be maintained.

3. Formal sampling and analysis programs shall be developed for the following:

- Nuclear Materials Control and Accountability (DOE Order 5633.3A),

- Radioactive and Air Contaminants (DOE Order 5480.11, DOE Order 5480.8A), 
- Soils (DOE Order 5400.5, DOE Order 5400.1),

- Occupational and Environmental Health (DOE Order 5483.1B, DOE Order 5480.11, DOE Order 5400.5), and

- Surface Contamination Monitoring (DOE Order 5480.11, DOE Order 5400.5).

4. Laboratories shall be certified or accredited, as appropriate, with federal, state, and local agencies or professional societies (such as AIHA). (DOE Order 5400.1).

5. Laboratories shall participate in measurement control and performance evaluation programs. (DOE Order 5400.1 and DOE Order 5633.3A).

6. Samples that could potentially be contaminated with radionuclides shall be shipped to DOE or NRC licensed laboratories for analysis.

\subsubsection{How Requirements Are Met}

1. Sampling and analysis is performed in accordance with documented approved procedures or "Standard Methods."

- The requirements, responsibilities, and actions used to implement a sound safeguards sampling and analysis program are outlined in specific NMC\&A Plans and Procedures. Nuclear Material (NM) sampling methods used at GDPs are tailored to the material matrix to be sampled and to the type of analyses to be performed (PGDP KY/D-3899, Environmental Monitoring Department Procedures Manual, and NMC\&A Procedures Manual, Sect. 5).

- Sampling and analysis programs for air, surface water, ground water, and soils are covered in Sect. 3.11 describing environmental protection (PGDP Technical Services Division Measure Control Program and Measurement Control Procedures).

- Surface contamination monitoring and air monitoring for radioactive materials are covered in the section describing Radiation Protection (both plants, UE-SPP-ESH-6).

- Chain of custody is maintained for all personnel samples (PORTS SPP R-4, IH-002).

2. The GDPs have comprehensive Measurements Control Programs which include the analysis of parameters for NMC\&A, Health Physics, and Environmental Protection. These programs include instrument control programs, control of standards and reagents, the use of NIST traceable calibration sources, frequency and type of quality control samples, instrument logs, etc.

- Both site laboratories also participate in Measurements Control Programs internal to the plant.

- Included in these programs are qualification programs for analysts and sampling personnel who perform job duties related to NMC\&A activities, blind and double blind control sample programs, as well as QA/QC activities initiated by each laboratory group.

- Control programs include the submission of samples, evaluation of sample results against control limits, a documented investigation and response system for nonconforming results, evaluation of control data, and reporting of results to management.

3. Formal Sampling and Analysis Programs have been developed for Nuclear Materials Control and Accountability, Radioactive Air Contaminants, Bioassay and Surface Contaminants Monitoring. 
These are further outlined in other sections of this chapter. Special urine samples are collected after job activities with radionuclide exposure potential. Selected workers participate in a routine urinalysis program to evaluate the effectiveness of personal protective equipment. Analysis is provided on-site with the exception that, for PGDP, transuranics are analyzed off-site. Blind urine samples are periodically submitted to the laboratory for performance checks. Analyses involved in blind controls programs include uranium, alpha, ${ }^{9} \mathrm{Tc}$, fluoride, and selected metals. Employees with elevated results are resampled, investigated, or restricted from exposure activities, as appropriate. At PGDP, a voluntary 24-hour urine sampling program is conducted for selected workers exposed to transuranic elements (PGDP P-ESH-7, P-ESH-53; PORTS SPP H-34, H-43).

4. The Analytical Laboratories are AIHA-accredited laboratories for certain procedures.

5. The laboratories participate in several performance evaluation programs, including the $\dot{P A T}$ Program administered for the NIOSH by the AIHA; the EML Program, administered by DOE; the EPA EMSL-LV Intercomparison Studies Program; the EPA DMR-QA Study; and the PET Program, a commercial A2LA-registered quality program administered by the Analytical Products Group of Belpre, Ohio. In addition, the PORTS participates in EPA's Water Pollution Laboratory. Performance Evaluation Study and Water Supply Performance Evaluation Study and the NIST asbestos bulk materials analysis program, and PGDP participates in the Bulk Asbestos Round Robin Testing Program administered by AIHA.

6. All samples that could be potentially contaminated with radionuclides are shipped to DOE or NRC licensed laboratories for analysis. All laboratories are audited and approved. Samples are shipped in such a manner that maintains the sample integrity according to EPA regulations and guidelines. Samples are surveyed by Health Physics. Also, gross alpha and gross beta analyses are performed prior to shipping department, as required. The HP survey and radiochemical results are forwarded to Transportation and the contract laboratory (PGDP: Analytical Laboratory Department Manual). Samples are packaged in accordance with applicable requirements. The hazard class of each sample is taken into consideration when choosing the appropriately designated UN Standard package (PGDP: P-ESH-66, 67, and Traffic Section procedures).

\subsubsection{Status of Conformance}

The requirements set forth in Section 3.15.2 are met as described in Section 3.15.3.

\subsection{WASTE MANAGEMENT PROGRAM}

\subsubsection{Basic Objective}

Management of waste shall be conducted in accordance with applicable federal, state, and local laws and regulations. The management of radioactive and mixed waste shall be conducted in such a manner to ensure that the radioactive releases, should they occur, are below reguiatory limits and ALARA.

\subsubsection{Implementation Requirements}

The regulatory requirements for mixed wastes (i.e., hazardous/radioactive and PCB/radioactive) are addressed in environmental law as well as under the Atomic Energy Act of 1954 as amended. The requirements under environmental law are codified in the Code of Federal Regulations of Title 40 Parts 260 through 272 in accordance with Subtitle $C$ of the Resource Conservation and Recovery Act (RCRA). Polychlorinated biphenyls (PCBs) are governed by regulations codified in Title 40 Part 761 in accordance with the Toxic Substances Control Act (TSCA). The radioactive components for these and for all lowlevel radioactive wastes are subject to the following implementing requirements. 
1. The safety and health of the public shall be protected by managing operations in a manner that provides for the safe handling, transportation, storage, of radioactive or mixed wastes generated. This is accomplished by managing according to the requirements of the Atomic Energy Act (AEA), and applicable state requirements (DOE Order 5400.3; DOE Order 5820.2A).

2. A Waste Minimization Program shall be in place to segregate, substitute, and minimize the amount of waste requiring disposal (DOE Order 5820.2A; DOE Order 5400.1).

3. All radioactive and mixed wastes shall be characterized with sufficient accuracy to permit segregation, handling, and transfer to treatment, storage, or disposal facilities (TSD). Additional characterization needed to ensure the actual physical, and radiological characteristics meet the waste acceptance criteria (WAC) of either a DOE or an off-site TSD facility shall be performed prior to shipment to the TSD (DOE Order 5400.3; DOE Order 5820.2A).

4. Off-site shipments of LLW and mixed waste shall be in accordance with all applicable DOT regulations and manifesting requirements (DOE Order 5400.3, DOE Order 5820.2A).

5. An operating record-keeping system shall be developed and maintained to document the following: (1) a historical record of waste generated, treated, stored, shipped, and/or disposed of; (2) data necessary to show that the waste was properly classified, treated, stored, shipped, and/or disposed of; and (3) waste manifests (DOE Order 5480.3, DOE Order 5820.2A).

6. A quality assurance program will be in place to inspect both on-site and off-site treatment storage and disposal facilities and practices (DOE Order 5700.6C).

\subsubsection{How Requirements Are Met}

Following July 1 , for the near term, USEC will not store mixed waste on-site for greater than 90 days. DOE has agreed to store USEC mixed waste. A Memorandum of Agreement (MOA) is in place which discusses the respective roles and responsibilities between DOE and USEC. USEC's role in handling DOE's PCB/radioactive regulated waste will be confined to proper containers, labeling, and interim storage until the waste can be transferred to DOE.

1. The requirements for handling radioactive and mixed wastes are specified through a series of written policies and procedures, which are implemented in waste operations (PGDP SPP-ESH-28, PORTS SPP-R-2).

2. The waste minimization and pollution prevention programs meet the requirements of DOE Orders as well as federal and state regulations. Both sites have published waste minimization plans (PGDP SPP-ESH-45, "Waste Minimization"; PORTS SPP-R2).

3. Process knowledge and analytical data are used to ensure that TSD waste acceptance criteria and regulatory requirements are met (PGDP SPP-ESH-28, PORTS SPP-R-2).

4. Off-site shipments of LLW and mixed waste follow DOT criteria incorporated in plant level procedures and criteria discussed in Sect. 3.14, "Packaging and Transporting Nuclear Materials," of this document. The traffic departments at the GDPs are responsible for administering programs and procedures that implement these requirements. Off-site shipments of RCRA and PCB waste follow criteria established in 40 CFR 263 and 761 for RCRA and PCB wastes, respectively (PGDP SPP-ESH-28; PORTS SPP-R2).

5. A record-keeping system has been established that contains information regarding stored waste, such as container type, waste characteristics or classification, and disposal records including off-site 
shipment manifests (MMES Policy ESH-14, V. Part II. B.3; PGDP SPP-ESH-28; PORTS SPP-R2).

6. USEC will maintain an active quality assurance inspection program of its own program and of the TSD services it receives from DOE and other commercial vendors.

\subsubsection{Status of Conformance}

The requirements set forth in Section 3.16.2 are met as described in Section 3.16.3 with the following general exceptions:

- USEC will need to develop a program and procedures for transferring USEC-generated wastes to DOE facilities.

- Waste minimization plans are not fully implemented.

\subsection{ACCDENT ANALYSES}

\subsubsection{Basic Objective}

A thorough evaluation of all operations shall be conducted to assure that hazards have been identified and that appropriate limits and controls exist to provide for safe operation under accident conditions. Hazards analyses, which are an integral part of safety analyses, shall examine the frequency and consequences of credible event sequences.

\subsubsection{Implementation Requirements}

1. Engineering analyses of each safety system and its components to determine failure modes and scenarios and consequences of failure shall be accomplished (DOE Order 5480.5, DOE Order 5480.23).

2. Each analysis shall be documented, and the documentation shall include the means used to protect against identified failure modes and effects (DOE Order 5480.5, DOE Order 5480.23).

3. The analysis shall include appropriate hazards that arise from outside the GDPs, such as natural phenomena and fire (DOE Order 5480.5, DOE Order 5480.23, and DOE 6430.1A).

4. USQDs are performed as necessary to assure that procedure, test or equipment modifications do not invalidate the results of accident analyses (DOE Order 5480.5 and DOE Order 5480.21).

\subsubsection{How the Requirements Are Met}

1. Safety analyses have been performed at both sites. The safety analyses are documented in the FSARs (PGDP FSAR, KY-734; PORTS FSAR, GAT/GDP-1073). Each site's FSAR is written to cover the entire plant, although under the leasing arrangement, the USEC will not lease all facilities at the plants. The OSRS (PGDP KY/S-15; PORTS GAT/GDP-1074, Parts A through L) are derived from the FSARs and provide a more concise listing of the safety limits, limiting safety 'system settings, surveillance requirements, administrative controls, limiting conditions of operation, and the bases for these limits. The FSARs and OSRs form the basis for operation of the facilities.

2. Safety analyses are performed on modifications and changes. The safety analysis results are documented and incorporated into the plant's OSRs and FSAR as appropriate. A listing of current 
safety analysis documentation is maintained. NCS evaluations are performed in accordance with the NCS requirements identified and discussed in Sect. 3.9.

3. The types of hazards and accidents evaluated in the FSARs include natural phenomena and fire.

4. A summary of representative safety analysis activity for each plant since the completion of the 1985 FSAR is presented in the Attachment of this report.

\subsubsection{Status of Conformance}

The requirements set forth in Section 3.17.2 are met as described in Section 3.17.3 with the following general exceptions:

- The 1985 FSARs do not fully reflect the current plant configuration.

- A comprehensive revision and updating of the FSAR has not been accomplished.

\subsection{SECURITY}

\subsubsection{Basic Objective}

A documented program shall be implemented to protect DOE security interests other than SNM, including classified information and material and sensitive unclassified information and material.

\subsubsection{Implementation Requirements} elements:

The program for protecting DOE security interests other than SNM shall include the following

1. Measures to ensure effective management and implementation of the security program, including the following:

a. a documented security program providing the level of protection mandated by DOE Orders (DOE Orders 5630.11A and 5632.1B);

b. security program planning activities providing the level of protection mandated by DOE Orders (DOE Order 5630.14A);

c. a security training program providing the level of protection mandated by DOE Orders (DOE Order 5630.15);

d. a protective force, providing the level of protection mandated by DOE Order 5632.7 ; the armed members of which are trained and qualified under a program providing the level of protection mandated by DOE Orders (DOE Orders 5632.7 and 5632.7.1);

e. measures to control the issuance and use of security badges, credentials, and shields, providing the level of control mandated by DOE Order 5632.9A;

f. a program of security-system performance testing, providing the level of assurance of security program effectiveness mandated by DOE Orders (DOE Orders 5630.16 and 5632.8); and 
g. a program for the investigation, and reporting to DOE, of violations of laws, losses, and incidents of security concern, providing the level of protection mandated by DOE Orders (DOE Order 5639.3).

2. Documented measures to protect classified information and materials from loss or unauthorized disclosure, including the following:

a. measures to identify classified information, providing the level of protection mandated by DOE Orders (DOE Order 5650.2B);

b. controls of classified documents and information, providing the level of protection mandated by DOE Orders (DOE Order 5635.1A);

c. physical protection measures for classified information and material, providing the level of protection mandated by DOE Orders (DOE Order 5632.5);

d. controls for hand-carrying of classified matter on air carriers, providing the level of protection mandated by DOE Orders (DOE Order 5635.3);

e. a personnel security program, providing the level of protection mandated by DOE Orders, to limit access to classified information and materials to trustworthy individuals (DOE Order 5631.2C);

f. a security education and awareness program, providing the level of protection mandated by DOE Orders (DOE Order 5631.1B );

g. a telecommunications security program addressing emissions security (TEMPEST), communications security, and protected distribution systems, providing the level of protection mandated by DOE Orders (DOE Orders 5300.2D, 5300.3B, and 5300.4C);

h. a classified computer security program, providing the level of protection mandated by DOE Orders (DOE Order 5639.6);

i. controls on classified visits, providing the level of protection mandated by DOE Orders (DOE Order 5631.4A ); and

j. a technical surveillance countermeasures program, providing the level of protection mandated by DOE Orders (DOE Order 5639.5).

3. Documented measures to protect unclassified sensitive information and materials from loss or unauthorized disclosure, including the following:

a. an operations security program, providing the level of protection mandated by DOE Orders (DOE Order 5639.7);

b. an information security program, providing the level of protection mandated by DOE Orders (DOE Order 5639.1);

c. a counterintelligence program, providing the level of protection mandated by DOE Orders (DOE Order 5670.3);

d. measures to identify unclassified controlled nuclear information (UCNI), providing the level of protection mandated by DOE Orders (DOE Order 5650.3A); 
e. measures to control and protect UCNI, providing the level of protection mandated by DOE Orders (DOE Order 5635.4);

f. an unclassified computer security program, providing the level of protection mandated by DOE Orders (DOE Order 1360.2B); and

g. a program to control unclassified visits and assignments by foreign nationals, providing the level of protection mandated by DOE Orders (DOE Order 1240.2B).

\subsubsection{How Requirements Are Met}

Described in the site Safeguards and Security Plans are measures employed by the GDPs to ensure the following:

(a) effective management and implementation of the security program,

(b) protection of classified information and materials from loss or unauthorized disclosure, and

(c) protection of sensitive unclassified information and materials from loss or unauthorized disclosure.

\subsubsection{Status of Conformance}

The requirements presented in Sect. 3.18.2 are satisfied as described in Sect. 3.18.3.

\subsection{CHEMICAL SAFETY}

\subsubsection{Basic Objective}

Chemical safety practices shall be such as (1) to prevent or minimize chemical releases potentially leading to the release of radioactive materials or increase radiation exposures in the work environment or offsite.

\subsubsection{Implementation Requirements}

Chemical safety programs shall be established and implemented to:

1. Ensure that the levels of air contaminants within the plant are less than established standards of OSHA (DOE Order 5483.1B).

2. Provide for the adequate storage of chemicals and other hazardous materials (29CFR1910, ANSI/NFPA 30.321, and .395, ANSI/UL, 1275).

\subsubsection{How Requirements Are Met}

Chemical safety programs have been implemented as described below:

1. An active program exists for monitoring various chemical contaminants (e.g., solvents, gases, heavy and other metals, dusts) usually found in conjunction with radioactive materials in workplace environments. Plant procedures are not in place at PGDP, but departmental procedures define monitoring requirements (PORTS SPP-H-7). 
2. Various storage areas are found at the facilities. Examples include designated hazardous material storage areas, compressed gas storage areas, $\mathrm{UF}_{6}$ cylinder storage yards, and miscellaneous storage areas. These areas are well identified, assigned to a responsible individual/organization, and inspected regularly by a variety of organizations to assess compliance with the appropriate standards. The responsible person for each storage area is notified of any nonconformances and initiates needed corrective actions. Findings are tracked in an existing data base from inspection to abatement. Compensatory measures are provided for high and medium risk nonconformances that cannot be abated in the near term (PORTS SPP-H-22).

\subsubsection{Status of Conformance}

The requirements set forth in Section 3.19.3 are met as described in Section 3.19.4 with the following general exceptions:

- Deficiencies exist at both plants with respect to the content of implementing procedures and record keeping programs.

- Procedures and technical basis documents need to be completed to suppor the design of the workplace air monitoring program at PGDP. 
DOE/ORO - 2051 


\section{DEPARTMENT OF ENERGY OVERSIGHT}

This chapter describes the DOE oversight program as planned for the GDPs during the initial lease period. This program addresses two areas. The first is nuclear safety and safeguards for SNM. In this area the DOE will provide oversight until the NRC has assumed responsibility for regulatory oversight. The second oversight area is the protection of DOE security interests, other than special nuclear materials. DOE oversight in this area will also continue until the NRC specifically assumes regulatory oversight of the GDPs in this area as well.

The oversight required to ensure adequate compliance with applicable environmental laws and Environmental Protection Agency (EPA) regulations (e.g., Title 40 of the Code of Federal Regulations) will be performed by the EPA and is not addressed in this document. Similarly, the oversight required to ensure adequate compliance with applicable Occupational Safety and Health Administration (OSHA) regulation will be performed by the Department of Labor and is also not addressed in this document.

\subsection{OVERSIGHT SCOPE}

The Implementation Requirements presented in Chapter 3 represent the essential nuclear safety, safeguards and security requirements derived from the Orders presented in Table 4.1. DOE Orders addressing safeguards and security requirements are also included in Table 4.1.

Table 4.1. Department of Energy Orders Impacting Nuclear Safety and Safeguards and Security

Order

Title

DOE Order $1240.2 \mathrm{~B}$

DOE Order $1270.2 B$

DOE Order 1324.2A

DOE Order 1324.5A

DOE Order 1360.2B

DOE Order 1540.1A

DOE Order 1540.2

DOE Order 4330.4A

DOE Order 4700.1

DOE Order 5000.3B

DOE Order 5300.2D

DOE Order 5300.3B

DOE Order 5300.4C

DOE Order 5400.1

DOE Order 5400.3

DOE Order 5400.5

DOE Order N5400.10

DOE Order 5480.1B

DOE Order 5480.3

DOE Order 5480.4
"Unclassified Visits and Assignments by Foreign Nationals"

"Safeguards Agreement with the International Atomic Energy

Agency"

"Records Disposition"

"Records Management Program"

"Materials Transportation and Traffic Management"

"Materials Transportation and Traffic Management"

"Hazardous Material Packaging for Transportation - Administrative Process"

"Maintenance Management Program"

"Project Management System"

"Occurrence Reporting" (replaces 5000.3A)

"Telecommunications: Emission Security (TEMPEST)"

"Telecommunications: Communication Security"

"Telecommunications: Protected Distribution Systems"

"General Environmental Protection Program"

"Hazardous and Mixed Waste Program"

"Radiation Protection of the Public and the Environment"

"Sealed Radioactive Source Accountability"

"Environment Safety and Health Program for DOE Operations"

"Safety Requirements for Packaging and Transportation of Hazardous Materials"

“Environmental Protection. Safety and Health Protection Standards" 
Table 4.1. Department of Energy Orders Impacting Nuclear Safety (continued)

Order

Title

DOE Order 5480.5

DOE Order 5480.7

DOE Order 5480.8A

DOE Order 5480.9

DOE Order 5480.10

DOE Order 5480.11

DOE Order 5480.15

DOE Order 5480.16

DOE Order 5480.18A

DOE Order 5480.19

DOE Order 5480.20

DOE Order 5480.21

DOE Order 5480.22

DOE Order 5480.23

DOE Order 5480.24

DOE Order 5482.1B

DOE Order 5483.1B

DOE Order 5484.1A

DOE Order 5500.1B

DOE Order 5500.2B

DOE Order 5500.3A

DOE Order 5500.4

DOE Order 5500.10

DOE Order 5630.11A

DOE Order 5630.12A

DOE Order 5630.14A

DOE Order 5630.15

DOE Order 5630.16

DOE Order 5631.1B

DOE Order 5631.2C

DOE Order 5631.4A

DOE Order 5632.1B

DOE Order 5632.2A

DOE Order 5632.5

DÓE Order 5632.7

DOE Order 5632.7.1

DOE Order 5632.8

DOE Order 5632.9A

DOE Order 5633.2A

DOE Order 5633.3A

DOE Order 5633.4

DOE Order 5633.5A

DOE Order 5634.1B

DOE Order 5635.1A

DOE Order 5635.3
"Safety of Nuclear Facilities"

"Fire Protection"

"Contractor Occupational Medical Program"

"Construction Safety and Health Program"

"Contractor Industrial Hygiene Program"

"Radiation Protection for Occupational Workers" and change 1 and 2

"DOE Laboratory Accreditation Program for Personal Dosimetry"

"Firearms Safety"

"Accreditation of Performance-Based Training for Category A Reactors and

Nuclear Facilities"

"Conduct of Operations Requirements for DOE Facilities"

"Personnel Selection, Qualification, Training and Staffing Requirements at DOE Reactor and Nonreactor Facilities"

"Unreviewed Safety Questions"

"Technical Safety Requirements"

"Nuclear Safety Analysis Reports"

"Nuclear Criticality Safety"

"Environment, Safety, \& Health Appraisal Program"

"Occupational Safety \& Health Program for DOE Contractor/Employees at Government-Owned Contractor-Operated Facilities"

"Environmental Protection Safety and Health Protection Information

Reporting Requirements"

"Emergency Management Systems"

"Emergency Categories, Classes, Notification and Reporting"

"Planning and Preparedness for Operational Emergencies"

"Public Affairs Policy and Planning Requirements for Emergencies"

"Emergency Readiness Assurance Program"

"Safeguards and Security Program"

"Safeguards and Security Inspection and Evaluation Program"

"Safeguards and Security Program Planning"

"Safeguards and Security Training Program"

"Safeguards and Security Performance Test Program"

"Security Education Briefing and Awareness Program"

"Personnel Security Program"

"Control of Classified Visits"

"Protection Program Operations"

"Physical Protection of Special Nuclear Material and Vital

Equipment"

"Physical Protection of Classified Matter"

"Protective Forces"

"Firearms Qualification Courses Manual"

"Protection program operations - Systems Performance Tests"

"Issuance and Control of Security Badges, Credentials, and Shields"

"Control and Accountability of Nuclear Materials: Responsibilities and

Authorities"

"Control and Accountability of Nuclear Materials"

"Nuclear Materials Transactions: Documentation and Reporting"

"Nuclear Materials Reporting and Data Submission"

"Facility Approval, Security Surveys, and Nuclear Materials Surveys"

"Control of Classified Documents and Information"

"Hand Carrying Classified Matter on Air Carriers:" 
Table 4.1. Department of Energy Orders Impacting Nuclear Safety (continued) Order Title

DOE Order 5635.4

DOE Order 5639.1

DOE Order 5639.3

DOE Order 5639.5

DOE Order 5639.6

DOE Order 5639.7

DOE Order 5650.2B

DOE Order 5650.3A

DOE Order 5670.3

DOE Order $5700.6 \mathrm{C}$

DOE Order $5820.2 \mathrm{~A}$

DOE Order $6430.1 A$
"Protection of Unclassified Controlled Nuclear Information"

"Information Security Program"

"Violation of Laws, Losses, and Incidents of Security Concern"

"Technical Surveillance Countermeasures Program"

"Classified Computer Security Program"

"Operations Security Program"

"Identification of Classified Information"

"Identification of Unclassified Controlled Nuclear Information"

"Counterintelijgence Program"

"Quality Assurance"

"Radioactive Waste Management"

"General Design Criteria" 


\section{PROGRAM FOR OVERSIGHT OF USEC}

\subsubsection{Regulatory Oversight Manager}

The DOE program for nuclear safety and safeguards and security oversight of USEC operation of the GDPs is based on the program, described in Chapter 2, that has been used successfully to oversee past operation of the GDPs. However, the transition in the DOE role from GDP manager to regulator necessitates changes in the structure of the oversight program. The DOE Regulatory Oversight Manager will be the DOE manager for nuclear safety and safeguards and security oversight of the GDPs. In this role, the DOE Regulatory Oversight Manager is responsible for discharging those oversight responsibilities traditionally assigned to both the DOE headquarters and field organizations.

\subsubsection{Audits and Appraisals}

The DOE Regulatory Oversight Manager is responsible for scheduling and managing DOE appraisals and reviews to verify conformance with the Implementation Requirements in this document. Where appropriate, the DOE Regulatory Oversight Manager shall use qualified ORO personnel and DOE Headquarters personnel, including personnel from the Office of Environment, Safety, and Health (EH), to serve as appraisal team members: Independent reviews and appraisals by DOE Headquarters oversight groups responsible for nuclear safety will also be coordinated by the DOE Regulatory. Oversight Manager.

DOE ápraisals are currently conducted in accordance with an "Integrated Master Schedule for the GDPs." Consistent with DOE's Uranium Enrichment Self-Assessment Program, DOE appraisals addressing the Implementation Requirements in Chapter 3 shall be continued at the frequencies provided in Table 4.2. Changes in these frequencies may result from changed trends in occurrence reports, from the results of the USEC internal appraisals, when identified nuclear safety issues indicate that additional appraisals are required, or when the DOE determines that additional reviews are required to protect the public health and safety or to provide for the common defense and security. More than one topical area may be addressed in a single appraisal. DOE appraisals addressing the protection of security interests, other than special nuclear material shall be conducted annually. The DOE appraisals may be announced or unannounced. At least one unannounced appraisal, addressing one or more of the basic objectives in Chapter 3, will be performed annually. DOE may, at its discretion, conduct appraisals concurrent with USEC independent internal appraisal activities or observe and review these activities as a part of the appraisals addressing managerial controls and oversight or quality assurance. An independent review or appraisal by select DOE Headquarters oversight groups may be conducted on a quarterly basis addressing one or more of the topical areas. These reviews will be coordinated with the Regulatory Oversight Manager.

In addition to the DOE appraisals, USEC shall ensure that internal appraisals are conducted (i.e., selfassessments), which shall address all of the Implementation Requirements in Chapter 3 at least annually, with the Implementation Requirements for half of the basic objectives in Chapter 3 addressed during the first half of each fiscal year. At the beginning of each fiscal year, USEC shall submit to the Regulatory Oversight Manager its schedule for internal appraisals. USEC shall submit internal appraisal reports and planned corrective actions, including completion schedules, to DOE within 30 days of the completion of the internal appraisal field work.

\subsubsection{Operational Oversight}

DOE site safety representatives shall be assigned to each GDP and shall be provided office space by USEC. These site representatives will report to the DOE Regulatory Oversight Manger and continue oversight of day-to-day operations by maintaining a site presence for surveillance and inspection of operational activities to ensure that plant continues to meet the Implementation Requirements set forth in 
Chapter 3. In addition, DOE shall conduct investigations of all events relating to nuclear safety or safeguards designated as requiring an investigation in DOE Order 5484.1A, "Environmental Protection, Safety, and Health Protection Information Reporting Requirements."

Table 4.2. DOE appraisal frequency

Chapter 3 Topical area

3.1 Organization Plan

3.2 Managerial Controls and Oversight

3.3 Operations

3.4 Engineering Reviews

3.5 Training and Qualification

3.6 Quality Assurance

3.7 Maintenance

3.8 Radiation Protection Programs, Systems, Designs and Permits

3.9 Nuclear Criticality Safety

3.10 Fire Protection

3.11 Environmental Protection

3.12 Nuclear Material Safeguards

3.13 Emergency Preparedness

3.14 Packaging and Transporting Nuclear Materials

3.15 Sampling and Analysis

3.16 Waste Management Program

3.17 Accident Analysis

3.18 Security
Appraisal frequency

Every 2 Years

Every 1 Year

Every 1 Years

Every 1 Years

Every 2 Years

Every 1 Year

Every 2 Years

Every 1 Year

Every 1 Year

Every 1 Year

Every 3 Years

Every 1 Years

Every 1 Year

Every 2 years

Every 2 Years

Every 2 Years

Every 1 Year

PORTS-1. Year

PGDP-1.5 Year 
DOE/ORO - 2051

B-114 DEPARTMENT OF ENERGY - OAK RIDGE OPERATIONS 


\section{CONCLUSIONS}

The original GDP designs, which were based on technology and requirements existing when the GDPs were constructed, incorporated an adequate degree of safety as shown through 40 years of safe operation. The overall safety of the original designs has been improved through upgrade projects and through the application of lessons learned over the GDPs' operational lifetime. The conclusion the plants' original designs incorporated an adequate degree of safety is reinforced by the 1985 FSARs and subsequent upgrade analyses.

The plants are operating safely under the auspices of the DOE nuclear safety and safeguards and security framework. This conclusion is supported by the results of both the DOE audit and appraisal program and special assessments.

The plants can continue to be operated safely in accordance with the requirements in Chapter 3. USEC's commitments to continue to meet the Implementation Requirements set forth in Chapter 3 coupled with DOE's oversight plan in Chapter 4 provide adequate assurance that the plants will continue to be operated safely during the interim period. 


\section{Blank Page}




\section{BIBLIOGRAPHY}

10 CFR 1046, "DOE Security Skills Training and Qualification Standards for Protective Forces" (Subpart 1046-15 and 1046-16)

10 CFR 19, "Notices: Instructions and Reports to Workers: Inspections and Investigations"

10 CFR 20, "Standards for Protection Against Radiation"

10 CFR 21, "Reporting of Defects and Noncompliances"

10 CFR 26, "Fitness for Duty"

10 CFR 30, "Rules of General Applicability to Domestic Licensing of Byproduct Material"

10 CFR 33, "Specific Domestic Licenses of Broad Scope for Byproduct Material"

10 CFR 34, "Licenses for Radiography and Radiation Safety Requirements for Radiographic Operations"

10 CFR 40, "Domestic Licensing of Source Material"

10 CFR 50, "Domestic Licensing of Production and Utilization Facilities"

10 CFR 70, "Domestic Licensing of Special Nuclear Material"

10 CFR 71, "Packaging and Transportation of Radioactive Material"

10 CFR 73, "Physical Protection of Plants and Materials"

10 CFR 74, "Material Control and Accountability of Special Nuclear Material"

10 CFR 75, "Safeguards on Nuclear Material-Implementation of the US/IAEE Agreement"

29 CFR 1903, "Inspections, Citations, and Proposed Penalties"

29 CFR 1904, “Recording and Reporting Occupational Injuries and Illnesses"

29 CFR 1910, "Occupational Health and Safety"

29 CFR 1926, "Construction Safety"

40 CFR 61, "Subpart H National Emission Standards for Hazardous Air Pollutants Radionuclide Emissions from DOE Facilities"

49 CFR 173, "Subpart I Hazardous Materials Regulations"

49 CFR 392, "Driver of Motor Vehicles"

ANSI/IEEE Standard 498-1985, "IEEE Standards Requirements for the Calibration and Control of Measuring and Test Equipment Used in Nuclear Facilities"

ANSI 8.1, "Nuclear Criticality Safety in Operation with Fissionable Materials Outside Reactors" 


\section{BIBLIOGRAPHY (Continued)}

ANSI 8.19, "Administrative Practices for Nuclear Criticality Safety" ANSI 8.3, "Criticality Accident Alarm System"

ANSI/ANS 3.1, "Selection Qualification and Training for Nuclear Power Plants" ANSI/ASAC MI-1987, "American National Standard for Calibration Systems" ANSI/ASME NQA-1, "Element 12 Control of Measurement and Test Equipment" ANSI N14.1, "Uranium Hexafluoride-Packaging for Transport" ANSI N323, "Radiation Protection Instrumentation Test and Calibration" ANSI/NFPA 30, "Flammable \& Combustible Liquids Code" ANSI/NFPA 231, "General Storage" ANSI/NFPA 395, "Flammable Liquids" ANSI/NQA-1, “Quality Assurance Requirements for Nuclear Facility Applications” ANSI/UL 1275, "Flammable Liquids" ANSI Z117.1-1989, "Safety Requirements for Confined Space" DOE 1240.2B, "Unclassified Visits and Assignments by Foreign Nationals" DOE 1270.2B, "Safeguards Agreement with the International Atomic Energy Agency" DOE 1324.2A, "Records Disposition" DOE 1324.5, "Records Management Program Management Program" DOE 1360.2B, "Unclassified Computer Security Program" DOE 1540.1A, "Materials Transportation and Traffic Management" DOE 1540.2, "Hazardous Material Packaging for Transportation - Administrative Process" DOE 4330.4A, "Maintenance of DOE Nonnuclear Facilities" DOE 4700.1, "Project Management System" DOE 5000.3B, “Occurrence Reporting” (replaces 5000.3A) DOE 5300.2D, "Telecommunications: Emission Securitỹ (TEMPEST)" DOE 5300.3B, "Telecommunications: Communication Security" DOE 5300.4C, "Telecommunications: Protected Distribution Systems" 


\section{BIBLIOGRAPHY (Continued)}

DOE 5400.1, "General Environmental Protection Program"

DOE 5400.3, "Hazardous and Mixed Waste Program"

DOE 5400.5, "Radiation Protection of the Public and the Environment"

DOE N5400.10, "Sealed Radioactive Source Accountability"

DOE 5480.1B, "Environment Safety and Health Program for DOE Operations"

DOE 5480.3, “Safety Requirements for Packaging and Transportation of Hazardous Materials"

DOE 5480.4, "Environmental Protection Safety and Health Protection Standards"

DOE 5480.5, "Safety of Nuclear Facilities"

DOE 5480.7, “Fire Protection"

DOE 5480.8A, "Contractor Occupational Medical Program"

DOE 5480.9, "Construction Safety and Health Program"

DOE 5480.10, "Contractor Industrial Hygiene Program"

DOE 5480.11, "Radiation Protection for Occupational Workers"

and change 1 and 2 (excluding change 3 )

DOE 5480.15, "DOE Laboratory Accreditation.Program for Personal Dosimetry"

DOE 5480.16, "Firearms Safety"

DOE 5480.18A, "Accreditàtion of Performance-Based Training for Category A Reactors and Nuclear Facilities"

DOE 5480.19, "Conduct of Operations, Requirements for DOE Facilities"

DOE 5480.20, “Personnel Selection Qualification Training and Staffing Requirements at DOE Reactor and Nonreactor Facilities"

DOE 5480.21, "Unreviewed Safety Questions"

DOE 5480.22, "Technical Safety Requirements"

DOE 5480.23, "Nuclear Safety Analysis Reports"

DOE 5480.24, "Nuclear Criticality Safety"

DOE 5481.1B, "Safety Analysis and Review System"

DOE 5482.1B, "ES\&H Appraisal Program" 


\section{BIBLIOGRAPHY (Continued)}

DOE 5483.1B, “Occupational Safety \& Health Program for DOE Contractor/Employees at GovernmentOwned Contractor-Operated Facilities" (replaces 5480.1A)

DOE 5484.1A, "Environmental Protection Safety and Health Protection Information Reporting Requirements"

DOE 5500.1B, “Emergency Management Systems"

DOE 5500.2B, "Emergency Categories Classes Notification and Reporting"

DOE 5500.3A, "Planning and Preparedness for Operational Emergencies"

DOE 5500.4, "Public Affairs Policy and Planning Requirements for Emẹrgencies"

DOE 5500.10, "Emergency Readiness Assurance Program"

DOE 5630.11A, "Safeguards and Security Program"

DOE 5360.12A, "Safeguards and Security Inspection and Evaluation Program"

DOE 5630.14A, "Safeguards and Security Program Planning”

DOE 5630.15, "Safeguards and Security Training Program"

DOE 5630.16, "Safeguards and Security Performance Test Program"

DOE 5631.1B, "Security Education Briefing and Awareness Program"

DOE 5631.2C, "Personnel Security Program"

DOE 5631.4A, "Control of Classified Visits"

DOE 5632.1B, "Protection Program Operations"

DOE 5631.6A, "Personnel Security Assurance Program"

DOE 5632.2A, "Physical Protection of Special Nuclear Material and Vital Equipment"

DOE 5632.3B, "Operations Security"

DÓE 5632.5, "Physical Protection of Classified Matter"

DOE 5632.7, "Protective Forces"

DOE 5632.7.1, "Firearms Qualification Courses Manual"

DOE 5632.8, "Protection Program Operations: System Performance Tests"

DOE 5632.9A, "Issuance and Control of Security Badges, Credentials, and Shields"

DOE 5633.2A, "Control and Accountability of Nuclear Materials: Responsibilities and Authorities" 


\section{BIBLIOGRAPHY (Continued)}

DOE 5633.3, "Control and Accountability of Nuclear Materials"

DOE 5633.4, "Nuclear Materials Transactions: Documentation and Recording"

DOE 5633.5A, "Nuclear Materials Reporting and Data Submission"

DOE 5634.1B, "Facility Approval, Security Surveys, and Nuclear Materials Surveys"

DOE 5635.1A, "Control of Classified Document and Information"

DOE 5635.3, "Hand Carrying Classified Matter on Air Carriers"

DOE 5635.4, "Protection of Unclassified Controlled Nuclear Information"

DOE 5639.1, "Information Security Program"

DOE 5639.3, "Violation of Laws, Losses, and Incidents of Security Concern"

DOE 5639.5, "Technical Surveillance Countermeasures Program"

DOE 5639.6, "Classified Computer Security Program" .

DOE 5639.7, "Operations Security Program"

DOE 5650.2B, "Identification of Classified Information"

DOE 5650.3A, "Identification of Unclassified Controlled Nuclear Information"

DOE 5670.3, "Counterintelligence Program"

DOE 5700.6C, "Quality Assurance"

DOE 5820.2A, "Radioactive Waste Management"

DOE 6430.1A, "General Design Criteria"

Final Safety Analysis Report (FSAR) for Paducah Gaseous Diffusion Plant: Facility and Process Description, KY-743

Chemical Toxicity of Uranium Hexafluoride Compared to Acute Effects of Radiation, NUREG-1391, February 1991

Investigation of Occurrence Involving Release of Uranium Hexafluoride from a 14-Ton Cylinder at the Portsmouth Gaseous Diffusion Plant on May 7, 1978, ORO-757, June 1, 1978

Investigation of a Uranium Hexaftuoride Release Incident on September 17, 1975, in the K-1423 Toll Enrichment Facility, K-P-6197, December 9, 1975

Portsmouth Gaseous Diffusion Plant Final Safery Analysis Report, GAT/GDP-1073

Uranium Hexaftuoride Manual of Good Handling Practices, AERO-651

RCRA Interim Status Regulations 3008h Consent Order, PORTS only 
Reauthorization Act (SARA) Title III Public Law 99-499 Sect. 303 and 31240 CFR Parts 355 and 370

USDOE Environment Safety and Health Management Performance Objectives and Criteria for Tiger Team Management Assessment

USDOE Performance Objectives and Criteria for Technical Safety Appraisals at DOE Facilities and Sites

USDOE Performance Objectives and Criteria for Conducting DOE Environmental Audits and Environmental Tiger Team Assessments (Undated)

NRC Regulatory Guide 7.9, "Standard Format and Content of Part 72 Applications for Approval of Type B Packaging"

Recommended Seismic Hazard Levels for the Oak Ridge, Tennessee; Paducah, Kentucky; Fernald, Ohio; and Portsmouth, Ohio Department of Energy Reservations, KJBD-1025/R1, Beavers, Manrod, and Stoddart

Hagenauer and Mayer, Methods for Nondestructive Asscy Holdup Measurements in Shutdown Uranium Enrichment Facilities, K/TP-424, 1991

KY-783, "Paducah Gaseous Diffusion Plant Continued Operation Hazards Analysis/Risk Evaluation," December 1989

POEF-2020, "Paducah Gaseous Diffusion Plant Continued Operation Hazards Analysis/Risk Exaraion" December 1989

ORO-651, Rev. 6, "Uranium Hexafluoride: A Manual of Good Handling Practices” October 1991

OR-690, "Historical Radionuclide Releases from Current DOE Oak Ridge Operations Office Facilities," May 1988

ES/ESH-22/V4, POEF-2090, "Portsmouth Gaseous Diffusion Plant Environmental Report for 1991," October 1992

ES/ESH-22/V2, "Paducah Gaseous Diffusion Plant Environmental Report for 1991," October 1992

Wilkerson and Workman, Gaseous Diffusion Plant Reliability Study Program, K/C-1375, Rev. 9, September 1988 


\section{Attachment \\ TYPICAL SAFETY ANALYSES ACTIVTTIES SINCE COMPLETION \\ OF THE 1985 FSAR}

PORTSMOUTH:

ESAR Revisions

Revision 1: November 25, 1986: Changes to incorporate the addition of the freezer/sublimers.

Revision 2: November 25, 1986: Changes to incorporate the addition of the UF 6 containment projects at the feed and withdrawal areas and various administrative changes.

Revision 3: January 20, 1988; Various administrative changes.

Revision 4: June 26, 1989: Various administrative changes.

Revision 5: March 2, 1990: Changes to incorporate the X-705 waste water treatment system.

Revision 6: May 21, 1990: Changes to incorporate modifications to the X-705 truck alley sump pit, the $\mathrm{X}-705 \mathrm{pH}$ adjustment system, and the $\mathrm{X}-705$ small cylinder rise pit.

Revision 7: November 7, 1990: Various administrative changes.

Revision 8: April 26, 1991: Various administrative and editorial changes.

Revision 9: July 27, 1992: Changes to incorporate the modifications to the.limiting safety system settings and safety limits for the X-705 microfiltration permeate bag filter pressure differential shutdown system.

\section{Safety Analysis Activities Since 1985}

1. Since 1985 , approximately 250 safety assessments have been approved for plant modifications and testing. This number does not include assessments that are still in progress or awaiting approval.

2. On August 24, 1992, PORTS instituted the Unreviewed Safety Question Program. Since that time, 35 USQDs have been approved, and approximately 75 others are in progress or awaiting approval.

3. A detailed Safety System Analysis was performed for the Highly Enriched Uranium Suspension Project. This analysis included all modifications required to ensure the safety of the shutdown cells, piping modifications, and extended range product withdrawal modifications. It also included the necessary OSR changes. DOE approved this analysis.

4. A detailed PRA was performed for the liquid UF, handling facilities at PORTS. The PRA examined all aspects of the operations, design, and construction of the facilities and quantified the friequency of events. 
Attachment (Continued)

TYPICAL SAFETY ANALYSES ACTIVITIES SINCE COMPLETION OF THE 1985 FSAR

OSR (GAT/GDP 1074 PARTS A THROUGH L) CHANGES SINCE 1985

PART A 08/86 General changes to reflect FSAR revisions.

03/87 Added section on deviation from an OSR.

PART B 08/86 General changes to reflect FSAR revisions.

10/92 HEU suspension modifications.

PART C 05/87 General changes to reflect FSAR revisions.

PART D 02/83 Dropped several safety systems.

07/86 Changed high weight setting to 8200 pounds plus other general changes.

09/87 Changed to show a valving modification for separating freon from UF ${ }_{6}$.

PART E 02/87 General changes to reflect FSAR revisions.

PART F 10/86 General changes to reflect FSAR revisions.

03/87 Changed section concerning deviation from OSRs.

04/92 Changed cylinder low pressure safety system basis.

PART G No changes.

PART H 11/89 Major changes to reflect new waste treatment systems.

05/92 Changed bag filter pressure differential safety limit and limiting safety system setting.

PART I 09/87 General changes to reflect FSAR revisions.

PART J No changes.

PART K 08/86 General changes to reflect FSAR revisions.

10/92 Changed to reflect raising assay limit of 10-ton cylinders to $5 \%$.

PART L 03/87 Changed to reflect concern over shaft seal lubrication pressure.

All PARTS are being revised during 1993. 


\section{Attachment (Continued) \\ TYPICAL SAFETY ANALYSES ACTIVITIES SINCE COMPLETION OF THE 1985 FSAR}

Operational Safety Requirements

X-330 and X-333 Uranium Enrichment Cascades-Part A

X-326 Uranium Enrichment and Purge Cascades-Part B

Freon Degraders-Part C

Freezer/Sublimers-Part D

X-330 and X-333 Cold Recovery Systems-Part E

$\mathrm{UF}_{6}$ Cylinder Heating Autoclaves-Part $F$

X-326 High Assay Sampling Facility-Part G

X-706 Decontamination Building-Part $\mathrm{H}$

X-345 SNM Storage Facility-Part I

HF Tank Farm-Part J

ERP, LAW, and TAILS Withdrawal Facilities-Part $K$

X-345 High Assay Sampling Facility-Part L

\section{PADUCAH:}

FSAR Revisions

Revision 1: Issued approved September 6, 1985; C-340 Metal Casting Facility.

Revision 2: Issued approved March 31, 1986; Miscellaneous Changes.

Revision 3 (originally submitted as Revision 5): Issued approved May 15, 1989; PICS Freezer/Sublimer Relocates.

Revision 4: Approved April 19; 1989; Normetex Pump Additions. 


\section{Attachment (Continued) \\ TYPICAL SAFETY ANALYSES ACTIVITIES SINCE COMPLETION OF THE 1985 FSAR}

Unapproved Submittals-Supporting Line Item Construction Projects (All Completed)

Revision 3: Chemical Operations.

Revision 6: Intermediate Gas Removal System and C-360 Toll Transfer and Sampling Facility Modifications.

Revision 7: Seismic Upgrade.

\section{Safety Analysis Activities Since March 1985}

1. Approximately 330 Safety Assessments (or PSRs) have been completed for plant modifications initiated by ESOs. Another 75 projects initiated through ESRs have also been assessed.

2. On September 27, 1991, a USQD program was instituted at PGDP. Since that time, 47 safety evaluations (or PSEs) of proposed changes, tests, or experiments have been completed. By September 1993, the USQD process will be integrated into PSRs in the form of a PSE to determine the applicability of the DOE order. Since September 1990, 92 safety evaluations have been made through the PSR process.

3. KY-792, System Safery Analysis (SSA) for the Higher Assay Upgrading Project (HAUP), has been submitted to DOE for final approval following comment and resolution activities. This SSA will provide the authorization basis (including interim OSR) for PGDP operation at an assay of 5 wt $\%$.

Operational Safety Requirements - Revisions

KYID-3971, Operational Safety Requirements for UF Enrichment Cascade

Issued: March 29, 1985.

Revision 1: April 28, 1986.

Revision 2: February 25, 1987.

Revision 3: November 1, 1991.

$:$

Revision 4: June 16, 1992. 


\section{Attachment (Continued) \\ TYPICAL SAFETY ANALYSES ACTIVITIES SINCE COMPLETION OF THE 1985 FSAR}

KY/D-3972, Operational Safery Requirements for C-360 Toll Transfer and Sampling Facilities

Issued: March 29, 1985.

Revision 1: March 27, 1987.

Revision 2: December 10, 1990.

Revision 3: February 4, 1993.

KY/D-3973, Operational Safery Requirements for Chemical Operations

Issued: March 29, 1985.

Revision 1: February 27, 1987.

Revision 2: September 20, 1988.

Revision 3: April 6, 1992.

KYID-3974, Operational Safety Requirements for Product and Tails Withdrawal Facilities

Issued: March 29, 1985.

Revision 1: June 30, 1986.

Revision 2: April 19, 1989.

Revision 3: June 9, 1992.

KYID-4151, Operational Safety Requirements for UF ${ }_{6}$ Feed Facilities

Issued: February 26, 1986.

Revision 1: June 23, 1989.

Revision 2: February 4, 1993.

Submitted but not Approved

KYIL-1493, Operational Safety Requirements for the PGDP C-710 Facility, submitted July 15, 1988.

KY/H-188, Operational Safety Requirements for Criticality Accident Alarm System, submitted July 1, 1992. 


\section{APPENDIX B TO EXHIBIT D}

ENFORCEMENT PROCESS 
DOE/ORO - 2051

B-130 DEPARTMENT OF ENERGY - OAK RIDGE OPERATIONS 


\section{APPENDIX B - ENFORCEMENT PROCESS}

\section{GENERAI APPROACH TO ENFORCEMENT PROCESS}

The Atomic Energy Act of 1954, as amended, requires DOE to protect the public health and safety, as well as the safety of workers at DOE-owned facilities, and to provide for the common defense and security in conducting its nuclear activities, and grants DOE broad authority to achieve these goals. Consistent with this responsibility, DOE will take prompt and vigorous enforcement actions when dealing with the USEC when it does not comply with applicable DOE requirements contained in Chapter 3 of the Plan. This Appendix establishes the procedures for (a) investigating the nature and extent of alleged violations of the Nuclear safety and Safeguards and security Requirements set forth in Chapter 3 of Appendix $A$, entitled "Safety Basis and Framework for DOE Oversight of the Gaseous Diffusion Plants;" (b) determining whether a violation has occurred; and (c) if a violation has occurred, imposing an appropriate remedy.

\section{1. . ENFORCEMENT ACTIONS}

\section{A. Shutdown Authority}

\section{i. Clear. and Present Danger}

Whenever a DOE Appraisal Team Member, site safety representative, or the DOE Regulatory Oversight Manager in carrying out his or her responsibilities, determines that the nuclear safety or safeguards and security conditions at any Ieased Facility constitute a clear And Present Danger, he or she shall immediately notify the cognizant operations supervisor. - If the supervisor fails to take what the appraisal team member/site safety representative believes is appropriate and timely action to curtail or suspend the activity or operation, or to mitigate the identified clear And Present Danger by other means, the appraisal team member/site safety representative shall notify the plant shift superintendent. The appraisal team member/site safety representative shall explain the situation and request that the plant shift superintendent take appropriate action to curtail or suspend the activity or operation, or to mitigate the danger by other means. The USEC agrees that the plant shift superintendent shall take timely action to curtail or suspend the operation, or to mitigate the danger by other means, when so requested by the DOE appraisal team member or site safety representative when said DOE representative perceives a clear And Present Danger to exist. The plant shift superintendent shall inform the 
DOE appraisal team member/site safety representative of the actions taken to curtail or suspend the activity or operation, or to initigate the identified clear and Present Danger by other means. If the appraisal team member/site safety representative believes that these actions are not sufficient, he or she shall notify the Site Manager who shall notify the DOE Regulatory oversight Manager, informing him or her of the details of the situation. If the DOE Regulatory oversight Manager agrees that the action taken is not sufficient, he or she shall contact the plant superintendent and direct that he or she take specific actions to curtail or suspend the activity or operation, or to mitigate the danger by other means. When so directed by the DOE Regulatory oversight Manager, the USEC agrees to take, or cause the operating contractor to take, these specific actions. DOE and USEC agree that no written notice is required for DOE to exercise its shutdown authority pursuant to this paragraph.

\section{Unreviewed Safety Questions}

The DOE Regulatory Oversight Manager may also order an activity or operation curtailed or suspended, in the absence of a Clear And Present Danger, when he or she concludes that continued operation would involve an Unreviewed Safety Question, as defined in DOE order 5480.21 , "Unreviewed Safety Questions."

\section{B. Notice of violation}

In the event of an alleged Violation, the DOE Regulatory oversight Manager shall provide USEC with a written Notice of Violation. The written Notice of violation shall concisely. describe the alleged failure of the USEC or its contractor(s) to meet one or more of the Nuclear Safety and Safeguards and Security Requirements in effect at the time of the alleged violation. In particular, the Notice of Violation shall specify the date or dates, facts, and the nature of the alleged acts or omissions constituting the violation, and shall identify specifically the particular provision or provisions of the Nuclear Safety and Safeguards and . Security Requirements involved in the alleged violation. Within 30 days of the date of the notice or other time period specified in the notice, USEC will submit a written reply. USEC may admit or deny the alleged violation and state the reasons for the violation, if admitted. In the event the alleged violation is admitted, this reply shall also contain an explanation or statement including: (1) corrective steps that have been taken by USEC or others and the results that 
have been achieved; (2) corrective steps that will be taken: (3) the date when full conformance with the Nuclear Safety and Safeguards and Security Requirements in the identified area will be achieved.

\section{c. Civil Penalties}

1. Prior to imposing any Civil Penalty on the USEC, the DOE Regulatory Oversight Manager shall provide to USEC a written Notice of Violation, as described above, and a Notice of Proposed Imposition of Civil Penalty and shall state that the Civil: Penalty may be paid in the amount specified therein or the proposed imposition of the civil.. Penalty may be protested in its entirety or in part, by a written answer either denying the violation or showing extenuating circumstances. The USEC agrees to either pay the Civil Penalty in the amount proposed or answer the Notice of Proposed Imposition of Civil Penalty within 30 days of the date of a Notice of Proposed Imposition of Civil Penalty or other time specified in that notice. The answer to the Notice of Proposed Imposition of Civil Penalty shall state any facts, explanations, and arguments, denying the alleged violation, or demonstrating any extenuating circumstances, error in the Notice of violation or other reason why the Proposed Civil penalty should not be imposed and may request remission or mitigation of the proposed Civil Penalty. If the USEC files an answer to the Notice of Proposed Imposition of Civil Penalty, the DOE Regulatory Oversight Manager, upon consideration of the answer, will issue a revised Notice of Proposed Imposition of Civil Penalty imposing, mitigating, or remitting. the Civil Penalty. The USEC agrees to either pay the Civil Penalty in the amount specified or appeal the decision to the DOE ORO Manager within 30 days of the issuance of that revised Notice of Proposed Imposition of Civil Penalty. Any appeal shall be presented in writing, with an opportunity for USEC to be heard, if so requested.

2. The amount of the Civil Penalty imposed shall be based upon the severity of the violation, including the potential for the violation to affect the public health and safety or the common defense and security and whether it was a repeat violation, the actions taken to respond to the violation, and any extenuating circumstances. violations shall be assigned by the DOE Regulatory Oversight Manager, to one of three severity levels. Severity 
Level I violations are determined: (1) to create or to have significant potential for creating a clear And Present Danger or (2) to significantly increase the hazard to plant workers or the risk of an accident with significant off-site consequences; or (3) to be indicative of a serious breakdown in the facility Nuclear safety and Safeguards and security Requirements program which results in a significant potential that plant structures, systems, or components important to nuclear safety, safeguards or security would fail to perform their intended function. Severity Ievel II Violations are serious or recurring violations determined: (1) to have potential to contribute to the creation of a clear And Present Danger or (2) to moderately increase the hazard to plant workers or the risk of an accident with offsite consequences; or (3) to be indicative of degradation of a facility nuclear safety or safeguards and security program. Severity Level III Violations are those determined to involve significant shortcomings in the measures employed to meet individual Nuclear safety and Safeguards and Security Requirements, but no overall degradation of the effectiveness of the nuclear safety or safeguards and security programs. Penalties for Severity Ievel I Violations may range from $\$ 10,000$ to $\$ 50,000$ per occurrence. Civil penalties for Severity Ievel II Violations may range from $\$ 5,000$ to $\$ 20,000$ per occurrence. Civil Penalties are generally not imposed for severity Level III Violations.

3. Civil Penalties imposed on the USEC pursuant to this Agreement shall not be subject to sections 5.1 and 5.2 of ARTICLE $V$, entitled "Allocation of Iiabilities," of the Iease.

D. Failure to Take Agreed upon Actions

In the event of the failure of USEC to take the actions in accordance with this Agreement, the DOE ORO Manager shall take such actions as he or she deems appropriate, consistent with the terms of this Agreement and the Lease, including, but not limited to, a recommendation to the Secretary of Energy that he or she take steps to initiate an orderly termination of the Lease, to provide adequate assurance that USEC operation of the Leased Premises does not pose undue risk to the public health and safety or result in failure to provide for the common defense and security. Notification of the actions taken under such circumstances will be provided 

to USEC in the form of directives issued by the DOE ORO
Manager. 


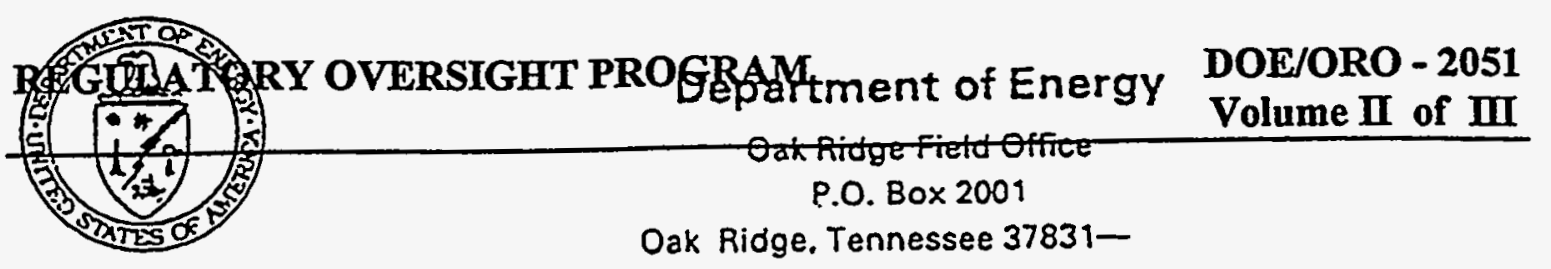

November 8, 1994

Mr. George P. Rifakes

Executive Vice President

United States Enrichment Corporation

Two Democracy Center, Fourth Floor

6903 Rockiedge Drive

Bethesda, Maryland 20817

Dear Mr. Rifakes:

EXHIBIT A OF THE LEASE AGREEMENT BETWEEN THE DEPARTKENT OF ENERGY AND THE UNITED STATES ENRICHMENT CORPORATION

Enclosed for execution is Revision I of Exhibit A, Leased Premises, to the lease agreement, dated October 28,1994 . Please provide this office a copy of the executed letter and enclosure.

I will be happy to discuss this with you at your convenience.

Sincerely,

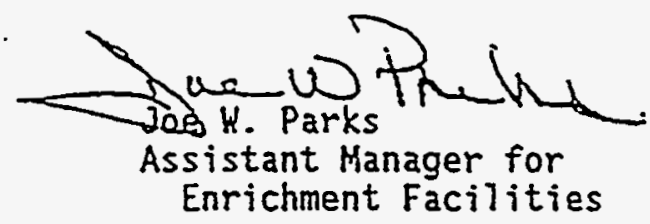

Enclosure

Concurrence:

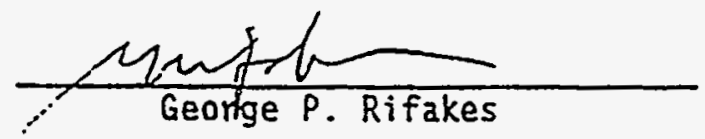


DOE/ORO - 2051 
EXHIBIT A

LEASED PREMISES

as agreed between

UNITED STATES DEPARTMENT OF ENERGY

and

UNITED STATES ENRICHMENT CORPORATION

Revision 1

Oclober 28, 1994 
PADUCAH FACIUTIES

Lersed TO USEC

EACUITY

C. 100

C. $100-A$

C.100-T-04

C-100-T.05

C. $100-T .08$

C.101

C-102

C-102-T.01

C-102-T-02

C. $102 . T-03$

C.102-T.04

C-102-T-05

C.102.T-06

C-200

C.200-A

C-201

C-201-A

C.201-B

C.201-C

$\mathrm{C} .202$

$\mathrm{C} 203$

C-206

C.206.A

C-205-8

C-212

C.212-A

C.215

C.218
DESSRIETION

ADMINISTRATION BUILOING

OFFICE TRAILER

TEMPORARY OFFICE

TEMPORARY OFFICE

TEMPORARY OFFICE

CAFETERLA

HOSPITAL

TEMPORARY OFFICE

TEMPORARY OFFICE

TEMPORARY OFFICE

TEMPORARY OFFICE

TEMPORARY OFFICE

TEMPORARY OFFICE

GUARD AND FIRE HEADQUARTERS

SECURITY PATROL \& FIRE TRAINING

EMERGENCY EQUIPMENT STORAGE BUILDING

EMERGENCY EQUIPMENT STORAOE BUILDINO

EMERGENCY EQUIPMENT STORAGE BUILDING

EMERGENCY EQUIPMENT STORAGE BUILDING

GUARD TRAINING BUILOING

EMERGENCY VEHICLE SHELTER

PUMPER DRAFTER PIT

STORAGE TRAILER

SMOKE TRAINING

OFFICE BUILDINB

MAIN GUARD POST (GATE 15)

PORTALS 18 AND 18

POST 47 


\section{PADUCAH FACIUTIES \\ LERSOd TO USEC}

ESCIVITY

C.21T

C..220-A

C.220-01

C.220.D2

C.230-A

C.230-B

$\mathrm{C}-230-\mathrm{C}$

C.230-0

C.230-E

C.230-F

C.230-C

$\mathrm{C} .230-\mathrm{H}$

C.230-J

C.232-A

C.232-B

C-232-C

C-232-D

C-232-E

C. 300

C-300-531

C. $300-533$

C- $300-535$

C.300.53T

C.302

C-303

C.304

C.310

C.310-331

C $-310-410$

C.310-A

C.315

C-315-331

C. 320

C.331

C.331-333

c.331.333

C.331.335

C. $331-410$

$\operatorname{cos33}$

C.333.A

C.335

C.335.337
DESCRIPTION

POST 43

POWER DISTRIBUTION SYSTEM

QELL TELEPHONE SYSTEM

PNX TELEPHONE SYETEM

SANITARY WATER SYSTEM

SANITARY SEWER SYSTEM

STORM SEWER SYSTEM

CHILLED WATER GYSTEM

PLANT (PROCESS) WATER EYGTEM

PROCESS WASTEWATER SYSTEM

RECIRCULATINO COOLING WATER SYSTEM

HIGH-PRESSURE FIRE WRTER SYSTEM

PROCESS WASTE HEAT UTILIZATION SYSTEM

NITROGEN SYSTEM

COMPRESSED AIR SYSTEN

RCETYLENEIOXYGEN SYSTEM

STEAM DISTRIBUTION SYSTEM

NATURAL GAS SYSTEM

CENTRAL CONTROL BUILDING

INSTRUMENTATION TUNNEL

INSTRUMENTATION TUNNEL

INSTRUMENTATION TUNNEL

INSTRUMENTATION TUNNEL

OPERATIONS DIVISION DATA CENTER

SUPERVISORY CONTROL \& DATR ACQUISITION SYSTEMS BUILDINO

TRAINING AND CASCADE OFFICE BUILOING

PURGE AND PRODUCT BUILDING

ENCLOSED BRIDGE

TIE LINE

PRODUCT. WITHDRAWAL BUILDING

SURGE ANO WASTE BUILOING

TIE LINE

COMMUNICATION BUILDING

PROCESS BUILDINO

ENCLOSED BRIDGE

TIE LINE

TIE LINE

TIE LINE

PROCESS QUILDINO

FEED VAPORIZRTION FACILITY

PROCESS BUILDINO

ENCLOSED BUILOING 
PADUCAN FACILITIES

Loased TO USEC

\section{EAclum}

C. $335-337$

C-337

C. $337 \cdot A$

c.350

C-380

C.375-E2

C-375-E3

C-373-E4

C-375-E5

C.375-N1

C.375.56

C.375-WT

C-375.WE

C-375-WO

$C-400$

C-400-A

$c-105$

C. 407

C.40B

C. 400

$\cos 0 \operatorname{se} A$

C.408-B

C.410-D

- C.531

C.539-1

C.539-2

C. $537-3 A$

C. $531.3 B$
DEBCRIPTION

TIE LINE

PROCESS EUILDING

FEED VAPORIZATION FACILITY

DRYINO AGENT STORAGE BUILOING

TOLL TRANSFER AND SAMPUNG BUILDING

OIL CONTROL DAM (EAST DRAINAGE DITCH) KPDES 002

OIL CONTROL DAM (EA8T DRAINAGE DITCH) KPDES 010

OIL CONTROL DAM (EAST DRAINAGE DITCH) KPDES 011

OIL CONTROL DAM (EAST DRAINAGE DITCH) KPDES 012

OIL CONTROL DASA KPDES 003

OIL CONTROL DAM (SOUTH DRAINAGE DITCH) KPDES 000

OIL CONTROL DAM MEST DRAINAGE DITCH) KPDEB OOB

OIL CONTROL DAM (WEST DRAINAGE DITCH) KPDES 015

OIL CONTROL DAM (WEST DRAINAGE DITCH) KPDES 001

CLEANING BUILDING AND APPURTENANT ETRUCTURES

EMERGENCY POWER FOR CRITICAL ALARMS

TRICHLOROETHYLENE STORAGE TANK

NITRIC ACID BTORAOE TANK

50.TON TRUCK SCALE

STABILIZATION BUILDING

STORAGE TRAILER

STORAGE TRAILER

FLUORINE STORAGE FACILITY

SWITCH HOUSE AND APPURTENANT STRUCTURES

SWITCH HOUSE

SWITCHYARD

FIRE VALVE HOUSE NO. 1

FIRE VALVE HOUSE NO. 2 


\section{PADUCAH FACILUTIES \\ Leasud TO USEC}

\section{EACILITY}

\section{C.532}

C.533

C.533-9

. .5333 .2

C.533-34

C.533-3B

C.533-3C

C.533.3D

$6-635$

C-535-9

C. $535-2$

C.535-3A

C. $535-38$

C.535-4

C.538

C. 537

C.537-1

C.537:2

C. $537.3 \mathrm{~A}$

C.537.38

C.537-3C

C.537-3D

C.637-4

C.540

C-540-A

0.510 .8

C.580.C

C.540.D

\section{QESCRIPTION}

RELAY HOUSE

SWTCH HOUSE AND APPURTENANT STRUCTURES

SWITCH HOUSE

SWITCHYARO

FIRE VALVE HOUSE NO. 9

FIRE VALVE HOUSE NO. 2

FIRE VALVE HOUSE NO. 3

FIRE VALVE HOUSE NO. 4

SWTCH HOUSE AND APPURTENANT STRUCTURES

SWITCH HOUSE

SWITCH YARO

FIRE VALVE HOUSE NO. 1

FIRE VALVE HOUSE NO. 2

TEST SHOP (MAINTEMANCE OFFICE)

RELAY HOUSE

SWITCH HOUSE AND APPURTENANT STRUCTURE

SWICH HOUSE ANO APPURTENANT STRUCTURE SWITCHYARD

FIRE VALVE HOUSE NO. 1

FIRE. VALVE HOUSE NO. 2

FIRE VALVE HOUSE NO. 3

FIRE VALVE HOUSE NO. 4

TEST SHOP

OIL PUMP HOUSE AND APPURTENANT STRUCTURE

OIL PUMP HOUSE

OIL STORAGE TANK (NORTHWEST)

OIL STORAGE TANK (SOUTHWEST)

OIL STORAGE TANK (NORTHWEST) 


\section{PADUCRH FACILITIES}

Lzased TO USEC

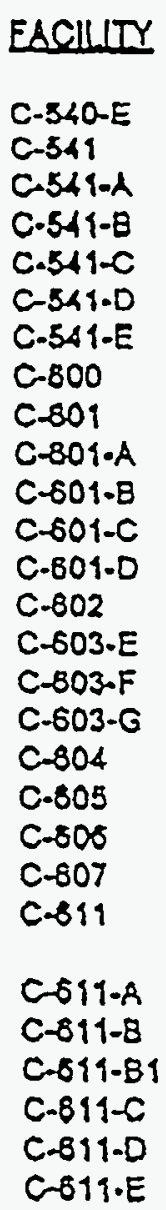

EACULTY

QESCRIPTION

OIL STORAOE TANK (SOUTHEAST)

OIL PUMP HOUSE AND AFPURTENANT STRUCTUREB

OIL PUMP HOUSE

OIL STORAGE TANK (NORTHWVET)

OIL STORAOE TANK (SOUTHWEST)

OIL STORAGE TANK (NORTHEAST)

OIL BTORAGE TANK (SOUTHEAST)

STEAM PLANT \& ASSOCLATED UTILTTY APPURTENANT STRUCTURES

NITROGEN GENERATOR BUILDING ADDITION

STEAM PLANT FUEL STORAGE TANK (CENTER)

STEAM PLANT FUEL STORAGE TANK (BOUTH)

STEAM PLANT FUEL OIL PUMP HOUEE

FUEL OIL STORAGE TANK (NORTK)

COAL STORAGE YARD

NITROGEN BTORAGE TANK (EAST)

NITROGEN STORAGE TANK (CENTER)

NITROGEN STORAGE TANK (WEST)

UTILITIES MAINTENANCE BUILDING

SUBSTATION BUILDING

COAL CRUSHER BUILDINO

EMERGENCY AIR COMPREGSOR OENERATOR BUILDING

WRTER TREATMENT PLANT DISTRIBUTION BYETEM AND

APPURTENANT STRUCTURES

BUILDING ANO SHOP STORAGE

HEAD HOUSE

POLYMER FEED SYSTEM ENCLOSURE

FLOCCULRTOR BASIN

SETTLINO BASIN (NORTHEAST)

SETTLING BASIN (NORTHWEST) 
P.ADUCAH FACIUTIES

LEבsed TO USEC

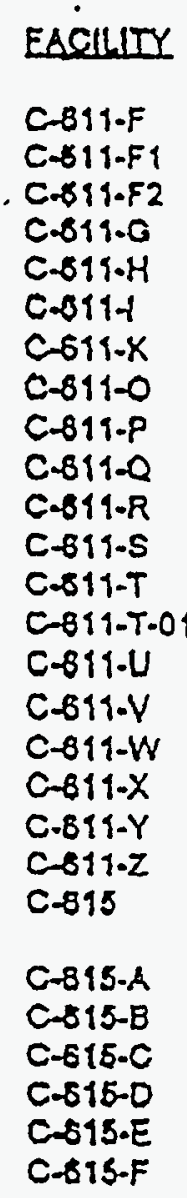

RESCRIPTION

SETTUNO EABIN(SOUTHEAST

SECONOARY COAOULATION BASIN

CHEMICAL FEED BUILDING FOR C-819-FI

SETTLING BAOIN (SOUTHWEST)

FILTER BUILDING AND PUMP ETATION

CLEAR WELL

NUMBER \& LAGOON

SANITARY WATER BTORLGE TANK

PUMP HOUSE

38 RAW WATER LINE BOOSTER STATION

WATER TANK-RCW FIRE WATER (HIOH PRESSURE)

CORROSION INHIBITOR EUILDING

BOOSTER PUMP STATION (PLANT WATER)

TEMPORARY OFFICE

SOFTENING FACIUITY (WEST)

SLUDGE LAGOON

SLUDGE LAGOON

SOFTENING FACILITY (EAST)

RECYCLE LAOOON

FLOCCULATOR BASIN

SEWATE DISPOSAL PLANT, COLLECTION SYSTEM AND

APPURTENANT STRUCTURES

PRIMARY SETTLING TANK

FINAL SETTLING TANK

CONTROL BUILDING

DIGESTER

TRICKLING FILTER

TRICKLING TILTER 


\section{PADUCAH FACIUTIES}

Leased to USEC

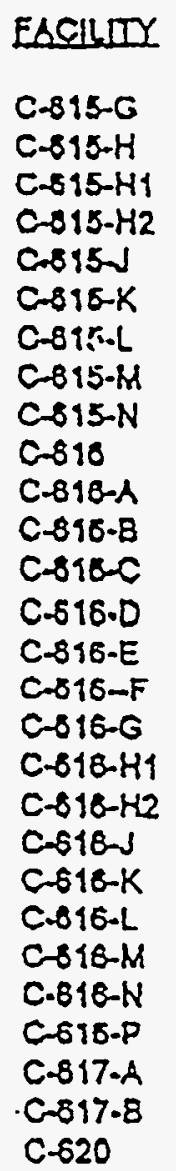

\section{DESCRIPTION}

SEWAQE LIFT STATION SEWAGE LIFT STATION SEWAGE LIFT STAMTON SEWHOE LITT BTATION UFT STATION

MANHOLE

OIL CONTROL MONITORING STATION

OIL CONTROL STRUCTURE

OIL CONTAINMENT LAOOON

LQUID POLLUTION ABATEMENT AND APPURTENANT ETRUCTURES

CHEMICAL FEED BUILDING

CLARIFIER-EAST

LIFT STATION

SLUDGE VAULT AND VALVE PIT

SLUDGE LAGOON

FULL FLOW LAGOON

SULFURIC ACID TANK

FERROUS SULFATE STORAGE TANK (EA8T)

FERROUS SULFATE STORAGE TANK (WEST)

REDUCTION TANK-EAST

SERVICE BUILDING

EFFLUENT CONTROL VAULT

CURIFIER-WEST

REDUCTION TANK-WEST

SLUDGE VAULT AND VALVE PIT

EFFLUENT CONTROL STATION

LAGOON

AR COMPRESSOR ROOM 
PADUCAK FACILTIES

Leased to USEC

EACIUITY

$\cos 31$

c.839-01

0.634 .02

C-831.03

Cos31.04

C-\$31-05

C. 831.06

cos31-0T

0.831 .08

0.631 .08

C.839.90

C.633

C. $833-1$

C. $833-2 A$

C-633-2B

C-633-3

c.833-4

C-533.5

$\cos 33-6$

$0-535$

$\cos 35-1$

C-835-2

c-835-3

C.835-4

C.635-5

C. $635-6$

C-83T

C-637-1
DESCEIPTION

RCW PUMP HOUSE AND APPURTENANT STRUCTURES

PUMP KOUSE

COOLING TOWER

PUMP KOUSE (FIREWATER)

BLENDINO PUMP HOUSE

BLENDING COOLING TOWER MEST)

- BLENDING COOLINO TOWER (EAST)

MAINTENANCE SHOP

CHANGE HOUSE

ASBESTOS CREW BREAKROOM

ASBESTOS CREW STORAGE

RCW PUMP HOUSE ANO APPURTENANT STRUCTURES

PUMP HOUSE

COOLING TOWER (SOUTH)

COOLNO TOWER (NORTH)

QLENDING PUMP HOUSE

BLENDING COOLING TOWER (NORTH)

BLENOINO COOLING TOWER (SOUTH)

SANO FILTER BUILDING

RCW PUMPHOUSE AND APPURTENANT STRUCTURE

PUMP HOUSE AND PIPING

COOUNG TOWER

BLENDING PUMP HOUSE

BLENDING COOLING TOWER (NORTH)

BLENOING COOLING TOWER (SOUTH)

PROCESS WASTE HEAT UTIUZATION PUMP KOUSE

RCW FUMP HOUSE AND APPURTENANT STRUCTURES

PUMP HOUSE 
PADUCAH FACILUTIES

Loxsed to USEC

\section{EACILITY}

C- $837.2 A$

C. $837-2 B$

C-837.3

C-837-4

C. $637-5$

C.537-6

$\operatorname{cor} 10$

C-710-A

C.710-8

C.711

C.712

c.720

C.720.A

C.720.B

C-720-C

C-720-C1

C-720-D

C.720-E

C-720-G

$\mathrm{C}-720-\mathrm{H}$

C-720-J

c.720-K

C.720-L

C. $720 . \mathrm{M}$

C.720-N

C-720-N1

C.720-P

C. $720-Q$

\section{DESGRIPTION}

COOLING TOWER (SOUTH)

COOLING TOWER (NORTH)

BLENDING PUMP HOUSE

GLENDING COOLINO TOWER (NORTH)

BLENDING COOUNO TOWER (SOUTH)

GAND FILTER BUILDING

TECHNICAL SERVICES BUILDING AND APPURTENANT STRUCTURES

GAS CYUNDER ETORAOE BUILOINO

BTORAOE FACIUTY

GAS MANIFOLD

ACID NEUTRALIZATION PIT

MAINTENANCE AND STORES BUILDING AND APPURTENANT

STRUCTURES

COMPRESSOR SHOP AOOITION

MACHINE SHOP ADDITION

CONVERTOR BHOP ADDITION

BARRIER STORAGE

TRANSFORMER BUILDING

CHANGE HOUSE ADOITION

PEM RECEIVING QUULDING

WAREHOUSE

RIR LOCK

INSTRUMENT SHOP ADOITION

OXYGEN FACILITY

FIELD INSTRUMENT TRAILER

RAILROAD SCALE HOUSE

RAILROAD CLASSIFICATION YARD

IHSTRUMENT MAINTENANCE TRAILER

INSTRUMENT MAINTENANCE STORAGE TRAILER 


\section{PADUCAK FACIUTTES \\ Lezsud to USEC}

\section{Esclutry}

$: 0.721$

C.722

C.724-A

C.724. B

C-724-C

C.724-D

C.725

C.726

C-727

C.T28

C.728

C.731

C.732

C.740

C-740k

C-740-B

C-740-C

C.741

C-742

C-742-B

C.743

C. $743-T-08$

C.T43-T-0T

C-743-T.08

C.7 $43-T-11$

C.743-T.12

C.743-T. 13

C.743-T-14

C-743-T-15
RESCRIPTION

GAS MANIFOLD STORAGE

ACIO NEUTRALIZATION PIT

CARPENTER SHOP ANNEX

CARPENTER SHOP

PAINT GHOP

LUMBER STORAGE BUILOING

PAINT SHOP

SANDBLAST BUILDINQ

HEAT TREATING FACILTY

MOTOR CLEANING FACILITY

ACETYLENE BUILDING

RAILROAD REPAIR EQUIPMENT STORAGE BUILDING

MAINTENANCE MATERIALS STORAGE BUILDINO

MATERIAL YARD

SEMI-TRAILER UNLOADING FACILITY

OIL DRUM STORAGE SHELTER

MISCELLANEOUS MATERIALS STORAGE YARD

MOBILE EQUIPMENT BUILDING

CYLINDER STORAGE BUILDING

DRYINO AGENT CYUINDER STORAGE

OFFICE BUILOING

TEMPORARY OFFICE

TEMPORARY OFFICE

TEMPORARY OFFICE

TEMPORARY OFFICE

TEMPORARY OFFICE

TEMPORARY OFFICE

TEMPORARY OFFICE

TEMPORARY OFFICE 


\section{PADUCAH FACILITES}

LeAsed 10 USEC

EACILITY
$C-743-T-16$
$C-744$
$C-745-A$
$C-715-B$
$C-748-81$
$C-745-E$
$C-745-H$
$C-745-J$
$C-746-Q$
$C-746-A 3$
$C-748-G$
$C-748-H 1$
$C-748-H 2$
$C-746-L$
$C-748-01$
$C-750$
.-751
$C-800$
$C-801$
$C-810$
$C-819$
$C-R W S$

DESCRIPTION

TEMPORARY OFFICE

LUBRICATION BUILDING

2 1/2 TON CYLINDER YARDS (NOTE 1)

10-TON CYLINDER YARDS (NOTE 2)

CYLINDER BTORAGE YARD OFFICE

KELLOOO STORAGE YARD

SAFEGUARD CYUNDER STORAGE YARD

FOREIGN CYLINDER STORAGE YARD

CYLINDER STORLGE YARD (NOTE 3)

TRAGH SORTING AND PROCESSINO FACILITY

ELECTRIC.EQUIPMENT STORAGE

PEM STORAGE SLAB

PEM STORLGE SLAB

TRACTOR STORAGE

HIGH ASSAY WASTE STORAGE FACILITY

GARAGE AND APPURTENANT STRUCTURES

FUEL DISPENSING FACILITY

MOTORCYCLE PARKING RREA

OHIO AVENUE BUS SHELTER

PARKING AREA $(C-100)$

PARXINO AREA $(C .720)$

RAW WATER PUMPINO STATION AND PIPELINES

NOTE 1: With excoptlon of DOE cylindar stor 20 e in rows $A$ through $F$. A through FF. R. and RR. NOTE 2: with exception of DOE cytnder storage in sows $C, E, l, N, O, R, S, X, C C, E E$, snd II. NOTE 3: With exception of DOE tail cyender storage in rows $h$ and $V$. 
PADUCAK FACILITIEE

Ounne BY USEC

CH10KK FLUORINE BUILDING 
PAOUCAH FACILITIES

Rotzined BY DOE

EACULIT
$C-103$
$C-E X P$
$C-200$
$C-204$
$C-218$
$C-301$
$C-340$
$C-340-A$
$C-340-B$
$C-340-C$
$C-340-D$
$C-340-E$
$C-342$
$C-342-A$
$C-370-E$
$C-370-W$
$C-400$
$C-400$
$C-400 \& C-404$
$C-402$
$C-103$
$C-404$
$C-405$
$C-409-C$
$C-410$
$C-110-A$
$C-410-B$
$C-410-C$
$C-410-E$
$C-410-F$
$C-410-G$
$C-410-H$

DESCRIPTION

DOE SITE OFFICE

CHANGE HOUSE

UNDEROROUND STORAGE TANKS

DISINTEGRATOR BUILDING

FIRING RANGE

STORAGE BUILDING

REDUCTION AND MEIALS FACILITY

POWDER BUILDINO

METALS BUILDING

SLAQ BUILOINO

MAGNEBIUM STORAGE BUILDING

EMEROENCY POWER FOR CRITICAL ALARMS

AMMONIA DISSOCLATOR AND STORAGE FACIUTY

AMMONIA OISSOCIATOR ADOITION

WATER OUALITY MONITORING STATION (LITTLE BAYOU CREEK)-

INACTIVE

WATER QUALITY MONITORING STATION (BIO BAYOU CREEK)

INACTIVE

GOLD DISSOLVER STORAGE TANK (NOTE 4)

TECHNETIUM STORAGE TANK (NOTE 4)

UNDERGROUND TRANSFER LINE (NOTE 4)

LIME HOUSE

NEUTRALIZING PIT

LOW-LEVEL RADIDACTIVE WASTE BURIAL GROUND

CONTAMINATED ITEMS INCINERATOR

HAZARDOUS WRSTE PILOT PLANT

FEEC PLANT AND APPURTENANT STRUCTURES

HYDROGEN HOLDER

SLUDGE LAGOON

HYDROFLUORIC ACID NEUTRALIZATION BUILDING

HYDROFLUORIC ACID EMERGENCY HOLDING POND

HYDROFLUORIC ACID STORAGE BUILDING (NORTH)

HYDROFLUORIC ACID STORAGE BUILDING (CENTER)

HYDROFLUORIC ACIO STORAGE BUILDING (GOUTH) 


\section{PADUCAH FACIUTIES}

Ralainod BY DOE

\begin{tabular}{|c|c|}
\hline EACULITY & DESCRIPTION \\
\hline C-s10-1 & ASH RECEIVER SHELTER \\
\hline C-1100 & HYDROFLUORIC ACID STORAGE BUILDING (EAST) \\
\hline C.411 & CELL MAINTENANCE BUILDING \\
\hline$c-415$ & FEED PLANT STORAGE BUILOING \\
\hline$C-496$ & EQUIPMENT CLEANING FACILITY \\
\hline$C \propto 20$ & GREENGALT PLANT \\
\hline C.603-A & NITROGEN MANIFOLD BUILDING \\
\hline $\cos 03-8$ & NITROGEN STORAGE TANK \\
\hline$c-603-c$ & NITROGEN RECEIVER (NORTH) \\
\hline C-803-D. & NITROGEN RECEIVER (SOUTH) \\
\hline C-803.H & NITROGEN GENERATOR-CONTROL HOUSE \\
\hline C- $503-1$ & NITROGEN GENERATOR-TOWER AREA \\
\hline C-511-M & NORTH CONCRETE SANITARY WATER STORAGE TANK \\
\hline$C-511 \cdot 6$ & SOUTH CONCRETE SANITARY WATER STORAGE TANK \\
\hline$c .623$ & NORTH GROUND WATER TREATMENT BUILDING \\
\hline C-832-B & ACID STORAGE TANK \\
\hline C-834-B & ACID ETORAGE TANK \\
\hline 0.710 & UNDERGROUNO STORAGE TANKS \\
\hline 0.720 & UNDERGROUND PETROLEUM NAPTHA PIPE \\
\hline 0.720 & TCE DEGREASER (INACTIVE) \\
\hline $0-730$ & MAINTENANCE SERVICES BUUILDING \\
\hline$C-730-D, E, F, H$ & M.K FERGUSON OFFICES \\
\hline C.730-G & EBASCO OFFICES \\
\hline C.733 & WRSTE OIL AND CHEMICALL STORAGE FACIUTY \\
\hline $2-7 \nmid 3-7-01$ & ENVIRONMENTAL RESTORATION OFFICE \\
\hline C-743-T-02 & ENVIRONHENTAL RESTORATION OFFICE \\
\hline C-743-T-03 & OFFICE TRAILER \\
\hline$C-743-T-24$ & CHANGE HOUSE \\
\hline C-743-T.05 & CHANGE HOUSE \\
\hline C-743-T-00 & ER OFFICE \\
\hline C-743-T-17 & FIELD LABORATORY \\
\hline C.74E-C & 14.TON CYLINDER YARD (NOTE 5) \\
\hline C-745-D & CYLINDER STORAGE YARD \\
\hline
\end{tabular}




\section{PADUCAK FACILITIES}

Relsined BY DOE

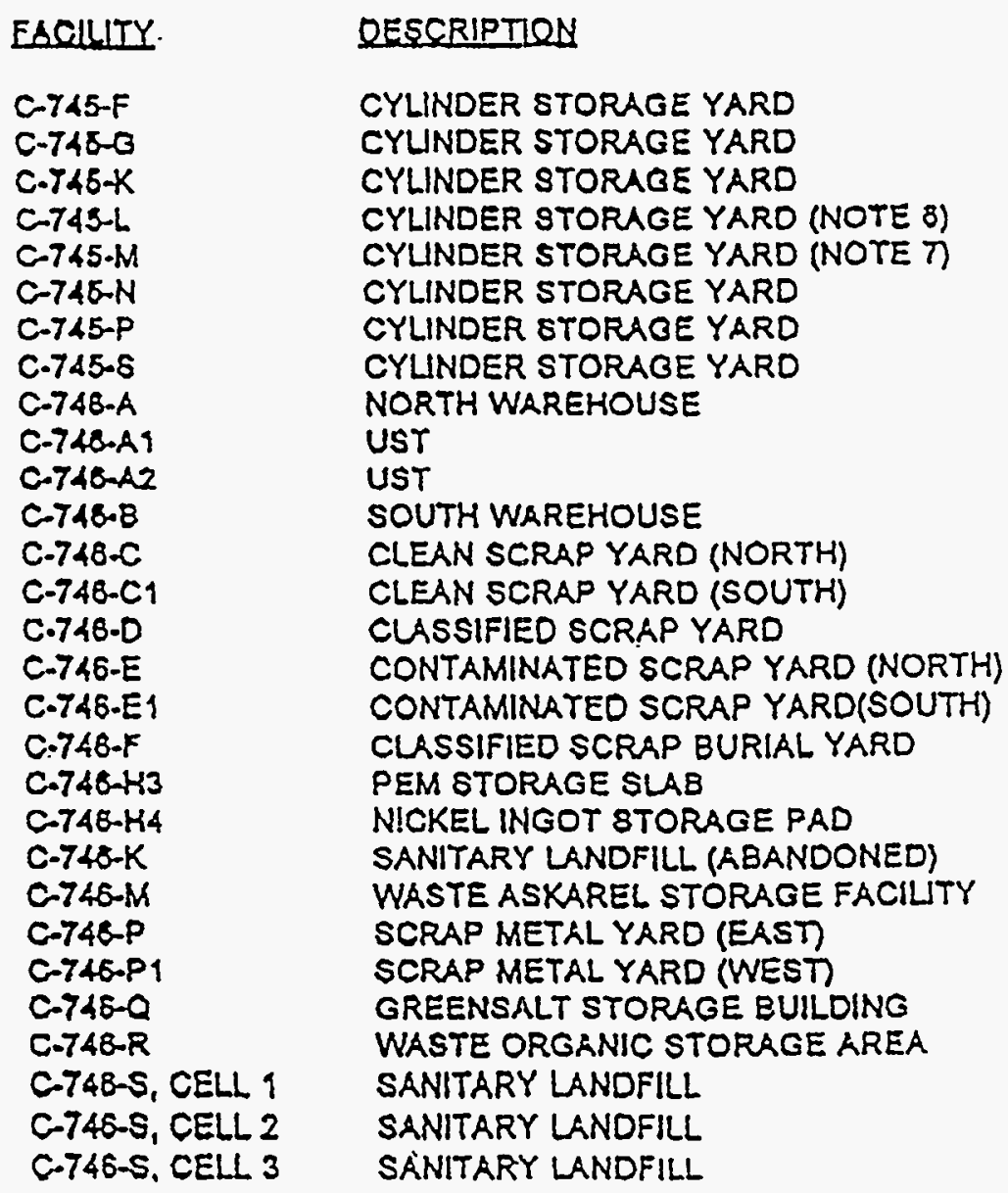




\section{PADUCAK FACIUTIES}

Rotained BY DOE

\section{Escullity}

C-748-81

C.746-T

C-740-V

C.747

C.747-A

C.74T-B

C.747-C

$\operatorname{co} 748 . \alpha$

C.748-B

C.748

C.750-D

C.752

C.752-8

C-752.C

c.753-A

2-SWMUL11

Z-SWMU. $\{2$

Z.SWMUL-30

Z.SWMU.31

Z.SWMU.74

Z-SWMU.76

Z-SWMU-77

Z-SWMU. 01

Z-BWMU-82

Z.SWMSU.83

Z-SWMUL-96

Z-SWMU-100

Z-SWMU-137

Z-SWMU-138

\section{DESCRIPTION}

LANDFILL SERVICE BUILOING

INERT LANDFILL

ER OTORAOE FACIUTY

BURLAL AREA (INACTIVE)

BURIAL AREA (INACTTVE)

BURIAL AREA (INRCTIVE)

OIL LANO FARM AREA

KOW DISPOSAL AREA (INACTIVE)

BURIAL AREA (INACTIVE)

URANIUM SCRAP BURIAL YARD (INKCTIVE)

UNDERGROUND STORAGE TANK

RA WASTE HOLDING FACILTY

DECONTAMINATION PAD

OFFSITE DECONTAMINATION PAD

TSCA STORAGE FACIUTY (FUTURE)

C-400 TRICHLOROETHYLENE LEAK SITE

C.747-A UF' 4 ORUM YARD

C-747-A BURN AREA

C-720 COMPRESSOR PIT WATER STORAGE TANK

C-34O PCB SPILL SITE

C-632-8 H2SO4 STORAGE TANK

C-634.B H2SO4 STORAGE TANK

UFB CYLINDER DROP TEST AREA

FILL AREA FOR DIRT FROM C-420 PCB SPILL 8ITE

CONCRETE DISPOSAL

COOLING TOWER SCRAP WOOD PILE

FIRE TRAINING ARER

C-746-A INACTIVE PCE TRANBFORMERISUMP

C-100 SOUTH BIDE LAWN (FILLED WIC-611 SLUDGE) 


\section{PADUCAH FACILITIES}

Relained BY DOE

ESEILTY

Z-8WMU-145

Z-SWMUL-159

Z-EMAUL 160

Z-SWMU-162

Z-sWMUL188

z-8WASU-170

Z-SWMU-183

z-SWMU-XXX

\section{DESCRIRTION}

RESIDENTIAL LANDFIL BORROW AREA

C-746 H3PAD

CTAS CYLINOER YARD SPOILS AREA-PCB SOIL CONTAMINATION C.817-A SANITARY WATER LINE-SOIL BACKFILL

CA10.E HF VENT SURGE PROTECTION TANK

C.722 ACETYLENE BUILOING DRAIN PITS MCGRAW UST

SOLID WASTE MANAGEMENT UNITS REFERENCED DN THE FOLLOWNG DRAWNOS:

C5E-16924-MO1 REY O MMES

C5E-16924-MO2 R\&V 4 MMEG

C5E-16824-8018 Sheet 18140 CH2M Hill

CSE-18921-8021 8hool 21/48 CH2M Hill

C5E-T6824-9034 Sheel 34148 CH2M HIII

NOTE 1: The Building C-100 is kesed lo USEC and DOE folains the tanks and teansfer lino NOTE 5: Empty cylindors trensfer to USEC but remain in $C-745-C$

NOTE B: Wilh exceplion of cylinders stored in rows $11-A, \| 1-B$, AND JJ through ZZ

NOTE 7: With exception of cylinders slored in rows $B$ through $L$ 
PORTSMOUTH FACILITIES

Lessod to USEC

EACUITY

$x-100$

$X-100-B$

$X-100-L$

$x-101$

$x-102$

$x-103$

$x \cdot 104$

$x-104 x$

$x-105$

$x-108$

$x-108-B$

$x-108-1$

$x-908-8$

$X-106-E$

$X-108-H$

$x-100-1$

$x-900-8$

$x-900-c$

$x \cdot 111-A$

$x-111-B$

$x \cdot 112$

$x-194-A$

$x-120$

$x-200$

$x-201$

$x-202$

$x-204$

$x-206-A$

\section{DESCRIPTION}

ADMINISTRATION BUILDING

AIR CONDITIONING EQUIPMENT BUILDING

ENVIRONMENTAL CONTROL TRAILER

HEALTH BERVICES

CAFETERIA

AUX OFFICE BUILDINO

QUARD KEADQUARTERS

INDOOR FIRING RANGE

ELECTRONIC MAINTENANCE BUILDINO

TACTICAL RESPONSE BUILDING

FIRE TRAINING BUILOING

SOUTH PORTAL AND SHELTER

NORTH PORTAL AND SHELTER

CONSTRUCTION PORTAL

PIKE AVE PORTAL

PERSONNEL MONITORING STATION

PERSONNEL MONITORINO STATION

PERSONNEL MONITORING STATION

SNM MONITORING PORTAL $(x-320)$

SNM MONITORING PORTAL (NW $X-326$ )

DRTA PROCESEING BUILDING

OUTDOOR FIRING RANGE

SOUTH WERTHER STATION

SITE PREP, GRLDING, LANDSCAPING

LAND AND LAND RIGHTS

ROADS

RAILRC DO ANO RAILROAD OVERPASS

MAIN F, RKING LOT (N) 


\section{PORTEMOUTH FACILITIES \\ Ltased to USEC}

EACUITY

$X-208-B$

$X-200-E$

$X-208 \cdot H$

$x-200 \mathrm{~N}$

$x-208$

$x-308-A$

$X-210$

$x-215-A$

$x-213-B$

$x-218-C$

$X-215-0$

$X-220-A$

$X-220-B 1$

$X-220-B 2$

$x-220-83$

$x-220-C$

$X-220-01$

$X \cdot 220-02$

$X \cdot 220-03$

X220-EI

$X-220-E 2$

$X-220 \cdot E 3$

$X-220-F$

$X-2200$

$x-220-H$

$x-220 \mathrm{~J}$

$\mathrm{X}-220 \mathrm{~K}$

$X-220-L$
DESCRIPTION

MAIN PARKINO LOT (S)

CONSTRUCTION PARKING

PIXE AVE PARKING LOT

SOUTH OFFICE PARKING LOT

8ECURITY FENCE

BOUNDARY FENCE

SIDEWALKS

ELECTRICAL DIBTRIBUTION TO PROCESS BUILOINOS

ELECTRICAL DIBTRIAUTION TO OTHER AREAS

EXTERIOR LUGHTING

ELECTRIC POWER TUNNEL

INSTRUMENTATION TUNNELS

PROCESS INQTRUMENTATION LINES

CARRIER COMMUNICATIONS BYSTEMS

WATER SUPPLY TELEMETERING LINES

SUPERIOR AMERICAN ALARM SYSTEM

GENERAL TELEPHONE

PROCESS TELEPHONE

EMERGENCY TELEPHONE SYSTEM

EVACUATION PUBLIC ADDRESS SYSTEM

PROCESS PUBLIC ADDRESS SYSTEM

POWER PUBLC ADDRESS SYSTEM

PLANT RADIO SYSTEM

PNEUMATIC DISPATCH SYSTEM

MCCULLOH ALARM SYSTEM

RADIATION ALARM SYSTEM

CASCADE RUTOMATIC DATA PROCESSING SYSTEM

CLASSIFIED COMPUTER SYSTEM 
PORTEMOUTH FACILITIES

Leased 10 USEC

EACLILITY

$x-220-N$

$X-220 . P$

$X-220-R$

$X-220.5$

$x-230$

$x-230-A$

$x-230-8$

$x-230-0$

$X-230-0$

$X \cdot 230-E$

$X \cdot 230-F$

$X-230-G$

$x-230-4$

$X \cdot 230,49$

$x \cdot 230 \mathrm{~N} 2$

$x-230-13$

$X \cdot 230.14$

$x-230-55$

$x \cdot 230-56$

$\mathrm{X}-230-\sqrt{7}$

$x-230.58$

$x \cdot 230-18$

$X-230-K$

$X-230-L$

$x \cdot 232 \cdot \hat{A}$

$X \cdot 232.8$

$x-232-C 1$

$x \cdot 232-C 2$

\section{DESCRIPTION}

SECURITY ALARM AND SURVEILLANCE BYSTEM MAINTENANCE WORK AUTHORIZATION AND CONTROL SYSTEM PUBLC WARNING SIREN EYSTEM

POWER OPERATIONS SCADA SYSTEM

WATER SUPPLY UNE

GANITARY AND FIRE WATER DISTRIBUTION SYSTEM

SANITARY SEWERE

GTORH WATER SEWERS

SOFTEN WATER DISTRIBUTION SYSTEM

PLANT WATER SY8TEM (MAKEUP TO COOLING TOWERB)

RAW WATER SUPPLY LINES

RCW EYSTEM

FIRE WATER DISTRIBUTION SYSTEM

ENVIRONMENTRL MONITORING STATION

SOUTH HOLDING POND EFFLUENT MONITORING STATION

WEET ENVIRONMENTAL MONITORINO ETATION

ENVIRONMENTAL AIR MONITORINQ STATION

WEST HOLDING POND \& ENVIRONMENTAL SAMPLING BUILDING NORTHEAST HOLOING POND \& MONITORINO FACILTY

EAST HOLDINO POND \& MONITORINO FACILI::

ENVIRONMENTAL STORAGE EUILDINO

NORTH ENVIRONMENTAL SAMPLING STATION

SOUTH HOLDING POND

NORTH HOLDINO POND

NITROGEN DISTRIBUTION SYSTEM

ORY AIR DISTRIBUTION SYSTEM

TIE UNE NO. $1 X-342$ TO $X-330$

TIE LINE NO. $2 X-330$ TO $X-326$ 
PORTSMOUTH FACILTIES

LaAxod to USEC

EscivITY

$x-232 \cdot c 3$

$\mathrm{X}-232-\mathrm{C} 4$

$x-232-C 5$

$x-232-0$

$X-232-E$

$X-232-F$

$X-232-G$

$x-240-A$

$x-300$

$x-300-1$

$x \cdot 300-B$

$x+300-c$

$x-326$

$x-330$

$x-333$

$x-334$

$x-342-A$

$X-342 \cdot B$

$x-343$

$x-344-\lambda$

$x-344-8$

$X-501$

X.601-A

$X \cdot 502$

$x-515$

$x \cdot 530-2$

\section{DESCRIPTION}

TIE UNE NO. $3 \times .330$ TO $\times .333$

TIE LINE NO. $4 \times-326$ TO $X-370$

TIE LINE NO. $5 \times 343$ TO $\times .333$

STEAM AND CONDENSATE SYSTEM

FREON DISTRIBUTION LUNES

FLUORINE DISTRIBUTION SYSTEM

SUPPORTS FOR DISTRIBUTION LINES

RCW SYSTEM (CATHODIC PROTECTION)

PUANT CONTROL FACILITY

PROCESS MONITORING BUILDING

PLANT CONTROL FACILITY CARPORT

EMERGENCY ANTENNA

PROCESS BUILDING (NOTE i)

PROCESS BUILDING

PROCSSS BUILDING

TRANSFORMER CLEANING BUILDING

FEED, VAPORIZATION AND SAMPLING FACILTTY

FLUORINE STORAOE BUILDING

FEED, VAPORIZATION AND SAMPLING FACIUTY

UFE SAMPLING FACILITY

MAINTENANCE STORRGE BUILDING

SUBSTATION

SUBSTATION

SUBSTATION

330 KV TIE LINE

SWTCH YARD 


\section{PORTSMOUTH FACILITIES}

Lassad to USEC

EACILITY

$x-530-8$

$x-530-c$

$X-530-0$

$X \cdot 530-E$

$X .530-F$

$x-530-6$

$x-533$

$x-533-x$

$X-533-B$

$X-533-C$

$X .533-D$

$X-533-E$

$X-833-F$

$x-533-H$

$x-540$

$x-600$

$x-800-A$

$X-800-B$

$\mathrm{x} \cdot 800-\mathrm{C}$

$x-805$

$x \rightarrow 005-A$

$x-605-H$

$x \cdot 605-1$.

$x-805-5$

$x-808$

$x-608-8$

$X-608-B$

$X-611$

\section{DESCRIPTION}

SWITCH HOUSE

TEST \& REPAIR FACIUTY

OIL HOUSE

VALVE HOUSE

VALVE HOUSE

GCEP OIL PUMPING GTATION

TRANSFORMER STORAGE PAD

SWITCH YARD

SWITCH HOUSE

TEST \& REPAIR FACIUTY

OIL HOUSE

VALVE HOUSE

VRLVE HOUSE

GAS RECLAIMING CART GARAGE

TELEPHONE BUILDING

STEAM PLANT

COAL PILE YARD

STEAM PLANT BHOP

ASH WASH TREATMENT BUILDINO

SANITARY WATER CONTROL HOUSE

SANITARY WATER WELLS

BOOSTER PUMP HOUSE AND APPURTENANCES

CHLORINATOR BUILOINO

DIESEL GENERATOR BUILDING

RAW WATER PUMP HOUSE

RAW WATER WELLS (I TO 4)

RAW WATER WELLS (5 TO 15)

WATER TREATMENT PLANT AND APPURTENANCES 
$x-611-8$

$x-691-0$

$x-619-0$

$x-612$

$x-614-4$

$X-614-6$

$X-61 \div D$

$X-514-P$

$X-616$

$x-517$

$x-618$

$x-621$

$x-626-1$

$x-626-2$

$x-630-1$

$x-530-2 A$

$x-630-2 B$

$x-630-3$

$x-633-1$

$x-522-24$

$x-633-2 E$

$x-633-2 C$

$x-633-2 D$

$x-540-1$

$x-640-2$

$x-700$

$x-700-A$
DESERTHAN

SLUDGE LAGOON

FILTER BUILDING

RECARBONIZATION INSTRUNENT EUILDING

ELEVATED WATER TANK

SEWAGE PUMPING STATION

SEWACE LIFT STATION

SOUTH SEWAGE LIFT STATION

NORTHWEST SEWAGE LIFT STATION

LQUID EFFLUENT CONTROL FACILITY

SOUTHIHOLDING POND AND PH CONTROL FACILITY

NORTH|HOLDING POND STORAGE BUILDING

COAL FILE RUNOFF TREATMENT FACILITY

RECIROULATING WATER PUMPHOUSE

COOLING TOWER

RECIROULATING WATER PUMPHOUSE

COOUNE TOWER

COOLING TOWER

ACID HANDLINE STATION

RECIRCULATING WATER PUMFHOUSE

COOLINS TOWER

COOLINE TOWER

COOUNG TOWER

COOLING TOWER

FIREWATER PUMP HOUSE

ELEVATED WATEF TANK

CONVERTOR SHOP AND CLEANING SUILDING

AIR CONSITIONING EQUIPMENT EUILDING 


\section{PORTSMOUTH FACILTIES \\ Leased to USEC}

EAClULTY
$x-701-A$
$x-701-D$
$x-705$
$x-705-D$
$x-710$
$x-710-A$
$x-710-B$
$x-720$
$x-720-A$
$x-720-B$
$x-720-C$
$x-729$
$x-740$
$x-741$
$x-742$
$x-743$
$x-744-B$
$x-744-H$
$x-744-J$
$x-744 L$
$x-744-W$
$x-745-B$
$x-746-D$
$x-745-F$
$x-74 B$
$x-747-A$
$x-747-B$
$x-747-C$

DESERIETION

LIME HOUSE

WATER DEIONIZATION BUILOING

DECONTAMINATION BUILDING (NOTE 2)

HEATING BOOSTER PUMP BUILDING

TECHWICAL SERVICES BUILDING

TECHNICAL SERVICES GAS MANIFOLD SHED

EXPLOSION TEST FACILTY

MAINTENANCE \& 8TORES BUILDING

MAINTENANCE AND STORES BUILOINO GAS MANIFOLD SHED

RADIO BASE STATION BUILDING

PAINT \& OIL STORAGE BUILDING

RADIATION INSTRUMENT CALIBRATION FACILITY

WASTE OIL STORAGE FACILITY

OIL DRUM STORAGE FACILITY

GAS CYLINDER STORAGE FACILITY

LUMBER STORAGE SHED

SALT STORAQE BUILDING

BULK STORAGE BUILDING

BULK STORAGE BUILDING

STORES AND MAINTENANCE

SURPLUS AND SALVAGE WAREHOUSE

TOLL ENRICHMENT PROCEES GAS YARD - UEA

CYLNDER STORAGE YARD

NORTH PROCESS GAS STOCKPILE YARD

MATERIALS RECEIVING \& INSPECTION BUILDING

MATERIAL STORAGE YARD

MATERIRL STORAGE YARD

MATERIAL STORAGE YARD 
EAClUITY

$x \cdot 747$ )

$X-747-E$

$X-747-F$

$X-747-J$

$x-748$

$x-750$

$x-750-A$

$x-760$

$x-1000$

$x-1007$

$x-1020$

$x-1107-A$

$x-1107-8$

$x-1107 \cdot 8 p$

$X-1107-0$

$x-2200$

$x \cdot 2202$

$x-2204$

$\mathrm{X}-2207 \mathrm{~A}$

$x-22070$

$x-2208$

$x-2210$

$x-2215-A$

$x-2275-8$

$x-2215-C$

$X-2220-C$
DESCRIPTION

MATERIAL STORLOE YARD

MATERLAL STORAGE YARD

MISCELLANEOUS MATERLAL STORAGE YARD

DECONTAMINATION BTORAGE YARD

TRUCK BCALE FACILTTY

MOBILE EQUIPMENT HAINTENANCE SHOP

GARAGE STORAGE BUILDINO

CHEMICAL ENGINEERINO BUILOING

ADMINIBTRATION BUILOING

FIRE STATION

EMEROENCY OPERATIONS CENTER (EOC)

ADMINISTRATIVE PORTAL

INTERPLANT PORTAL

AONINISTRATIVE PORTAL

NORTHEAST PORTAL

SITE PREPARATION, GRADING, ANO LANDSCAPING

ROADS (GCEP)

GCEP RAILROADS

PARKING LOT

PARKING LOT

SECURITY FENCE

SIDEWALKS

UNDERGROUND ELECTRICAL DISTRIBUTION TO PROCESS

EUILDINGS

ELECTRICAL DISTRIBUTION TO AREAS OTHER THAN PROCESS

BUILDINGS

EXTERIOR LIGHT FIXTURES

FIRE AND SUPERVISORY ALARM SYSTEM 
PRTSMOUIHFECTLITIES

Leased to USEC

FACILITY

$x-2220-0$

$x-2220-L$

$X-2220-N$

$x-2230-\alpha$

$x-2230.3$

$X-2230-C$

$X-2230-F$

$X-2230-G$

$X-2230-H$

$x-2230 \mathrm{w}$

$X-2230-T$

$x-2232-\hbar$

$x-2232-5$

$X-2232-D$

$x-2232-\varepsilon$

$x-3000$

$x-5000$

$x-5001$

$x-5001-A$

- $X-5001-B$

$x-5015$

$x-6000$

$x-6001$

X-6001-A

$x-6609$

$x-6613$

\section{DESCRIPTION}

TELEPHONE SYSTEM

CLASSIFIED COMPUTER SYSTEM

SECURITY ACCESS CONTROL AND ALARM SYSTEM

SANITARY WATER DISTRIBUTION SYSTEM

GCEP SANITARY SEWERS

STORM SEWERS

RAW WATER SUPPLY LINE

RECIRCULATING WATER SYSTEM

FIRE WATER DISTRIBUTION SYSTEM

LUQUID EFFLUENT SYSTEM

RECIRCULATING HEATING WATER SYSTEM

NITROGEN DISTRIBUTION SYSTEM

DRY AIR DISTRIRUTION SYSTEM

STEAM AND CONDENSATE SYSTEM

SUPPORTS FOR DISTRIBUTION LINES

ELECTRRONICS MAINTENANCE BUILDING

GCEP SWITCH HOUSE

SUBSTATION

VALVE HOUSE

OIL PUMFING STATION

HV ELEGTRICAL SYSTEM

GCEP CDOLING TOWER PUMP HOUSE

COOLING TOWER

VALVE HOUSE

RAW WATTER WELLS

SANITARY WATER STORAGE TANK 
EScluTY

$X$ RS94-E

$X-8814-G$

$X \times 894 \mathrm{H}$

$x+8014 \mathrm{~J}$

$x-8818$

$x-\infty 643$

$x-\cos 44$

$x \cdot 7721$

XT.801

\section{QESCRIPTION}

SEWAGE UFT STATION SEWAGE LIFT STATION SEWAOE UFT STATION SEWRQE UFT STATION SEWAGE TREATMENT PLANT FIRE WATER STORAGE TANKB $\$ 1 \& \$ 2$ FIRE WATER PUMP HOUSE MAINTENANCE STORE\& TRAINING BUILDING (TRAINING) SOUTH OFFICES BUILDING

NOTE 1: The seven araas containing RCRA wasto in X-32B will not be leasud.

NOTE 2: The oxide convarsion arep (X.705E) will not be leased. 


\section{PORTSMOUTH FACILITIES \\ Retainod BY DOE}

EACIIITY

$X-208-B$

$x-230-M$

$x-239 \times 1$

$x-231-8$

$x-235$

$x \cdot 237$

$x-342 \cdot c$

$x-344-c$

$X-344-D$

$X-344-E$

$X-344-F$

$X \cdot 345$

$X-811 A$

$x-615$

$x-622$

$x-522-T$

$x+823$

$x+824$

$x-824-1$

$X-701-B$

$X-701-C$

$X-701-E$

$x \cdot 705-k$

$x-705-8$

$x-734$

$x-735$

$x-735-A$

$x-736$

$x-744-G$

$x-744-k$

$x-744-N$

$X-744 P$
DESCRIPTION

SNM SECURITY FENCES $X-326$ AND X-345

CLEAN SITE NE OF XT-801

BOUTHEAST OIL BIODEGRADATION PLOT

SOUTHWEGT OIL BIODEGRADATION PLOT

SOUTH GROUNO WATER COUECTION SYSTEM

LTTLE BEAVER OROUND WATER COLLECTION SYSTEM

WASTE HF NEUTRALIZATION PIT

HF STORAGE BUILDING

HF NEUTRALIZATION PIT

GAS VENTILATION STACK

SAFETY BUILDINO

BNM GTORAGE BUILDING

LIME SLUOGE LAGOONS (NORTH. MIDDLE. SOUTH)

OLD BEWAGE TREATMENT PLANT

SOUTH GROUND WATER TREATMENT BUILOING

CARBON FILTRATION (X-705 SUMP WATER)

NORTH GROUND WATER TREATMENT BUILDING

LITTLE BEAVER GROUNDWATER TREATMENT FACILTY

UTTLE BEAVER GROUNDWATER TREATMENT FACILITY

(DECONTAMINATION PAD)

HOLDING POND (DRAINED)

NEUTRALIZATION PIT AND TANK

NEUTRALIZATION BUILDING

INCINERATOR

CONTAMINATED BURNABLE STORAGE FACIUTY

OLD SANITARY LANDFILL

SANITARY LANOFILL

LANOFILL UTIUTY BUILDING

WEST CONSTRUCTION SPOILS LANOFILL

BULK STORAGE BUILDING

WAREHOUSE $K$ (NOTE 3 )

WAREHOUSE $N$ - NON UEA

WAREHOUSE P - NON UEA 
EACHITY

$x .7440$

$x-7448$

$x-744-T$

$X-744-U$

$X-744 Y$

$X-746-C$

$X \cdot 745-E$

$X-745-H$

$x-717-G$

$X-747-H$

$X \cdot 748$

$x-740-A$

$x-751$

$x-752$

$x-770$

$X-1107 \cdot E(V \& P)$

$X \cdot 1907 \cdot F$ (V\&P)

$X \cdot 2207-E$

$X-2207-F$

$X-2230-M$

$X-2230-N$

$x-3001$

$x-3002$

$x-3012$

$x-3346$

$x \cdot 7725$

$x-7725-A$

$x-7728$

$X-7727$

$X-7745-R(N)$

$X-7745-R(S)$

$X T-847$

Z-SWMU-QUAD-IV

Z-BWMULQUAD-IV

Z-SWMU-X70

Z.SWMU-X710

Z-SWMU-X734-A

\section{DESSRIPTION}

WAREKOUSE Q - NON UEA

WAREHOUSE S - NON UEA (NOTE 3)

WAREHOUSE T - NON UEA (NOTE 3)

WAREHOUSE U - NON UEA (NOTE 3)

WASTE QTORAGE YARD

WEST DEPLETED STORAGE YARD

NW DU STORAGE YARD

DU STORAGE YARD (NOTE \&)

NORTHEAST CONTAMINATED STORAGE YARD

NORTHWEST SURPLUS AND SCRAP YARD

SOUTH CONTAMINATED MATERIALS STORAGE YARD

SOUTH CLASSIFIED BURIAL YARD

MOBILE EQUIPMENT GARAGE, PARKING LOT, AND LANO ADACENT

WAREHOUSE

MECHANICAL TEST

NORTHWEST VEHICLE ANO PEDEGTRIAN PORTALB

SOUTH VEHICLE AND PEDESTRLAN PORTALS

NORTHWEST PRRKUNG LOT

SOUTH PARKING LOT

HOLDING POND \#1

HOLOING POND

PROCESE BUILDING

GCEP PROCESS EUILOING *2

PROCESS SUPPORT BUILDING

FEED AND WTHDRAWAL FACIUTY, PARKING LOTE, AND LAND BETWEEN BUILDINGS

RECYCLEI ASSEMBLY BUILDING, PARKING LOTS AND LAND

ADJACENT TO 7725

WASTE R CCOUNTABILITY FACILTY, PARKING LOTS AND LAND

ADJACENT TO T725-A

CENTRIFUGE TRAINING AND TEST FACILITY

INTERPLANT TRANSFER CORRIDORS

RECYCLEIASSEMBLY STORAGE YARD-NORTH (NOTE 5)

RECYCLEIASSEMBLY STORAGE YARD -SOUTH

CONSTRUCTION WAREHOUSE (NOTE E)

SOUTHERN END OF RAILROAD SPUR WHICH IS USED AS DRUM STORAQE RREA

CHEMICAL AND PETROLEUM CONTAINMENT TANKS EAST OF $X-6330$ NORTHEAST OIL BIODEGRADATION PLOT AREA, WHICH WAS FORMERLY USED FOR THE DISPOSAL OF X.815 SLUDGE INACTIVE "HOT PIT IN THE AREA OF X710 THAT WAS ONCE USED FOR THE STORAGE RADIOACTIVE WABTEWATER INACTIVE CONSTRUCTION SPOILS DISPOSAL AREA 
PORTSMOUTK FACIUTIES

Rotalned BY DOE

ESCIUITY DEECRIPTION

Z-SWMU.X734.8 INACTIVE CONSTRUCTION SPOILS DIBPOSAL AREA Z-SWMU-X744 RETRIEVABLE WASTE STORAGE AREA

$2 \cdot 8$ WhiU.XXXx SOUD WASTE MANAGEMENT UNITB, AS IDENTIFIED ON PORTSMOUTH ENVIRONMENTAL INFORMATION MANKOEMENT SYQTEM DRAWING, PRINTED 2/9/93.

NOTE 3: DOE will leaxe to USEC the nisl of those warehousex $(X \cdot 744-K,-S$, $-T$, or $-U)$ to be vacaled.

NOTE 4: Thls arex (approximately 5 acres) has been identified as a potenllal slle for DU cyllndor Slorage for USEC.

NOTE 5: USEC can conthus to use this spact as lonp as needod or unill an altemative storage area is mado aveilable by DOE.

NOTE 8: DOE will offor this facility to USEC for lease no tater than Juty 1, 1893. USEC can begh site speciflc design and preparation (nol to disturt DLA). DOE wall allempt to expedlle removal of DLA. 
DOE/ORO - 2051 


\author{
A Transitional Program for Regulation \\ of the Gaseous Diffusion Plants at \\ Paducah, Kentucky, and Portsmouth, Ohio
}

\title{
APPENDIX C
}

\section{REGULATORY OVERSIGHT PROGRAM}

July 1, 1993 to March 3, 1997

\section{Prepared by}

Regulatory Oversight Office

for

U. S. Department of Energy

Oak Ridge Operations

Oak Ridge, Tennessee 37830 


\section{APPENDIX C}

Joint Statement of Understanding between The Nuclear Regulatory Commission and The Department of Energy on Implementing The Energy Policy Act Provisions on Regulation of Gaseous Diffusion Uranium Enrichment Plants, Signed December 20, 1993, Ivan Selin and Hazel R. O'Leary. 


\section{memorandum}

ORlt : DE? ? ? $\$ 993$

REPLYTO OfFice of Nuclear Energy

SUENES- Joint Statement of Understanding Between the Department of Energy and the Nuclear Regulatory Conmisston

10: J. H. Parks

Oak Ridge Operations office

Attached is a copy of the signed Joint Statement of Understanding between the Department of Energy and the Nuclear Regulatory Commission for your information and files.

This joint statement addresses matters relating to the process by which the Commission will assume and the Department will relinguish responsibility for regulatory oversight for the Department facilities leased by the United States Enrichment Corporation as specified by the Energy Policy Act of 1992 .

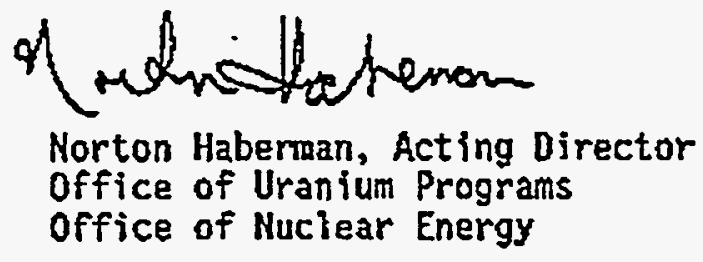

At tachment

cc w/attachment:

D. A. Dreyfus, NE-1

J. G. Keliher, IS-1

G. L. McFadden, SA-1

R. R. Nordhaus, EC-1

T. J. O'Toole, EH-l

E. C. Brolin, NE-2

R. H. George, NE-32

C. A. Caves, NE-32

T. A. RoTlow, EH-14

J. D. Jackson, $\mathrm{OR}$

E. H. Glllespie, PORTS

J. C. Hodges, PGDP 


\begin{abstract}
JOINT STATEMENT OF UNDERSTAKDING BEIWEEN THE WUCLEAR REGULATORY COMIISSION AWD WHE DEPARTMENT OF ENERGX ON IMPLEMENTINE THE ENERGY POITCY ACT

PROVISIONS ON THE REGUIATION OF GASEOUS DIFEUSION URANIUN ENRICHNENT PIRNTS
\end{abstract}

By Detober 24, 1994; pursuant to Title XI of the Energy Pollcy sct of 1992 (the ifctx), the Nuclear Regulatory commission (the "NRC") Is directed to establish standards (the "standards") for regulation of the gaseous diffusion uranium enrichment facilities (the "facilities" or "GDPs") owned by the Department of Energy (the "DOE") in order to protect the public health and gafety from radiologlcal hazard and provide for the common defense and security. Title XI of the Act also specifles that NRC establish in certification process to ensure that the U.S. Enrichment Corporation (the "Corporation"), which is to lease the facilities from DOB, complies with the NRC atandards. After NRC establishes the standards, the corporation is reguired to apply at least annually to kRC for a certif licate of compliance with the standarda. The reghirement for a certificate of compliance is in lieu of any reguirement for a license for the facilities leased by the corporation. The Act also provides that the corporation may not operate the facilities unless the NRC makes a determination that the facilities are in wompliance with the MRC standards to be established by october 24. 1994, or NRC approves a plan prepared by DOE for achleving compliance with such standards.

Title XI of the Aet also provides that the NRC, in consultation with the Environmental Protection Agency (the "EPA"), shall review the operations of the corporation to ensure that public health and safety are adequately protected. Further, Title IX of the Act provides the corporation shall lease the gaseous diffusion facilities of DOE at paducah, Kentucky and portsmouth, ohio for a six-year period, beginning July 1, 1993.

Pursuant to the Atomic Energy act of 1954 , as amended, including in particular the provisions of the Energy Policy hct of 1992 on regulation and certification as generally described above, NRC and DOE are issuing this joint statement of understanding (the "Joint statement") to adoress matters relating to the process by which NRC will assume, and DOE will relinguish at the time and to the extent provided by law, responsibility for regulatory oversight under the fot for the DOE faclidties leased by the corporation as specified by the Energy Policy Act of 1992. In view of the explicit framework of the act under which NRC is to assume responsibility for the radiological protection of the public health and safety and the comon defense and security after NRC standards are established and become effective for that purpose, this Joint statement of Understanding identifles certain responsibilitles of NRC and DOF with respect to the process, provides for cooperation between NRC and DOE necessary to the successful implementation of the process, and serves such other purposes as may be related thereto. 
In NRC reguesting ard DOE agreeing to supply information, DOE and NRC understand that the purpose is to help establish vRC's regulatory framiework under the dct, not for WRC to establish overslght before NRC assumes regulatory furlsdiction over the faclitities.

1. Under the fot, by October 24, 1994, NRC is directed to establish its standards to protect public health and safety and comon defense and security for the facilities leased to the corporation.

2. In order to support WRC in developing the standards laentified in paragraph 1 , DOE will supply available information, permit site visits, and provide other similar assistance in Eupport of KRC standards development in response to NRC's request. In : particular, DOE will provide any available description of the Safety Basis and Framework for DOE oversight of the Gaseous Diffusion plants, including:

(i) A description of the safety analyses, operational safety reguirements, and the bases for maintaining the safety basis for the GDPs. The desoription will include the Information which DOE relies on to demonstrate that the current regulatory base is adequate to protect the public health and safety and provide for the comoon defense and seourity. .

(1i) A description of the operational requirements, consisting of the basic operational satety objectives, implementation requirements, implementation measures, status of conformance with the implementation requirements, and the corrective actions being taken to address non-conformances.

(iii) A description of DOE's program for continuing regulatory oversight over the GDPs, including a description of the program for compliance reviews and audits, followup actions to assiure that audit findings are addressed, and the status of open audit findings.

At NRS's request, DOE will supply copies of applicable DoE orders, other documents referenced in the aforementioned descriptions, and such other documents as are necessary to support NRC's standards development.

DOE will also permit NRC to locate observers at the facilities on or after July 1, 1993, to obtain information and knowledge that may be useful to $\mathrm{KRC}$ in developing or implementing its standards. Interlm guidance for the NRC observers will be established by the DOE Regulatory Oversight Manager and the NRC covering the period before NRC assumes regulatory jurisdiction over the facilities.

3. As indicated above, the Energy Policy Act amendments to the Atomic Energy Act of 1954 condition NRC regulation (through the annual certification process) of the facilities leased to the corporation on the promulgation of the new NRC standards. JRC anticipates that it will require the corporation to rile the first 
annual application for a cortifioate of compliance within Bix (6) months after promuigation by NRc af the standards. Mhus, until such time as NRC has promulgated its standards and they have become effective and the ilist certification process based on NRC standards has been completed, DOE w11 continue to exerelso its public health and safety and common defense and security regulatory oversight over the operation of the facilitien.

4. viring the entire perlod that the facilities are in operation, and thereafter as long as necessary, on a full cost reimbursable basis from the corporation, DoE will retain responsibility for all access authorization programs with respect to the facilities leased by the corporation and the corporation itself. DOE will be responsibie for the administrative determinations relating to grasting, suspending, adjuaicating; ox: denying a security clearance, and for reinvestigating an individual's background for continued access.

5. At all times during the period the faclitties are in operation by the corporation after NRC assumes responsibility for regulatory oversight, NRC wilI be responsible for granting security facility approvals and for establishing an information security program to ensure that Restricted Data. Including both information and equipment, is appropriately classified and protected with respect to the facilities leased by the corporation and the corporation itself.

6. During the entire period that uranium enriched to 20 percent or more $U^{235}$ is located at the Portsmouth facility. DOE will retain title to and possess such uranium and will be solely responsible for providing for, establishing and maintaining nuclear safety, safeguards and security controls applicabla to such uranium.

This Joint staterent is not a regulation and is not intended to create or alter legal reguirements or obligations of NRC, DOE, the corporation or any other interested person.

For the Nuclear Regulatory comission,

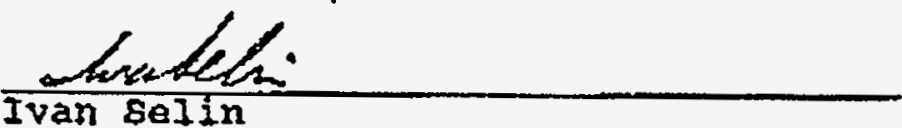

Ivan SeIin

Chairman, Nuclear Regulatory Comaistion

Dated: December $7,1993$.

For the, Departmgnt of Energy.

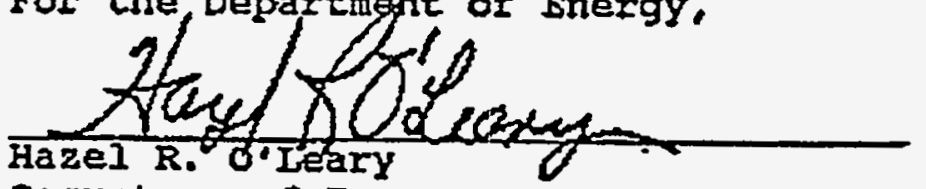

Secretary of Energy

Dated: Dacamber 20, 1993. 
A Transitional Program for Regulation of the Gaseous Diffusion Plants at

Paducah, Kentucky, and Portsmouth, Ohio

\section{APPENDIX D}

\section{REGULATORY OVERSIGHT PROGRAM}

July 1, 1993 to March 3, 1997

Prepared by

Regulatory Oversight Office for

U. S. Department of Energy Oak Ridge Operations

Oak Ridge; Tennessee 37830 


\section{APPENDIX D}

Memorandum of Agreement Establishing Guidance for NRC Inspection Activities at the Paducah and Portsmouth Gaseous Diffusion Plants between Department of Energy Oversight Manager and Nuclear Regulatory Commission, Signed August 11, 1994, J. Dale Jackson and NRC, which establishes guidance for NRC observation activities at PGDP and PORTS. 


\author{
AGREEMENT ESTABLISHING GUIDANCE FOR NRC INSPECTION \\ ACT IVITIES AT \\ THE PADUCAH AND PORTSHOUTH GRSEOUS DIFFUSION PLANTS \\ BETHEEN \\ DEPARTHENT OF EKERGY REGULATORY OUERSIGHT MANAGER \\ ANO \\ NUCEEAR REGULATORY COMHISSIOA
}

I. Authority

The United States Department of Energy (DOE) and the United States Huclear Regulatory Cormission (NRC), Region III, enter into this Agreesent under the authority of Section 1701 (c) (4)B of the Atomic Energy ACt (RER) of 1954, as amended and the Joint statement of Understanding between the Nuclear Regulatory Contmission and the Department of Energy on Implementing Energy Policy Act Provjsjons on Regulation of Gaseous Diffusion Uraniun Enrichment Plants (Joint Statement), 59 Fed. Res 4729 (Febrtary 1, 1994).

II. Backoround

The Atomic Energy Act of 1954, as amended by the Energy Policy Act of 1992 (42 U.S.C. 2297 et seq.), created the United States Enrichment Corporation (USEC), a government corporation for the purpose of managing and operating the uranium enrichment enterprise previously owned and operated by the DOE. The Energy Policy Act (the ACt) 2150 required that by October 24, 1994, the HRC establish its standards for the regulation of the gaseous diffusion plants leased by the USEC in order to protect the public health and safety and to provide for the compon defense and security. After these standards are promulgated, the USEC is required to apply at least annually for a certificate of compl lance with the standards. Until such time as the NRC assures regulatory jurisdiction at the gaseous diffusion plants (GDPS), DOE will exercise nuclear safety and safeguards and security oversight authority at the leased portion of the gaseaus diffusion plants located in Paducah, Kentucky, and Piketon, Ohio. The regulatory framework of DOE's authority is contained in the - Regulatory Oversight Agreement, Exhibit D to the Lease Agreement between DOE and USEC dated July 1, 1993. Pursuant to the Jolnt Statement, it is agreed that the KRC will focate observers at the facilities on or after July 1, 1993, to obtzin information znó knowledge that may be useful to NRC in develaping or implementing 1ts standards. The Joint statement also provides that interim guidance for the NRC inspectors/observers will be established between the DOE Regulatory Oversight Manager and the HRC covering the period before NRC assumes regulatory jurisdiction over the facilities. 
NRC/DOE AGREEMENT

\section{Seope}

A. This Agreement defines the way in which DOE and NRC will caoperate to facilitate the NRC's obtzining of information and knowledge regarding the gaseous diffusion plants and USEC's operation thereof through routine and special inspection activities during the interin period before NRC assumes regulatory responsibility. The ARC inspection activities will be conducted for the purpose of gathering information useful to the NRC in developing the 10 CFR Part 76 standards and making the initial certification deciston for the GOPs as directed in the Atonic Energy Act of 1954, as amended. This Agreement does not apply to investigations or inquiries conducted by DOE.

B. For the purpose of this Agreement, the ter "inspection" as appl ied to DOE shall mean the examination, revies, or eyaluation of any program or activity of the USEC with respect to: (1) the effectiveness of the program or activity in ensuring that the health and safety of the public and plant personnel are adequately protected: (2) the safe operation of the facjitities; (3) compliance with any applicable DOE Nuclear 5afety and Safeguards and Security Requirements as defined in the Regulatory Oversight Agreenent (ROR). With respect to the NRC, the term "inspection" is defined as the onsite or Regional/Headquarters Office revjew of any program or activity of USEC with respect to prospective compliance with proposed NRC standards for the regutation of the leased portions of the gaseaus diffusion plants.

c. Nothing in this Agreement is intended to restrict or expand the zutfiority of DOE or to affect or otherwise alter the terms of the ROR.

D. Nothing in this Agreement confers upon the NRC Inspectors authority to (1) interpret or modify DOE requirements imposed on the USEC; (2) take enforcement actions; or (3) direct or recommend gaseous diffusion plant employees to take or not to take any actions. Authortity for 271 such actions is reserved exciusively to DOE, until the KRC assumes regulatory oversight for the leased portion of the gaseous diffusion $p$ lants in accordance with the Act.

E. Nothing in this agreement is fntended to restrict or otherwise 7 init the authority of the NRC to exercise its fuli regulatary authority, including both -inspection and enforcement authority, at such time as NRC assumes regulatory autfority over the leased portion of the gaseous diffusion plants in accordance with Title II of the Atomic Energy Act of 1954, as zmended.

F. Under this Agreement, up to three NRC Resident Inspectors may be located at each gaseous diffusion plant site with visits from Regional and Headquarters staff to become familiar with plant operatians. 
NRC/DOE AGREEKENT - 3 -

IV. DOE's General Responstbilities

DOE is responsible for conducting nuclear safety and safeguards and security inspections of the leased portions of the gaseous diffusion plants to ensure that the plants are designed, constructed, tested, operated, maintained, and decomissioned in accordance with DOE regui atory requirements. These inspections are conducted in accordance with the DOE Regulatory Oversight Inspection and Enforcement Manual (Manual) using personnel appropriately quatified and trained to perform the necessary tasks. Only the DOE may take approprizte enforcement actions for alj inspections conducted under this Agreement.

Y. $\quad \mathrm{MRC}^{\prime} 5$ General Responsibilittes

A. The HRC, through its Resident and other inspectors, will conduct inspections and make observations for the purpose of obtaining information and knowledge of the gaseous offfusion plants and USEC's operation thereof. Such Inspections shall be coordinated with the authorized DOE representative to ensure that both the scope and findings of the inspections are clearly communicated.

B. NRC activities will be performed in accordance with Federal standards and requirements and DOE practices, with no undue burden on the DOE or the USEC.

VI. Implementation

The BOE and KRC agree to work in concert to ensure that the following staffing, inspection and enforcement, communications and information exchange, and canflict resolution protocol regarding tho NRC Inspector activities are followed.

A. Staffing

1. The NRC wi17 select its inspectors in accordance with fts own procedures and qualifications.

2. The MRC is responsib]e for obtaining security clearances for its inspectors.

3. The ARC is responstble for ensuring that NRC Inspectors coaply with safety requirements established by the USEC. The HRC is not required to follow USEC's fitness-for-duty program but will instead follow its om internal fitnessfor-duty program. DOE is not responsible for ensuring access or space for NRC personnel. USEC is responsible for easuring access and space for NRC personne?.

4. NRC and Office of Covernment Ethics Confict of Interest regulations will be in effect for WRC Inspectors conducting inspection activities related to the Gaseous Diffusion Plants. 
DOE/ORO - 2051

NRC/OOE AGREEHENT - -

B. Inspections and Enforcement.

1. The NRC Inspectors' activfties are intended to provide information for use in developing standards for the gaseous diffusion plants and in determining whether to issue the initial certificate and/or approve a compliance plan $1 \pi$ accordance with the Act. NQC inspection activities are also intended to assist USEC in becoming familiar with NRC practices.

2. The NRC Inspectars are responsible for adhering to safety requirements imposed by USEC related to personal safety and radiological protection.

3. The NRC Inspectors may accompany the DOE Site Safety Representative during inspections, inspection entrance and exit interviews, and enforcement meetings.

4. The DOE will provide the KRC with a copy and current updates of the COE Manual.

5. Safety/technical allegations or concerns received by the NRC Inspectors will be provided to the DOE for processing in accordance with DOE procedures, including DOE procedures for confidential sources.

6. If an NRC Inspector identifies situations with inmediate safety significance, he or she will immediately communicate this information to the USEC and the DOE Site Safety Representatives. It is essential that this information be discussed with a DOE site representative immediately upon discovery so that DOE may take prompt action as dictated by the situation. If the DOE Site Safety Representatives are ynayailable, the NRC Inspector will transmit this information immedfately to the DOE Regulatory Oversight Hanager or hì designee.

7. DOE will receive copies of all written cormunications between USEC and NRC relating to activities of HRC Inspectors under this agreement.

8. If potential violations of DOE regulatory requirements are identified as a result of the NRC's inspection attivities, DOE may take appropriate enforcement action as set forth in Appendix $B$ of the ROA. Enforcement action, if any, will be taken only by DOE.

c. Communications and Information Exchange .

1. The DOE and ARC agree in good faith to make available to each other information within the intent and scope of this Agreement. 
2. The DOE and KRC agree to meet every 6 manths at wutualiy agreeable tikes and locations to exchange infarmation on matters of common concern pertinent to this Agreement.

3. The DOE and ARC agree to consider each other's identified information needs and concerns when deve7oping inspection plans.

4. The NRC will conform to DOE pract jces regarding information disclosure. For instance, the NRC nust abtde by DOE protocol not to publicly disclose DOE inspection findings prior to the release of the DOE inspection report. However, the KRC may discuss with USEC any HRC finding relative to: the deveiopment of 10 CFR Part 76 standards or certification of the gaseous diffusion plants in accordance with the Act, as anended.

5. To preclude dissemination of information which may be exempt from disclosure pursuant to the Freedom of Information Act, the DOE and NRC shaif consult with each other before disclosure of information reiated to this Agreement.

6. The NRC will notify DOE before stationing an NRC Resident Inspector at a site.

VII. Contacts

A. The principal senior management contacts for this Agreement witl be the Director, Diylsion of Radiation Safety and Safeguards, Region III, NRC, and the OOE Regulatory Oversight Hanager. These individuals may designate appropriate staff representatives for the purpase of adrinistering this Agreement.

B. Identification of these contacts is not intended to restrict communication between DOE and KRC staff members on technical and other day-to-day activities.

VIII. Resolution of Conflicts

A. If disagreements or conflicts about matters within the scope of this Agreement arise, DOE and NRC will work together to resolve these differences.

B. Resolution of differences between DOE and NRC staff over the significance of findings will be the initial responsibility of the DOE Regulatory Oversight Hanager.

c. The DOE Office of Chief Counsel, Dak Ridge Operations, witl have the final authority to interpret DOE's regulatory raquirements. 
NAC JOOE AGREEMEKT

$-6-$

Ix. Effective Date, Termtnation, and Modification

This Agreement shall became effective upon signing by the Region III Administrator, HRC, and the DOE Regulatory Oversight Hanager, and shall remain in effect until NRC issues the initial certificate and/or approves a compliance plan, which teralnates this Agreement. A formal review, not less than 6 months after the effective date, wi7l be performed concurrently by the DOE and NRC to evaluate implementation of the Agreement and resolve any problems identified. This Rgreement will be subject to periodic reviews and may be amended or modified upon written agreement by both parties.

x. Separability

If any provision(s) of this Agreement, or tho application of any provision(s) to any person or circurstances, is held invalid, the remainder of this Agreement and the application of such provisions to other persons or circumstances shall not be affected.
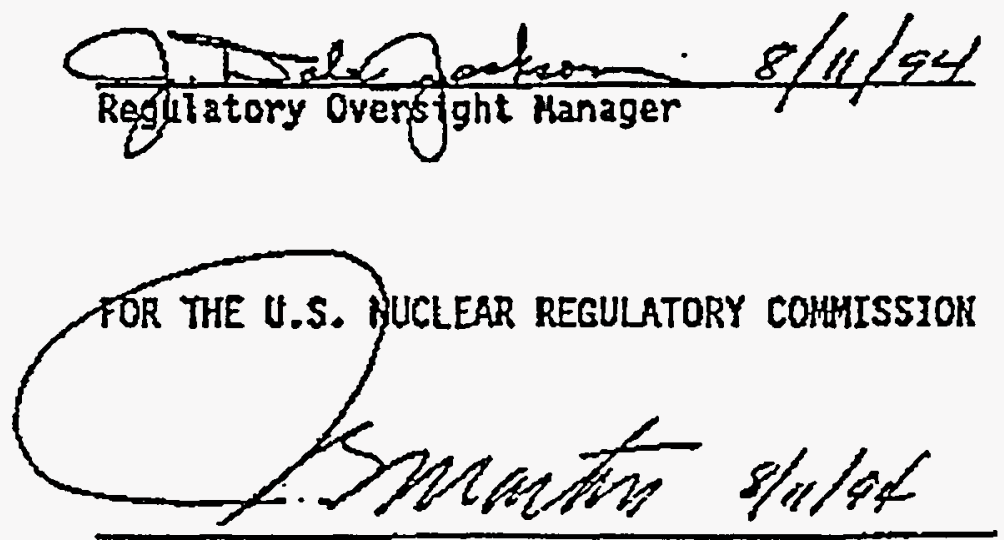

Regional Administrator 
A Transitional Program for Regulation of the Gaseous Diffusion Plants at

Paducah, Kentucky, and Portsmouth, Ohio

APPENDIX E

REGULATORY OVERSIGHT PROGRAM

July 1, 1993 to March 3, 1997

Prepared by

Regulatory Oversight Office

for

U. S. Department of Energy

Oak Ridge Operations

Oak Ridge, Tennessee 37830 


\section{APPENDIX E}

Memorandum of Agreement Relating to the Transfer Functions and Activities from the United States Department of Energy to the United States Enrichment Corporation, Signed December 15, 1994, Hazel R. O'Leary and William H. Timbers, Jr., which relates to the agreement between DOE and USEC in which DOE retains title and control of HEU material until it is blended to less than $10 \%$ of the $\mathrm{U}^{235}$ isotope. 


\section{memorandum}

OATE: Janaury 10, 1995

REPC T TO

ATTH OF:

SUaECT:

TO:
NE-30

Memorandum of Agreement (MOA) Relating to the Transfer of Functions and Activities from the United 5tates Department of Energy (DOE) to the United States Enrichment Corporation (USEC)
Oak Ridge Operations office

Jimite Hodges. Paducah site office

Eugene Gillespie, Portsmouth Site office

Attached for your information and use is a copy of the MOA between DOE and USEC, signed December 15, 1994. I want to thank you, your staff, and the Mart in Marietta Energy Systems, Ins., personnel who helped develop this document and look forward to working with you in implementing the MOA.

Please call me if you have any questions.

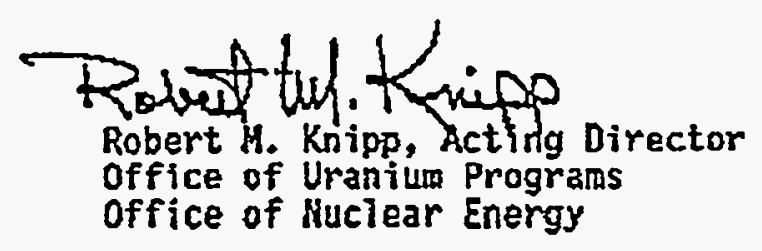

Attachment

cc:

Jim Colsh, NE-13

Doug Newton, ME-13

David Leotta, HR-53I

Ran Personett, $C R-14$

Jil1 Drain, CR-147

Judy Penry, OR

Kancy Fitchpatrick, OR

1/17/95--EF-20:CJL

c wrattachment:

D. L. Mason, MS 7603/3MAIH

J. D. Jackson, EF-20/3MAIN

A. M. LoYe]?, EF-20/3MAIN

T. T. Slack, CC-10/FB 


\section{YEMORAMDUM OF AGREEMENT RELATINE TO THE TRANSFER OF FUTCTIOUS AND ACTIVITIES FROM UWITED STATES DEQARTHEXT OF ENERGY TO TEE UNITED STAIES EXRICEMENT CORPORATION}

This Memorandum of Agreenent is entered into as of the $15^{\text {th }}$ day of December, 1994, by and between the UNITED STRTES DEPARTHENT DF ENERGY ("DOE* or "the Department") acting by and through the Secretary of Energy, and the UNITED STATES ENRICHMENT CORPORATION ("USEC" or "the Corporation"), ecting by and through its Chief Executive officer ("CEO").

\section{RECITRIS}

FHEREAs, Title IX of the Energy Policy Rct of 1992, Fublic Law 102-486 ("Energy Policy kCt"), established OSEC by amending the. Atomic Energy Act of 1954 ("Atomic Energy Act") to add a new Title' II - Dnited States Eurichnent Corporation;

WFEREAS, Section 1300 (b) of the Atomic Energy ACF provides for the transfer of the unexpended balances of appropriacions and other monies available to DOE and accounts receivabie related to functions and activities acguired by USEC from DOE under TitIe IX of the Energy Policy Act;

MEREAS, to effectuate the transfer requirec by section 1308 (b) of the Atomic Energy Act, the Office of Managenent and Budget issued a Jnne 30, 1993; Interin Determination Order authorizing DOE to transfer to USEC a total of approximately \$106.S million in appropriated balances, which DoE transferred to USEC; as well as approximately $\$ 143$ million in net accounts receivablef

WHEREAS, to further resolve matters relating to the transfer of Iunctions and activities, the office of Management and Budget issued a second Interim Determination Order on November 29, 1993 , authorizing DOE to transfer to USEC an additional $\$ 106.5$ million of unexpended balances not authorized or transferred under the - June 30, 1993 Interim Determination Order;

WHERESS, DOE subsequently paid USEC approximately \$52.6 nillion of the $\$ 106.5$ mililon in urexpended balances leaving $\$ 53.9$ million still unpaid;

WHEREas, pursuant to Section 1403 of the Atomic Energy Act, USEC and the Department entered into an egreement, dated Iuly 1 . 1993, (the "Lease") for the lease of portions of two gaseous diffusion plants ("GDP's") owned by DOE and located in piketon, Ohio ("PORTS") and Paducah, Kentucky ("gGDP")i

HrERER, the Lease provided that the Department shali reinoure USEC for certain costs incurred by the Corporation in connection with bringing the GDP's into compliance with certain laws and Iegulations that aze or will be applicable to the GDF's; 
WHEREAS, by letter dated septerber 30, 1993, DOE requested the approval of the Congress to reprogram funds needed to correct identified Occupational safety and Health fact deficiencies at the two leased facilities and to cover certain costs related to nuclear safety oversight and compliance requirements;

MHEREAS, Section 5.1 (b)(ii) of the Iease required the Department to reimburse the Corporation for vork required to obtain an Initial certificate of compliance from the Nuclear Regulatory Comraission ("NRC") or NRC approval of a Department plan for achieving compliance;

WHEREAS, on July 12, 2994, the Board of Directors of USEC: decided to proceed with the commercialization of AVIS;

WHEREAS, Sections 1601(b) and 1602 (b) of the Atomic EnergY kct authorize the transfer from DOE to USEC Of certain rights and property relating to AVIS;

WHEREAS, Section 1401 of the Atomic Energy Act establishes USEC as the exclusive marketing agent on behalf of the United States Government for entering into contracts for providing enriched uranium and uranium enrichment and related services after July 1, 1993, and

WhEREAS, Section 161j. of the Atomic Energy Act authorizes the Department to make such disposition as it deems desirable of radioactive material, the special disposition of which is, in the Department's opinion, in the interest of the national security.

WOW, THEREFORE, under authority of the Energy Polley ket and the Atomic Energy Act, and subject to their provisions, and in order to carry out the mandate congress has given DOE and USEC, to fully satisfy DOE's obligations under Section $1308(b)$ of the Atomic Energy Act, and to resolve certain other issues relating to the transfer of Eunctions and activities from DOE to USaC, the parties bereto agree as follows:

I. AVIIS

A. Termination Costs

(i) USEC shall be solely responsible for all costs, exclusive of internal DOE overhead costs and the cost of work performed by DOE employees, that are associated with the ternination and close-out of the atomic vapor laser isotope separstion ("AVIIS") program up to a maximum of $\$ 40$ million. These costs are limited solely to the termination of AVIIS activities at the Lawrence Livermore National laboratory ("LLNL") site and relocation costs of Martin Marietta Energy Systems, Int. employees from LLNdr back. to Oak Ridge for which DOE is obligated to gay. 
Except as provided in Section I.A. (ii) below, DOE shall remain responsible for all other costs associated xith the termination and elose-out of the AVLIS program.

(id) In addition to tho costs specisied in section I.A.(i), if USEC's use of operation of AVLIS after July 12. 1994 increases the cost, exclusive of internal DOE overhead costs and the costs of work performed by DOE employees, associated with the termination and close-out of the AVLIS program over that wich would have been incurred in the absence of such use or operation, USEC shall be responsible for such increased costa.

B. Decontamination and Decomnissioning Costs

Except as provided in this paragraph, the pepartment shall remain responsible for all costs assoclated with the decontamination and decommissioning, as defined in section 1201 of the Atomic Energy Act, of AVIIS Eacilities. If USEC's use or operation of AVLIS facilities increases the costs paid by the Departraent, exclusive of internal DOE overhead costa and the cost of work performed by DOE employees, for the decontamination and decommissioning of tho BVLIS facilities over that wich the Department would have incurred in the absence of such use or. operation, then USEC shall reimburse the Department for Buch increased costs incurred.

\section{REPROGRBMATE :}

The Department agrees to use its best. efforts to obtain Congressional anthorization for the pending request to reprogram funds necessary to accomplish this Agreenent. UseC vill actively assist the Departrent's efforts to obtain Congressional authorization to reprogram funds necessary to accomplish the purposes of this Agreement.

\section{DETERMINATIOY ORDER}

The Department agrees to satisfy its remaining $\$ 53.9 \mathrm{million}$ obligation to oSEC under the OMB Interim Determination orders dated June 30, 1993 and Novenber 29, 1993 as Eollows:

B. BVITS Texmination Funde

Within 30 days of the execution of this Agreement, the Department ohall transfer the remaining funds reserved for Avis termination activities is the amount of $\$ 34,3$ milizon. 


\section{B. Remaining Comitment}

The remaining arount due under the Interim Determination. Orders, $\$ 19.6$ million, shall be provided through direct transfers of uranlum or by assignoent of the accounts receivable from gales of uranium inventories held by DOE in accordence with the terms specified in sections VI. . (1) (131) below. If the anount recefved by usEc from the accounts receivable from the sales of uranium inventories exceed the remaining amount due under the Interim Determination Orders then USEC shall credit the excess toward the Department's obligations for the reimbursable costs as defined in section VI.X. below.

\section{COSTS TO BRING GDP'E IFTO COMPLIAXCE HIME OSHA STARDARDS}

Section 5.1 (a) of the Lease requires the Department to provide to OSEC $\$ 35$ million in complete satisfaction of all the Department's obligation for any and all modifications to bring the GDP' into compliance with applicable OSHA standards. The Department has paid to USEC $\$ 5.63$ million, leaying $\$ 29.37$ million unpaid. In satisfaction of that obligation, the Department shall pay to USEC $\$ 29.37 \mathrm{mili}$ ion inmediately upon receiving Congressional autborization for reprogramaing of funds for that purpose.

\section{FORTSKOUTE EIGEIT EMRICEED URRYIUR}

The Department agrees to provide to USEC 13.198 metric tons of highly eariched uranium, in the form of UF, which can be introduced into the uranium enrichment stream to produce a product that will meet the current AST speciflcation for $0 F_{6}$ enricbed to lesa than five percent (58) From natural uranium feed (C-996-90), (the 13 MTU"I located at PORTS in accordance with the following terms:

A. Upon execution of this agreement, DOE will transfer rights to the 13 MTV to USEC, but DOE will retain title and control of it until it enters tho uranium enrichment process stream through the feed station at PORTS and is blended to below 10 percent $\nabla_{235}$. USEC shall accept, take delivery of and title to the 13 MTU at the time the material enters the uranium enrichnent pfocess stream through the feed station at porss and is blended to below 10 percent $U_{235}$ *

Once USEC takes title to the $13 \mathrm{MTU}$, it assumes all responsibility for that material, lncluding for the guality of the resulting product.

B. Until September 30, 1994 the Department shall bear the costs of complying with all nuclear safety, safeguards and security controls for any and all uranium enriched to concentrations of 10 percent $U_{235}$ or greater ("Nuclear 
Safeguards Requirements"). Subject to the reductions provided in section V.B., USEC shall reimburge the - Departoent for the costs incurred in complying with the Nuclear Safeguards Requirements ulth respect to the 13 HTU covered by this Agreenent beginaing on . Dctober $l_{1}$ 1994 up to a maximun of $\$ 9.9$ militon per fiscal year. The Department shall be responsible for the costs incirred in complying with the Nuclear safeguards Requirements with respect to ang highly eariched uranium other than the 13 MTU. Notwithistanding this allocation of financial responsibility, the Department agrees that it will be solely responsible for providing for, establishing and maintaining ruclear safeguards Requirements for all uranium enriched to concentrations of 10 percent $U_{23 s}$ or greater. usec shall essume phyeical responsibility for nuclear safety. safeguards and security for uranium covered by this Agreement only after such material is processed, as necessary, to. concentrations of less than 10 percent $v_{235}$.

C. USEC will compensate DOE for the $13 \mathrm{kTU}$ in the following amounts: (i) $\$ 82.8$ raillion for the separative work unit ("SwU') value, and (ii) $\$ 36$ million for the natural uraninu composent of the same material, for a total of $\$ 118.8$ million.

D. The $\$ 118.8$ mIlion compensation by USEC shell be paid as follows: (i) a credit of $\$ 12.5$ million for the adilional costs to USEC of processing and banding the $13 \mathrm{MH}$, which credit includes all costs associated with transporting the material from $x-345$ to $x-326$, sampling and analyzing the material, installing and operating chemical traps for contaminant treatrent, feeding the material into the uranium enricbnent processing stream, removing heels material from all (approximately 1,322 ) cylinders currently stored in $x-345$, cleaning and decontaminating such cylinders, and any safeguards costs associated with storage of such cylinders prior to cleaning, (il) a credit of $\$ 9.9$ mililion per year for fiscal years 1995 through 1999 , totalling $\$ 49.5$ million, for Nuclear Safeguards Requirements costs associated with naintaining the 13 MTU at PoRms (except as that number may be affected by sections $\forall . E$. and V.P. below), and (iii) the balance to reimourse ISEC for its costs to bring the GDP'g into cormiliance with standards in accordance with section VI of this Agreement. After cleaning and decontanination, DOE shall be responsible for the cost of storage and eyentual disposal of the cylinders and the resulting waste and other product. 
E. The $\$ 49.5$ mitlion credit for Nuclear Safeguards Requirements costs shall be reduced pro raca by weight for each month for any anount of highly enriched uranium

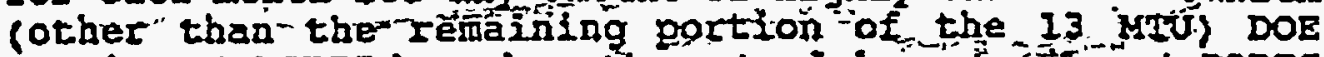
Ietains at porTs based on the actual inventorites at poRTs during the priot manth. Appendix A reflects DOE's current profection of bighly enriched inventories at PORTs through September 1995 and includes the formula for calculating the reduction in credit, if any.

F. A ratable portion of the credits of $\$ 9.9$ million for fiscal years 1998 and 1999 shall be reduced for any months after USEC has completed feeding the 13 WTO into the uranium enrichment processing stream and the anount ghall be rebated to the Department in accordance vith Section VI.D. Except as provided in Section V.E., no reduction shall be nade for fiscal years $2995 \cdot t h r o n g h$ 1997.

VI. COSTS 20 BRING DOE ODP'S INTO COMPLIANCE WITE MRE CERMIFICATION STANDARDS AYD TEE REGUIATORY OUERSIGRI AGREEMENT

\section{A. Reimburgable Costs}

(i) Except as provided below, the Department and USEC agree that the costs reimbursable pursuant to section $5.1(b)$ of the lease (hereinafter "Ieimbursable costs") include all costs, exclusive of internal USEC overbead costs and the cost of USEC employees not fully dedicated to this effort, reasonably incurred by ISEC for all work necessary either (1) to bring the Leased Premises and Leased Personality into compliance with the Regulatory Oversight agreenent (Exhibit $D$ to the Lease) and any amendment thereof, or to achieve any other bafety improvements required or directed by DOE; or (2) to obtain Initial NRC certification or NRC approval of a plan to achieve compliance (including all vork related to preparing, submitting, galning WRC approval, and achleving initial compliance vith NRC standards). Such work includes, but is not linited to, physical rork, architectural and engineering services, preparation and revision of procedores, preparation of the application, application fees, and training of personnel. The reimbursable costs shall exclude fifty percent (507) of the costs of outside consultants providing training cervices and fifty percent (50\%) of the costs of outside legal services. 
(ii) Xny request by USEC : for reimbursement of relmbursable costs pursuant to this Agreenent shall include adequate documentation of the basis for the request, including the amount and nature of the cost by category, along with supporting third party involces. Upan request, USEC shall permit DOE access to any records mairtained by tSEC that support USEC's request for payment of reimbursable costs.

B. Safetr Analysis Reports

(i) If USEC requests any work on the safety Aralysis Reports for the GDP'8, after November 30,-1994 USEC Ehall fully reimburse DOE for all costs, exclusive of internal DOE overhead costs, and the cost of DOE employees not fully dedicated to this effort, incurred in providing such assistance. Upon request, DOE shall provide a written cost estinate to USEC prior to commencing any work.

(ii) Any request by DOE for reimbursement of costs for any work on the Safety Analysis Reports requested by USEC pursuant to this Agreement shall include adequate documentation of the basis for the request, iricluding the amount and nature of the cost by category, along with supporting third party invoices, Upon request, DOE shall permit USEC access to any records maintained by DOE that support DOE's request for payment of reimbursable costs.

C. Reprograming Funds

Upon receiving Congressional authorization for the reprogramang of funds, the Departuent shall transfer $\$ 11$ million to USEC.

D. DoE Credit

Upon receipt of the IIghts to the 13 uro described in section $V$. above, USEC shali credit the Department with $\$ 56.8$ million toward the reimbursable costs as defined in Section VI.A. ( $\$ 118.8$ million less $\$ 49.5$ million Nuclear Safeguards Requirements costs and less $\$ 12.5$ million processing and handling costs). Should any of the credits for the cost of Nuclear Safeguards Requirements be reduced pursuant to Sections V.E. or V.F., USEC shall credit the Department in the amount. of the reducition toward the reimbursable costs as defined in VI.A., or toward other amounts owed to USEC by the Departrent. If no such obiligations are outstanding, USEC shall rebate those anounts in cash. 
E. Sales, Pransfers and Valuation of Inventories

To the extent usEc's reimbursable costs exteed the amount provided for in Sections VI.C. and D.s the Departiment shall resmbursa usec through diroct cransters of uraniam or 8 assignment of the accounts recelvable resulting yrom anlas of uranium inventories held by DOE as follows:

(i) DOE shall have the right to elect in the first instance whether to provide USEC with uraninm or to sell uranium to a third party, subject to the provisions of Section 1401 of the Atomic Energy bet, and transfer the accounts receivable from such sale to USEC in full or partial satistaction of the DOE obligation. DOE shall notify USEC of its election within 30 days of .its receipt of USEC's reguest for reimbursement of reimburabile costs. Except as provided in section VI.E(iii) belor, DOE thell arrange for and be solely responsible for any and ell costs associated uth the transfer of inventory fncluding the costs of processing before the naterial enters the uraniuni enIichment process strean (and waste disposal and decontaraination associated with such pre-enrichneat strear processing), packaging; handling, and transportation. DOE may elect to satisfy its obligation to pay for such transfer costs by transferring to USEC additional uranium to compensate USEC for auch costs.

(ii) In the event DOE elects to provide USEC with uranium, uSEC way request it in the form it can best utilize at that time, and DOE shall make reasonable efforts to make the requested form available. It shall be delivered by DOE as soon as posslble to either PORTS or PGDP as designated by USEC and in accordance with a schedule for delivery egreed upon by USEC and DOE. If DOE does not have available for transfer uranium in the form USEC requests or meeting the epecifications required by USEC, DOE agrees to sell uraning to a third party, subject to section 1401 of the Atomic Energy Ret, and transfer the accourts receivable to USEC.

(iii) In the event DOE provides USEC with natural uranium In the form of $\mathrm{UF}_{6}$, the $\mathrm{UF}_{6}$ shall be valued at $\$ 15$ per $\mathrm{Rg}$ unless otherwise agreed by the parties. In the event that such natural uranium is located at PORTS or PGDR, delivery shall occur at the GDP where the material is located and USEC Ghall arrange for and be solely responsible for any and all costs associated with the transfer of the inventory. 


\section{ADDITIOHAL TERHS}

1 The secretary and the CEO shall each designate a rept--intative to andise best efforts to develog a zasolution by necember 31, ig9: within the Administratior, for any compensatiod due USEC with respect to the purchase of the Russian eniched uranium.

B. DOE and lisic agree that the terms under which DSEC will act as DOE's exclusive marketing agent for future sales of enriched uraniun and related services shall be the subject of a future Memorandur of agreement between DOE and USEC, which the parties will make best efforts to enter into by Norember $30,1994$.

IN FITNESS FHEREOR, the Department and USEC have caused. this agreement to be executed and delivered, as of the date first written above, and hereby affix the bignatures of their duly guthorizegi representatives:

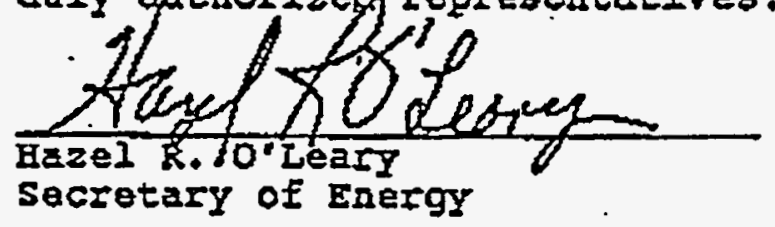

AND

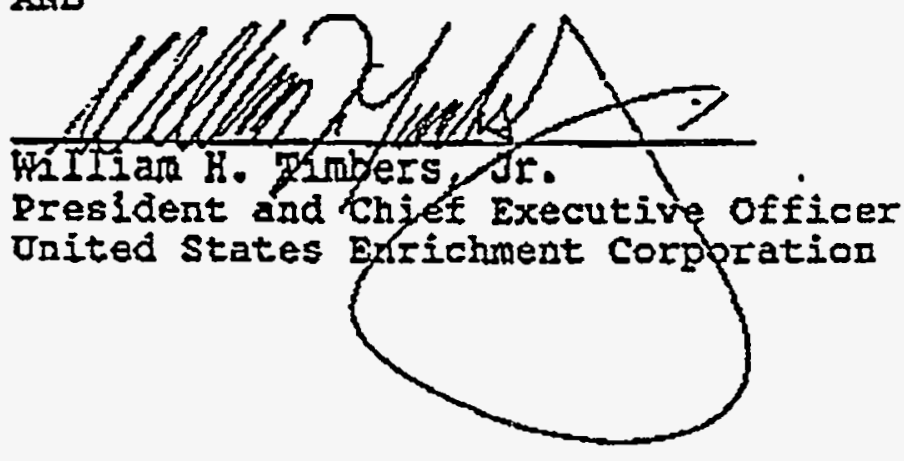




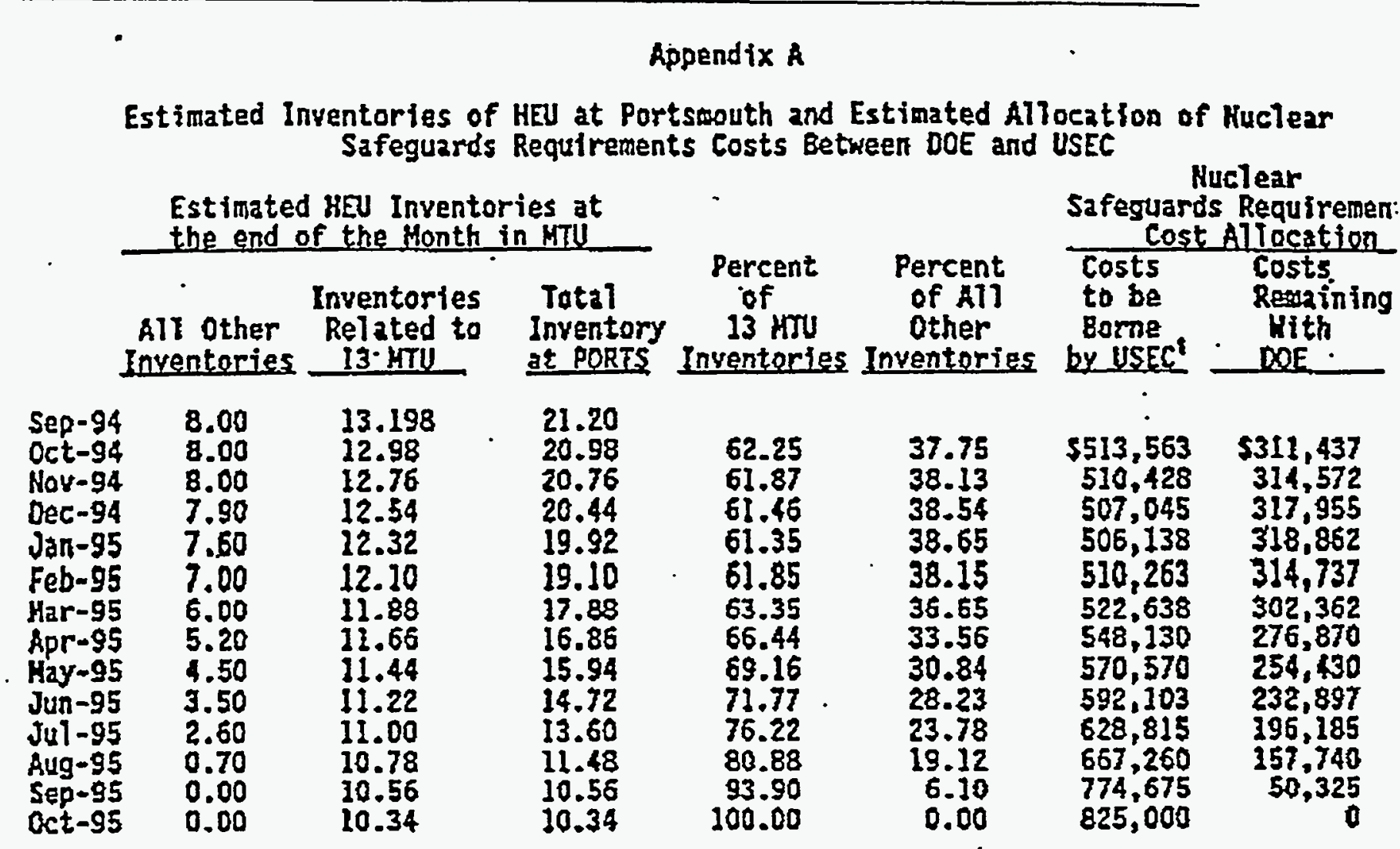

Anount to be credited against the $\$ 49.5$ million for nuclear safeguards costs described in paragraph Y.E. of thís NOA.

\section{Assumptions:}

The formuta for calculating pro-rata safeguards credit amount to be figured at the end 0 each month is as follows:

Inttial Credit (\$49.5 million)-[\{A\}1 other inventories at month end\}/(AlT other inventories at month end + Inventories related to 13 kTU at nonth end $]^{*} .825$ milition=ne credit.

Assumptions:

Annuat Muclear Safeguard Requirements Costs

$\$ 9,900,000$

Honthly Nuclear Safeguand Requirements Costs $\$ 825,000$

Estimated Months to Feed HEU

Honthly HEU Feed Rate, MTU

0.22

Inventory amounts above are based on metric tons of uranium (HTU) in the HEU.

The inventories related to 13 MTU in the zbove formula are the remaining inventory of th original 13.198 HTU inventory suppliad by DOE to USEC.

The "New Credit" value, calculated monthly, is substituted for the "Initial Credit" yalu at the beginning of the following month.

When the inventories related to the 13 HTU equal 0.00 , then all reductions to credits shall be made in accordance with Section $Y . F$. of the Agreement without regard to this formuta . 
Intentionally Blank 

A Transitional Program for Regulation of the Gaseous Diffusion Plants at
Paducah, Kentucky, and Portsmouth, Ohio

\begin{abstract}
APPENDIX F
REGULATORY OVERSIGHT PROGRAM

July 1, 1993 to March 3, 1997
\end{abstract}

Prepared by

Regulatory Oversight Office

for

U. S. Department of Energy

Oak Ridge Operations

Oak Ridge, Tennessee 37830 
Memorandum of Understanding Between the U.S. Department of Labor Occupational Safety and Health Administration and the U.S. Department of Energy Office of Environments, Safety and Health, Signed December 21, 1994, Joseph A. Dear and Tara O'Toole, M.D., to minimize potential gaps (OSHA) 


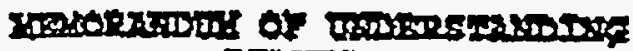

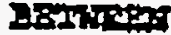

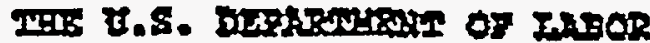

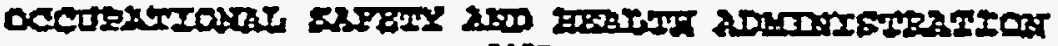 \\ 2800

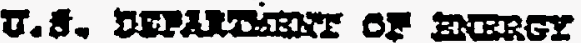

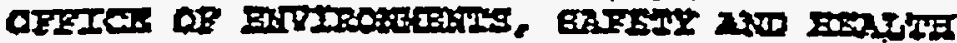

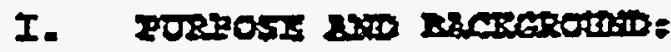

A. The purpose of this treworandun of tuderetradiag butwerd

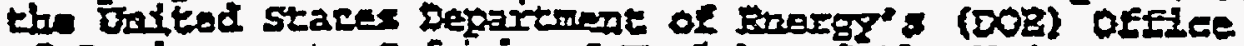
of envirconent, Safecy and Elaplth ond the United states: Departwent of labor's ocespaciomaI Safety and Eealtb Adrinistration losax is to delinexte tha aroas of rasponsibility of each agency at the gaspous diftusion

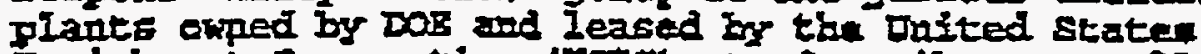
knylehment Comporation (USEC) to deseribe generaliy the afforts of the ugenefes to assure worket protection af these1 and, to provlde procedures for cooraination of activitiea between DOB and OSRa.

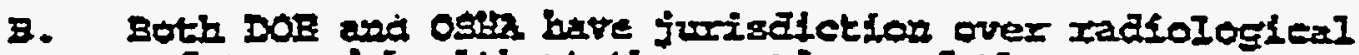
gafety and bavith et khe portions of the gaseorta

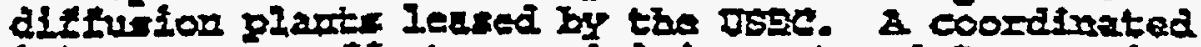
inter-agency ettort can minimize potersel gaps in the pratection of workero and, at the same time, avofa possible contlueting requirements.

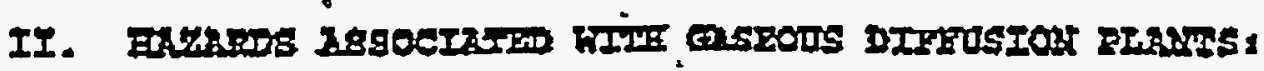

Forr baste categories of bazards are asociated with the gaseous diffurion plants:

B. Intrutrlel safety hazards due to the plare'g physicel conditsion or ite ogaretions:

B. Health harardi cue to chemical and toxicologiear. exposores associated uith non-radioactive materiala:

c. Hialth hazareis tus to poteritinl exposure assoctated. with radioactive metrielsj and,

D. Radfation hazaris to the general pubIto atad the envisenment.

Osta. roill regulate the hazarois Iisted in paragraphs II. As B: wad C. Dor will reguiate the homats listed in peragraphs II. C, and D. 


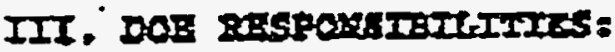

The Energy Eolfoy. Iot of 1992, the Dergy Folley Aet, 2

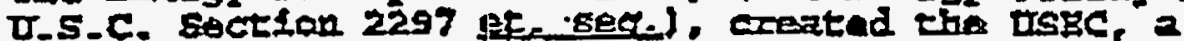

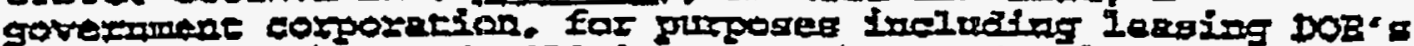
uraniun erichmer fuciritlas to warket and rell enriched virantur aro vranim enrichment and relatad gervioen to the Departwent and domestic sal Forelgu ifterests. Tho mergy

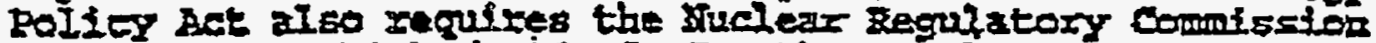

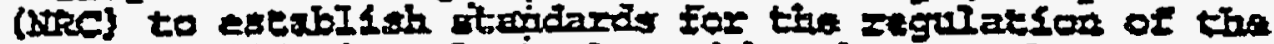

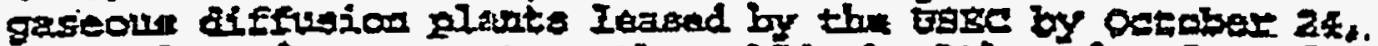
3994. in order to protect the pubilic beafth and bafety trou

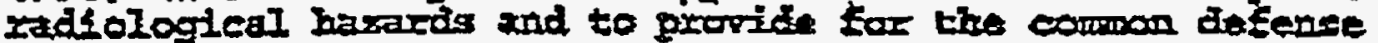
and security. After these gkandarea are prowilgated, tha

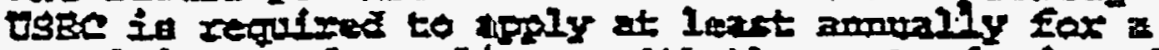

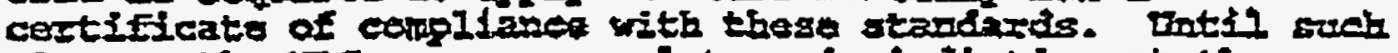
time as the IRT agnumles Iegulatory jurisdiction at the

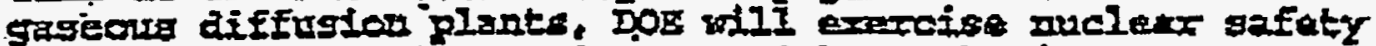
and safegruaris and security oversight authority to grotect - the priblic at the lez.ged poitlous of the gaseous diffustar

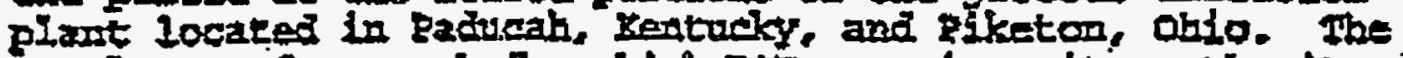

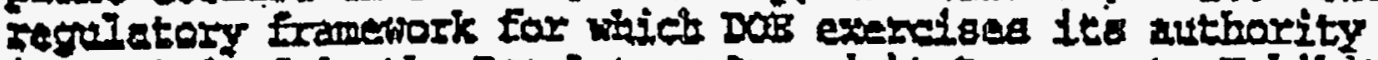
is cantataen in the requiatory oreralght Agreement, Exhtist

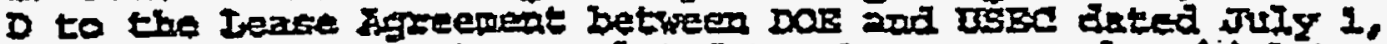
1993. Specific matters releted to the procass by diach yed

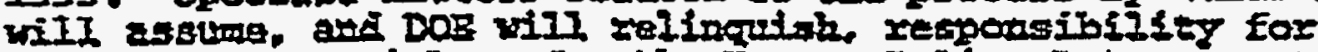

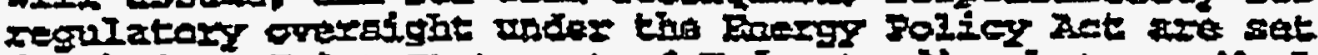

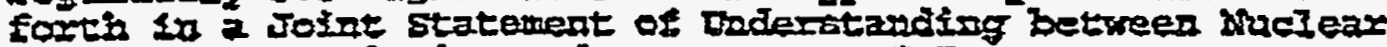
Regulatory Cowission and Depertuent of Energy on Inplementing Energy Eol Lo\% AGt Rrovigions on Regulation of Gascous DEffuster Uranlum Enrichment RIant 59 Red. Reg. 4729 (Folpesary $I, 1934$ ).

DOE's regponstbelity is to propote and proesct the

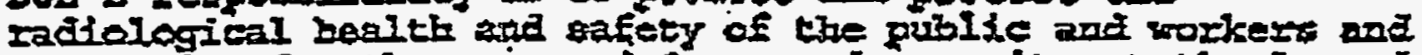
to provite for the coumon defense and security at the leaged partion of tha Dos-orined saseous diffobion plants. These

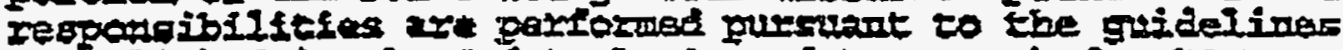
estubliahed id the safaty. Basis and Framevork for DoE orergight of the Gaseons Diffusion pients (Appendix $\mathrm{A}$ to the Regulatofy orersight Agrement/ and the conoueting of inspections, xeviows, Investigations, and enforcemedt

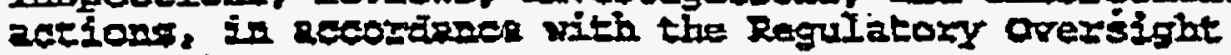
agreement. 


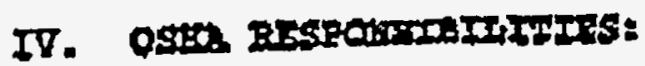

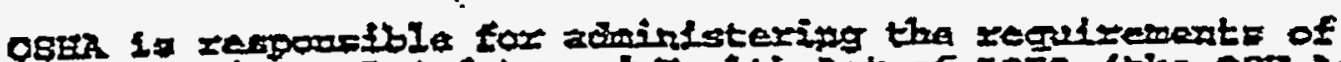

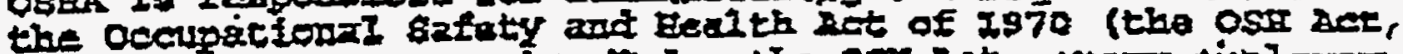
29 U.S.C. 651 eE. seq. I: Dnder the 0si Act. every einoloyer has a general duty to tivist exch ofloye a place-of

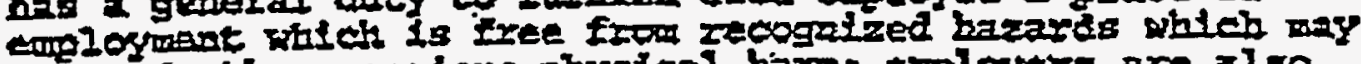

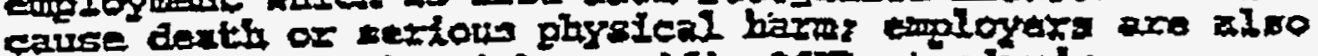
zechired to comly vith specific OSEA standacds. regulatilons, end obhei: Iequidremeats.

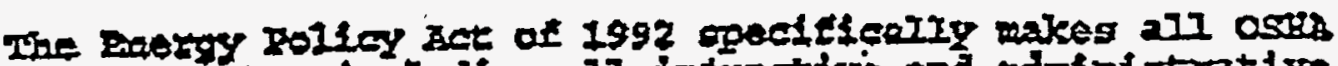

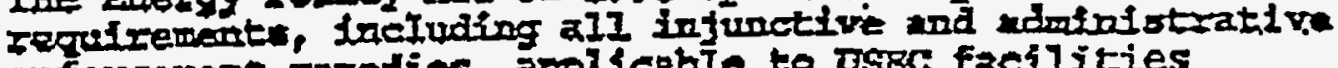

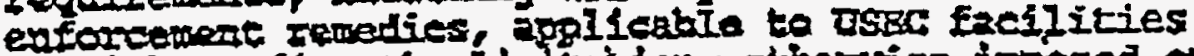

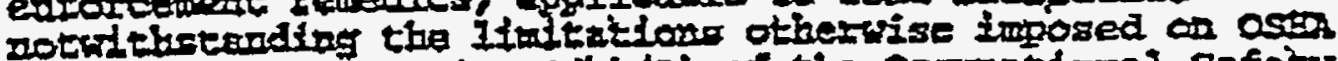
onforeatart by section 4 (b) (I) of the ocerpatsonal. 8xfety

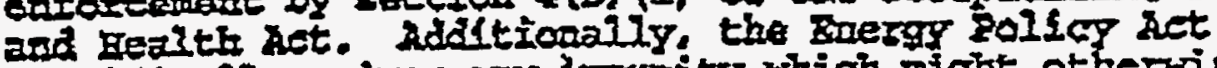
speatelcally raites any Inwmity which might otherwise be Fpplicaila to USEe. 42 J.S.C. Secton $22976-12$ (c) (1992).

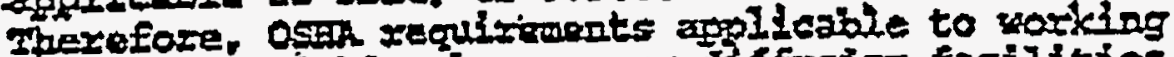
condition sithin the gaseous diffurian facilities andinfstered by usic of its subcontrictors are not subject to preawetion by regulations .188ued by other Eedaral agenciea.

Bccordingly, Osten will enforce aIl appI Lable standards, 707 es and zequirements including, but not Ijoited to, the

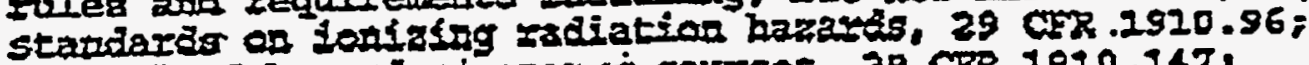
control of bazertoud enexgr colscces, 29 CPR 1910.147: bajardous vaste opezations and energency resporse, 29 CFB

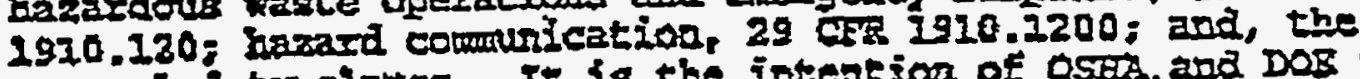
general atyy clatsa. It is the intention of OSFA. and DOS to cosxabato thefr regulatoxy and oversight activitias in 2 namas wich noids, to the extent posibible, the zuposition of Inẹonsistent obligations or USse.

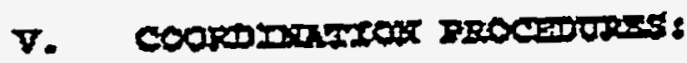

In recogaltion of the agencies' atthoritles and zesponsibilities enumerated above, the folioning procedures YII be solIoret: 


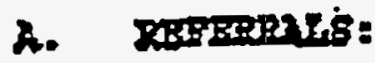

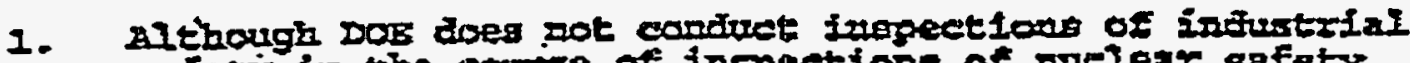
safety in the cowrize of ingpections of zuelear safrty wod safeguards ad security. poz Regulatory Overnight

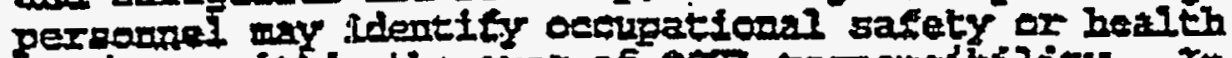

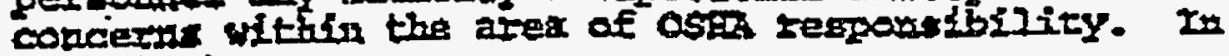
auch Instances:

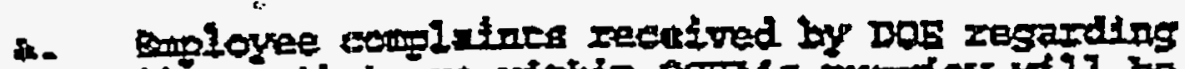

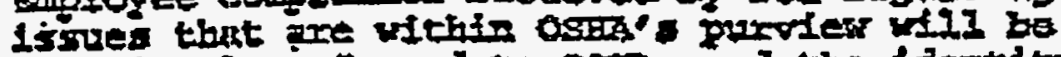
inemadiately referced to oser and tha identity of the complatufus aploted abil not bo disclosed to ary Ioper by elebrex oseri cor DOB.

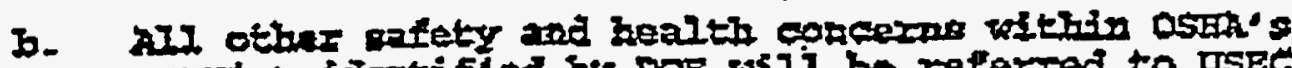
purvies icientifled by. DOF rasi be relexred to USEC prorgement in incitesng for expedient sorrection.

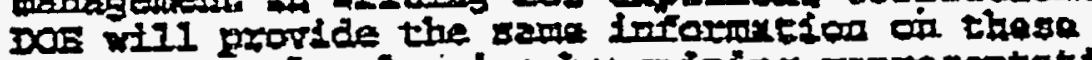

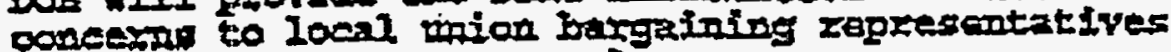
of the tost contractor mioyees.

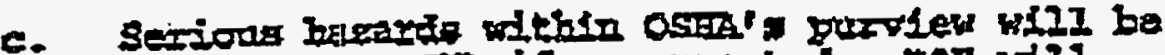

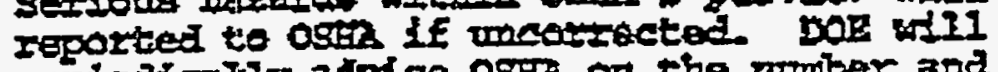

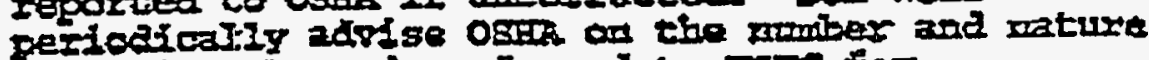
of Bexfous bagarat refered to USFe for correction.

z. OSHA Reglosal OEfices will inform the DOE Regulatory

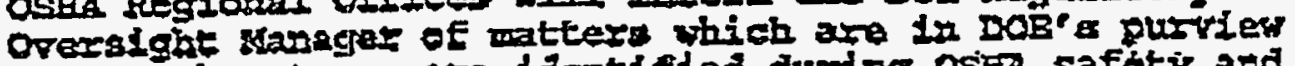
whes such pateress are dentiffed during oses safity asd hasith inapections ot througi comilaines

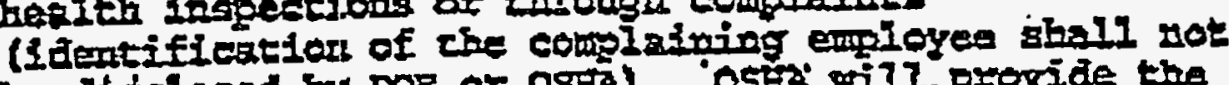

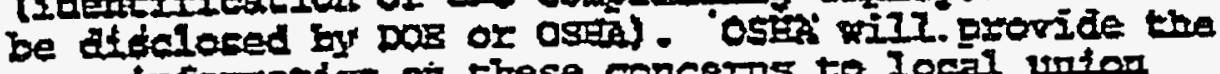

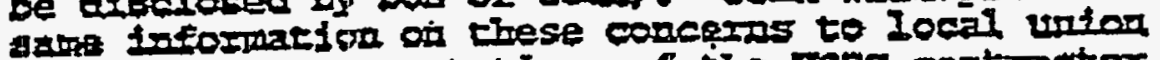
bargafring tepresentativen of the dsad contcactor oreyos.

a.

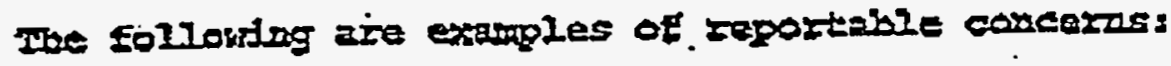

1). Insdiflicient security control affecting rovear or sadiological fealth and rafety.

2) Imprear postisc of radixtion areas.

3) - Ezbandous conatuiand relating to zadiologtcal or prelegr safety. 
B. 2uspremenss:

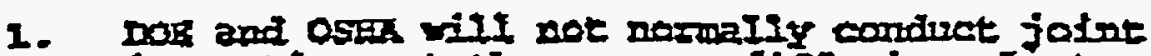
ingpections at the gaseous deffucion pIanth.

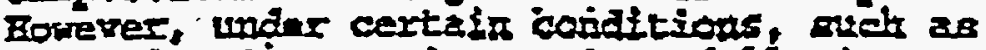
investigations or inopections following accidents or rabuleing from reported activitlex as discussed In paragraph $\nabla$. A.. It may be mitudily agreed on $t$ care-by-case banis that jotne imrastigations tre epprepriate.

2. The procesing of uranlum maturals of tho gaseous Giffusion plants thay preseat orexlapplog chencel :

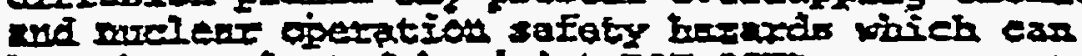
bert bit epalvated by joint DOB-OSEA assessoments.

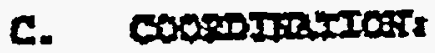

I- DOB and OStR wiII, to tho fullest extent posaibia, cooperate and coisidinate it all orgarizat Ional levels to dexelog and carty out. information

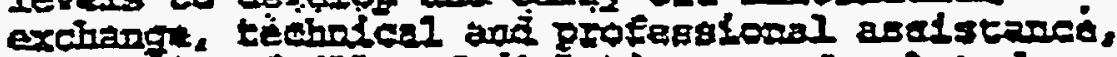
refertals of jileged riolations, end zalated natters conceintog complisice and lav enforcement activity to etsure tba healih and rell-belogs of the rorkforde and the general public.

2. Resolution of policy igstes concerning asency Jurindiction and operations of II be cooxdlaxted by apipopiciate DoE and OSEx staft orth lopus from the offlce of the Solicitor. DOS and OSPR will desigante points of contalt for cerrying out iatericace setiviteles.

3. The wistleblower potatetion provisions af the

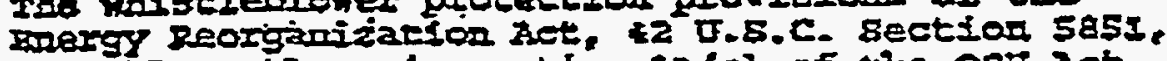
25 well as byose in section if (c) of the osf hct. 29 U.S.C. Section 6ro (c), 200 epplicable to ouployees of USEC and contrastors at USSC adrobiraterad faedinties.

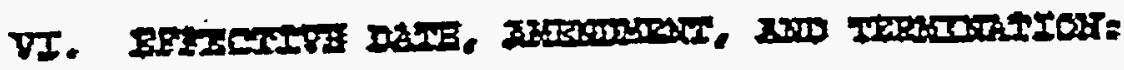

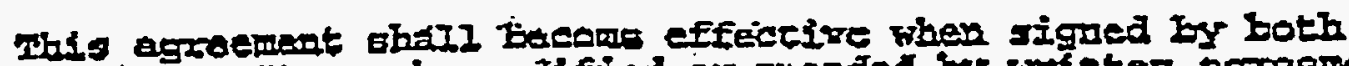

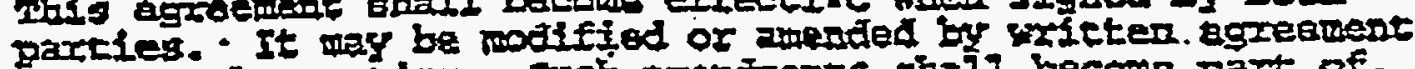
between the parties. Such amendineats abill becomo paxt of. and aball be attabhed to, this agreement. Mhis agreenent

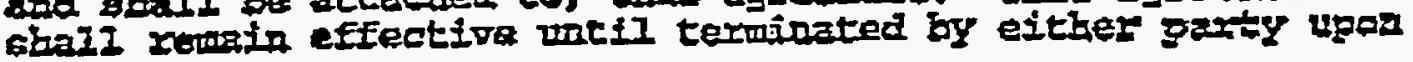


30 days witten notled to the other, or weil conietsori of

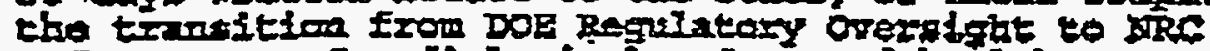
enforcemest of zaciological defery and health matera at usec Eac131ties. The parties agfee that 15 the trangition process is not completed by october I, 1595, the parties will Ieview this Mơ and make a decijion on wathat to

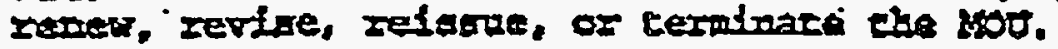
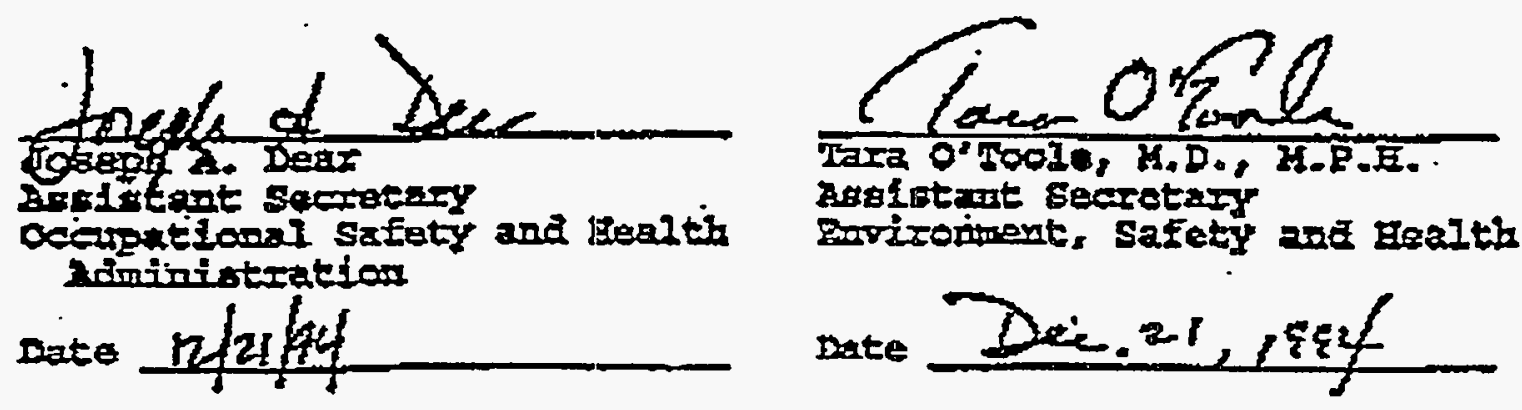


\section{A Transitional Program for Regulation of the Gaseous Diffusion Plants at Paducah, Kentucky, and Portsmouth, Ohio}

\section{APPENDIX G}

\section{REGULATORY OVERSIGHT PROGRAM July 1, 1993 to March 3, 1997}

Prepared by

Regulatory Oversight Office

for

U. S. Department of Energy

Oak Ridge Operations

Oak Ridge, Tennessee 37830 


\section{APPENDIX G}

Joint Policy Statement by USEC and DOE on Resolution of Shared Site Issues at the Gaseous Diffusion Plants, Sent by USEC Letter, Dated: January 25, 1996, in which an administrative policy statement addresses PGDP shared site issues the surrounding DOE-retained reservation as well as other issues that requireformal mechanisms for interface and control. 
Tel: (501) 564-3200 Fax: (307) 584-3201

Dir. (305) $561330 t$

Fox (30I) 5640208

Japuary 25, 1996

Dr. Cari 3. Paperiello

Director, Office of Nuclear Material

SERIAL: GDP 96-0018

Safety and Safeguards

Atlention: Documedt Control Desk

U.S. Nuclear Regulatory Commission

Washington, D.C. 20555-0001

Paducah Gaseaus Diffusion Plant

Portsmouth Gaseous Difiusion Plant

Docket Nos. 70-7001 \& 70.7002

Resolution of USEC/DOE Slared Site Issues

Dear Dr. Paperiello:

Enciosed for your iuformation, is a joint USECIDOE approach to cerrain "shared-siten issues which will assure that, once the N"RC assumes regulatory oversight over USEC's operations, our respertive activities will be coordinated to provide contimued regulatory complianee and adequate safety, snfeguands, security and expironmental protection.

Some "shared site" issues are not addressed in the enclosure because they have boen, or are being, addressed through other mechanisus. These issues include:

- HEU suspension/refeed operations (Refetence1).

- Transition frota Operalional Safety Requitements to Technical Safery Reequirement (References 1.2, and 3).

- Transition to NRC event reporting (Referemce 4) 
Dr. Carl J. Paperiello

Jaznary 25, 1996

GDP 96.0018 Page 2

Other isstes that may have common USEC and DOE interest have already been addressed or are being asdressed in other documents such as the Certification Application, DOE Compliance Plan, or the ISECIDOE lease agreement. The enciosure addresses the remaining "shared site issues."

While no specific NRC response to this letter is required, we are availabie to discuss any commonts or questions you may have.

Please feel free to contact Mr. Russ Wells, USEC Senior Regulacory Engineer, at (301) 564-3245 regarding this submitral.

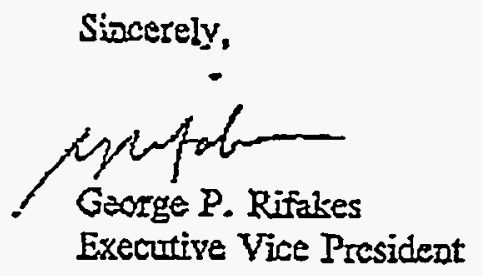

Enclosure

cc: NRC Region III Office

NRC Resident Inspectors, PGDP and PORTS

DOE Site Safety Representative, PGDP and PORTS

DOF. Regulatony Oversighr Mannger 
Dr. Carl J. Papariello

January 25, 1996

GDP 95-0018 Page 3

\section{References}

1. USEC letter to NRC dated October 19, 1995, George P. Rifakes to Dr. Carl J. Paperiello, "DOE/NRC Regulatory Transizion."

2. USEC letter to DOE đated December 7, 1995, Robern 2. Woolley to J. Dale Iackson, "Transition from Operational Safety Requirements (OSRs) to Technical Safery Requirements (TSRs).

3. DOE Jetter to USEC dared Jamuary 2, 1996, J. Dale Jackson to Robert L. Woolley, "Transition from Operarional Safety Requirements (OSRs) to Technical Safety Requirements (TSRs)."

4. USEC letter to DOF dated Ocrober 16, 1995, I. Dale Yackson to Robert L. Woolley, "Iroposal to Implement Joint NRC-DOE Event Notification Criteria at the Gaseous Diffusion Plants (GDPS)." 
Dr. Carl J. Raperiello

Januasy 25, 1996

GDP 96-0018 Fage 4

Distrifution:

Robert I. Woolley Reader File

bec:

J. Adams, HQ

J. Adkins, HQ

D. Allen, PORTS

B. Anold. HQ

J. Dietrich, HQ

L. Fints, PORTS

R. Gaston, PORTS

J. Labarraque, PGDP

J. Miller, HQ

S. Polston PGDP

S. Routh, $\mathrm{EXQ}$

D. Scott, HQ

D. Silveman, ML\&B

B. Sykes, FGDP

K. Wells, HQ

s:ierslletters. srcigdp960018

Concurrence line

CRS $/ 195$ 


\section{USEC AND DOE RESOLUTION OF \\ SHARED SITE ISSUES}

AT TIIE

GASEOUS DIFFUSIOR PLANTS

\section{- Backpround}

Once the NRC assumes nuclear regulatory oversight for USEC activicies at the GDFS, there will be a need to coordinate DOE and USEC activities at the GDPs to ensure that:

1. USEC and DOE activilies at the GDPs do not adversely affect the operations of the other party in terms of health and safety, environmental protection, safeguards and securiy, and muclear regulatory compliance.

2. Siruations with the potential to affect both DOE and USEC operations and personnel, such as emergencies trid directed toward site activities, are managed in a coordinated mamer that protects the safety and hesith of DOE and TISFC personnel, including their respective contractors/subcomrisctors, and the public.

\section{- Premises}

The following premises support the proposed resolution of shared site issuts:

1. This joint USEC and DOE approach to shared site issues does; not modify, amend, or alter in any way the lease between USEC and DOE for the GDPs, or any memoranda of agrement, or any ocher agrements between USEC and DOE.

2. The site can be dividad into three types of areas: 1) DOE areas (generally nonleased) in which DOE managed or oversoen activities, which are exempt from NRC regulation under Section 110.a of the Atomic Energy Act of 1954, as

\footnotetext{
'The term "leasc" refers to the Lease Agreement between the United States Department of Frergy and the Linited States jiorichment Corporation dated as of July 1, 1993.
}

$-1-$ 
Enclosare 1

amended, are conoucted; 2) USEC leased areas in which USEC activities subject to $\Lambda 2 C$ Iegulation are conducted; and 3) common areas (e.g., site roads) which are used for USEC and DOE activities.

3. DOE will silf-regulate DOE acivities conducred in DOE areas and comonon areas in accordance with applicable DOE requirements. This includes DOE personnel and their contractors!subcounactars. DOE assumes furl respodsibility for the safery, safeguards, and security of DOE activities. .

4. USEC activinies conducred in USEC areas and common areas are subject to NRC regulation under terns of the certification applitation. This includes USEC personnel, their contrattors, and subcontractors. USEC assumes foll responsibility for the sarety, safeguards, and security of USEC activities.

\section{- Shared Site Iosues}

\section{Shared Systems and Continuity of Essential Services}

USEC provides certain services and utilities (e.g., lighring, beat) to DOE that are pecessary for the safety, safeguands, or conduct of DOE activities. Similarly, USEC and DOE activities are protected or supported by shared systems (e.g., nuclear criticality and security alarm systems, fire protection sprinklers) that are inportant to the safery and safeguards of USEC and DOE activities.

USEC and DOE will work together to easure that internoptions to services necessary for the safery, safeguards and security of the GDPs are minimized and that shaned systems remain operable. Additionally. USEC will apply configuration managemear controls to thess systems, in a manner commensurate with that applied to equivalent USEC systems, to ensure that the safety, safeguards and security systems, and coutuct Of USEC and DOE activitics are not adversely aflected. Similarly, USEC and DOE will work together to establish a process for concrolling the schectuling of interruptions to essential services to ensure that the safery, safeguards, and security of the GDPs are not aciversely affected.

\section{Control of Work Activities}

DOE and USEC agree that activines in Icased spaces must be conducted in accordance with USEC commiments to NRC. Accordingly, DOE (including their contractors/subcontractors) will obtain USEC's approval prior to conducting work in leased spaces. Similarly, prior to conducting work in non-leased spaces, USEC (incluaing their contractorsisubcontractors) will obtain DOE's appropal. Both pariess 
Enclosure 1

will strive to ensure that such approvals do not inpede the schedule for the work activities of either party. Additionally, both parties will ensure that work activities that affect eifher party are conducted in accoxdanec with the appropriate procedures.

3. Plant Changes

DOE and USEC agree to establisin proceducal controls to ensure that each party is promptly notified, and appropriate approvals obtained, prior to conducting activities . that affect the design, construction, operation or mintenance of faeilitios and systems on treir respecitve portions of the GDP sites. This process will allow the other party to evaluate the potemtial sasety impact of such a change on its own facilities, systems, : and activities at the site.

USEC will provide DOEE with a copy of each approved written Safety Analysis issued in accordanre wift 10 CFR $\$ 76.68$ with respect to any changes to the lessed premises or the operation of the leased premises at eirher GDP site. Similarty, DOE will provide USEC with a copy of each Unreviewed \$afety Question Detenuination (USOD) or Safety Analysis prepared by or for DOE with respect to auy changes to DOE's farililies, systerns, or operations at eilher GDP site. Each party will provide the other with pertinent information concerning any Unreviewed Safety Question (USQ) identified in cowwection with its operations and activities at eirber GDP site, including any Justiñcation for Continued Operntion (JCO) or similar documens prepared in connection with such USQ. In the event that either parcy has a concern about the porectial impact of any plant changes by the ofher party on the safety of ins OWn operations and activities at eilher GDI sire, the appropriate USEC and DOE representatives for that site shall joints' review the change and take appropriate action is resolve the concem (including any required plant modifications) in a prompt Ioanner.

\section{Emergency MLanagebaeut Caordination}

In accordance with Exhibit $F$ of the lease, USEC will provide energency response

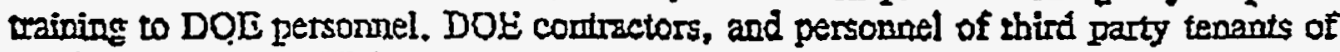
DOE at exch of the GDPs.' In accordance with the lease, DOE will reiruburse USEC for the cort of his scrvice. DOE will make the Decessary arrangendents to assure that these persornel attend such taining and be responsible for macking their paricipation to assure luy recenve the required brivial ant periodic training.

The Tunnergency Plan for both GDPs describes the roles and responsibilities of USEC and DOE in the eyent of an entergency. For a declared emergency, UISEC bas ife lead in responding to the emergency and DOE serves as an onsite menuler of the 
Enclosure 1

Emergency Operations Center. This relationship will contimue to be maintained when NRC assumes regularory aversight of the GDPS.

In the event of an emergency, in coordination with the USEC emergency management tesm, DOE will ralie the appropriate actions to cantrol activities in the reservation areat surnounding each of Giv Gites, as defired in the current Emergency Plan for each GDP. This includes the exclusion or evacuation of personnel from such ared during an emergcncy. Addirionslly, USEC has ample authorify to restrict access to the coutrolled area of the GDPs for tife purposes of plant protection, security, emergency preparedness, and sadiation protection. ${ }^{3}$

\section{Third Party Activities on GDP Sitcs}

DOE and USEC agres to prompily provide each other with perainent information conceming any operations or activities being conducted on their respective portions of cach of the GDP sites, and the survounding DOE-owned reservation on which that site is located, by or on thehalf of third parties (e.g., the Niational Guard and other DOE tenants or lessees) that could have a potential impact on the operations or activinies of the other party at that site. Specifically, DOE will provide USEC (and vice versa) with a written description of each existing thind party lease agreement for each GDP site, incluoing a detailed descripion of (a) any hazardous materials used or stored on site in connection with such lease, (b) any opmations or activities being conducted under soch lease that could pose a hazard to USEC's operarions on the loased premises or act as an initiating eveat for an accidens on the leased premises, and (c) any transportation or other access requirements on the leased premises or common areas of the site associated with such lease, particulariy with respect to the ransportacion or storage of bazardous materials or equipment. Such descriptions shall be updated promptly to reflect changes in tirid party activities. In the even that either party has a concern about the potential inpart that third party activities could have on the saft operation of eitber GDP site, the appropriate USEC and DOE representatives for that site shall jointily review the issue and take appropriate action to resolve the concern in a prompt and cost-effective manner.

\footnotetext{
'The controlled area is defined as an area outside the restricted area but inside the site (reservation) boundary.
}

'See USEC letter to NRC dated December 13,1995, in response to Question 2.005 of the applicaition for PGDP and PORTS. 


\section{Eoclosire 1}

\section{Physical Protection Coordination}

Effective access control and resporse to threats against site 2ctivities and facilities requires integrated access control for USEC and DOE activities and coordinated command and control in responding to threats against site facilities and activities. USEC will coutime to maintain a physical security protection plan for the GDPs which detines the roles and responsibilities of the site security organizations. In the event of a security threst at the GDPs (including both leased and mon-leased areas), USEC's . security force has ine responsibility to initially respond to the threar and determine the appropriate course of action. Depending on the sfoulficance of the security treat, the Eimengency Operstions Cenier at the affected site will be activated and, as discussed In Irem 4 of this enclosure, LiSEC and DOE will respond accordingly. This relationship will contimue to be maintained when NRC assumes regulator: oversight of the GDPs.

\section{Event Nivtification}

USEC will promptly notify DOE of any reporable events required by 10 CFR 76 or other applicable NRC regulations. This notification will normally be made by the Plant Shift Superiosendent's (PSS) office. However, this motification will nor take precederce over the prompt notification of the NRC as required by NRC regularions. Similarly DOE will promply inform USEC of any ruartable events. woder DOE's oceursence reporting system, for which DOE is responsiblc. Such notification will nornally be made to the PSS's office.

\section{Helipad}

USEC will establish written controls for belicapter access to the GDP sites, and the air space over the sites for use by USEC, DOE, or othar DOE renamt organizarioss at the sites and to assist state or local lew enforcement or errergency response personnel. Once established, DOE agrees to abide by these controls. As part of these controls, DOE will obtain USEC's concurrence from the PSS prior to utilizing the site helipad.

\section{Communication of Incident Information and Media Coordination}

DOE and USEC will coordinate information releases to the media in the following manner:

a. DOE bas the lead role in providing information relating to DOE acrivities and USEC will refer the media to DOE in such cases; and 


\section{Enclosire 1}

b. USEC has the lead role in providing information relating to USEC activities and DOE wrill refer the media to USEC in such casts unless there is a need for DOE to provide information in its role as site landlord.

c. DOF and TiSEC will promptly provide each ouher with information copies of utws releases of eyents that occur ar the GDPs.

\section{Radiatton Procection}

Radiation Protection (e.g., exposure unonitoring) of employee is the responsibility of the employer (USEC or DOE) and is independent of the activities upon which they are working. That is, radiation protection for DOE personnel and their contractors/subcontractors is performed under the DOE radiation prolection program. Similsrly, radiation prorection for USEC personnal and their cuntractors/subcontractors is performed under the USEC radistion program, In addition:

2. Radiarion exposure information for irdividuals who work on both DOE and USEC activitics will be shared to permir DOE and USEC to satisfy their radiation exposure reporting requiremeats; and

b. DOE will provide NRC with the radiation exposure infomation for DOE exployees and their contractors/subcontractors, as requested, in order to meet NRC's reparting requirements.

If accordance with Exhibit $F$ of the lease, USEC will provide radiation pratection training to DOE personnel, DOE contrators, and personnel of thind party tenants of DOE at each of the GDPs. In accordance with the lease, DOE will reimburse USEC for the cost of this service. DOE will make the necessary arrangements to ussure that thesc personnel arrets such training and be responsible for tracking their participation to assure they receive the required injtial and periodic training.

11. International Atomic Energy Agency (LAEA) Safeguards Agreement Implementation

DOE and USEC will cooperate with the NRC in the development, review, and revision of Subsidiary Arrangements and Facility Atachments for DOE and USEC activiries at the sites which are applicable to the safeguards requirements of the TAEA. 
Enclosire 1

12. Uaclassified Coulrolled Nuclear Infarmation (UCN)

DOE is developing guidelines with consultation and technical support from USEC for the ideatification of UCNI at the GDPS and will provide these gridelines to NRC.

CONCURRED BY:
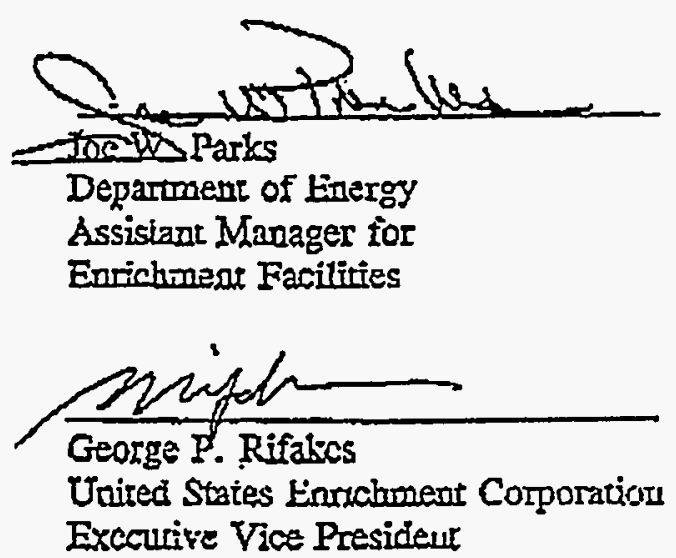

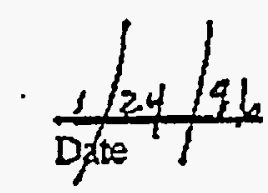

$$
\frac{1 / 22 / 86}{\text { Dare }}
$$




\section{EVCLOSURE 2 \\ LIST OF USEC COMMTIMEENTS \\ giote: this enclusure will not be transmitted to NRC, it is for internal use only)}

1. TSEC will worl with DOE to ensure that internuptions to services necessary for the Safety, safeguards and security, or conduct of DOE activities are minimized and that shared systcus remain oparable.

2. USEC win apply configuration managesnent controls to these systems in a matruer commensurate with that applied to equivalent USEC systens to ensure that the safety, safegunrds and security systems, and conduct of DOE activities are not adversely affected.

3. USEC will work with DOE to establish a process for comirolling the scheduling of interroptions to essential services to ensure that the safety, safeguards, and security, or conduct of DOE activities are not adversely affecred.

4. Prior to conducting worl in non-leased spaces, USEC will obtain DOE ${ }^{2}$ approval.

5. USEC will provide DOE with a cony of each witten Safety Analysis issued in accordance with 10 CFR \& 76.68 with respect to any changes to the Leased Premises or the operation of the Ieased Premises at either GDP site.

6. UUSEC will establish a process to ensure that if either USEC or DOE bas a corcern about the potential impact of any plant changes by the other party on the safert of its own operations and activities at pither GDP site, the appropriate USEC and DOE. representarives for that site shall jointly review the change ard take appropriate action to resolve the concern (inclnding any plant modifications) in a prompt and cost-effective manner.

7. USEC will provide emorgency response trajuing to DOE personnel, DOE contractors, and personnel of third party tenants of DOL at each of the GDPs.

8. LSEC will work with to establish a process to promptly provide each other with pertinent iuformation conscraing any operations or acrivities being conducted on their respective porrions of each of the GDP sites, and the surrounding DOE-qwned reservation on which that site is located, by third parties (e.g., the National Guard and other DOE renants or lessecs) that could have a porential impact on the operations or activities of the other party at that site.

9. USEC will establish a ptocess to cnsure that if either USEC or DOE bas a contern about the potencial impact that third pary activities could have on the safe operation of eithes GDP site. the appropriare USEC and DOE representatives for that site shall jointly review 
the issue and take appropriate action to resolve the concern in a prompt and cost-effective maner.

10. USEC will promptly notify the DOE of ary reporable events required by 10 CPR 76 or other applicable NRC regulations.

11. USEC will establish controls for belicopter acoss to the GDP sites, and the air space over the sites for use by USEC, DOE. or other DOE tenant organizations at the sites and to assist state or local law enforcoment or emergensy response personnel.

12. Radiation exposure information for individuals who work on both DOE and USEC activitics will be shared to permit DOE and USEC to satisfy their radiarion exposure reporting requiremencs.

13. USEC will provide radiation prouxtion training to DOE personnel, DOE conmactors, and personnal of third party tenants of DOE at each of the GDPs.

14. DOE and USEC will cooperate with itre NRC in the development, review, and revision of Subsidiary Arrangements and Facility Attachments fOr DOE and USEC activitics at the sites which are applicable to the safeguards requirements of the IAEA.

15. DOE and USEC will derelop guiduoce for the idewtification of UCNI at the GDPs and will provide this guidsnet to NRC.

16. DOE and LSEC will provide each other with information copies of news releases of evenis that oceur that at the GDPs. 
Intentionally Blank 


\section{A Transitional Program for Regulation of the Gaseous Diffusion Plants at \\ Paducah, Kentucky, and Portsmouth, Ohio}

\section{APPENDIX H}

REGULATORY OVERSIGHT PROGRAM

July 1, 1993 to March 3, 1997

Prepared by

Regulatory Oversight Office

for

U. S. Department of Energy

Oak Ridge Operations

Oak Ridge, Tennessee 37830 


\section{APPENDIX H}

DOE/ORO RO STAFF MONTHLY PROGRAM HIGHLIGHTS

(This is a detailed list of month-by-month activity/events summaries.) 


\author{
APPENDIX $\mathrm{H}$ \\ U.S. Department of Energy \\ Monthly Highlights of the Regulatory Oversight Program
}

This appendix provides a historical account of the RO activities from July 1993 through March 3, 1997. Highlights from the monthly activities reports and correspondence files from the ORO/RO administrative records are presented below.

July-August 1993

- The basic organizational setup and objectives and goals were defined, and contract engineering specialists were employed to support ROA requirements.

- GDP Regulatory Oversight policy, program, procedures, and training efforts were initiated.

- The administrative staff support contract for RO was established.

\title{
September 1993
}

- The RO Manager initiated the first recurring weekly report to Joe La Grone through the Assistant Manager for Enrichment Facilities, providing accomplishments, initiatives, and concerns fọr each week.

- GDP Site Safety Representatives (SSRs) started providing a weekly status report.

- Newly assigned DOE GDP SSRs received gaseous diffusion plant process technology training as well as nuclear criticality safety theory and practice training.

- The September 7, 1993, PGDP $\mathrm{UF}_{6}$ release from building C-337A was reviewed, inspected, and investigated

- A regulatory engineer with NRC experience was contracted through support services to lead the development of the Regulatory Oversight Manual-Inspection and Enforcement.

October 1993

- The First Notice of Violation, EA-70-7001/PAD-93-10-01 (Severity Level D), was issued on October 5, 1993, as a result of the PGDP building C-337A UF ${ }_{6}$ release on 
September 7, 1993. A Nuclear Safety Review Team completed its review of this event which resulted in 21 concerns being identified ( 21 Issue Form sheets).

- SSRs completed NRC Nuclear Safety Resident Engineer and NRC Inspection Training programs.

- LLNL completed a Criticality Safety Assessment of PGDP and PORTS.

- The Joint Statement of Understanding between DOE and NRC was reached on Implementing The Energy Policy Act on the Regulation of Gaseous Diffusion Uranium Enrichment Plants.

$\underline{\text { November } 1993}$

- USEC submitted a response to Notice of Violation (NOV), EA-70-7001/93-001, Category I Level violation.

- RO staff completed the Safety Evaluation Review (SER) to allow PGDP to increase enrichment from $2 \%$ to $23 \%$.

\section{December 1993}

- The Regulatory Oversight Inspection and Enforcement (I\&E) Manual was approved for initial issue.

- Additional contract support personnel were added to the RO staff.

- RO and DOE staffs met with NRC to discuss enforcement philosophy and the NRC rule making status.

- A PGDP C-337 compressor coupling failure event was reviewed by SSRs and RO staff.

- SSRs completed the NRC course dealing with performance-oriented inspection and completed the milestone of required off-site training.

\section{January 1994}

- On January 5, 1994, a Severity Level III, NOV was issued against PORTS, NOV 94001, because the Radiation Work Permit requirements were not followed.

- The RO Manager and Office of Chief Counsel participated in the Price-Anderson Amendments Act (PAAA) Workshop which focused on identifying issues pertaining to PAAA activities. 
- The Office of Chief Counsel, NRC/Region III, and the RO Manager and staff attended a meeting in Chicago, $I L$ to discuss NOVs, the RO Inspection and Enforcement Manual, and on-site NRC office space.

- The RO staff received training on implementation of the RO Inspection and Enforcement Manual.

- RO staff attended DOE's Regulatory Review Meeting in Oak Ridge with USEC and LMUS on January 25, 1994. Major issues discussed included the status of NOVs and the need to commence billing for USEC's nuclear safety upgrades and DOE's reimbursable expenses.

- The RO Manager attended the Ogden Environmental and Energy Services presentation in Albuquerque, NM on January 31 and February 1, 1994, at which the inspection modules for appraising the compliance of the GDPs' nuclear safety, safeguards and security program with the ROA were reviewed.

\section{February 1994}

- An RO staff member and a PGDP site representative met with LMUS staff to perform an overview of the procedural methods used to maintain the Integrated Resource Management System (IRMS) "open items" list.

- Members of the RO staff attended a DOE/USEC meeting at PORTS to discuss the proposed NRC Rule--"Certification of Gaseous Diffusion Plants," Operational Safety Requirements (OSRs), Independent Safety Assessment (ISA) status, NOV status, Events Reporting Criteria, DOE Appraisal schedule, and the Office of Nuclear Safety concerns.

- RO staff sent a copy of the ISA report on PORTS and PGDP to DOE/HQ for formal submittal to the Secretary of Energy.

- RO staff sent the ISA report to USEC with the statement that certain findings of the report related to USEC activities in the 19 nuclear safety, security and safeguards functional areas of the ROA. USEC was advised that the RO Manager expected that USEC would review the findings and implement appropriate corrective actions. In addition, the RO staff would be inspecting these areas to determine compliance with policies and procedures cited in the ROA.

- The RO staff received and reviewed four appeals for the five violations in the PGDP NOVs EA-70-7001/93-001 through -005 and issued formal responses. 
March 1994

- RO staff performed a Special Inspection on PGDP C-310 Product Withdrawal Facility Cylinder Burp Station, because of a UF 6 release on February 17, 1994. This first RO Special Inspection resulted in Inspection Report PGDP 94-13, which cited one violation and one deviation. The $\mathrm{RO}$ staff reviewed the history of $\mathrm{UF}_{6}$ releases since July 1991.

- The acting RO Manager was officially appointed RO Manager. Four contractors were added to provide technical support to the RO Program.

- The RO Inspection Appraisal Program development was finalized with program elements established, inspection team member guidelines and training program formalized, and logistics to support inspection teams implemented., The first audit team was scheduled to begin on April 18, 1994.

- DOE/HQ and RO staffs met to discuss and draft a consolidated response to the NRC draft proposed rule for the certification of the gaseous diffusion plants.

- The RO Manager requested that DOE/ORO divisions provide names of individuals to serve on RO inspections.

- RO staff gave PGDP limited conditional approval to operate the C-337-A UF Feed Facility and required that a continuous dedicated "smoke watch" be posted.

\section{April 1994}

- DOE/RO staff met with NRC, Robert Bernero, to discuss regulatory transition and compliance activities.

- DOE comments on Proposed Rule 10 CFR 76 were submitted on April 12, 1994.

- DOE/HQ, the Office of Chief Counsel, and RO staffs met with Gary Shear of NRC Region III to discuss entering into agreement under the authority of the Joint Statement of Understanding between NRC and DOE. This agreement pertained to the establishment of guidance for NRC observers; the division of DOE/NRC general responsibilities; as well as implementation processes to ensure that staffing, inspection and enforcement, communications and information exchanges, and conflict resolution protocol regarding the NRC Resident Inspector Program were followed.

- The RO staff completed an extensive review of USEC's request to increase the allowable enrichment percentage from $2 \%$ to $23 \%$ and issued a revised SER; however operation at the new enrichment limit was not allowed until an acceptable operational readiness review was performed by the RO staff. 
- Meetings were held with USEC to resolve open issues pertaining to $\mathrm{UF}_{6}$ detectors and C-337A re-routed piping. Progress was made in the reduction of $U_{6}$ detector false alarms.

- The RO staff met with SSRs at PGDP, April 8-11, 1994, to discuss the roles and responsibilities of SSRs and RO staff and how they interfaced.

- The Fundamentals of GDP Operations Training course was conducted for DOE/HQ, LMES, and RO staff persons.

- USEC, DOE/HQ, DOE/ORO, RO staff and SSRs attended the first Regulatory Oversight Enforcement Conference in Oak Ridge on April 28, 1995. The focus of the discussion was on USEC's corrective action plans to ensure continued safe operation of the GDPs. The meeting stressed the need for USEC to communicate completely the plans for resolution of DOE concerns:

adherence to and/or adequacy of procedures,

management controls by USEC, and

timely characterization and reporting of events.

- The RO Manager issued a letter to LMES requesting that LMES (1) develop a clear, well-defined understanding of the NRC's expectations for a compliance plan; (2) recommend to DOE a strategy for preparation, review, and approval of the compliance plan; (3) prepare an outline of a compliance plan for DOE's use; (4) assess the extent to which the GDPs met NRC's final certification requirements; (5) evaluate alternative approaches to meeting the requirements; (6) develop recommended positions for DOE on corrective actions needed; and, (7) review USEC's initial draft compliance plans and provide recommendations to DOE regarding the compliance steps proposed in the plans.

May 1994

- The RO Manager issued a letter to USEC that outlined the compliance plan assignment made to LMES and that requested USEC's active support of that effort..

- RO staff conducted a Special Inspection at PGDP to investigate a $\mathrm{UF}_{6}$ release at the C-310 Burp Station.

- A DOE/HQ, DOE/ORO, and RO staff Program Review Meeting addressed the 19941995 budget projections. 
- The RO staff, DOE/HQ, and USEC held an ISA Review Meeting to discuss issues relating to the ISA Team findings in the areas of (a) ROA adequacy, (b) Defense Nuclear Facilities Safety Board requirements, and (c) nuclear safety at the GDPs.

- The RO staff reviewed a Justification for Continued Operation (JCO) from USEC that described the continued safe operation of the PORTS cascade as identified in event report PTS-1994-0046. The RO granted an interim JCO approval contingent on USEC providing an acceptable proposed OSR revision. The event involved the pressure ratings of some of the pressure relief devices (rupture discs) in the cascade coolant system exceeding the Limiting Safety System Settings (LSSSs) limits, in violation of the OSRs.

- The RO staff, DOE/HQ, and USEC held a Regulatory Issues Group Meeting in which the following key topics were discussed: High Enrichment Uranium (HEU) Refeed Safeguard and Security Issues, NOVs status, and DOE Appraisals and Inspections.

- The RO staff and LMES GDP Safety Analysis Report (SAR) Upgrade Program personnel met with NRC/HQ and NRC/Region III personnel to discuss the scope, status, and anticipated outputs of the GDP SAR Program, the intended use of the program results with regard to certification, and the impact that the SAR might have on NRC and DOE with regard to transition. Clarification of these issues would be addressed in future meetings.

June 1994

- On June 7, 1994, the RO Manager served an Order on USEC, imposing a $\$ 20,000$ civil penalty for five separate violations identified in NOV 70-7001/93-001. This ' penalty pertained to the unplanned $\mathrm{UF}_{6}$ release at $\mathrm{PGDP}$ on September 7,1993 . It was determined that the USEC had not conducted its activities in full compliance with the requirements of the $\mathrm{ROA}$.

- RO staff completed the PGDP Operational Readiness Evaluation (ORE) for the $23 \% 4$ assay upgrade. Based on the results, the authorization could not be modified until identified open items were completed.

- PGDP and PORTS SSRs completed their Oral Board Certification at the completion of their extensive nuclear safety training, individual training, and on-the-job training.

- The contract with American Technologies, Inc. for RO support was finalized and started.

- The Office of Chief Counsel, DOE/ORO, and RO staff met with NRC and OSHA representatives to clarify areas of responsibility with regard to worker radiation protection. OSHA staff agreed to evaluate their legal and technical positions on this issue. 
- The Office of Chief Counsel and the RO Manager attended the DOE/USEC Regulatory Issues Group Meeting which primarily focused on the compliance plan, violations in the fire protection systems, and USEC/LMUS failure to appropriately implement the Unreviewed Safety Question Determination (USQD) process.

\section{$\underline{\text { July } 1994}$}

- RO staff received a check from USEC in the amount of $\$ 20,000$ payable to DOE as a result of the EA-07-7001/93-001, June 7, 1994, Order imposing Civil Monetary Penalty.

- The Office of Chief Counsel (OCC) and the RO staff met with representatives from DOE/HQ-NE (Nuclear Energy) and DOE/HQ-HE (Environmental Safety and Health) to review and determine the applicability of the PAAA of 1988 to USEC. Two PAAA rules which would apply to USEC are Occupational Radiation Protection (10 CFR 835) and Quality Assurance (10 CFR 830.120); USEC will be exempted from these rules when NRC assumes jurisdiction. Therefore, USEC was required to submit implementation plans or seek an exemption from PAAA. Another meeting was held later with USEC, DOE/HQ, DOE, MMES, and RO staff to discuss the legal and technical implications of PAAA to the GDPs and to reach an understanding on the direction, time frame, and assignment of responsibility regarding PAAA obligations for both leased and non-leased facilities.

- Interaction with the NRC increased significantly with activities that included the GDP Operations training for both NRC/HQ and NRC/Region III senior personnel, the transmittal of GDP pre-decisional draft SAR upgrade documentation to NRC (Both HQ \& Region III), draft rule 10 CFR 76 clarification and implementation, and resolution of issues to facilitate transition of the GDPs to NRC regulation.

- OCC and the RO staff along with NRC staff met in a public meeting in Bethesda, MD, on July 28,1994 . DOE representatives reiterated their comments on selected 10 CFR 76 rulemaking issues including the Decontamination and Decommissioning (D\&D) Funding, and Emergency. Planning (EP). DOE indicated that they wanted to continue with the written D\&D Funding position, but would accept an alternative position with USEC documenting acceptance of responsibility for their generated waste.

\section{August 1994}

- OCC and RO staff members attended the monthly DOE/USEC Regulatory Issues Group Meeting that addressed transition to NRC regulation and included open communication by both agencies to develop solutions for achieving certification of PGDP and PORTS. LMUS discussed ongoing corrective actions taken since the Enforcement Conference in April 1994, and discussed the compliance plan which will address the differences between the existing plant configuration and programs, and what was required to meet 10 CFR 76 . 
- Senior NRC managers, DOE/HQ and LMES personnel, OCC, and RO staff met for training/briefing of NRC/Region III personnel on gaseous diffusion technology, DOE regulatory operations, nuclear safety overview, and SAR Upgrade Program. The RO Manager presented an overview of the Energy Policy Act of 1992, regarding provisions for leasing of GDPs and DOE transitional role in regulatory oversight function until NRC takes over as regulator. Emphasis was made on the role of RO in ensuring that the planned and existing operations were conducted in accordance with the ROA to ensure nuclear safety and safeguards and security at the GDPs.

- NRC/Region III Administrator and RO Manager signed the Inter-Agency Agreement between DOE and NRC regarding the protocol for onsite NRC Inspectors at GDPs during the transition from DOE regulatory oversight to NRC Regulation.

- The RO Manager, RO staff, and OCC representative attended a presentation that USEC made to update the NRC on USEC's activities since July 1993.

- DOE/HQ, through Lawrence Livermore National Laboratories (LLNL), performed an assessment to ensure that program deliverables provided to USEC for GDP certification efforts contain no methodological errors and no significant omissions.

- LLNL personnel met with LMES SAR Upgrade staff and RO staff in Oak Ridge and reached a mutual agreement on how pre-decisional draft documents were to be identified and transmitted to the assessment team and to NRC as well. The intent of the subject assessment was to identify issues of major significance which could bring into question the validity of the documents for support of GDP certification.

- A SER on requested changes to OSR for PORTS Freezer/Sublimers was issued which permitted a change of the-allowable enrichment stored in the freezer/sublimers pending a modification to a USQD to address reclassification of an operational load limit indicator.

- The final report on DOE ORE for PORTS operation at increased assay (up to $23 / 4$ weight percent) was issued.

- The RO Functional Inspection Program entered the final phase with seven of ten scheduled inspections performed and five reports were nearing completion. All of the 19 ROA functional areas have been investigated for at least one of the two plants. With the wrap-up of the Functional Inspection effort, the RO staff will transition into close-out of inspection findings as they are address by USEC.

\section{September 1994}

- A Regulatory Issues Group Meeting was held to discuss the Authorization Basis, ROA changes and inspections status, the PAAA, and the Compliance Plan status. 
- The OCC representative and the RO staff met with DOE/HQ and USEC to discuss USEC's request for exemption from the PAAA of 1988, nuclear safety regulations. The primary basis for the exemption request was the adequacy of the existing nuclear safety controls contained in the ROA, the schedule for NRC assumption of regulatory oversight (at which time PAAA regulations no longer apply), and the PAAA regulations implementation schedule.

- The RO staff conducted a Special Inspection of the PGDP emergency management activities during an emergency practice exercise that involved state and local agencies, Oak Ridge Emergency Operations Center, and USEC's Washington Emergency Operations Facility. The exercise demonstrated that in event of a real emergency, the participants would have been successful in providing adequate protective measures for health and safety of the general public and the plant workers.

- An OCC representative, RO staff, and USEC personnel attended a Gaithersburg, MD, NRC briefing on the final version of 10 CFR 76 and to discuss NRC's planned activities for initial certification of PGDP and PORTS. This meeting served as "day one" of the certification process. DOE's critical role in the action plan was recognized. A major part of the action plan was to include over 100 person-days (per site) onsite assessment by NRC and contractor personnel. The RO staff made presentations on Safety Analysis, the Compliance Plan, and Regulatory Oversight at the Gaithersburg FY 1995 Baseline Program Review Meeting for the purpose of providing a programmatic baseline for the upcoming fiscal year.

October 1994

- Representatives of the RO staff attended a Compliance Plan Kickoff Meeting with LMUS in Oak Ridge, TN. The purpose was to review the initial Compliance Plan submitted by PGDP, to discuss Compliance Plan issues, and to discuss potential noncompliance issues.

- A Regulatory Oversight Group Meeting was held for discussion of the status of PAAA, IRMS open items, Enforcement Conference corrective actions and Compliance Plan.

- A meeting on Radiological/Toxicological Sabotage was held in Oak Ridge, TN. A "blue-ribbon" team was established to evaluate the GDP vulnerability areas for improvement.

- On October 12, 1994, RO representatives attended meetings at NRC/Headquarters in White Flint, Md. The NRC presented the planned GDP Assessment Action Plan. 
- On October 20, 1994, RO representatives and DOE/HQ met with USEC/LMUS at PORTS to discuss preparation of the initial draft of the Compliance Plan and Nuclear Safety Upgrade Program.

- NRC's GDP Assessment Action Plan was kicked off at PGDP and PORTS to obtain baseline data for the current status of the GDPs relating to requirements of $10 \mathrm{CFR}$ Part 76.

- Final scheduled RO Functional Inspections were completed at PGDP and PORTS of the 19 functional areas of the ROA.

\section{November 1994}

- NRC held a GDP Assessment Program Workshop on November 3, 1994, to establish assessment objectives and protocols, define responsibilities, lay out assessment activities and estimate resource needs.

- On November 1,1994 , a walkdown was performed to review the leased/non-leased facility boundaries of PORTS Process Building X-326. This was done in part to facilitate transition to NRC.

- A Regulatory Issues Group Meeting was held between USEC and DOE. Key topics of discussion included: ROA Inspection status; PAAA exemption status; Enforcement Conference action status; OSR status; funding of analysis to support Certification Application; Transuranic Closure; Regulatory Boundaries; Readiness Review Criteria; USEC Production Organization Change; Corrective Action Process Improvements; 19 CFR 76 Public Meetings; and Accident Analysis issues.

- USEC briefed NRC on USEC's role in preparation of the Compliance Plan and status of format and content of the Certification Application for the GDPs.

- RO staff met with USEC on November 10,1994, to follow-up on areas of concern, including: overdue regulatory commitments, as-found conditions related to seismic supports at PGDP, the Compliance Plan, and the IRMS open items which were deleted.

- A DOE/HQ representative led a team in support of the SSRs to verify corrective actions related to recent trend of $\mathrm{UF}_{6}$ releases at Portsmouth. Findings supported . major areas of improvement in procedures, maintenance, and training.

- Fundamentals of GDP Operations Training Course was conducted November 15-17, at the K-25 Site for NRC staff assigned to assess compliance of GDPs with 10 CFR 76. 
- A special task group-was established to prepare the $10 \mathrm{CFR} 76$ Compliance Plan for DOE. This effort was to support DOE's obligation under the Energy Policy Act of 1992 to assess status of compliance with NRC rule 10 CFR 76.

- Three RO Functional (Matrix) Inspection Reports were issued. One addressed Nuclear Material Safeguards, Packaging and Transporting Nuclear Materials, Sampling and Analysis, and Security at PGDP. The second addressed Radiation Protection, Nuclear Criticality Safety, Environmental Protection, Waste Management and Chemical Safety at PORTS. The third was a Special Inspection Report evaluating the PGDP Emergency Exercise.

- RO staff received the initial NRC observation report for PORTS addressing observations made of USEC/LMUS during inspections conducted by the Resident Inspector from July 12 through October 7, 1994.

\section{December 1994}

- RO Program Workshops were conducted December 12-13 and 15-16, 1994. Key topics included: Enforcement Process, Implementation of RO Responsibilities, and Event Response and Reporting.

- DOE altered its approach to meeting its compliance plan commitments from one of review, comment, approval and finalization of the mature, substantive USEC drafts to one of DOE development and preparation of the compliance plans. This was done because of failure of USEC to provide DOE with timely drafts of applications and compliance plans, and the rapidly approaching transmittal date to NRC (April 1995).

- During a follow-up inspection of the X-705 building Microfiltration Process System restart, the PORTS SSRs discovered a failure of the operations personnel to follow procedures and failure of the procedures to adequately. include requirements of Nuclear Criticality Safety Approvals. The facility was taken off-line by USEC/LMUS. RO staff was evaluating appropriate steps or enforcement actions to take.

- Two RO Functional Inspection Reports were issued. One report addressed Security, Nuclear Material Safeguards, Packaging and Transporting Nuclear Materials, and Sampling Analysis at PORTS. The other report was for SSR inspection activities conducted September 1-30, 1994.

- A December 13, 1994, release of $\mathrm{UF}_{6}$ at PGDP refocused RO efforts. A Special Inspection was scheduled for the week of January 9, 1995. This was to be a joint DOE/OSHA inspection. Arrangements were orchestrated by RO staff. 
- An Inspector Follow-up Item was initiated to track an event on December 7, 1994, involving a full 14-ton cylinder of depleted $\mathrm{UF}_{6}$ being struck by a railcar. The event was under investigation.

- Defense Nuclear Facilities Safety Board toured the cylinder storage yard at the GDPs on December 13-14, 1994.

- RO staff met with senior representatives of USEC and PORTS on December 20, 1995 , to discuss the as-found conditions relating to seismic supports at PGDP, PORTS X-705 Microfiltration system restart, IRMS open items USQD status, USEC's Regulatory Assurance Program, corrective action process improvements and SAR funding status.

- RO staff briefed DOE/HQ staff on GDP topics including: the DOE Compliance Plan for $10 \mathrm{CFR} 76$, status of USQD for the 7/1/93 IRMS open items, and the .SAR Upgrades Program.

- OSHA announced completion of a Memorandum of Understanding between DOE and OSHA on delineation of health and safety responsibilities at GDPs.

- The final report for failure to follow Radiation Control procedures during Fundamentals of GDP training at K-25 was transmitted to Occurrence Reporting and Processing System.

\section{$\underline{\text { January } 1995}$}

- Effective January 9, 1995; USEC assumed responsibility for the Occurrence Reporting and Processing System for Event Reporting.

- RO staff performed a Special Inspection at PGDP with OSHA on January 9-13, 1995, to investigate the December $13,1994, \mathrm{UF}_{6}$ release at C-337-A-Feed Facility.

- RO staff performed a Special Inspection at PORTS on January 11-13, 1995, for the restart of the X-705 Waste Treatment Microfiltration System.

- On January 13, 1995, RO submitted a revised cost estimate and schedule for the GDP Compliance Plan Project to DOE/NE.

- A Regulatory Issues Meeting was held at PGDP on January 11, 1995. The main topics of discussion were: regulatory boundaries (DOE/NRC) and HEU Refeed (OPS/Security), investigation of PGDP C-337-A event of December 13, 1994, application/ Compliance Plan status, and unauthorized transport of liquid cylinder at PORTS. 
- RO staff and DOE/HQ performed a Special Inspection of the Emergency Response Exercise at PORTS on January 14, 1995.

- Entry of data into the database to link compliance plan issues to plant identified or acknowledged issues continued.

- The Fundamentals of GDP Operations Training course was conducted on January 1718, 1995.

- RO staff attended a technical meeting with DOE, USEC, and NRC in Washington, DC. USEC discussed the classification of structures, systems, and components in the quality assurance program. The NRC addressed the regulation of chemical safety.

- RO staff received an observation report from the NRC for PGDP which addressed routine safety and safeguard observations made from October 25 through December 25,1995 , and a special review of the chemical safety program.

- RO staff completed major milestone three, First Technical Draft, on schedule, January 26, 1995.

- RO staff met with USEC on January 25,1995 , to discuss regulatory oversight options for the HEU Refeed operations.

- RO staff members visited PORTS on January 30-31, 1995, to examine facilities in the HEU Refeed operations including a walkdown of X-326 and X-705 facilities.

- The Uranium Programs First Quarter Baseline Program Review meeting was held in Oak Ridge on January 31, 1995. A summary of progress on Compliance Plan, cost estimates, and schedule was presented.

- RO staff hosted a visit from DOE/HQ representative and provided a tour on how the IRMS issues were reviewed, tracked, and documented.

February 1995

- Ongoing weekly meetings were held with NRC, DOE and USEC.

- Dick Dierlam accompanied the Compliance Plan Manager to review the progress of the project on site.

- RO staff noted that USEC would assume responsibility of HEU Refeed activities when the refeed material enters Bldg X-326 at PORTS and that the ROA would be implemented to provide oversight. 
- On February 1, 1995, RO staff attended a management meeting between DOE, USEC and NRC in Washington, DC to review HEU Refeed activities and NRC proposal for regulation of Unclassified Controlled Nuclear Information at the GDPs. NRC reinforced their position on USEC being certified in October 1995, for possession of $U^{235}$ with less than $10 \%$ assay; USEC would not be allowed by NRC to be involved with any HEU activities after NRC took over regulation of the GDPs.

- A second draft of technical sections of the Compliance Plan were completed, ahead of schedule, on February 3, 1995. Noncompliance issues from the Compliance Plan were transmitted to USEC for review. SME and peer reviews from DOE/HQ and DOE/ORO were ongoing. An initial classification review of the draft compliance plan was completed.

- RO staff closely monitored ongoing NRC Observation Reports at both GDPs to validate the consistency of NRC observations with RO inspection findings.

- The Compliance Plan project received technical briefings on SAR upgrade program.

- RO attended a technical meeting between USEC/DOE/NRC concerning quality assurance program implementation at GDPs on February 7, 1995.

- A technical meeting on the methodology for Accident Analysis was held on February 9,1995 , at which USEC presented to DOE and NRC how and why a selected set of accidents were chosen for analysis.

- In a February 9, 1995, letter to USEC, the RO staff announced that an investigation team had been formed on the occurrences involving autoclaves. USEC was asked to prepare a presentation on the autoclaves for the February 22, 1995, Regulatory Issues Meeting at PORTS and the letter listed the topics to be included in the presentation.

- NRC staff visited the Compliance Plan project to attend a briefing on the status of project and methodology used to develop the compliance plan.

- DOE issued a letter to USEC on February 13, 1995, which documented the agreements reached regarding funding for preparation of USEC's portion of the GDP SAR activities and the refeed of HEU at PORTS.

- SSRs and RO staff attended training classes in Oak Ridge addressing Security Classification, Nuclear Materials Control and Accountability, and Safeguards and Security for the GDPs on February 14 and 15, 1995.

- The SAR for revised OSRs governing operations at assays up to $23 / 4 \% \mathrm{U}^{235}$ was completed and OSRs were approved on February 16, 1995. 
- On February 17, 1995, the RO Manager indicated that in addition to inspection and enforcement activities of the RO effort, significant attention would be placed on the DOE Compliance Plan to NRC's 10 CFR 76, HEU refeed at PORTS and $23 / 4 \%$ assay at PGDP.

- Three Inspection Reports for SSR inspection activities were issued with emphasis given to inspection report timeliness.

- A draft compliance plan dated February 20, 1995, was sent to USEC for review.

- RO staff noted that the revised USEC application sections that had been submitted had less detail than expected.

- On February 22, 1995, a meeting held between NRC and RO staff to review the Compliance Plan project.

- RO staff visit to PORTS February 21-23, 1995, to review HEU refeed activities, potential safety risks, and regulatory oversight boundaries. Performed walkdowns of X-326 Process Building, X-345 Special Nuclear Material Storage Building, and X-705 and held a special meeting with USEC and LMES on February 23, 1995, to discuss refeed effort.

- A Regulatory Issues Group meeting was held on February 22, 1995. Topics included: autoclave events, Compliance Plan completion, open item closure process, HEU refeed, post NRC certification boundaries, OSR/TSR transition, and DOE inspection report status. The USEC/LMES presentation on autoclaves did not identify any near term fixes to reduce the number of events.

\section{March 1995}

- DOE/HQ (Nuclear Safety) requested a copy of March 8 draft for review.

- RO staff directed an independent technical evaluation to be performed by autoclave SMEs on autoclave problems including root cause analysis.

- Mr. Rob Woolley of USEC visited Oak Ridge on March 2, 1995, to discuss the DOE compliance plan effort and to develop an understanding of the DOE methodology in preparing the Compliance Plan and how it paralleled the USEC application.

- On March 3, 1995, the RO Manager noted a milestone that USEC had no overdue regulatory commitments.

- Compliance Plan peer reviews from DOE/HQ and DOE/ORO as well as coordination with DOE/HQ-NS were completed. 
- The RO Manager issued a list of possible vulnerabilities for the Compliance Plan and proposed contingency plans to address the items on the list.

- RO staff prepared for the ORE for refeed of HEU at PORTS and PDGP.

- Two consultants representing DOE visited on March 7, 1995, to perform a more detailed evaluation of USEC/LMUS autoclave failure.

- The RO Manager and staff attended a USEC/DOE/NRC meeting in White Flint, MD on March 7, 1995. USEC made a presentation on methodology for developing accident scenarios, etc. USEC raised the issue of NRC jurisdiction for protection of onsite workers from accidents versus protection of public only.

- In a March 7, 1995, meeting, Mr. Rifakes and Mr. Woolley of USEC, key NRC officials, the RO Manager, and Robert Burnette, Director of Fuel Cycle Safety and Safeguards, expressed serious concerns about the completeness of USEC's application.

- USEC representatives were in Oak Ridge to discuss differences between DOE and USEC on non-compliance issues, on March 6-7, 1995.

- On March 8, 1995, the Compliance Plan Manager issued memo to request internal DOE/ORO review and approval of DOE compliance plans and submitted the drafts for review.

- On March 14, 1995, RO staff received preliminary copy of the USEC/LMUS investigation report on autoclave system occurrences at PORTS. RO staff closely monitored ongoing analysis of autoclave concerns.

- RO staff participated in the onsite portion of the DOE ORE for HEU refeed at PORTS. On March 16, 1995, they conducted a mock exercise and documented concerns to USEC.

- The Fundamentals of GDP training was offered at K-25 on March 14-16, 1995.

- On March 16, 1995, DOE and NRC held a closed meeting on the status of the Compliance Plan, USEC's application for certification, and transition of regulatory authority.

- RO staff issued two RO Inspection Reports for PGDP.

- RO staff initiated discussions on USEC's plan to request approval for operations at $5 \%$ assay at PGDP. 
- RO staff worked with DOE/ORO reviewers to satisfy comments and to further document linkages within the database for an auditable trail for Compliance plan issues.

- SMEs from RO staff attended the first of four subject matter meetings held by the NRC to provide USEC with their expectations on detail required in the application.

- RO staff attended a Regulatory Issues Group meeting between USEC and DOE in Gaithersburg, MD, on March 22, 1995. Key issues discussed included Compliance Plans, HEU refeed and transition plan. A presentation was made on conclusions on autoclave problem. They addressed a preliminary report from PGDP on problems with Freon cooler pressure relief system and what corrective actions would be implemented.

- The Compliance Plan project transmitted the DOE/ORO Compliance Plans for PORTS and PGDP to DOE/HQ with a request for comments on March 24, 1995.

- RO staff received a preliminary report from PGDP indicating that rupture disks in several Freon cooler pressure relief systems might not operate as designed. The condition also applied to PORTS. A USQD and JCO were being prepared.

- A representative from RO attended a USEC/DOE/NRC meeting on accident analysis source term and consequence evaluation on March 24, 1995.

- RO staff received the NRC observation report for PGDP covering December 13, 1994 - January 31, 1995.

- NRC issued two letters - one on NRC's concern with USEC's organizational changes to site management, quality and level of detail in USEC's application for certificate and the other on NRC's announcement of public meetings regarding certification of GDPs.

- A meeting was held on March 27, 1995, in Washington, DC, between ORO and DOE/HQ to discuss remaining activities related to HQ's review of DOE Compliance Plan.

- On March 28-30, 1995, members of RO staff were at Lawrence Livermore National Laboratory, to participate in a meeting with DOE/HQ for review of GDPs' SAR program documents.

- On March 29, 1995, USEC submitted a request for an OSR change to permanently remove the Freon cooling system relief valves at both GDPs. DOE requested more information. A SER was being prepared. RO authorized continued operation with an interim corrective action which required USEC to place a dedicated operator on all 
shifts at a control room with coolant system alarms to monitor Freon coolant system parameters and to shut down the system on receipt of alarm.

- A member of RO staff met with NRC to discuss USEC's application in the areas of fire protection and management controls.

\section{April 1995}

- DOE/HQ review of the Compliance Plan was progressing with the ES\&H review team in PORTS for onsite evaluation.

- RO staff met with NRC to review the March 24 draft (Revision A) of the Compliance Plan and to receive feedback. The NRC indicated that the documents were adequate for their review.

- RO staff attended USEC/NRC/DOE meeting on April 6, 1995, on USEC's transition of OSRs to TSRs, the scope of TSRs and status of IRMS items.

- Two USEC violations were being considered for escalated enforcement actions. One at PGDP involved failure to post fire watches. The other at PORTS involved improper movement of a liquid $\mathrm{UF}_{6}$ cylinder using a straddle carrier.

- Three RO Inspection Reports for PORTS and two for PGDP were issued.

- DOE/HQ-EH staff were at PORTS during the week of April 7, 1995, to assess level of compliance with $10 \mathrm{CFR} 76$.

- The Compliance Plan project met informally with NRC to review recent revisions of compliance plan.

- USEC/LMUS requested that the ORE for HEU refeed of five inch cylinders be postponed.

- The Compliance Plan project received informal review comments from DOE/HQ and USEC. It was noted that two new compliance issues were at USEC and not returned and that (1) ongoing SAR development might generate data that would require revision of the USEC SAR, including seismic; and (2) the scope of the TSRs did not adequately address worker safety.

- As a result of SSR issues on cranes, RO staff scheduled a Special Inspection.

- After review of as found condition at PORTS involving noncompliance with OSRs for cold trap relief valves, $R O$ Manager authorized interim operation. 
- - SERs and implementing OSRs for removal of Freon cooling system relief valves were transmitted to USEC for PDGP on April 11, 1995, and PORTS on April 12, 1995.

- The RO Manager made a presentation on the past and current oversight and enforcement functions of DOE RO program associated with the GDPs leased to USEC at a DOE Rules Enforcement Program, Roles and Responsibilities Workshop held in Washington, DC on April 13, 1995, to formulate PAAA enforcement programs in DOE. DOE Compliance Plan to the NRC rule 10 CFR 76 was approved and signed through DOE/ORO and DOE/HQ.

- RO staff granted an exception from OSR for 13 overpressure protection system relief valves in Freon cooling at PGDP.

- RO staff formed a team to perform special inspections at both GDPs on crane operations to start May 8, 1995.

- RO staff granted a 30 day extension for continued operations at PORTS Extended Range Product and Low Assay Withdrawal facilities.

- The onsite ORE for HEU Refeed was completed at PORTS, with anticipated DOE approval to begin refeed by May 12, 1995.

- RO staff held Enforcement Conferences in Oak Ridge on April 26, 1995, to determine appropriate actions to take on two violations: the need for fire watches at PGDP and improper movement of a cylinder at PORTS.

- The Compliance Plan was transmitted to USEC and USEC submitted it to the NRC on April 24, 1995. RO staff provided the NRC with a courtesy copy of DOE's transmittal of the Compliance Plan.

- On April 26, 1995, PGDP SSRs prepared a draft Fact Sheet to address an incident involving a person with weapons in his car on an access road of the plant.

- On April 27, 1995, a Mid-Year Program Review meeting was held in Oak Ridge at which RO accomplishments, inspection and enforcement history, and a Compliance Plan project report were presented.

- On April 28, 1995, two expansions joints were discovered at PORTS that had not been modified to assure proper behavior during an earthquake as identified in ROA. This item was treated as an "as found" condition with a JCO prepared by USEC/LMUS and submitted to the RO Manager. The JCO was approved on May 2, 1995. SSRs continued to monitor to ensure modifications were completed as scheduled. 


\section{May 1995}

- The Compliance Plan team received and responded to comments from USEC on the Compliance Plans USEC intended to submit to NRC. They evaluated USEC's application for differences between the submitted document and application information used by Compliance Plan team. Work continued on the database of IRMS issues tied to the Compliance Plan.

- On May 5, 1995, the NRC rejected USEC's application for Certificate of Compliance for PORTS and PGDP.

- Two Level $\Pi$ events occurred at PORTS concerning $\mathrm{UF}_{6}$ smoke head detectors. On April 30, 1995, smoke heads in Building X-326 were activated due to a residual release of $\mathrm{UF}_{6}$ from a compressor that was undergoing maintenance. On May 2, 1995, the smoke head detectors for cell 33-4-4 in Building X-333 were inadvertently disabled. The SSRs continued to evaluate these items to determine if additional regulatory actions were required.

- An occurrence occurred at PORTS involving 2.5 ton Test Cylinder being placed on scales by an overhead crane. The operator failed to remove two crane hooks after the test. All cylinder movement was temporarily suspended. RO staff followed the investigation of the incident and performed more detailed observations of cylinder movement practices at PORTS.

- RO staff issued an Inspection Report for observation of activities associated with the PORTS Emergency Response Exercise held on January 14, 1995. RO staff issued an Inspection Report for Engineering Reviews, Maintenance, Nuclear Criticality Safety, Fire Protection, and Self-assessments at PORTS.

- The crane operations inspection team preparation was completed. May 15,1995 . The crane inspection team completed their review of crane operations at PGDP on May 24, 1995, and for PORTS on May 26, 1995, and submitted their draft report to the SSRs for their review.

- Refeed of HEU into low enriched uranium portion of cascade at PORTS was approved after RO staff conducted an ORE and the authorization letter issued on May 11,1995 . HEU refeed was initiated on May 15, 1995, and suspended by USEC that day when a valve misalignment resulted in the HEU sublimating from the cylinder into a closed path. RO staff closely followed the event.

- A Level II Violation related to fire watches at PGDP was issued to USEC on May 15, 1995, with mitigation of Civil Penalty to zero. . 
- On May 16, 1995, the Compliance Plan project issued a memo on Compliance Plan Project Scope Modifications: Tracking and Verification. DOE requested that present scope of the Compliance Plan be expanded and noted that USEC was unresponsive to DOE and NRC suggestions and guidance.

- The SMEs continued to finalize their project documentation packages.

- The Fundamentals of GDP Training was held May 16-18, 1995, at the K-25 Site in Oak Ridge.

- RO and DOEE staff attended a public meeting held between NRC and USEC on May 17,1995 , concerning NRC's rejection of USEC's certification application. This was followed by a private meeting between NRC and USEC to discuss the physical security plan to be submitted in the new application.

- RO staff performed ORE for $23 / 4 \%$ assay upgrade at PGDP on May $16-19,1995$, and conducted an exit meeting.

- On May 22-23, 1995, RO staff attended a public NRC/USEC meeting in Rockville, $\mathrm{MD}$, to address the accident analysis chapter of the application for certification. NRC provided USEC with details on their expectations regarding USEC's resubmittal of their application for certification of the GDPs.

- On May 25, 1995, four members of the DOE HEU ORE team returned to PORTS to observe activities involved in preparing for restart of HEU refeed. The restart of this operation did not require RO authorization because USEC had shut down the HEU refeed.

- A Level II Violation was issued on May 24, 1995, to USEC with proposed civil penalty for improper use of straddle carrier. The violation was discussed in an Enforcement Conference on April 26, 1995.

- SMEs attended USEC/NRC technical meetings on May 26 and May 30-31 and June 1, 1995 , to discuss various topics to support resubmittal of USEC's application.

- On May 31, 1995, during corrective action that resulted from the HEU refeed valve error at PORTS on May 15, two more valves in incorrect position were found. A member of RO HEU team was on site to monitor the corrective actions.

June 1995

- At the DOE/ORO Staff Meeting on June 6,1995, the RO Manager presented the current status of the RO program and addressed DOE/ORO's proposed roles and 
responsibilities in the PAAA enforcement program.

- HEU Refeed was reestablished at PORTS on June 5, 1995.

- The Compliance Plan project was placed on hold except for two activities: the document center continued to process correspondence and reports for the Compliance Plan and SMEs continued to attend select NRC/USEC meetings in Washington, DC.

- On June 6, 1995, RO staff attended a working level meeting between NRC and USEC in Washington, DC, on how to submit TSRs in the next submittal of application for certification.

- RO staff began a special inspection at PGDP to determine USEC's compliance with requirements for implementation of the USQD Program.

- One RO Inspection Report for PORTS issued.

- RO staff announced that on July 1, 1995, RO staff would begin a Special Inspection regarding items canceled from USEC/LMUS IRMS Database.

- DOE sent a letter to Mr. Rifakes of USEC which discussed the requirements for validation of SAR upgrades including invoicing and future offsets.

- SSRs at PORTS closely monitored disassembly of a compressor at X-705 which had been removed from $X-326$ as part of the HEU suspension activities and which was found to contain a large deposit of material. No anomalies were found. The RO Manager kept the NRC informed on this matter.

- RO staff went to PGDP and PORTS to obtain copies of safety-related procedures in support of the NRC's request that DOE supply copies of these procedures from both GDPs to establish a baseline.

- RO staff completed an unannounced inspection at PGDP to USQD process and held an exit meeting on June 15, 1995.

- The Compliance Plan team prepared for the meeting on shared systems. On June 13, 1995, RO staff attended DOE/NRC/USEC meeting in Germantown, MD regarding shared-site issues.

- In the June 14, 1995, Regulatory Issues Group meeting held between USEC and DOE in Bethesda, MD, the issues discussed included OSR to TSR conversion, accident analysis upgrade status, and USEC application status.

- The Compliance Plan project prepared for restart and developed a project schedule. 
- On June 21,1995, PGDP was authorized to conduct operations at up to $23 / 4 \%$ assay enrichment.

- The RO Manager attended a senior management meeting with USEC and NRC in Washington, DC, on June 20,1995, to discuss strengthening USEC's management presence on site at the GDPs.

- RO staff attended technical meetings with NRC and USEC on June 22, 1995, in Rockville, $M D$, to follow-up on configuration control and implementation of a graded approach for QA.

- RO staff noted an increase in autoclave occurrences at PORTS and communicated this concern to USEC.

- An RO staff member substituted for an SSR at PGDP and performed a follow-up inspection on a non-cited violation concerning nuclear criticality safety issues in building C-720.

- RO staff reviewed activities in X-705 decontamination facility at PORTS to evaluate regulatory transition options between DOE and NRC.

- RO staff prepared a press release regarding USEC's payment of a $\$ 10,000$ fine imposed by DOE as a result of a PORTS liquid cylinder being moved by a straddle carrier.

- DOE approved page changes for X-330 and X-333 Cold Recovery System at PORTS. RO staff continued its efforts to resolve issues associated with a proposed OSR revision involving the maximum allowable assay limits at the Low Assay Withdrawal and Extended Range Product Withdrawal areas during cylinder filling.

- On June 27-28, 1995, RO staff attended a series of meetings with NRC and USEC in Rockville, $\mathrm{MD}$, on configuration management, quality assurance, and transportation. USEC presented draft sections of the application in these areas.

- On June 28,1995 , the RO Manager participated in a panel on NRC certification of DOE-owned USEC-operated enrichment facilities at the ANS conference.

- The RO Manager and staff prepared and submitted an abstract which was accepted for inclusion in the Annual DOE ES\&H Conference to be held November 13-17, 1995. 


\section{$\underline{\text { July } 1995}$}

- Compliance Plan staff attended a meeting between USEC and NRC on radiation protection and material control and accountability.

- The Compliance Plan team developed a representative Compliance Plan issue on configuration management as an example to discuss with NRC.

- On July 6, 1995, a member of RO staff attended a meeting in Bethesda, MD between USEC and NRC on the status of USEC's application. Issues discussed included USEC's proposal to continue the HEU refeed at PORTS in the current manner after NRC certification, USEC's request for meetings to confirm the DOE's 1995 SAR and SAR upgrade would meet the NRC's SAR requirements, USEC's suggestion to not . certify the X-705 facility and leave it under DOE ROA, transition of OSRs to TSRs in the four months following NRC certification, and the NRC/OSHA memorandum of understanding under development to allow the NRC to be responsible for radiological issues.

- DOE granted USEC interim operation of the Low Assay Withdrawal and Extended Range Product withdrawal areas pending final approval of OSR changes and supporting safety analysis documentation.

- RO staff went to PGDP and PORTS to gather copies of procedures to be sent to the NRC: Copies of the procedures were sent to the NRC.

- On July 10,1995, the RO Manager met with Keith Christopher from DOE/HQ to discuss how enforcement had been accomplished under the RO agreement and how program elements could apply to PAAA.

- The Compliance Plan project team held a teleconference held with NRC to prepare for the July 13, 1995, meeting on the Compliance Plan.

- The RO staff attended the July 12, 1995, Regulatory Issues Group Meeting between USEC and DOE in Paducah, KY. Issues discussed included the SAR upgrade program, DOE review of canceled IRMS items, OSR to TSR transition, changes to event reporting criteria, status of special inspections, HEU suspension and refeed, and shared site issues.

- On July 14,1995 , the RO staff attended a meeting at PORTS regarding HEU program. Topics included the suspension effort and the refeed of HEU.

- On July 19, 1995, DOE RO and Compliance Plan staff met with USEC and NRC to provide NRC with a good understanding of the scope, analytical methods and content that NRC could expect from site-wide SAR. 
- RO staff received an NRC observation report for PORTS covering April 4 - June 9, 1995, and noted significant improvernent in identififuäiviull of non-conformance's.

- An Inspection Report for PGDP was issued, documenting the special inspection conducted January 9-12, 1995. Two violations were cited in the report: One involved the failure to terminate $\mathrm{UF}_{6}$ cold feeding operations in accordance with OSRs when abnormal conditions occurred; the other was for implementation of operational changes involving a USQ without prior DOE consent and written approval.

- RO staff attended ORR training on July 19-20, 1995, in Oak Ridge.

- On July 14, 1995, the Compliance Plan project received the first five sections of the application for each plant and distributed them to SMEs for review.

- On July 25, 1995, DOE sent a letter to Mr. Rifakes of USEC regarding revision of the Compliance Plans and which requested that a member of his staff come to Oak Ridge to expedite coordination of Compliance Plan issues. The letter conveyed concerns and requested specific dates on the schedule.

- The Compliance Plan project transmitted comments to USEC on the event reporting application section that had been received and prepared to send comments on document control and record management section.

- The Compliance Plan project met with John Dietrich and discussed how DOE and USEC schedules must work together as well as DOE concerns about the first drafts that had been received. It was also announced that a Compliance Plan staff member would be placed in Washington as of July 26, 1995.

- On July 21, 1995, USEC notified RO staff of a deficiency at PGDP regarding inadequate testing of certain valves. The RO Manager granted verbal authorization to operate until July 28,1995 , contingent upon receipt of an adequate JCO.

- On July 26, 1995, the RO staff attended a NRC/USEC meeting in Rockville, MD, on the transition from OSRs to TSRs. Three transition options were discussed at that meeting.

- On July 27, 1995, DOE, the RO staff attended NRC/USEC meeting in MD, to discuss HEU suspension and HEU refeed regulatory requirements after NRC certification.

- RO staff went to PGDP to perform a follow-up evaluation of problems related to $\mathrm{UF}_{6}$ detectors.

- RO staff received the NRC observation report for PGDP for April 4-June 26, 1995. 
- RO staff attended a senior management meeting on July 31,1995 , in Bethesda, MD, between NRC, USEC and DOE on current status and schedule of certification.

\section{August 1995}

- The Compliance Plan project received notification that USEC had changed plans and would put draft sections through on-line and parallel reviews at the same time. The Compliance Plan project noted that the USEC schedule continued to slip.

- On August 1, 1995, results of natural phenomena studies, performed under the SAR upgrade and in which LMES indicated seismic vulnerability, were presented to PGDP by LMES.

- RO staff gave approval for interim operation of feed autoclaves at PORTS under the conditions of USEC's JCO, for 45 days or until the redundant autoclave isolation valves could be independently tested to current OSRs, whichever occurred first.

- The Fundamentals of GDP Operations Training was conducted on August 1-3, 1995, at $\mathrm{K}-25$.

- RO and Compliance Plan staff attended a meeting on August 3, 1995, in Bethesda, MD, with NRC and USEC on regulatory activities for Material Control and Accountability and security of HEU after NRC certification.

- RO and Compliance Plan staff attended a follow-up meeting on the Chemical Safety portion of USECs application.

- The Compliance Plan project received six additional draft sections of the USEC application for certification.

- On August 9, 1995, the RO staff attended a meeting among NRC, USEC, and DOE regarding the status of USEC's applications. NRC identified a certification schedule with effective date 90-120 days later, with the ROA to stay in place.

- RO staff continued to monitor seismic vulnerability at PGDP.

- RO staff attended TSR training session in Oak Ridge to support DOE review of new TSRs.

- On August 8, 1995, "The OSRs for ERP, LAW and Tails Withdrawal Facilities," GAT/GDP-1074, part $\mathrm{K}$ was approved, which allowed the maximum assay in cylinders during filling to be increased and incorporated new moderation control. Approval of OSR revision of GATG/GDP-1074, Part B, "OSRs for X-326 Uranium Enrichment and Purge Cascades," which allowed the seal exhaust pump to be filled during operation, was expected that week. 
- Compliance Plan staff attended a meeting at DOE/HQ in Washington, DC, to review the compliance plan project on August 10, 1995.

- On August 10, 1995, a separate Compliance Plan meeting was held between NRC, USEC, and DOE in Washington, DC, to follow up on a prior meeting on organizational structure.

- SMEs visited sites and drafted Compliance Plan issues.

- RO staff participated in the ORE for proposed refeed of HEU from 8 to 12 inch cylinders at PORTS.

- Two unusual occurrences (UO) and one Level III event were reported. PORTS had a UO for violation of an OSR. The PGDP UO was for failure of a freezer/sublimer motor operated value. The PGDP Level III event resulted from to two major power suppliers declaring system emergency and reducing power to plant.

- The RO Manager attended the PAAA Enforcement Coordinators Workshop in Denver, CO, August 16-18, 1995, and made a presentation on PAAA implementation plans at DOE/ORO.

- On August 18, 1995, the RO Manager transmitted the first round of draft sections of Compliance Plan to DOE/HQ for review.

- On August 18, 1995, the RO Manager transmitted to USEC and DOE/HQ five issues applicable to both plants.

- Two RO staff attended an EP Tabletop Exercise at PORTS on August 21, 1995.

- On August 22, 1995, RO staff attended the USEC/NRC meeting in Rockville, MD, to discuss organization sections of USEC's application for certification.

- On August 23, 1995, RO staff attended Regulatory Issues Group meeting at PORTS between USEC and DOE. Topics discussed included the status of applications for certification, schedule, status of Compliance Plan, OSR to TSR transition and postNRC certification regulatory approach.

- RO staff granted USEC interim approval for continued operation of Extended Range Product, Low Assay Withdrawal, Tails Withdrawal and X-340 facilities pending DOE approval of OSR revision.

- An RO staff member attended the IAEA workshop on August 23-24, 1995, at PGDP on potential application of IAEA safeguards at GDPs. 
- One RO Inspection Report for PORTS and one for PGDP, with no violations, were issued covering the period from May 1-31, 1995.

- RO staff reviewed draft TSRs from USEC and identified several potential inadequacies.

- RO Manager issued a letter on August 24, 1995, to Mr. Rifakes of USEC with comments on Compliance Plans for certification of the GDPs. The letter outlined the need for significant changes and commented on the lag between documents submitted to $\mathrm{DOE}$ and draft at plants.

- SSRs were notified in a memo on the GDP Inspection Strategy, dated August 29, 1995 , that the USEC certification process would take longer than originally anticipated. It refined the focus of inspection plans which used ROP-IP-001 to conduct activities. SSRs were asked to concentrate on (1) inspection of functional areas and related buildings that may not have been addressed in recent past and (2) closure of open items. The memo reiterated the sampling approach and the need to focus on issues that had a safety significance.

- On August 25, 1995, the Compliance Plan project transmitted to DOE and USEC seven issues applicable to both plants for review and continued to prepare remaining issues.

- RO staff received a copy of NRC Policy Issue document which addressed current certification status, proposed approach of regulatory transition from DOE to NRC and discussion of alternatives for enforcement actions after NRC regulatory authority.

- RO staff performed a preliminary review of draft TSRs submitted by USEC and identified areas in need of work.

- On August 25, 1995, RO staff attended USEC/NRC management meeting in Rockville, $M D$, to discuss USEC's application status.

- The RO Manager granted authorization for continued operations at PGDP Bldgs. C333A and C-227A until September 6, 1995, contingent on receipt of a JCO.

- The ORE team's observations from evaluation of HEU refeed from 8" to 12" cylinders was formally transmitted to USEC on August 30, 1995.

- On August 30, 1995, RO staff transmitted formal review comments regarding OSR GAT/GDP-1074, Part B, X-326 Uranium Enrichment and Purge Cascades Elimination of Area Control Room 5 Operator.

- RO staff discussed shared site issues with an LMES representative. 
September 1995

- HEU refeed activities resumed at PORTS with 3 five-inch cylinders being connected to the feed facility on September 1,1995. Corrective actions for the ORE team's evaluations on 8 and 12 inch cylinder refeed were being pursued.

- On September 1, 1995, the Compliance Plan project transmitted issues for seven additional sections of the Compliance Plan to DOE/HQ for review and comment.

- On September 5, 1995, DOE/ORO transmitted the revised DOE Compliance Plan items to the NRC for review.

- On September 7, 1995, RO staff attended a seminar on development and definition of the High Confidence Low Probability of Failure (as it related to seismic).

- Based on a JCO, RO Manager granted continued operation of autoclaves at PGDP on September 6, 1995, until the revision to the OSR for the $U_{6}$ Feed Facilities was completed, up to September 22, 1995.

- The Compliance Plan project received comments from DOE and USEC reviews on the second group of issues transmitted August 25, 1995. SMEs revised the Compliance Plan to incorporate these items.

- RO staff issued a letter on September 8, 1995, to Mr. Rifakes of USEC to confirm concurrence with document proposing regulatory approach for post-NRC certification of GDPs that involved DOE and NRC.

- RO staff held a meeting with GDP SAR Upgrade personnel, LMUS, and USEC. Seismic results that were finalized or near final were presented. RO staff as preparing a draft Directive for Information to require USEC to evaluate the safety significance of this information.

- On September 8, 1995, remaining Compliance Plan issues, except QA, HEU Refeed, and HEU suspension, were transmitted to DOE for review and comment.

- September 8, 1995, the RO Manager granted authorization for continued operation of PORTS autoclaves in Bldg. nos. X-342 and X-343 until October 10, 1995, subject to receipt of USEC's JCO by October 2, 1995.

- RO staff finalized the document to address regulatory approach for post-NRC certification of GDPs.

- A teleconference was held among DOE, NRC, and USEC on September 14, 1995, to discuss apparent weaknesses and omissions in draft TSR documents. 
- Two RO staff attended Facilities Representative Advanced Nuclear Course training.

- The RO Manager attended the RO Program Support Activities Program Review meeting in Oak Ridge.

- On September 15, 1995, the third group of draft Compliance Plan issues was transmitted to NRC for advance review. The Chemical Safety issue for PORTS and C-360 Crane issue for PGDP were also transmitted.

- NRC completed advance review of the initial submittal of Radiation Protection and Transportation issues and indicated that the issues contained sufficient information.

- The Compliance Plan project received USEC's application for certification, Revision 1 submitted to NRC September 15, 1995. SMEs reviewed the document.

- On September 19, 1995, RO staff attended a training session in Oak Ridge on SAR and TSR Implementation Plan Review.

- On September 20, 1995, RO staff attended a NRC/USEC meeting regarding NRC's review of USEC's application for certification. NRC noted that TSRs did not contain sufficient safety controls to mitigate all of the accident scenarios in 1985 SAR. NRC raised the issue about whether HEU activities in X-705 could be segregated and discussed the impact on Regulatory Oversight.

- The RO staff made presentations at the Fiscal Year 1996 Uranium Programs-Preview of the Baseline Program Plan held in Oak Ridge on September 21, 1995.

- Compliance Plan team representatives met with DOE/HQ on September 21, 1995, to present final Compliance Plan issues and to suggest an approach to comment resolution.

- The RO staff's review of TSRs in four key areas was 50 percent complete.

- The RO Manager transmitted a Directive for Information to USEC regarding concerns about seismic capacity and cascade buildings behavior at PGDP being a potential USQ in a September 22, 1995, letter to Mr. Woolley.

- DOE/ORO transmitted "near final" revisions to DOE Compliance Plan issues to the NRC for advance review on September 22, 1995.

- On September 25, 1995, the Compliance Plan project transmitted the Fundamental Nuclear Material Control issue to the NRC for advance review. 
- $\mathrm{DOE} / \mathrm{HQ}$ representatives visited Oak Ridge to discuss the resolution of DOE/HQ comments on the near final draft of Compliance Plan issues with the Management Review Committee. Three issues remained to be finalized.

- RO staff evaluated the trend of increased autoclave occurrences reported and prepared a position paper in response.

- On September 26, 1995, RO staff transmitted comments to the Advisory Committee on External Regulation of DOE Nuclear Safety, relating RO staff's perspective on regulation of GDPs during transition to NRC.

- On September 26, 1995, the RO staff attended a senior management review of the certification effort for GDPs, which involved DOE, NRC, and USEC, in Rockville, $\mathrm{MD}$.

- On September 27, 1995, the RO staff met with USEC for the monthly Regulatory Issues Group Meeting in Bethesda, MD. Items on the agenda included: Status of NRC certification, OSR/TSR review status, Compliance Plan schedule/status, Inspection Program status, C-337A startup, shared site issues, and status of PAAA exemption request.

- On September 27, 1995, RO staff met with NRC to discuss DOE review of the initial draft of USEC TSRs. DOE and NRC comments were consistent: not sufficient controls for an adequate safety basis

- On September 27, 1995, DOE gave approval to allow interim operation of cylinder movement and storage operations at PGDP C-310 cool-down yard until December 15, 1995 , based on a JCO concerning spacing requirements for liquid $U_{6}$ cylinders.

\section{October 1995}

- On October 3, 1995, RO staff sent a letter to Mr. Woolley of USEC to acknowledge receipt of September 5, 1995, letter which revised the commitment to perform a review of performance measures on monthly rather than weekly basis.

- On October 4, 1995, the fifth group of Compliance Plan items was transmitted to USEC and DOE/HQ for review. With a few exceptions, the Compliance Plan was frozen.

- DOE/ORO transmitted revised application compliance plan issues for NRC review on October 4, 1995, and on October 17, 1995.

- RO staff continued to review autoclave occurrences. 
- On October 4, 1995, an RO staff member attended NRC/USEC technical meeting in Bethesda, MD, on the preparation of TSRs.

- RO staff sent USEC the latest version of the document describing proposed regulatory approach for post-NRC certification of GDPs on October 11, 1995.

- On October 12, 1995, RO staff was scheduled to send two PGDP issues to NRC "Inventory of $\mathrm{UF}_{6}$ " and "Radioactive Calibration Source Accuracy."

- RO staff received "acceptable for review" responses from NRC on 58 of 83 issues.

- RO staff were at PGDP the week of October 12, 1995, to conduct routine inspections to verify conformance with Implementation Requirements of the ROA.

- On October 10,1995, the RO Manager granted approval of USEC's request for PORTS autoclaves to continue operation for additional 90 days pending development and implementation of new testing procedures.

- DOE completed its evaluation of X-705 Decontamination Bldg. Microfiltration pH Shutdown Safety System modification. Approval was granted on October 10, 1995.

- RO staff were in PORTS on October 11-12, 1995, to observe the plant's review and approval process for documents that DOE requested as part of ORE.

- On October 12, 1995, RO staff attended a meeting with NRC in Washington, DC, to discuss seismic analysis.

- Revision 1 of DOE Compliance Plans for PGDP and PORTS were transmitted to DOE/HQ for review and approval on October 13, 1995. Three EH issues were identified.

- On October 16, 1995, RO transmitted a Request for Information to USEC regarding cylinder spacing in the C-310 cooldown yard at PGDP.

- The RO Manager met with SSRs to discuss various topics.

- The Regulatory Issues Group meeting was held in Oak Ridge, on October 18, 1995. Items discussed included: Shared site issues, NRC certification, Compliance Plan, OSR revisions, C-337A startup, and inspection programs.

- RO staff met with SAR Upgrade program to discuss requirements for developing adequate future TSRs. 
- RO staff received NRC Group B questions and passed them on to SMEs for review and possible impact on Compliance Plan.

- DOE concurrence and approval of the Compliance Plan was proceeding, with concurrence received from ES\&H and Nuclear Non-Proliferation.

- SMEs reviewed USEC's Business Prioritization System issues (which replaced IRMS). They reviewed summaries for over 7000 entries made since January 1995, for impact on the Compliance Plan. At PORTS, SMEs found 1200 reports not entered and determined that further review was required.

- DOE sent 30 copies of Revision 1 of the Plan for Achieving Compliance for GDPs to USEC.

- DOE sent a letter to USEC on October 25, 1995, in response to USEC's letter of October 17, 1995, regarding reimbursement for work required to obtain an initial certificate of compliance and for operational enhancements under Lease Agreement DOE indicated it did not need to provide certification of the availability of funds in the Compliance Plans and that it was not responsible for certain operational enhancements which were not necessary for obtaining certification. DOE outlined its position on compliance plan issues in an attachment to the letter and reiterated its position that it had regulatory authority over USEC's activities affecting nuclear safety, safeguards, and security until the NRC assumed regulatory oversight. DOE indicated that changes from OSRs to TSRs would fall under DOE review. DOE noted that USEC had a noncompliance in that it had not properly inventoried depleted $\mathrm{UF}_{6}$ in accordance with 10 CFR 74.33(c) (4). DOE took issue with USEC's position on the upgrade to the SAR and USEC's concern about the specification of dates for actions due prior to transition to NRC oversight.

- On October 23, 1995, RO staff received a response from USEC on the Directive for Information regarding analysis of seismic capacity at PGDP. USEC said consequences of current analysis were bounded by results of 1985 SAR and thus no USQ existed. RO staff commented that the assumptions and conclusions in the USEC response were not supported by any analysis and determined that a USQ existed.

- RO staff met with SSRs and LMUS and USEC representatives at PGDP to discuss the pending OSR change for operation of C-337-A facility, October 23-24, 1995.

- On October 28, 1995, refeed of 5" cylinders of HEU was re-established in Bldg X-326 at PORTS.

- On October 31, 1995, RO staff issued a Directive to USEC to implement immediate compensatory actions at Bldg. nos. C-331 and C-335 at PGDP and to provide an 
acceptable engineering solution within 60 days. The Directive ordered operations at reduced atmospheric pressure and restricted access.

- RO staff conducted functional inspections at PORTS.

- RO staff met with NRC Region III in Chicago, to discuss transition and shared site issues.

- On October 31, 1995, Revision 1 of the Compliance Plan was transmitted to USEC, meeting the Compliance Plan delivery goal.

- RO staff went to PGDP to investigate seismic questions in Bldg. nos. C-331 and C335 and to identify waste storage areas in process buildings and to document quantities and types of materials.

- RO issued one Inspection Report for PORTS covering June 1-30, 1995, and cited two Level III violations. RO staff issued an Inspection Report for PGDP covering RO inspections for July 1-31, 1995, in which two Level III violations were cited.

$\underline{\text { November } 1995}$

- A copy of USEC's response to NRC's Group A questions was provided to the Compliance Plan team and SMEs reviewed responses.

- The RO Manager sent a letter to Mr. Woolley of USEC on November 7, 1995, indicating that the proposed revision to the Event Reporting System UE2-MCRE1030 (Revision 1) would be acceptable provided that certain information regarding notification of the RO Manager was reflected in the revision.

- On November 8, 1995, the RO staff met with NRC chair, Shirley Jackson, to discuss the seismic issue.

- RO staff noted that because of USEC's willingness to correct deficiencies, an inspection report would be modified and a violation would be issued as Level II without enforcement conference.

- The RO staff attended a DOE/NRC/USEC senior management meeting in Rockville, $\mathrm{MD}$, on November 3, 1995, to discuss the status of NRC review of the USEC application resubmittal and other management issues.

- RO staff conducted a Special Inspection of PORTS Emergency Management Program on November 4, 1995, and found performance generally acceptable and improved from the prior year. 
- RO staff presented the first draft of a report on identification of waste storage at PGDP to DOE/ORO on November 7, 1995.

- On November 9, 1995, the exit interview for RO Functional Inspections at PORTS was held.

- One RO Inspection Report for PGDP was issued covering June 1-30, 1995; it included one Level III violation. One RO Inspection Report for PORTS was issued for August 1-31, 1995, with no violations but noted inadequate corrective actions.

- USEC forwarded the Compliance Plan to the NRC on November 7, 1995, as scheduled. NRC said it would accept DOE's Plan for review. RO staff noted that USEC's comments were unexpected, however, after review, the Compliance Plan project noted that most changes requested by USEC could be accommodated.

- Two members of the Compliance Plan project staff went to PORTS to help them retrieve Business Prioritization System items that had been incompletely entered. The items that had been incompletely entered were distributed to SMEs for review

- RO staff implemented a change control process for modifications to the Compliance Plan through "change packages."

- On November 8, 1995, RO staff attended a meeting between representatives of DOE, USEC, and LMUS on the transition of regulatory oversight from DOE to NRC. The group listed initial items that needed to be addressed: DOE regulatory inspection items open at the time NRC assumed regulatory responsibility, transition from OSRs to TSRs, DOE materials stored in USEC leased space, event reporting system, emergency classification, and shared site issues.

- The RO Manager received a letter dated November 14, 1995, from USEC requesting additional information from DOE on seismic analysis and other matters which were being developed by the SAR Upgrade project.

- On November 15, 1995, RO staff approved OSR changes for $\mathrm{UF}_{6}$ Cylinder Heating Autoclaves and Extended Range Product, Low Assay Withdrawal, and Tails Withdrawal Facilities GAT/GDP-1074, Parts F and K.

- On November 16, 1995, the RO Manager approved a change to OSR GAT/GDP1075, Part $\mathrm{H}$ for elimination of restrictions on cleaning equipment in the X-705 Decontamination Building Truck Alley.

- RO and DOE staff attended a meeting on November 17, 1995, between USEC and NRC, in Rockville, $M D$ to discuss the uranium concentration limit in solid and liquid waste that is suitable for release to unrestricted areas. 
- RO and DOE/HQ staffs attended NRC/USEC meeting on November 20, 1995, in Rockville, MD, for a follow-up discussion on USEC's Nuclear Criticality Safety Program described in their certification.

- RO staff and LMES personnel working on SAR Upgrade Project met with NRC in a closed meeting on November 21, 1995, to discuss seismic analysis.

- RO staff received NRC observation reports for PORTS for September 14-November 9, 1995, and RO staff reviewed the reports to ensure findings were consistent with the RO inspections.

- RO staff continued to review Emergency Classification Notification issues.

- The RO staff attended a public meeting held by NRC in Piketon, Ohio, on November 28,1995 , to receive comments on certification of PORTS.

- The RO staff met with USEC at PORTS on November 29, 1995, to discuss OSR to TSR transition issues and also attended a Regulatory Issues Group meeting.

\section{December 1995}

- RO staff attended a public meeting held by the NRC at PGDP on December 5, 1995, to receive comments on PGDP certification.

- RO staff and Compliance Plan personnel met in Washington, DC, with NRC and USEC to discuss USEC's activities and other items.

- NRC issued a letter to USEC indicating a delay in the schedule for the initial certification dates of the GDPs.

- On December 4, 1995, RO staff approved a revision to OSR GAT/GDP-1076, Part B to eliminate the need for an operator to be in Control Room 5 when cells in area 5 were shut down.

- The Compliance Plan project prepared a summary of USEC's revisions to DOE Compliance Plans for reference at a December 7, 1995, meeting.

- RO staff attended a meeting between USEC, DOE, and NRC on the DOE Compliance Plans on December 7, 1995. Issues discussed included: DOE Compliance Plan changes by USEC without prior NRC approval, DOE material in leased USEC space, Upgraded SAR, PGDP seismic issue, JCOs, plans of action and schedule, TSRs, and worker safety. NRC indicated that the DOE Compliance Plans were responsive to the CFR requirements and that, although NRC reviewers had some questions, the documents were good. Discussion of the certification schedule was postponed. 
- A letter was sent to Mr. Woolley of USEC on December 11, 1995, approving USEC's request for PAAA Regulation - Exemption.

- RO staff met with USEC and LMUS at PGDP on December 12-14, 1995, to discuss an increase to $23 / 4 \%$ assay plant wide, sublimers, and plant response to seismic concerns.

- RO staff conducted a tour at PGDP with the NRC seismic review team.

- Two Unusual Occurrences were reported at PGDP.

- On December 12, 1995, a letter was sent to USEC regarding KY/D-4151, Revision 2, "OSRs for $\mathrm{UF}_{6}$ Feed Facilities" requiring that a change be added to the OSR to prevent heatup of an overfilled cylinder.

- The Compliance Plan team met with a USEC representative to discuss the NRC questions. Some differences were resolved; others required more work.

$\underline{\text { January } 1996}$

- On January 2, 1996, RO staff provided letter to USEC concurring, in principle, with their phased approach regarding transition from OSRs to TSRs.

- RO staff approved a temporary exemption to the PGDP OSRs associated with obtaining $a \mathrm{UF}_{6}$ negative pressure prior to opening a system for maintenance.

- Compliance Plan staff provided responses to NRC questions and developed a detailed description of the SAR upgrade scope.

- On January 11, 1996, RO staff met with USEC and LMUS staff to obtain concurrence on shared site issues and event reporting criteria.

- RO staff was notified on January 12,1996 , of a degraded condition of the autoclave systems in Buildings C-333-A and C-337-A at the PGDP. The degraded condition involved an as-found condition which allowed a path for steam/condensate to enter the autoclave which had not been analyzed. USEC provided JCO and SE. RO staff granted authorization to continue operation until January 22, 1996, when USEC was to submit additional information to correct the condition.

- RO staff attended a Regulatory Issues Group Meeting on January 18, 1996. Major topics were: Action items status, OSR review status/transition schedule, status of seismic issues, and autoclave update. 
- On January 19, 1996, RO staff was notified of an "as found" condition related to PGDP's C-310 and C-315 Normetex pump "local/remote" controller switch. An SE was initiated and the potential for defeating the safety system shutdown circuit was determined to be an USQ. Compensatory measures were implemented to ensure safety.

- On January 22, 1996, RO staff reviewed USEC's revised JCO and SE related to operation of the autoclaves at PGDP in buildings C-333-A and C-337-A. Authorization to continue operation of the subject autoclaves was given, provided compensatory measures were implemented.

- Three routine Inspection Reports were issued for PGDP. Four violations were cited based on the results of the inspection activities.

- On January 22,1996 , the Inspection Report was issued for a special inspection conducted to evaluate the integrated emergency response capabilities of the event. No violations were cited.

- January $25,1996, \mathrm{RO}$ staff was notified that the "as-found" condition related to the emergency (fluorine) shutdown system in X342B at PORTS was determined to be a USQ. The oral approval for continued operation and subsequent follow-up letter were retracted. The Fluorine Generation System was shutdown by USEC and was to remain shutdown until the USQ was resolved, SE, and proposed modification to the system was submitted to and approved by DOE.

- USEC requested and DOE gave concurrence to implement the agreements reached by DOE and USEC on event reporting criteria. The action was intended to facilitate transition to NRC reporting criteria.

- On January 30, 1996, RO staff participated in a Senior Management Review meeting between USEC, DOE and NRC to discuss the status of the NRC's review of USEC's application for certification of GDPs as well as open items including: Seismic risk, higher than expected enrichment levels, worker protection, quality assurance, SAR upgrade, storage of DOE materials, TSRs, criticality safety, Material Control and Accountability, shared site issues/emergency coordination, transportation package certification and uranium bioassay.

- On January 31, 1996, RO staff gave approval to continue operation of the C-310 and C-315 Normetex pump controller local/remote switches at PGDP.

- Revision 2 of the DOE Compliance Plans for PGDP and PORTS was transmitted to the NRC by USEC. Issues still to be finalized included: SAR, storage of DOE materials, and seismic and $\mathrm{UF}_{4}$ issues at PGDP. 


\section{February 1996}

- On February 2, 1996, RO staff participated in a meeting to discuss key issues that resulted from the NRC's questions concerning Fire Protection at the GDPs.

- On February 14, 1996, RO staff participated in a meeting with representatives of USEC, LMUS and NRC to discuss control of assay levels in the top purge portion of the cascade at the PORTS.

- On February 14, 1996, interim approval for operation was granted for operation of the Fluorine Generation System at PORTS based on review of USEC's draft USQD for the as-found condition of the system.

- RO staff attended the Regulatory Issues Group meeting on February 21, 1996, at PGDP to discuss status of resolution of DOE materials stored in leased space, seismic issues at PGDP, status of open regulatory items, application/compliance plan status, Shared Site Issues, and OSRs to TSRs transition status.

- On February 16, 1996, approvals were given to PGDP OSR changes for C-360 Toll Transfer and Sampling Facility and Product and Tails Withdrawal Facilities.

- RO staff participated in a senior management meeting with DOE, NRC and USEC to discuss status of open items related to certification of GDPs.

- On February 21, 1996, Revision 2A of KY/D-4151 "OSRs for UF 6 Feed Facilities" for PGDP was approved.

- On February 26, 1996, a unit expansion joint failed in Building X-326 at the PORTS, resulting in considerable air inleakage in the cascade. The cascade was put in recycle mode for more than 40 hours with no apparent safety significance.

- On February 28, 1996, the design analysis and calculation report, prepared by LMES, for the GDP SAR Upgrade Program was provided to USEC. The non-linear design analysis was related to seismic capacity of Buildings C-331 and C-335 at PGDP.

\section{March 1996}

- RO staff participated in joint teleconference among the NRC, DOE and USEC to discuss the Compliance Plan including JCO definition. NRC concerns with the JCOs were associated with a desire for better "inspectability."

- On March 6, 1996, the DOE TSRs Review Team met with USEC/LMUS staff from PORTS and PGDP to discuss the transition from OSRs to TSRs. 
- RO staff met with USEC/LMUS staff at PORTS on March 5, 1996, to initiate a Compliance Plan review of the adequacy of the procedure upgrade program at the plant.

- On March 7, 1996, approval was granted by RO staff for the OSR changes due to a design modification of the Autoclave Steam Isolation System at PGDP. The changes resolved an USQ.

- On March 13, 1996, RO staff met with USEC/LMUS staff at PORTS to discuss HEU refeed activities for the cleaning of five, eight and twelve inch cylinders. The scope and schedule of these activities were reviewed.

- Meetings were conducted with senior representatives of USEC and LMUS PORTS personnel on HEU Assay and Technetium Control as concerns in these areas had potential to be major certification issues.

- On March 8, 1996, DOE concurred with USEC's request to delay implementation of a change to the PGDP OSR for UF ${ }_{6}$ Feed Facilities - Cylinder Weight Verification. This action was done to facilitate the elimination of duplicate or repetitive work in the conversion of OSRs to TSRs.

- RO staff granted USEC's "Request for Waiver from PGDP OSR (KY/D-3971) ownership of the Criticality Accident Alarm System (CAAS) Testing Requirements" on March 8, 1996.

- On March 12, 1996, Inspection Reports for the period October 16, 1995, through November 30 1995, for eàch GDP were issued. The PGDP report cited two violations pertaining to not observing OSRs. The PORTS report cited one violation pertaining to the lack of required instrument calibration program documentation for gauges used to test the performance of fire water pumps.

- On March 15, 1996, RO staff gave authorization for the PORTS to continue operation in accordance with the JCO for the Cascade Coolant Systems.

- On March 18, 1996, Inspection Reports for the period December 1, 1995, through January 15, 1996, for PGDP were issued. The report cited two violations. One pertained to failure to adhere to OSRs. The other involved the failure of plant personnel to follow the lockout/tagout permit procedure requirements.

- On March 27, 1996, RO staff attended the Regulatory Issues Group Meeting at PORTS. Accomplishments included: Resolution to evaluate the facilities as part of the corrective action plan for Problem Report PTS-96-1654, USEC provided extensive briefings on the three significant Compliance Plan issues of autoclave upgrades, criticality safety and configuration management, and the remaining schedule for OSR changes to be implemented prior to TSR transition was established. 
- An NRC observation report for PORTS was received on March 25, 1996, noting programmatic weaknesses in the areas of calibration, control of valving operations, and safety system component reliability.

- On March 28, 1996, RO staff gave authorization for PORTS to initiate refeed activities for the 8 -inch and 12 -inch cylinders.

- RO staff updated the OSR/TSR database and developed a cross reference for OSR and TSR transition criteria.

- RO staff met with representatives of USEC and LMUS (PORTS and PGDP) to discuss transition issues and USEC's proposed approach to the justification for continued operation of PGDP's process buildings C-331 and C-335. A scope of work needed to accomplish the proposed approach was identified for presentation to DOE management.

\section{April 1996}

- On April 10-11, 1996, an unannounced special inspection was conducted at PORTS to review USEC's waste minimization program at PORTS and compare it with the ROA implementation requirements. This inspection was prompted by the apparent lack of maintenance and poor housekeeping by USEC which contributed to an increase in the amount of PCB waste that was generated.

- On April 9, 1996, approval was given to PGDP OSR changes for the C-360 Toll Transfer and Sampling Facility Autoclave Steam Isolation System (KY/D-3972, Revision 3D).

- On April 9, 1996, a NOV was issued to USEC in the area of the Nuclear Safety and Safeguards and Security requirements of the ROA. The violation involved the retraining of personnel at required intervals.

- On April 16, 1996, RO staff instructed GDP sites to prepare a DOE Site Transition Plan in coordination with the RO Manager, with the objective of the plan being to identify those topics which must be transitioned to the USEC and/or would require an interface with USEC after NRC assumes regulatory oversight.

- On April 16, 1996, RO. staff attended a meeting of NRC, DOE, and USEC representatives concerning DOE responses to NRC comments/questions on the LMES seismic evaluations of the GDPs performed as part of the GDP SAR update. The meeting closed out and addressed most of the NRC comments. 
- The NRC observation report for PGDP covering the period February 1 through March 18,1996 , was received. Findings were reviewed to ensure consistency with findings of the RO inspections conducted in accordance with the ROA.

- The Fundamentals of GDP Operations Training course was conducted April 16-17, 1996, for LMUS management, DOE, and contractor support staff.

- On April 18, 1996, RO staff participated in a Senior Management meeting with the NRC and USEC to discuss certification status of GDPs. Submittal of an acceptable Quality Assurance Plan by USEC was identified as a primary obstacle to certification.

- DOE approved $23 / 4 \%$ plant operations at PGDP on April 24, 1946. A SER proving the basis for approval was a'so issued.

- On April 18, 1996, the Inspection Report for the period January 16 through February 29,1996 , for PGDP was issued. No violations of the ROA were identified.

- On April 23, 1996, RO staff demonstrated the concept of a new compact disk at PORTS. The disk contained detailed information that will be useful in regulatory activities of the GDPs.

- On April 24, 1996, the GDP Compliance Plan Status Report identified seven unresolved issues which affect the Compliance Plans. These included: 1) HEU refeed operations, 2) storage of DOE material in USEC leased space, 3) quality assurance, 4) autoclaves, 5) the PGDP seismic issue, 6) SAR upgrades, and 7) $\mathrm{UF}_{6}$ Detectors. The status of each issue was presented.

- On April 30, 1996, RO staff was notified by USEC that seven new noncompliances were identified: 1) Part 21 reporting, 2) Cell Trip Batteries (PGDP), 3) Tenant Signatures - Emergency Plan, 5) Overtime Limits (PORTS), 6) Operational Trips, and 7) $\mathrm{UF}_{6}$ Detector Sensitivity. RO staff assigned subject matter experts for each new noncompliance.

\section{May 1996}

- On May 5, 1996, the RO Manager authorized performance of a Special Inspection of the USEC's implementation of the actions specified in their April 25, 1996, letter to verify that the USEC's actions were consistent with their response procedures.

- On May 3, 1996, RO staff approved the change in design for new seal exhaust pumps in the X-326 facility at PORTS. Approval was dependent upon double contingency requirements. 
- On May 6, 1996, RO staff authorized PGDP to continue normal operations in buildings C-331, C-333, C-335 and C-337. Approval was based on review of the JCO and SE related to the inaudibility of the Criticality accident Alarm System in this buildings.

- Remaining unresolved Compliance Plan issues were reviewed on May 3, 1996, with USEC management. New issues were: 1) Operational Trips, 2) Criticality Accident Alarm System Claving (PORTS), 3) $\mathrm{UF}_{6}$ Detector Sensitivity (PGDP), 4) Cell Trip Batteries (PGDP), 5) Codes and Standards, $\left.{ }^{\circ} 6\right)$ DOE obtain tenant Signatures Emergency Management, 7) CAAS Horns Audibility (PGDP), and 8) Overtime Limits (PGDP).

- A management conference was held on May 9, 1996, for USEC to present their position on: 1) assessment and status of their management controls that assure safe operation of the GDPs; 2) actions taken or to be taken to strengthen management controls over procedures, corrective action program, and maintenance of the authorization basis; and 3 ) the management organization and individual responsibility for defined action and authorities.

- USEC submitted a projected schedule for submitting the final revised Certification Applications and Compliance Plans for PGDP and PORTS to the NRC. The Certification Applications were scheduled for May 31, 1996, and the Compliance Plans were tentatively scheduled for July 12, 1996.

- On May 17, 1996, the DOE JCO concerning seismic capacity improvements at the PGDP was completed. DOE concluded that the risk associated with continuing operation of the process buildings was acceptable until modifications were complete.

- On May 20, 1996, RO staff approved PGDP OSR KY/D-3972, Rev. 3B, C-360 Toll Transfer and Sampling Operational Systems. USEC submitted a revised SE to address the change to the Cylinder Roll Interlock system opening prevention pressure. The SE was reviewed and determined to adequately address the change.

- An Inspection Report was issued on May 20,1996, for the special inspection performed by members of the RO staff at the PORTS. The inspection involved Waste Management as related to the generation and control of PCB/Radiological mixed waste. One violation was cited in the report involving plant operations not being effective in minimizing the generation of $\mathrm{PCB} / \mathrm{R}$ mixed waste at its source.

- On May 20, 1996, the Inspection Report for the period January 15-February 29, 1996, for PORTS was issued. No violations of the ROA were identified. 


\section{June 1996}

- The process for preparation of transition plans to the NRC regulation for GDPs was established. Topics addressed by the process include those items where responsibility will transition from the DOE to USEC or that would require an interface with USEC/NRC.

- DOE granted approval for USEC to resume shipping product, utilizing the PGDP Tiger, under DOE Certificate of Compliance No 6553, Rev. 16.

- On June 5, 1996, a proposal for revised Compliance Plan milestones for fiscal year 1996 was developed and submitted. The revision was due to delays in the NRC certification process for the GDPs. USEC posturing on issues with the NRC delayed the certification process beyond initial estimates.

- RO staff attended the Regulatory Issues Group Meeting on June 11, 1996, with USEC and NRC. Topics included: OSR review status and how changes to OSRs and TSRs will be handled during the period of transition to NRC regulation following certification, status of Compliance Plan issues and process for completion, DOE/NRC regulatory boundaries, status of seismic upgrades at PGDP, and USEC's Performance Improvement Program response.

- RO staff performed an ORE on Phase II of the PGDP Higher Assay Upgrade Program.

- On June 14, 1996, RO staff gave approval to USEC for the use of the Russian sample cylinder (number L4437) for filling and shipment at PORTS.

- A report on the PGDP seismic issue was submitted to the NRC on June $18,1996$.

- The ORE for addition of six new feed stations in the Product Withdrawal area of Building X-326 at PORTS ran from June 24 through .27, 1996. The ORE concluded that the USEC/LMUS ORR was incomplete. LMUS concurred and rescheduled for completion of the ORR.

- NRC completed its review of Revision 3 of USEC's Application for Certification, dated May 31, 1996. Over 200 questions and comments from the review were transmitted to USEC for resolution by July 9, 1996.

- On June 20,1996, DOE transmitted a letter to NRC validating that DOE would retain jurisdiction over USEC transportation activities under the ROA until the NRC assumed regulatory jurisdiction.

- On June 21, 1996, RO staff granted USEC approval to perform a decontamination demonstration on gaseous diffusion processing equipment that was no longer needed. 
- The JCO of the PORTS Cascade Coolant System Rupture Disc was granted on June 26, 1996.

- On June 27, 1996, RO staff participated in a presentation to DOE/HQ-NE staff on the SER project plan for the upgraded Final SARs of the GDPs.

- RO staff attended a meeting on June 27, 1996, to discuss the Nuclear Materials Control and Accountability portion of the USEC application. The primary topic of discussion was the greater than $10 \%$ assay issue at PORTS.

- A DOE/NRC/USEC Senior Management meeting was held on June 28,1996 , to discuss the status of USEC's application for certification.

- The revised JCO related to operation of the PGDP Criticality Accident Alarm System in buildings C-331, C-333, C-335 and C-337 was reviewed by RO staff.

- On June 28, 1996, the revision to PORTS OSR GAT/GDP-1074, Part B, "X-326 Uranium Enrichment and Purge Cascades - Top Purge Oxidant Concentration" was approved by $\mathrm{RO}$ staff.

$\underline{\text { July } 1996}$

- Revision 3 of the Compliance Plans was forwarded to the DOE/HQ for approval. This revision addressed review comments from DOE/HQ, USEC, and the NRC.

- On July 2, 1996, RO staff granted approval to USEC's request to utilize a previously approved safety limit for Autoclave High Pressure Steam Shutdown instead of the safety limit in the current OSRs.

- On July 9, 1996, RO staff participated in a telecon discussion with DOE/HQ-EH to address comments on the PGDP seismic JCO included in the Compliance Plan.

- On July 3, 1996, a determination was made that USEC's SE for safety aspects of longterm Low Temperature Treatment Test was adequate and the implementation of the test in a manner specified in the document was approved.

- During the week of July 12,1996 , a management team from the Compliance Plan Project worked with DOE/HQ to obtain HQ approval of Rev. 3 Compliance Plans. Approval from HQ was received that week.

- RO staff delivered Rev. 3 of Compliance Plans to USEC on July 11, 1996. The following day USEC submitted the Plans to the NRC. With completion and transmittal of the Rev. 3 Compliance Plans, the team staffing level was reduced. 
- USEC, NRC, and DOE reached agreement on the SAR Upgrade issues on July 15 , 1996, the Seismic issue on July 16, 1996, and the Autoclave issues on July 17, 1996.

- Two safety system valves on a freezer/sublimer failed at PGDP. These are large vessels that are used to adjust the $\mathrm{UF}_{6}$ inventory in the enrichment cascade. The major safety concerns were preventing nuclear criticality and containing toxic materials. The incident was classified as an unusual occurrence. RO staff were assigned to investigate the issue.

- On July 16, 1996, RO staff approved USEC's cancellation of the PGDP and PORTS IRMS issues, since resolution of the safety significant issues were committed to in the DOE Compliance Plan.

- On July 15,1996 , a draft of the Joint Policy Statement/Procedure for PGDP shared site issue coordination was sent to the DOE Site Manager at PGDP for review and comment.

- On July 19, 1996, DOE authorized USEC to transition from the OSRs to the TSRs for the X-705 Decontamination Facility at PORTS. This authorization was in support of making necessary preparations for transition to NRC regulation.

- On July 19,1996 , RO staff transmitted comments to USEC regarding their request for DOE approval of changes to two procedures that were part of the authorization basis for PGDP. Some of the changes diminished the margin of safety for heating cylinders in autoclaves and the changes were not approved.

- On July 18-19, 1996, Inspection Reports for the period March 1 through April 15, 1996, for each GDP were issued. Three violations were cited in the PGDP report. The violations involved procedural problems, plant management's failure to perform required assessments of plant operations and personnel performance, and failure to perform liquid sampling of cylinders from suppliers. No violations of the ROA were identified within the scope of the PORTS inspection.

- On July 25 1996, RO staff gave approval to USEC to transfer responsibility for maintaining and implementing the OSR for the Hydrogen Fluoride Tank Farm and the X-345 Special Nuclear Material and High Assay Sampling Area facilities to DOE.

- On July 30, 1996, RO staff attended the Regulatory Oversight Transition Meeting at PGDP. The general transition protocol, TSR transition, and compliance plan activities were discussed.

- RO staff attended the Regulatory Issues Group meeting on July 31, 1996, at PGDP. Discussion included: Shared site issues, OSR to TSR transition status, Compliance Plant status, PGDP improvement initiatives, and PGDP seismic upgrade status. 
August 1996

- On August 6,1996, USEC's request to change a commitment date associated with the HEU Suspension Project was found acceptable. The completion date for the cleaning of all compressors, expansion joints, seals and vacuum pumps which were remnants of the HEU program was changed from June 30 to August 16, 1996.

- A major milestone was reached in transition to NRC regulation of GDPs with implementation of the first TSR. The TSRs for the X-705 Decontamination Facility at PORTS were implemented on August 6,1996. DOE authorization to use the revised TSRs was granted on August 5, 1996.

- During the week of August 7, 1996, RO staff response was provided to an employee concern regarding alleged lowering of dosimeter badge readings at PORTS by LMUS. The allegation could not be definitely proven to be true by an investigation team. However, the practice of "zeroing out" dosimeter badges was to be further pursued to determine if there was a violation of procedures or standard industry practices.

- RO staff issued the Cost Validation Progress Report as of July 31, 1996. The DOE cost validation team was assigned to validate costs for nuclear safety upgrades that were necessary for compliance with the ROA and for initial NRC certification.

- During the week of August 14, 1996, NRC staff indicated that all certification issues had been resolved and that USEC had agreed to make all appropriate changes to the TSRs. The NRC staff anticipated an affirmative certification recommendation to the Commissioners on July 28, 1996.

- On August 15-16, 1996, RO staff attended a DOE/LMES Senior Management Meeting. Progress was made in many areas related to the transition of regulatory authority from DOE to NRC as well as support of DOE activities in the non-leased facilities of the GDPs.

- On August 16,1996, the JCO related to the inability to warn personnel located in the Evacuation Zones of CAAS alarmed buildings at PGDP was granted approval by RO Manager.

- A member of the RO staff was assigned to PORTS to support the DOE Site Office on issues such as: shared site issues, transition from OSR to TSRs, and the closure of Compliance Plan and RO inspection open items.

- On August 20, 1996, the JCO related to handling of contaminated waste material in the X-326 facility at PORTS was determined to be acceptable by RO staff. Approval was contingent upon USEC submitting the as-found USQD for this non-compliance by August 30, 1996. 
- During the week of August 20, 1996, RO staff received Revision 6 of the GDP Applications. The Compliance Plan team reviewed the information and determined that the revision did not affect the content of the Rev. 3, change A Compliance Plans.

- On August 16, 1996, RO staff was notified that USEC had requested a change to the date for transition to regulatory oversight by NRC to March 3, 1997.

- On August 26, 1996, a change to the ROA regarding USEC management's assessment of plant operations and personnel performance was submitted to USEC for concurrence. The change was in response to USEC's request to transition to the Internal Audit Program described in their Application for Certification to the NRC.

- By August 28, 1996, DOE had completed its obligation regarding the shared site issue of third party legal authority at the GDPs. Except for the Ohio Department of Transportation (DOT), DOE outgrant holders provided signed agreements acknowledging that USEC had authority for the purpose of responding to emergencies affecting land under outgrant from DOE. The Ohio DOT easements in question were adequately addressed in the PORTS Emergency Plan and acknowledgment was not essential.

- On August 30, 1996, RO staff submitted to USEC management a report on the HEU refeed ORE observations made during the period of August $14-22$, 1996. The report expressed ongoing concern about the level of effort included in the USEC contractor ORR. This represented the third occurrence in which RO staff encountered numerous non-conformities following USEC's declaration of operational readiness--negatively impacting progress in refeeding HEU material.

\section{September 1996}

- On September 3, 1996, the Inspection Report for the period April 16 - May 31, 1996, for PORTS was issued citing two violations. One involved the implementation of compensatory actions differing from those described in a JCO and in the FASR. Additionally, DOE was not notified and a safety assessment of the actions was not provided. The other violation pertained to the use of the wrong procedure for performance testing of a safety system.

- RO staff attended the Regulatory Issues Group Meeting on September 4, 1996, at PORTS. Agenda items included: the OSR/TSR transition plan, DOE post certification activities, regulatory process activities during the transition period, flow down of commitments, Compliance Plan status, and the HEU refeed schedule.

- DOE authorization for USEC to use the TSRs for $\mathrm{UF}_{6}$ Feed Facilities at PGDP was granted on September 4, 1996. 
- During the month of September 1996, RO staff restructured its organization to effect the transition to post-certification activities. Evaluations of required tasks and staffing levels were conducted. Positive steps were taken to reduce costs during the period of transition from the DOE regulating the GDPs to NRC becoming the regulatory authority.

- On September 5, 1996, the Inspection Report for the period April 16 through May 31, 1996, for PGDP was issued. The report cited five violations and closed nineteen previously identified inspection items.

- Revision 1 of the Master Security Plan for Microcomputer Systems Processing Classified Information for PORTS was approved for use on September 5, 1996.

- RO staff provided clarification to USEC that specific plant procedure requirements regarding the PORTS Fluorine Generation System and Seal Exhaust Pumps were made part of the authorization basis and that any changes required DOE review and approval, not that the OSRs would be modified.

- On September 13, 1996, NRC issued its initial certification decision for USEC to operate the GDPs.

- A meeting between NRC, USEC, and DOE was held on September 17, 1996, to discuss the 10 CFR 76 change process, certification amendment requests, and discretionary enforcement.

- Review was completed of the USQD, Long Term Corrective Plan, and JCO for the Criticality Alarm System regarding unslaved buildings at PORTS. The compensatory measures identified in the JCO were considered acceptable until permanent modifications were completed and tested. However, the USQD and Long Term Corrective Action Plan were found to be unacceptable and the items required for acceptance were provided to USEC.

- On September 16, 1996, RO staff presented to the NRC their plan for closure of completed Compliance Plan Action Items.

- On September 13, 1996, RO staff delivered to the NRC and USEC a database of all USEC commitments extracted from PGDP and PORTS Compliance. Plans JCO and Plan of Action and Schedules. This information was to be used during the closure reviews and as part of the commitment information turned over to the NRC at transition.

- RO staff completed review of the as-found USQD regarding OSRs Part B/Nuclear Criticality Safety Approval discrepancies and found it to be acceptable. 
- On September 25, 1996, RO staff granted approval to USEC to utilize DOE Order $5300.4 \mathrm{D}$ in lieu of $5300.4 \mathrm{C}$ to satisfy the requirements of the ROA. The change involved the level of protection mandated for the protected distribution systems of the telecommunications security program at GDPs.

- RO staff evaluated the PGDP Full Participation Exercise on September 26, 1996. RO staff was pleased with overall performance of the exercise and reviewed corrective actions for the one objective that was not met.

- On September 30, 1996, RO staff granted USEC's request for approval OSRs, KY/G557 to replace Addendum A to the Phase 1 SAR for interim operations at $23 / 4 \%$ enrichment at PGDP.

\section{October 1996}

- DOE review of the changes to the PGDP procedure CVP4-CO-CM023, Rev. 1, Change B, "Shipment, Receipt, and Inspection of $\mathrm{UF}_{6}$ Cylinders" was completed. The review concluded that the changes did not impact the authorization basis of the plant and approval was granted on October 1, 1996.

- On October 4, 1996, information requested by the NRC was provided regarding DOEowned material stored in USEC-leased space. The letter provided assurance that the activities described in the Compliance Plan for this issue would be completed on or before the schedule dates. The last activity was scheduled for completion on or before December 31, 1996.

- Upgraded site-wide SARs for PORTS and PGDP were transmitted to USEC on October 7, 1996.

- On October 8, 1996, the JCO associated with Cell Treatment and Freon Coolant System Pressures at PORTS was granted approval.

- On October 11, 1996, the DOE approved the TSR for the Enrichment Cascade Facility at PGDP.

- On October 9 and 10, 1996, RO staff and members of the LMES SAR Upgrade Program met with LLNL personnel to review and comment on a draft of a seismic risk study performed by LLNL.

- Revision 4 of the Compliance Plans was approved and issued, as scheduled, on October 11, 1996. With issuance of Rev. 4, DOE had met its obligation to "develop and approve" a plan in support of initial certification by the NRC. 
- On October 16, 1996, the RO Manager issued a letter to USEC senior management concerning failure to fully address corrective actions discussed in DOE Management Conference, EA-70-7003/96-001. In the letter, DOE stated that USEC did not provide any new, immediate, and tangible corrective actions to improve overall management involvement during the remaining time $\mathrm{DOE}$ had responsibility for the regulatory oversight of the GDPs.

- Compliance Plan team members began Compliance Plan action item closure activities at PORTS. The scope of the review consisted of 16 action items involving 11 Compliance Plan issues including hardware, procedures, training, and emergency planning activities. Of the 16 actions, 14 were recommended for closure, one was to remain open, and one was still under review due to the volume of information involved.

- On October 22, 1996, RO Manager denied USEC's request for an extension of the completion for the seismic modifications to Buildings C-331 and C-335 at PGDP. Denial was based on the fact that the current schedule would not expire for another ten months and USEC should make every effort to complete the modification work under that schedule before requesting an extension. Additionally, no safety reasons were presented as a basis for the request.

- Revision 1 of the SER for PGDP Enrichment Cascade Facilities TSR was transmitted to USEC on October 22, 1996.

- On October 31,1996, the Inspection Report for the period June 1 through July 15, 1996 , was issued. No violations of the ROA were identified.

\section{November 1996}

- On November 1, 1996, RO staff sent a letter to USEC concerning DOE's reimbursement of costs related to procedure upgrades at the GDPs. The letter stated that USEC must provide an itemized list of all procedures with their associated revisions that they proposed were required for initial certification by the NRC. USEC was to provide a justification describing how each procedure and procedure revision met a Compliance Plan requirement or was related to a nuclear safety class system.

- On November 7, 1996, USEC transitioned the PORTS Feed Facilities based TSR as approved by the DOE .

- On November 15, 1996, an RO staff representative attended a GDP Emergency Tabletop Learning Exercise in Rockville Maryland. The purpose was to provide a greater understanding of the NRC's expectations, needs, and requirements during a classified emergency. The exercise also determined the compatibility of the NRC Emergency Operations Center (EOC) with the EOCs at the GDPs. 
- Refeed of HEU at PORTS was re-established on November 8, 1996.

- On November 8, 1996, RO Manager approved USEC's request to implement an increase in assay from 2.3 percent to a maximum of 3.0 .

- RO issued the report "Transition to Nuclear Regulatory Commission Regulation at the GDPs." The report was to be upgraded to identify topics required to be addressed, and their status.

- On November 19, 1996, RO staff met with senior management of LMUS and LMES to discuss shared site issues at the PORTS facility, including resolution of issues involving DOE-owned material currently stored in the USEC-leased space.

- On November 18,1996, RO staff toured building X-705 at PORTS with USEC and LMUS staff to observe progress of modifications to the cylinder cleaning area.

- Inspection Report 96-05 for PGDP was issued on November 20, 1996. Two violations and one deviation were cited and sixteen previously identified inspection items were closed.

- On November 27, 1996, DOE approval was granted to procedure changes associated with "OSRs for C-360 Toll Transfer and Sampling Facility" at PGDP. Changes were reviewed for impact on the verification of $\mathrm{UF}_{6}$ cylinder weight and assurance that void volume requirements were met prior to heating a $\mathrm{UF}_{6}$ cylinder in an autoclave.

- On November 27, 1996, DOE granted approval for USEC to transition to the NRC event reporting criteria for PGDP and PORTS. Once the provisions of USEC's Nuclear Event Reporting system procedure were implemented, DOE was to be notified and USEC would no longer be required to report to the Occurrence Reporting and Processing System.

\section{December 1996}

- A JCO for the PORTS Cell Treatment and Freon Coolant System Pressures was extended to January 15, 1997. The JCO approval was extended while reviews of the FSAR change and SEs were completed.

- The week of December 2, 1996, the Compliance Plan team finalized closure basis write-ups for actions reviewed during the last two visits to the GDPs. At total of 87 actions had been reviewed as of this date. The team began development of criteria for plant visits in the beginning of 1997, and will issue the criteria during the week of December 16, 1996. 
- On December 10, 1996, RO staff met with USEC, LMUS and LMES staff to discuss the Compliance Plan cost increases forecast by USEC. The criteria for validating the increased costs was reemphasized.

- On December 11, 1996, the Regulatory Issues Group met to discuss OSRs to TSRs review and transition status, Compliance Plan status review, and follow-up to the DOE Management Conference held on May 9, 1996.

- Inspection Report 96-06 for PGDP was issued on December 6, 1996. One violation was cited for failure to observe OSRs. Additionally, two previously identified inspection items were closed.

- On December 6, 1996, a revision to the SER included in the DOE authorization of revised TSRs for PGDP Enrichment Cascade Facilities was issued. The revision removed a clarification included in the Freezer/Sublimer section of the SER, involving a potential criticality in the vessel, to allow more flexibility of operation within applicable Nuclear Criticality Safety Approvals.

- Inspection Report 96-06 for PORTS was issued on December 9, 1996: One violation was cited in the report for failure to follow procedures. Four previously identified inspection items were also closed during the inspection period.

- On December 9, 1996, copies of the Final PGDP and PORTS SARs were submitted to $\mathrm{DOE} / \mathrm{HQ}$.

- RO staff scheduled a Management Conference with USEC for December 19, 1996, to discuss recent improper movement of a $\mathrm{UF}_{6}$ cylinder using a straddle carrier at PORTS before it had completed the required cooldown period. The purpose of the management conference was for RO staff to gather information as to whether USEC could provide reasonable assurance that $\mathrm{UF}_{6}$ cylinder handling operations could be performed safely and in accordance with requirements and approved plans and procedures.

- On December 12, 1996, RO staff participated in the augmented inspection of the PORTS Full Participation Emergency Response Exercise. Findings were prepared to be provided in the next PORTS Inspection Report.

- RO staff were at PORTS on December 17, 1996, to observe conditions regarding the potential use of the High Assay Sampling Area in X-326 for storage of cylinders containing HEU.

- A USEC/NRC meeting was held on December 18, 1996, to discuss transition issues associated with the GDPs. Major topic of discussion was the Compliance Plan completion dates. 
- Two Compliance Plan Review Teams were assigned to review actions at GDPs. During week ending December 20, 1996. Team 1 finalized and issued the closure basis for actions reviewed during week of December 13, 1996, and finalized and issued acceptance criteria for next plant visits. Team 2 visited PORTS and reviewed 24 actions - 22 were closed, 2 were left open.

\section{January 1997}

- RO staff visited PORTS on January 6 and 7, 1997, to review interim measures implemented as a result of the December 16,1996, event in which a 14 ton cylinder of liquid $\mathrm{UF}_{6}$ was moved prior to completion of the cooldown period.

- On January 9, 1997, the interim measures for handling of UF ${ }_{6}$ cylinders at PORTS were approved until February 14, 1997.

- On January 9, 1997, RO staff approved a request by USEC to transition from TSRs for the X-340 Complex CAAS at PORTS to previously approved OSRs. Requirements were written as Transitional Requirements and included in the SER.

- Authorization was granted for USEC to transition from OSRs to TSRs for the Toll Transfer and Sampling Facility at PGDP on January 14, 1997.

- RO staff participated in an Enforcement Conference with USEC on January 15, 1997, regarding the improper handling of $\mathrm{UF}_{6}$ cylinders at PORTS. USEC admitted to the violations and provided a comprehensive corrective action plan. A Severity Level II violation with a civil penalty of $\$ 20,000$ was issued on January $17,1997$.

- RO staff received the NRC observation report for activities conducted between October 26, 1996, and December 6, 1996.

- USEC was informed in a letter dated January 17, 1997, that Mr. J. Dale Jackson had been reassigned to the Oak Ridge Y-12 Facility to support restart effort and that Mr. Randall DeVault has been appointed as the Regulatory Oversight Manager, effective January 20, 1997 until March 3, 1997.

- On January 17,1997, DOE issued a NOV, 70-7002/96-08-03, with Severity Level II and a $\$ 20,000$ civil penalty for not performing a safety evaluation prior to initiating work to repair a valve to ensure that work would not involve a USQ. The incident involved motor vehicle traffic being rerouted through $\mathrm{UF}_{6}$ cylinder lot $\mathrm{X}-745 \mathrm{~B}$.

- A Severity Level III violation with no civil penalty was cited on January 17, 1997. 
- The Compliance Plan Review Team 1 finalized the closure basis for actions reviewed at PGDP during week ending January 10,1997, and finalized criteria for actions to be reviewed week ending February 7, 1997. Team 2 finalized the closure basis for actions reviewed at PORTS during the week ending December 20, 1996.

- RO staff participated in the ORE at PGDP for site-wide operation at higher assay of $23 / 4 \%$, during January 21-24, 1997.

- On January 22, 1997, RO staff attended the Regulatory Issues Group meeting held at PGDP. Issues discussed included DOE activities until transition, OSR/TSR status, Compliance Plan status, and Seismic Upgrade status.

- RO staff arranged for the PORTS and PGDP SERs to be reviewed at the sites by the Authorized Derivative Classifier.

- On January 28, 1997, the Assistant Manager for Enrichment Facilities recommended that DOE negotiate a lump sum settlement with USEC for the safety upgrades at PORTS that were to be paid out of the HEU credit.

- DOE approved an extension of a Limiting Condition for Operation request from USEC for the CAAS in PGDP's C-337 building.

- On January 29, 1997, RO staff participated with DOE/HQ, LMUS, LMES, NRC, and USEC in a meeting/video conference/teleconference on Emergency Classification. At that meeting, it was agreed that the vehicle for changing the DOE requirements on Emergency Classifications would be a Category 3 change to the Environmental Management Enrichment Facilities S/RIDS.

- During week ending January 24, 1997, Compliance Review Team 1 closed 10 of 16 action items at PGDP. Team 2 closed 15 of 21 actions reviewed at PORTS.

- The RO staff participated in the DOE/NRC Regulatory Oversight Transition Meeting in Rockville, MD on January 30, 1997. Topics included coordination of regulatory activities between DOE and NRC, the turnover of DOE inspection items, and DOE's support to the NRC after transition.

- On January 30, 1997, RO staff and LMES staff conducted a briefing in Bethesda, MD, for USEC on the SARs for both GDPs.

- RO staff issued a letter directing LMES to follow the NRC emergency classification structure for the non-leased facilities at PORTS and PGDP on January 30, 1997. 


\section{February 1997}

- USEC's request for authorization to transition from OSRs to TSRs for the X-326 Extended Range Produce, X-333 Low Assay Withdrawal and X-330 Tails Withdrawal Stations at PORTS was approved on February 3, 1997.

- The RO manager authorized that a special inspection be conducted at PORTS during the week of February 5,1997 , in response to information anonymously received by the NRC. The inspection involved a review of the NCS program documents to determine their compliance with the ROA.

- On February 6, 1997, DOE granted approval of USEC's JCO regarding the operations of the C-310 and C-315 facilities at PGDP. The JCO resulted from the identification of an USQ created between the FSAR and the implementation of USEC's "See and Flee" policy.

- RO staff attended the DOE/NRC/USEC meeting in Rockville, MD, to discuss the status of USEC's exclusion request regarding the CAAS coverage at PORTS and PGDP.

- Two inspection reports for PGDP and one for PORTS were issued on February 10, 1997. One violation was cited in each of the PGDP reports for failure to observe OSRs, and 16 previously identified inspection items were closed. The PORTS report identified a deviation from a commitment made to DOE and 5 previously identified open inspection items were closed.

- On February 11, 1997, USEC was informed via a letter to Mr. Woolley of the results of the Compliance Plan Action Item Closure review effort for the months of December 1996, and January 1997.

- .USEC's request for authorization to transition from OSRs to TSRs for the X-330 and X-333 Cold Recovery Systems was approved on February 11, 1997.

- The inspection report for December 1, 1996, through January 10, 1997, for PORTS was issued with no violations identified and five previously identified inspection items were closed.

- On February 13-14, 1997, the RO staff received training on the GeneSys optical disk system configuration.

- RO staff extended interim approval regarding resumption of cylinder movement for USEC operations at PORTS by means other than use of a rail car to the overhead crane area and by overhead crane to the cooldown area to February 21, 1997. 
- The RO staff went to PORTS to review the effectiveness of USEC's corrective actions regarding the improper handling of liquid $\mathrm{UF}_{6}$ cylinders.

- RO staff received the NRC observation report for PORTS activities conducted between December 7, 1996, and January 24, 1997, and the NRC observation report for PGDP activities conducted between November 19, 1996, and January 6, 1997.

- RO staff completed their review of USEC's revised JCO related to CAAS inauditability at PGDP and determined that the JCO revision was not warranted because the TSRs and corresponding TR implemented January 17, 1991, provided for the appropriate actions for inaudibility discovery in the C-331 building.

- A revision to the SER included in DOE's authorization of TSRs for PGDP UF 6 Feed Facilities was issued on February 12, 1997. The rerouted feed header piping and additional $\mathrm{UF}_{6}$ detection relative to the rerouted piping were deemed acceptable and operation of autoclaves 3,4 , and 5 was allowed.

- USEC's request for authorization to transition from OSRs to TSRs for the X-326 Cascade Facility and the X-330 and X-333 Cascade Facilities, excluding the Freezer/Sublimer TSRs, at PORTS was approved on February 18, 1997.

- RO staff provided comments to USEC regarding the TSRs for the X-326 Product Withdrawal Facility HEU refeed activities at PORTS and the need for TSRs for HEU refeed cylinder cleaning activities in Building X-705.

- During the week ending February 14, 1997, Compliance Review Team 1 was in Oak Ridge, to review completed actions at PGDP and draft the closure basis for action reviewed during week ending February 7, 1997. Team 2 was at PORTS to review completed action items. Twenty-two of the 32 actions reviewed at PORTS were closed.

- On February 20, 1997, DOE provided USEC, in a letter to Mr. Woolley, with the results of the Compliance Plan Action Item Closure review effort for the month of February 1997, and noted that final reviews had been completed at both plants.

- On February 20,1997, review was completed of the USQD that analyzed changing the requirement for slaved buildings from a 500 foot to a 200 foot radium for the Immediate Evacuation Zone for the CAAS at PORTS. It was determined that the USQD provided adequate justification for the change and approved, contingent upon compensatory actions being in place.

- DOE transmitted a letter to USEC on February 21,1997 , to confirm DOE's understandings relative to a violation of the double contingency controls applicable to 
the NCS approval for the C-400 UF 6 cylinder washing operation at PGDP. The operation was shut down and an investigation started.

- On February 21, 1997, USEC was granted an extension to March 3, 1997, of the approval to operate under the JCO for the cell treatment coolant system pressure at PORTS. The extension was granted to allow for DOE review of additional changes to the FSAR regarding this issue.

- The RO Program and Compliance Plan Program reviews were presented at the Uranium Programs Monthly Activity Review meeting in Oak Ridge, on February 21, 1997.

- The restriction regarding $\mathrm{UF}_{6}$ cylinder movement for USEC operations at PORTS by means other than use of a rail car to the overhead crane area and by overhead crane to the cooldown area was removed, allowing normal operations to resume on February 21, 1997.

- On February 24, 1997, DOE sent a letter to Mr. Pierson of the NRC to provide the final turn-over status of the Compliance Plan issues and associated actions.

- On February 25, 1997, the Compliance Plan Manager notified DOE Office of Inspections of two employee concerns relating to PGDP and PORTS and described how the issues had been addressed. Initial inspection of the concern at PORTS for safety implications did not identify any adverse conditions. One aspect of the concern at PGDP that involved violation of work procedures and work packages had previously been identification during routine inspection activities and was being addressed by the Procedures Upgrade Program at PGDP. The other area which involved sexual harassment, intimidation and falsification of documents was transmitted to the OIG for investigation.

- Authorization was granted to USEC on February 26,1997 , to continue crane operations in the feed facilities at PGDP while TSR revision was being processed by the NRC.

- Review was completed of USEC's request to maintain X-326 OSRs and X-705 TSRs and associated TRs for activities pertaining to the HEU refeed activities at PORTS. OSRs for HEU refeed operations in X-326 were to be maintained until appropriate TSRs were prepared and approved. Operation of the Small Cylinder Cleaning Area in the X-705 Decontamination Facility was not authorized pending completion of an ORE, resolution of all outstanding issues, and issuance of a SER.

- During the week of February 26, 1997, the Compliance Plan Review Teams reviewed completed actions at the GDPs, finalized and issued the closure basis for the actions items reviewed at the GDPs, and consolidated and transferred Compliance Plan files. 
- On February 27, 1997, DOE sent a letter to the NRC with a summary of employee concerns and noted that one outstanding concern was still active with DOE.

- USEC was authorized to remove the HEU Suspension Program SAR from the authorization basis at PORTS on February 27, 1997.

- The conditional authorization for PGDP to operate at the increased enrichment level of $23 / 4 \%$ was granted on February 28,1997 . Operation at the increased assay was restricted for certain areas and equipment.

- On February 28, 1997, the report for the special inspection of the PORTS Nuclear Criticality Safety Program was issued. No violations were identified during the inspection.

- RO staff reviewed USEC's request to establish additional DOE Material Storage Areas (DMSA) at PORTS which, if retained by USEC, would exceed the NRC certification requirements for PORTS. USEC and LMUS were to complete the establishment of the DMSAs prior to March 3, 1997.

\section{March 1997}

- On March 3, 1997, the NRC assumed regulatory authority of the PORTS and PGDP plants operated by USEC under a lease from DOE.

- The RO Manager informed Enterprise Advisory Services, Inc. (EASI) on March 4, 1997, of the types of information that were not to be included in the transfer of the RO Database to the NRC.

- The RO Manager attended the final SSR exit meeting at PGDP on March 5, 1997, for the period covering January 11 to March 2, 1997.

- The RO staff attended the final SSR exit meeting at PORTS on March 12, 1997, for the period covering January 11 to March 2, 1997.

- The final Regulatory Issues Group Meeting was held at PORTS on March 12, 1997. The NRC was a participant rather than observer. Issues discussed included the status of the HEU refeed effort at PORTS; NRC activities such as inspections and changes to 10 CFR Part 76; a briefing on the status of selected Compliance Plan items such as autoclaves, procedure upgrades, criticality accident alarms for nearby buildings, and Nuclear Material Control and Accountability; and applicability of the ASME Pressure Vessel Code to heating operations of $\mathrm{UF}_{6}$ cylinders. 